\title{
Materiales carbonosos de distinta indole para el almacenamiento y la conversión electroquímica de energía
}

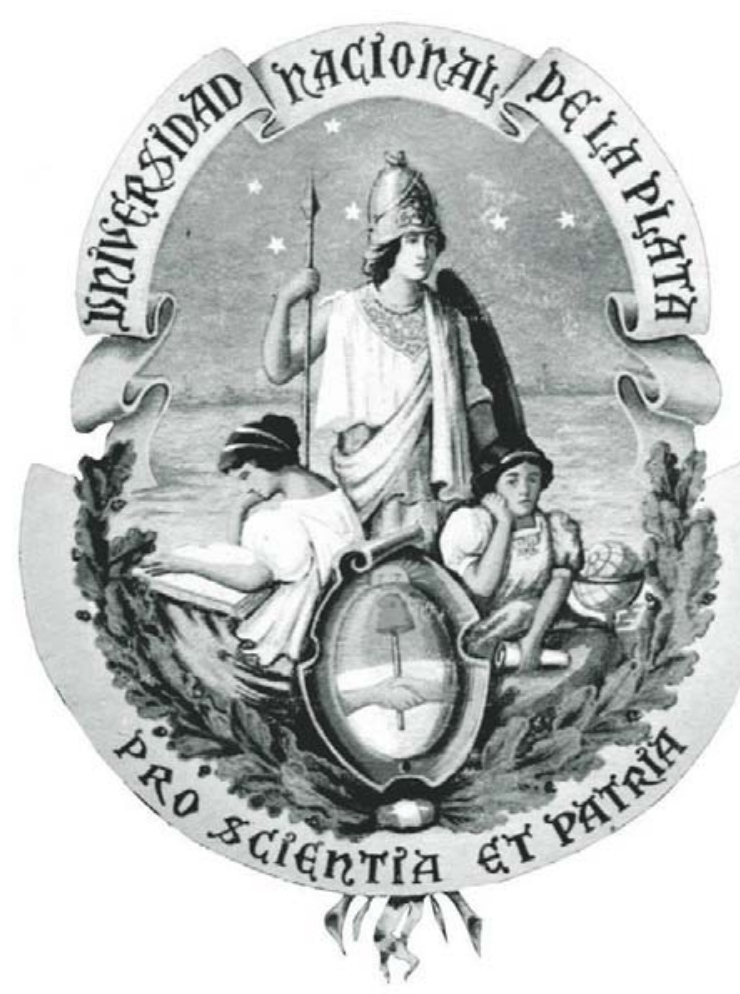

Lic. Pablo Sebastián Fernández

Dirección: Dra. María Elisa Martins

Co-dirección: Dr. Arnaldo Visintín 
A Cristina y Omar

A Pame y Luis

Al tío Aníbal (in memoriam) 


\section{Agradecimientos}

En primer lugar quiero agradecer a mi directora, la Prof. Dra. y amiga María Elisa Martins, porque siempre mostró la mayor de las predisposiciones para guiarme y ayudarme en este hermoso camino, el cual siempre viene acompañado de dudas, vaivenes y contratiempos.

A mi co-director, el Dr. Arnaldo Visintín, quien con su curiosidad y alegría siempre estuvo apoyándome y motivándome para que cada día intente realizar investigaciones mas ambiciosas.

A las Dras. Silvia Real y Beatriz Castro quienes realizaron una contribución esencial a este trabajo introduciéndome tanto en la parte experimental como en la teórica de la técnica Espectroscopía de Impedancia Electroquimica. Sin embargo, mi agradecimiento se debe principalmente a que siempre me acompañaron con una actitud muy motivadora, demostrándome con muchas vivencias que los problemas experimentales serian parte de mi vida.

Al Dr. Giuseppe Câmara y a la Dra. Janete de Giz, de la Universidade Federal de Mato Grosso do Sul, quienes me recibieron en su casa sin conocerme, brindándome más de lo que tenían a su alcance. Además de esta ayuda invalorable realizaron un gran aporte a mi formación profesional y a mi tesis.

A todos los compañeros y amigos del cuarto piso con quien he compartido muchas charlas de diversos temas. A los compañeros de trabajo de la UFMS, los cuales se mostraron siempre muy dispuestos a hacer más fácil mis estadias en Brasil. Si bien todos estuvieron y están dispuestos a colaborar en lo que necesite, deseo realizar un 
agradecimiento especial al Dr. Jorge Thomas, quien me ha ayudado innumerables veces teniendo una gran predisposición.

Un agradecimiento muy especial a mi familia y amigos, quienes siendo ajenos a lo que yo hago siempre tuvieron confianza en mi trabajo y se alegraron de forma muy sincera con cada uno de mis progresos.

A mi novia. Pame me acompañó y acompaña en este camino de la ciencia. Ella simplificó mucho mi vida con el cariño y amor que me brinda cada día y por comprender y disfrutar el mundo en el cual elegimos vivir. Todo esto hizo que comprenda claramente mis vueltas del laboratorio con diferentes estados de ánimo y que podamos compartir los logros académicos de una manera muy especial. 


\section{Índice General}

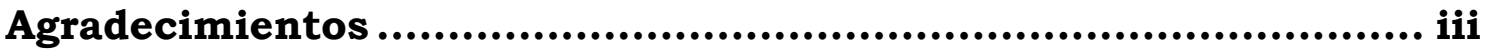

Índice General .......................................................................v

Resumen.............................................................................1

Capitulo 1 ......................................................................4

Introducción General ..........................................................4

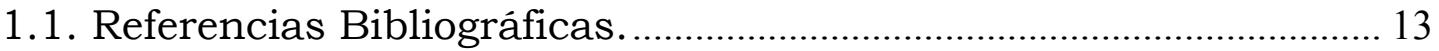

Capitulo 2 ......................................................................15

Métodos.......................................................................15

2.1. Caracterización textural de los materiales ........................................ 15

2.1.1. Isotermas de adsorción .................................................................. 15

2.1.2. Distribución de Tamaño de Poros (DTP) ...................................... 19

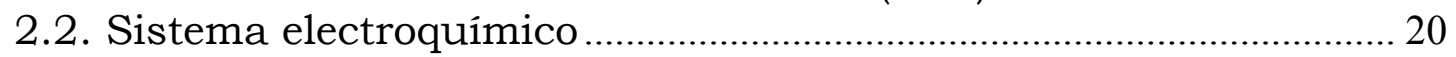

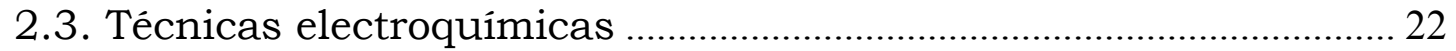

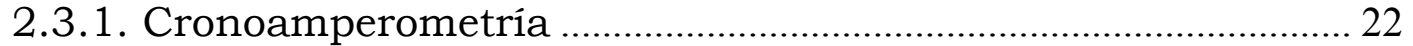

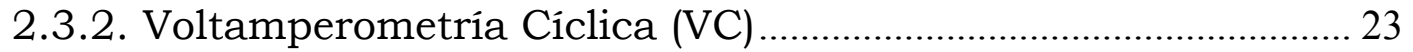

2.3.3. Cronopotenciometría....................................................................... 25

2.3.4. Espectroscopia de Impedancia Electroquímica........................ 26

2.4. Modelo físicoquímico para electrodos porosos .................................. 33

2.4.1. Ecuaciones involucradas en el modelo........................................ 33

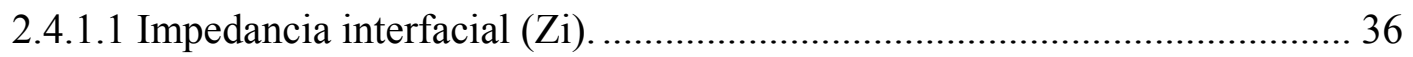

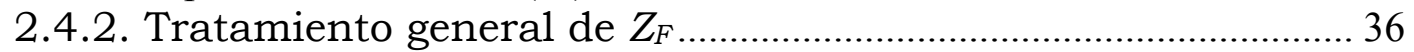

2.5. Espectroscopia infrarroja de Transformada de Fourier in situ

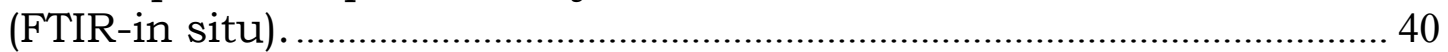

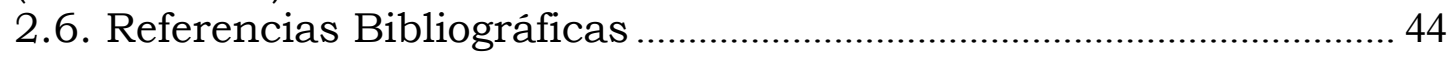

Capitulo 3 .........................................................................47

Supercapacitores Electroquimicos .....................................47

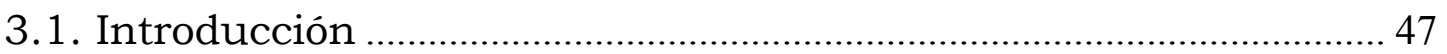

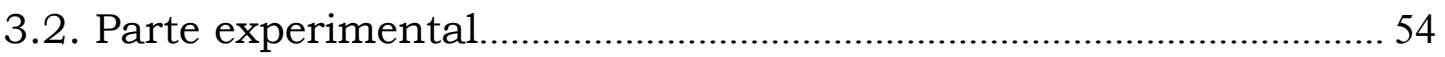

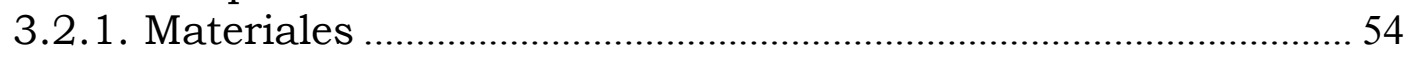

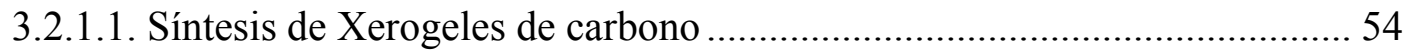

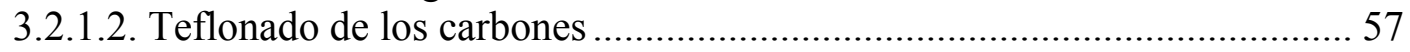


3.2.2. Sistema electroquímico ………………………………………….... 57

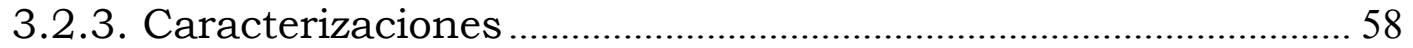

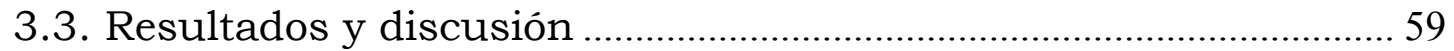

3.3.1. Caracterización de los carbones....................................................... 59

3.3.1.1. Microscopía de transmisión electrónica (TEM) ....................................... 59

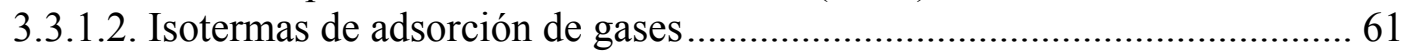

3.3.2. Medidas electroquímicas ................................................................ 65

3.3.2.1. Voltamperometría Cíclica (VC) y Potenciometría (CD por carga-descarga)

3.3.2.2. Espectroscopía de Impedancia Electroquímica ........................................ 68

3.3.2.2.1. Análisis Teórico-Aplicación del modelo fisicoquímico descrito en el

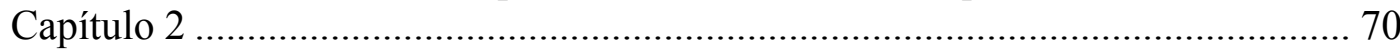

3.3.3 Efecto de la adición de NTCM a un material altamente

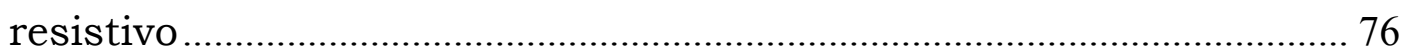

3.3.3.1 Obtención del nanocompuesto y preparación de los electrodos.................. 77

3.3.3.2 Caracterización de los materiales .............................................................. 78

3.3.3.3 Resultados electroquímicos ...................................................................... 78

3.4. Referencias Bibliográficas ..................................................................... 83

Capitulo 4 .........................................................................87

Almacenamiento electroquímico de hidrógeno en nanotubos de carbono - Reacción de evolución de hidrógeno (REH) ..................87

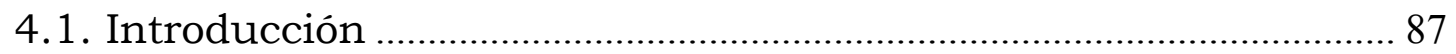

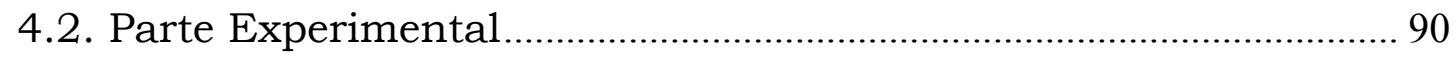

4.2.1. Materiales y métodos .................................................................. 90

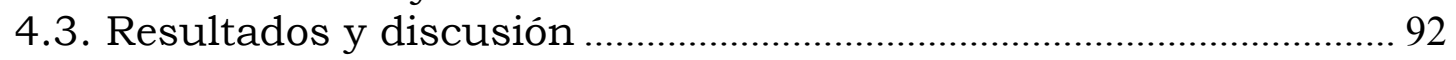

4.3.1. Caracterización .......................................................................... 92

4.3.1.1. Espectroscopia Raman........................................................................... 92

4.3.2. Experimentos electroquímicos ........................................................ 93

4.3.2.1. Voltamperometría cíclica ........................................................................ 93

4.3.2.2. Experimentos de carga y descarga galvanostáticos .................................... 97

4.3.2.3. Espectroscopia de impedancia electroquímica .......................................... 99

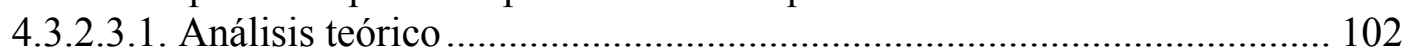

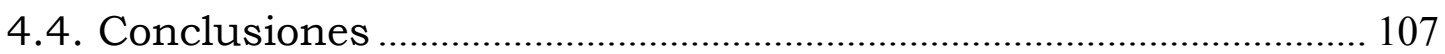

4.5. Referencias Bibliográficas .................................................................... 109

Capitulo 5 ...................................................................115

Primeros estudios de las vías de electrooxidación de Glicerol sobre nanopartículas basadas en Pt soportadas sobre diferentes carbones.

115

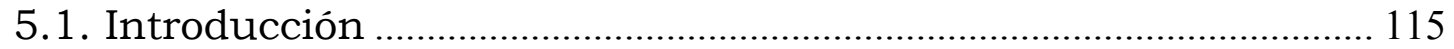

5.1.1. Biodiesel y glicerol en la Argentina ............................................ 115

5.1.2. Celdas de combustible.................................................................... 116

5.1.3. Reacción de electrooxidación de glicerol (REG) .......................... 119

5.2. Parte Experimental...……………………………………………….... 121

5.2.1. Sintesis de los catalizadores....................................................... 121

5.2.2. Sistema electroquímico ………………………………………..... 123

5.2.3. Preparación del electrodo de trabajo ............................................. 123

5.2.4. Experimentos de FTIR-in situ...................................................... 125 
5.2.5. Caracterización de los materiales .............................................. 126

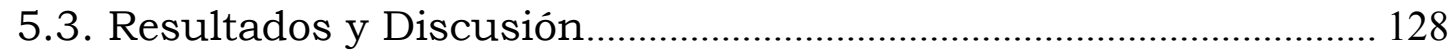

5.3.1. Caracterización física y electrocatálisis ..................................... 128

5.3.2. Resultados electroquímicos ........................................................ 132

5.3.3. Resultados espectroelectroquímicos ............................................. 138

5.3.3.1. Reacción de electrooxidación de CO ................................................... 138

5.3.3.2. Vías de electrooxidación de glicerol ...................................................... 144

5.3.3.2.1. La generación de $\mathrm{H}^{+}$..................................................................... 145

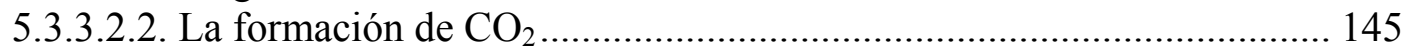

5.3.3.2.3. Las vías de reacción paralelas ........................................................... 146

5.3.3.2.4. La formación de ácidos carboxílicos .................................................. 150

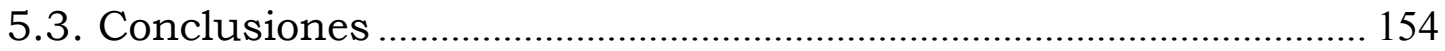

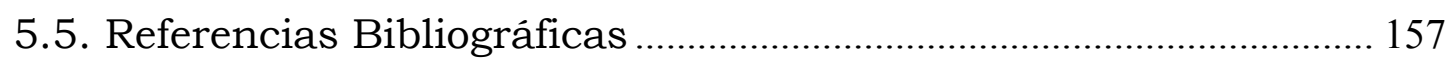

Conclusiones Generales .................................................160 


\section{Resumen}

En este trabajo de tesis se estudian carbones porosos de diferentes características, las cuales hacen que sean aptos para su utilización en distintas aplicaciones relacionadas con el almacenamiento y la conversión electroquímica de energía.

En su Introducción está contenida la motivación del trabajo, considerado como un aporte que intenta contribuir al avance del conocimiento en tópicos relacionados con recursos energéticos no convencionales y ambientalmente limpios. Debido al rol fundamental que han desempeñado los materiales carbonosos en el desarrollo de las investigaciones, consideramos conveniente hacer una breve introducción sobre el carbono, sus características, propiedades y variedades.

Si bien los estudios fueron abordados desde un punto de vista fundamental, este trabajo involucra tres aplicaciones concretas, las cuales son descritas en tres capitulos diferentes.

Capítulo 3: Supercapacitores Electroquímicos.

Capítulo 4: Almacenamiento electroquímico de hidrógeno en NTCS Reacción de evolución de hidrógeno. (NTCS=Nanotubos de carbono de pared simple).

Capítulo 5: Primeros estudios de las vias de electrooxidación de glicerol sobre nanopartículas (NPs) de platino soportadas sobre diferentes carbones.

El trabajo fue organizado de esta manera, de modo de ir desde sistemas más simples a otros más complejos. Así, en el Capítulo 3 se 
estudiaron algunos carbones porosos, incluyendo los utilizados en los demás capítulos, haciendo énfasis en los procesos de carga y de descarga de la doble capa eléctrica (DCE) de cada uno de los materiales estudiados y en la relación del comportamiento electroquímico con parámetros fisicoquímicos de los electrodos. Desde el punto de vista electroquímico, los estudios realizados en el Capítulo 3, comprenden una parte de los realizados en el Capítulo 4. En éste se estudia el comportamiento electroquímico de NTCS en medio $\mathrm{KOH} 6 \mathrm{M}$, con el objetivo de estudiar el almacenamiento electroquímico de hidrógeno en ese material. Por lo cual, si bien está involucrada la región de DCE, parte de la cual incluye la adsorción de átomos de hidrógeno, posteriormente se hace especial énfasis en lo que ocurre a potenciales favorables para que se produzca la reacción de formación de hidrógeno molecular. En ambos capítulos se utilizaron técnicas electroquímicas básicas como la voltamperometría cíclica (VC), la cronopotenciometría $(\mathrm{CD}=$ de "carga-descarga") y la espectroscopía de impedancia electroquímica (EIE). Los resultados de EIE fueron interpretados en base a un modelo fisicoquímico que se describe en el Capítulo 2.

Por último, en el Capítulo 5, se decoraron algunos carbones con NPs de Pt, PtSnRh y PtRuRh y se estudió la reacción de electrooxidación de glicerol (REG) sobre estos materiales, visualizando su aplicación en celdas de combustible de alcohol directo. Para ello fueron utilizadas las técnicas VC y cronoamperometría (CA). Utilizando NPs de Pt soportadas se determinaron y/o propusieron las principales vías de reacción del alcohol y la relación de éstas con el potencial del electrodo de trabajo. En esta última parte se utilizó la VC acoplada con Espectroscopia Infrarroja por Transformadas de Fourier in situ (FTIR - in situ).

Fueron aplicadas diversas técnicas de caracterización como espectroscopía Raman, isotermas de adsorción de nitrógeno, medidas de conductividad eléctrica, medidas de composición elemental, microscopias de transmisión electrónica y de barrido con medidas de dispersión de rayos $\mathrm{X}$ y espectrometría de rayos $\mathrm{X}$. Estos temas conjuntamente con la descripción de las técnicas electroquímicas y la 
Espectroscopia Infrarroja por Transformadas de Fourier in situ están contenidos en el Capítulo 2. 


\section{Capítulo 1}

\section{Introducción General}

El crecimiento exponencial del mercado de dispositivos electrónicos portátiles y la necesidad de producir vehículos eléctricos eficientes, ha estimulado un esfuerzo intenso de investigación para el desarrollo de fuentes de energía de alto rendimiento, principalmente baterías, supercapacitores y celdas de combustible. En cuanto a las celdas de combustible se refiere, el almacenamiento seguro de hidrógeno y de bajo costo es uno de los principales problemas que deben resolverse antes de considerar una introducción masiva de estos sistemas en el mercado actual.

Además de los métodos convencionales de almacenamiento, es decir, el hidrógeno líquido y cilindros de gas a alta presión [1], la adsorción de hidrógeno en los poros de los materiales específicos de alta área superficial y la inserción de hidrógeno en los metales y aleaciones, son alternativas atractivas y ampliamente estudiadas [2]. Entre todos los materiales posibles, los carbones micro-mesoporosos presentan varias ventajas, tales como una gran variedad de formas, un bajo costo, la posibilidad de modificar fácilmente la porosidad y la funcionalidad de la superficie. El hidrógeno se puede almacenar en átomos de carbono nanoporoso sea por adsorción bajo una cierta presión de gas o por la descomposición electroquímica de un electrolito acuoso [3-7].

Las baterías convencionales, ( $\mathrm{Pb}$-ácido, Ni-Hidruro metálico, NiCd) e incluso las de ión-Li pueden considerarse como dispositivos de baja potencia y alto almacenamiento de energia. Por otra parte, se ha 
dedicado mucho esfuerzo en el desarrollo de vías de almacenamiento electroquímico de energía a través de sistemas de supercapacitores o ultracondensadores $[8,9,10]$ debido a su aplicación en vehículos eléctricos y otros dispositivos como sistemas de telecomunicaciones digitales. Estos dispositivos, de alta potencia pero poca capacidad de almacenamiento, en numerosas aplicaciones trabajan en forma complementaria con las baterias.

En consecuencia, atendiendo al tema de la necesidad de desarrollar fuentes de energía de alto rendimiento, el presente trabajo de tesis doctoral constituye un aporte que intenta contribuir al avance del conocimiento en tópicos relacionados con recursos energéticos no convencionales y ambientalmente limpios. Este trabajo comprende diversos temas que están estrechamente vinculados entre sí y tienen un denominador común que es la Electrocatálisis, que involucra a las celdas de combustible, los materiales de electrodo y las reacciones que tienen lugar durante la operación de las celdas. En este sentido, se ha emprendido el estudio exhaustivo de tres tópicos fundamentales e interrelacionados entre sí. Los mismos comprenden i) el almacenamiento electroquímico de hidrógeno en nanotubos de carbono y el estudio del mecanismo de la reacción de hidrógeno en esos materiales; ii) estudio de supercapacitores electroquímicos; iii) primeros estudios de las vías involucradas en la electrooxidación de glicerol, con el objetivo de ser empleado en celdas de combustible.

A medida que se avanza en la lectura del trabajo, se advierte que en los tres principales temas estudiados se ha empleado al carbono como material fundamental para la construcción de los diferentes electrodos, sea para el almacenamiento de hidrógeno, para la investigación de supercapacitores electroquímicos y para el estudio electrocatalítico de la oxidación de glicerol.

Por esa razón y debido al rol fundamental que han desempeñado los materiales carbonosos en el desarrollo de estas investigaciones, consideramos conveniente hacer una breve introducción sobre el carbono, sus características, propiedades y variedades. 
El carbono es el elemento más versátil de la tabla periódica, debido a los tipos, la fuerza y el número de enlaces que este átomo puede formar con muchos elementos diferentes. La diversidad de estos enlaces y sus correspondientes geometrías permiten la existencia de isómeros estructurales (cadena, posición y función), estereoisómeros (geométricos, enantiómeros y diastereoisómeros). Todas estas características permiten la existencia de una variedad muy grande de moléculas orgánicas [11].

Las propiedades del carbón son una consecuencia directa del arreglo de electrones alrededor del núcleo del átomo. El elemento carbono, con un número atómico de 6 , posee una configuración electrónica [He] $2 \mathrm{~s}^{2} 2 \mathrm{p}^{2}$, por lo cual, los átomos de $\mathrm{C}$ pueden formar tres tipos de orbitales híbridos, esto es, $\mathrm{sp}^{3}, \mathrm{sp}^{2}$ y $\mathrm{sp}$. Estas estructuras, de configuración espacial tetraédrica, trigonal plana y lineal, respectivamente, dan lugar a tres estructuras básicas del carbono: diamante $\left(\mathrm{sp}^{3}\right)$, grafito $\left(\mathrm{sp}^{2}\right)$ y carbinos $(\mathrm{sp})$.

Debido a que en la segunda parte del siglo pasado la cantidad de alótropos de carbono aumentó notablemente, muchos autores han adoptado por clasificar las diferentes sustancias de carbono conocidas teniendo en cuenta el tipo de unión que poseen los átomos de carbono que la constituyen [12]. A continuación se presenta un cuadro mostrando una pequeña clasificación de algunos compuestos de carbono y luego, teniendo ésta en cuenta se describen los más significativos. 


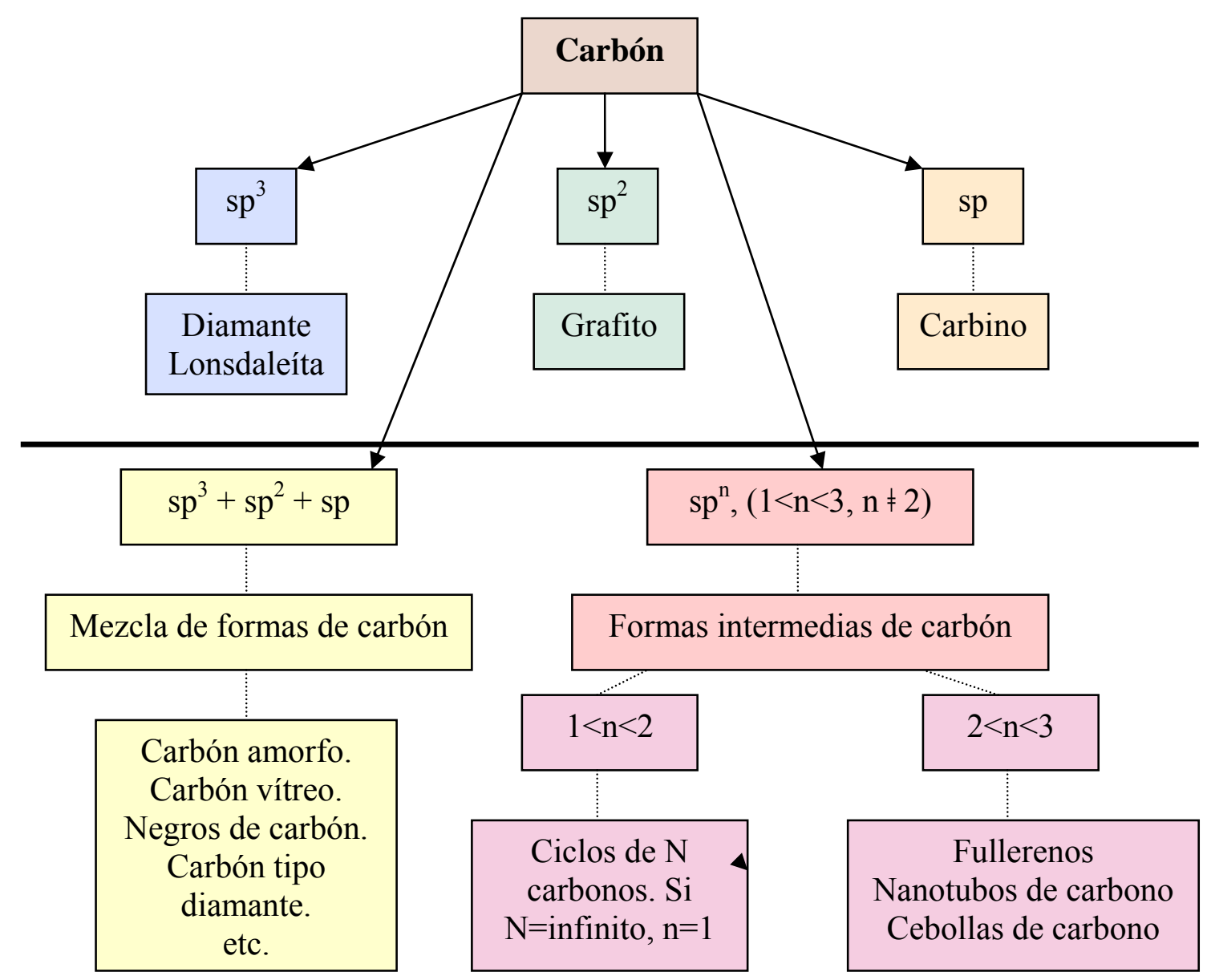

Figura 1.1: Clasificación de estructuras de carbono según su grado de hibridación.

En el diamante, los átomos de carbono se encuentran en el estado de hibridación $\mathrm{sp}^{3}$, con una estereoquímica tetraédrica y una estructura cúbica centrada en las caras. Existe otra estructura de átomos de carbono con hibridación $\mathrm{sp}^{3}$, denominada Lonsdaleíta, constituida por tetraedros ensamblados entre sí en una red hexagonal tipo wurtzita. Esta estructura, muy poco frecuente, ha sido encontrada en meteoritos, y puede ser preparada a partir del grafito por presión estática.

Los fullerenos son los únicos sólidos moleculares en el conjunto de los materiales de carbono. Presentan una estructura a base de poliedros formados por pentágonos y hexágonos de átomos de carbono ensamblados entre sí. Fueron descubiertos en 1985 por Rick Smalley y colaboradores [13]. Su estado de hibridación es intermedio entre $\mathrm{sp}^{3} \mathrm{y}$ $\mathrm{sp}^{2}$ (el carácter $\mathrm{sp}^{3}$ deriva de la curvatura del poliedro), siendo de $\mathrm{sp}^{2.28}$ 
para el caso concreto de la molécula de $\mathrm{C}_{60}$ (buckminsterfullereno), el primer fullereno descubierto. En 1990, en un workshop sobre compuestos de carbono, Smalley propuso la existencia de un fullereno tubular, imaginando un tubo que se origina elongando la molécula de $\mathrm{C}_{60}$ [14]. En agosto de 1991 en otro workshop especial sobre fullerenos, Dresselhaus propuso una simetría para nanotubos de carbono, la cual incluía semiesferas de fullerenos para cerrar los extremos [15]. La primera evidencia experimental de este compuesto tan conocido en estos días se produjo en 1991 cuando Iijima observó nanotubos de carbono de paredes múltiples (NTCM) usando un microscopio de transmisión electrónica [16]. Dos años después, Iijima y colaboradores y Bethune y colaboradores, simultáneamente observaron nanotubos de carbono de una sola pared (NTCS) $[17,18,19]$.

El grafito es otra forma alotrópica del elemento carbono, consistente en láminas de átomos de carbono (grafenos) que forman un sistema de anillos condensados planos. Cada átomo del grafeno tiene una hibridación $\mathrm{sp}^{2}$, lo cual permite la formación de las láminas planas de átomos de carbono, y el solapamiento de los orbitales $\mathrm{p}$ perpendiculares a las láminas para formar una nube de electrones $\pi$ que se encuentran por encima y por debajo de las láminas de grafenos. La unión de las láminas se produce en dirección perpendicular a éstas a través de la interacción de Van del Waals entre las nubes de electrones, apilándose unas sobre otras. Debido al éxito tenido en la producción, aislamiento, identificación y caracterización del grafeno, Andre K. Geim y Konstantin S. Novoselov recibieron el Premio Nobel de Física en el año 2010 [20].

Los carbinos son sólidos de color blanco constituidos por átomos de carbono con hibridación sp. Existen dos posibilidades para esta estructura lineal: poliino $(-\mathrm{C} \equiv \mathrm{C}-\mathrm{C} \equiv \mathrm{C}-)$ y policumuleno $(=\mathrm{C}=\mathrm{C}=\mathrm{C}=\mathrm{C}=)$. De acuerdo con la clasificación basada en el tipo de enlace presente, son los carbinos (y no los fullerenos, como se afirma frecuentemente) los que deben ser considerados como "la tercera forma alotrópica del carbono". Hay que tener en cuenta que la lonsdaleíta y el grafito 
romboédrico son politipos en lugar de nuevas estructuras con una ecuación de estado netamente diferente, por lo que no deben ser considerados como verdaderos alótropos del carbono. El escaso conocimiento sobre los carbinos, y las dudas sobre su existencia real en forma pura, son factores que han contribuido a dicha interpretación.
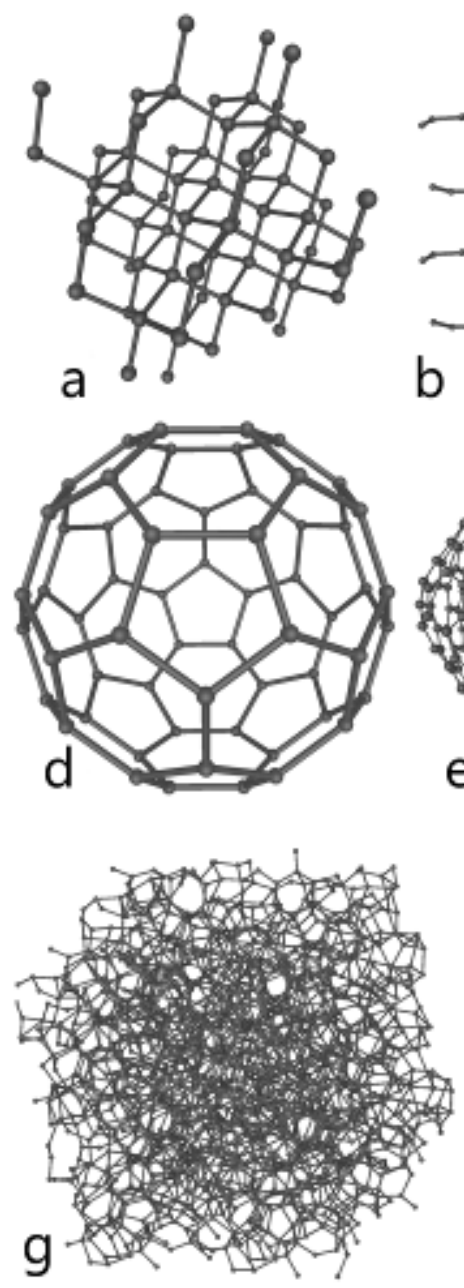

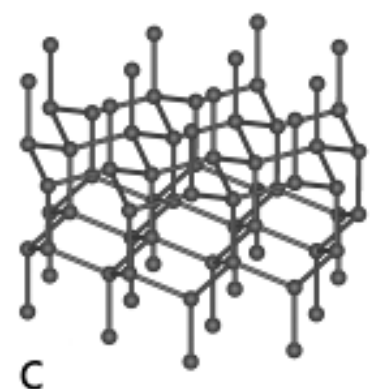

C
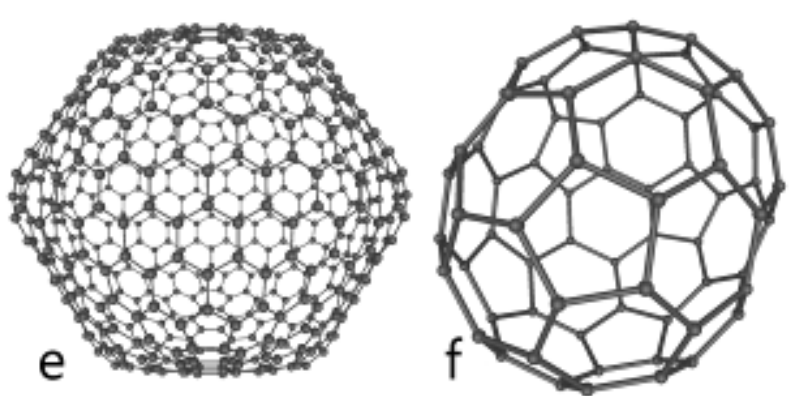

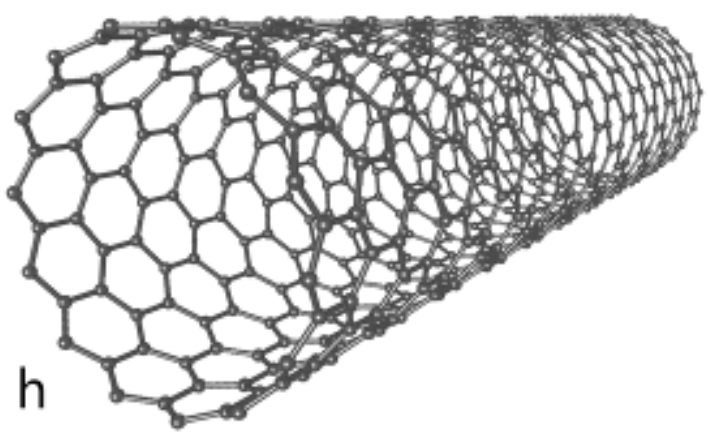

Figura 1.2: (a) Diamante, (b) Grafito, (c) Lonsdaleita, (d) $\mathrm{C}_{60}$, (e) $\mathrm{C}_{540}$, (f) $\mathrm{C}_{70}$, (g) Carbono amorfo, (h) Nanotubo de carbono de pared simple (extremos abiertos) [21].

Los diagramas de fase del carbono se limitan generalmente a recoger las zonas de existencia del diamante y el grafito (además de las fases líquida y vapor) sin incluir al resto de las fases sólidas. Los más detallados, muestran a lo sumo las zonas de existencia de fases metaestables o transformaciones espontáneas, unas y otras derivadas de los esfuerzos de convertir grafito en diamante. 
En la Tabla 1.1 se colocaron algunos términos en español y en inglés relacionados con distintos tipos de carbones, los cuales aparecen frecuentemente en la literatura especializada.

\begin{tabular}{|c|c|}
\hline Español & Inglés \\
\hline Alquitrán & Tar \\
\hline Brea & Pitch \\
\hline Carbón mineral & Coal \\
\hline Carbón vegetal & Wood Charcoal \\
\hline Carbonizado & Char \\
\hline Hollín & Soot \\
\hline
\end{tabular}

Tabla 1.1: Terminología relacionada con tipos de carbones.

Se ha dirigido la atención poniendo énfasis en la cantidad de materiales de carbono, lo que hace muy dificil enumerarlos. La gran diversidad de éstos y sus características hace que sea imposible relacionar la mayoría de los materiales de carbono con sus aplicaciones actuales y potenciales sin escribir un número más que importante de hojas. Probablemente no haya industria en el mundo que no esté utilizando algún compuesto de carbono en alguna etapa muy significativa de su proceso de producción. Más adelante se enumeran algunos compuestos de carbono y sus aplicaciones [22] relacionadas con el tema de este trabajo de tesis.

La extrema dureza, conductividad metálica (en condiciones ideales) o semiconductividad, alta área específica y la posibilidad de ser funcionalizados, entre otras características, han hecho que los NTC sean propuestos y se utilicen para un sinfin de aplicaciones. Así, algunas de éstas son: i) electrodos para celdas de combustible y baterías de litio; ii) nanocompuestos, para mejorar la dureza, elasticidad y conductividad de materiales (raquetas de tenis); iii) Supercapacitores electroquímicos (autos eléctricos).

Las interesantes fibras de carbono también tienen múltiples aplicaciones, entre las que podemos citar: i) adsorbentes; ii) separación 
y almacenamiento de gases; iii) soportes de catalizadores; iv) precursores de materiales porosos (catalizadores, soportes de catalizadores, etc.).

La gran variedad de geles de carbono, con diferentes distribuciones de meso y microporos y por ende de áreas interfaciales, pueden tener propiedades tan disímiles que algunos se utilizan como conductores y otros como aislantes eléctricos. En electroquímica se los utiliza como soportes de catalizadores y como supercapacitores. Aquellos con gran área son efectivos como adsorbentes y por lo tanto se usan para adsorber gases y purificar agua.

Los negros de carbono, los cuales poseen una predominancia de uniones químicas $\mathrm{sp}^{2}$ son aglomerados de partículas de tamaños similares entre sí. Sin embargo, cada negro de carbono tiene partículas de distinto tamaño, modificando las propiedades de cada material. Uno de los carbones más conocidos y utilizados de este grupo, el Vulcan $\mathrm{XC72}{ }^{\circledR}$, debido a su muy buena conductividad y facilidad para ser dispersado se utiliza en baterías y en celdas de combustible.

Sin duda, uno de los tipos de carbones más utilizados en la industria son los carbones activados. Éstos son materiales que luego de ser sintetizados, con el objetivo de aumentar la porosidad y el área específica, se les aplica un proceso de activación. Éste puede ser físico o químico. En el primer caso se lo expone a vapor de agua y $\mathrm{CO}_{2}$ (pueden utilizarse las dos sustancias o sólo una). Estos agentes son capaces de extraer átomos de $\mathrm{C}$ de la estructura original, originando huecos $\mathrm{o}$ poros en ella. Para la activación química se utilizan muchas sustancias, entre ellas: $\mathrm{H}_{3} \mathrm{PO}_{4}, \mathrm{ZnCl}_{2}, \mathrm{KOH}$ y $\mathrm{Na}_{2} \mathrm{CO}_{3}$, las cuales tienen la capacidad de deshidratar los materiales. Así, se obtienen materiales con áreas específicas de $500-2000 \mathrm{~m}^{2} \mathrm{~g}^{-1}$, los cuales pueden utilizarse en catálisis y en supercapacitores electroquímicos, pero efectivamente, los de mayores áreas específicas han generado una producción gigante de este tipo de materiales para ser utilizados como adsorbentes [23].

En esta tesis se planteó abordar el estudio electroquímico de electrodos porosos de la manera más general posible, tratando de 
comprender los procesos básicos que gobiernan el funcionamiento de este tipo de electrodos en cada uno de los sistemas estudiados. Asimismo, se eligieron sistemas que están directamente relacionados con aplicaciones concretas de estos materiales. 


\subsection{Referencias Bibliográficas.}

[1] S. M. Aceves, J. Martínez-Frías, O. Garcia-Villazana. Analytical and experimental evaluation of insulated pressure vessels for cryogenic hydrogen storage. Int. J. Hydrogen Energy,25 (2000) 1075-1085.

[2] T. Sakai, I. Uehera, H. Ishikawa. R\&D on metal hydride materials and Ni-MH batteries in Japan. J. Alloys Compd., 293/295 (1999) 762-769.

[3] C. Nützenadel, A. Züttel, D. Chartouni, L. Schlapbach. Electrochemical Storage of Hydrogen in Nanotube Materials. Electrochem. Solid-State Lett. 2 (1999) 30-32.

[4] C. Nützenadel, A. Züttel, L. Schlapbach, en: H. Kuzmany (Ed.), Electronic Properties of Novel Materials- Science and Technology of Molecular Nanostructures, American Institute of Physics, 1999, p. 462.

[5] N. Rejalakshmi, K. S. Dhathathreyan, A. Gowindraj, B. C. Statishkumar. Electrochemical investigation of single-walled carbon nanotubes for hydrogen storage. Electrochim. Acta, 45 (2000) 4511-4515.

[6] X. Qin, X. P. Gao, H. Liu, H. T. Yuan, D. Y. Yan, W. L. Gong, D. Y. Song. Electrochemical Hydrogen Storage of Multiwalled Carbon Nanotubes. Electrochem. Solid-State Lett., 3 (2000) 532-535.

[7] A. Züttel, P. Sudan, Ph. Mauron, T. Kiyobayaschi, Ch. Emmenegger, L. Schlapbach. Hydrogen storage in carbon nanostructures. Int. J. Hydrogen Energy, 27 (2002) 203-212.

[8] B. E. Conway. Electrochemical supercapacitors: scientific fundamentals and technological applications. New York: Kluwer Academic/Plenum; 1999.

[9] E. Frackowiak, F. Béguin. Carbon materials for the electrochemical storage of energy in capacitors. Carbon 39 (2001) 937-50.

[10] Carbons for Electrochemical Energy Storage and Conversion Systems. Editores F. Béguin, E. Frackowiak. CRC Press Taylor \& Francis Group, Boca Raton, London, New York; 2010.

[11] J. M. D. Tascón. Materiales de carbono: estructuras y formas. Opt. Pura Apl., 40 (2) (2007) 149-159. 
[12] R. B. Heimann, S.E. Evsyukov, Y. Kocac. Carbon allotropes: a suggested classification scheme based on valence orbital hybridization. Carbon 35 (1997) 1654.

[13] H. W. Kroto, J. R. Heath, S. C. Obrien, R. F. Curl, R. E. Smalley. C60-Buckminsterfullerene. Nature, 318 (1985) 162-163.

[14] R. E. Smalley. Formation and properties of C60 and the fullerenes, National Institute of Standards and Technology, Dec. 6-7, 1990.

[15] M. S. Dresselhaus. Oral presentation at fullerene workshop. University of Pennsylvania, 1991.

[16] S. Iijima. Helical microtubules of graphitic carbon. Nature, 354 (1991) 56-58.

[17] S. Iijima, T. Ichihashi. Single-shell carbon nanotubes of 1-nm diameter. Nature, 363 (1993) 603-605.

[18] D. S. Bethune, C. H. Klang, M. S. de Vries, G. Gorman, R. Savoy, J. Vazquez, R. Beyers. Cobalt-catalysed growth of carbon nanotubes with single-atomic-layer walls. Nature 363 (1993) 605-607.

[19] Carbon nanotubes: properties and applications. Editor Michael O'Connell. Taylor \& Francis Group, LLC; 2006.

[20] K. S. Novoselov, A. K. Geim, S. V. Morozov, D. Jiang, Y. Zhang, S. V. Dubonos, I. V. Grigorieva, A. A. Firsov. Electric Field Effect in Atomically Thin Carbon Films. Science, 306 (2004) 666-669.

[21] http://www.esacademic.com/dic.nsf/eswiki/70421.

[22] Boletín n 9 del Grupo Español del Carbón (GEC). Junio 2008. www.gecarbon.org.

[23] H. Marsh, F. Rodríguez-Reinoso. Activated carbon. Elsevier. 2006. 


\section{Capitulo 2}

\section{Métodos}

Con el objetivo de facilitar la lectura de este trabajo de tesis, en este capitulo se describen de manera breve diversas técnicas experimentales, sistemas electroquímicos y un modelo fisicoquímico para electrodos porosos. Debido a que muchos de estos conceptos, sistemas, etc., aparecen reiteradas veces en este trabajo, decidimos oportuno presentar un capítulo dedicado a esos tópicos a continuación de la Introducción General y antes de la presentación de los diferentes resultados experimentales y su consiguiente análisis.

\subsection{Caracterización textural de los materiales}

\subsubsection{Isotermas de adsorción}

La cantidad de gas adsorbido ( $n$ ) sobre la superficie de un sólido es proporcional a la masa de adsorbente y depende de la presión $(P)$, la temperatura (T), y de la naturaleza tanto del adsorbato como del adsorbente. Por lo tanto,

$$
n=f(P, T \text {, gas, sólido })
$$

Dados el gas que actúa como adsorbato, el sólido como adsorbente y manteniendo la temperatura fija, la cantidad de gas adsorbido será únicamente función de la presión, lo que nos permite escribir que

$$
n=f(P)_{T, \text { gas, sólido. }}
$$


La representación de la cantidad de gas adsorbido versus la presión absoluta de equilibrio $(P)$ o la presión relativa $\left(P / P_{0}\right)$ se denomina isoterma de adsorción. Si la temperatura está por debajo de la temperatura crítica del gas, entonces, $P_{O}$ es la presión de vapor del líquido a la temperatura de adsorción.

$\mathrm{Si}$ bien existe una cantidad innumerable de adsorbentes de diferente constitución química, simplemente teniendo en cuenta las diferentes familias de carbones que logran ser sintetizados en la actualidad de manera controlada, las medidas de adsorción de diferentes gases resultan en isotermas con diferentes formas. No obstante, la IUPAC ha logrado clasificar las isotermas de adsorción física en seis grupos principales [1]. Sin embargo, muchos de los materiales utilizados como adsorbentes poseen una extensa variedad de poros caracterizados por su forma y tamaño, haciendo que se generen isotermas con formas intermedias de la clasificación de la IUPAC.

En la Figura 2.1 se resume las isotermas de manera esquemática, de acuerdo a la clasificación de IUPAC [1]:

I- Son características de sólidos microporosos cuya área superficial externa es relativamente baja (carbón activado, zeolitas, etc.). Usualmente son obtenidas con carbones activados con la mayoría de los gases o vapores comúnmente utilizados.

II- Son isotermas típicas de adsorbentes no porosos o macroporosos (esto es, $\mathrm{N}_{2}$ a $77 \mathrm{~K}$ sobre carbono grafito, NTC y negro de carbono). Estas isotermas muestran adsorción en mono y multicapas. El punto B indica el estado en el cual se completa una monocapa y comienza la adsorción en multicapas. 


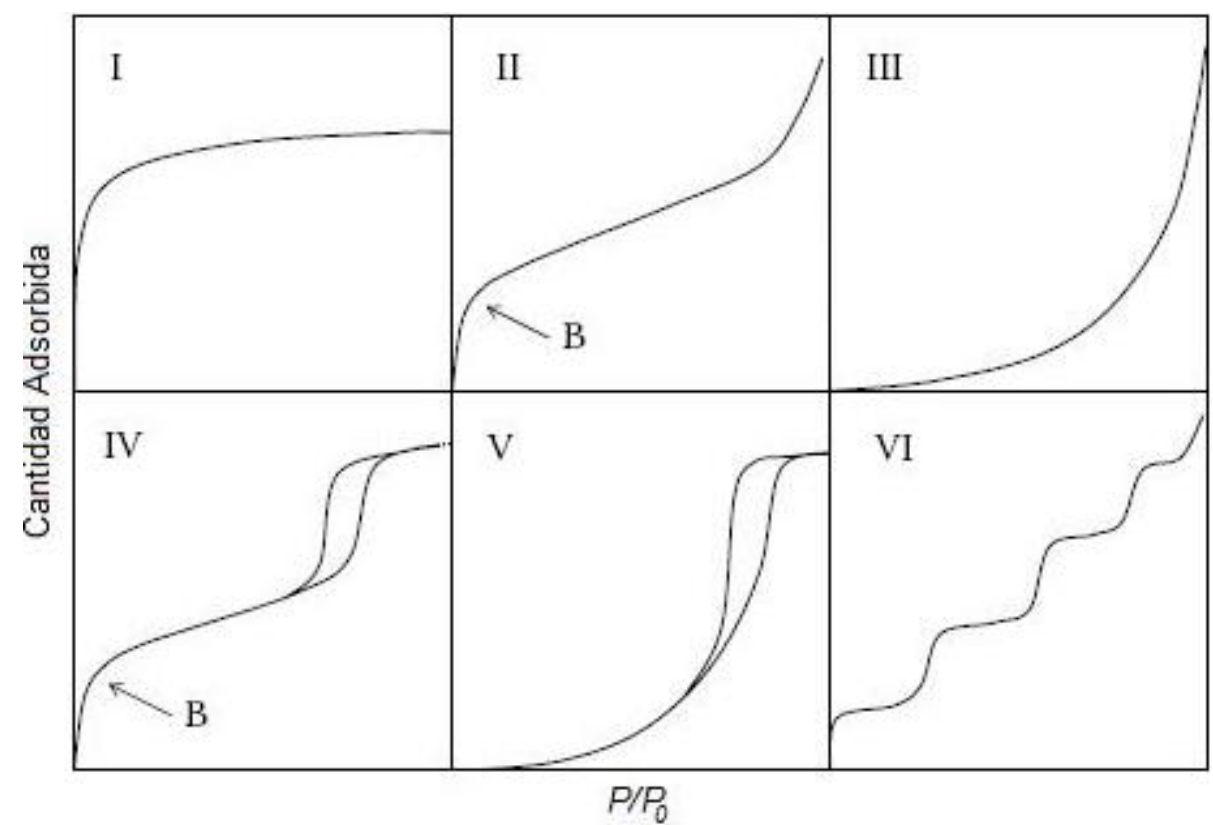

Figura 2.1: Clasificación de isotermas IUPAC [1].

III- Son isotermas poco comunes, características de sistemas en que las interacciones adsorbato-adsorbente son muy débiles y son típicas de una adsorción cooperativa. Se presenta, por ejemplo, en la adsorción de vapor de agua sobre negro de carbono grafitizado.

IV- Las isotermas de este tipo se caracterizan por presentar un ciclo de histéresis, esto es, las curvas de adsorción y de desorción no coinciden, debido a la condensación capilar que ocurre en los mesoporos. Estas curvas son características de adsorbentes que presentan una alta proporción de mesoporos (por ejemplo, negros de carbono compactados, carbones nanoestructurados preparados utilizando moldes de sílice, etc.).

V- Este tipo de isoterma está relacionada con la tipo III. Son también características de interacciones adsorbato-adsorbente débiles, como ocurre por ejemplo cuando se adsorbe vapor de agua sobre carbón vegetal.

VI- Son típicas de adsorbentes con una superficie muy uniforme y que no es porosa. Cada escalón representa la adsorción de una monocapa. Este tipo de isoterma es observada cuando se adsorbe un gas noble sobre negro de carbón grafitizado. 
La selección del adsorbato debe cumplir con algunas características generales:

1- Ser químicamente inerte para evitar interacciones específicas con el adsorbente.

2- Tener una presión de saturación $\left(P_{0}\right)$ relativamente alta a la temperatura de adsorción, para cubrir todo el ámbito de porosidad.

3- Que la molécula tenga una forma lo mas esférica posible para minimizar el error en el cálculo de la sección transversal. Esto es importante para la estimación del área superficial del adsorbente.

De todos los adsorbatos, el $\mathrm{N}_{2}$ adsorbido a $77 \mathrm{~K}$ es el más utilizado. Este adsorbente cumple razonablemente bien con las características mencionadas anteriormente. La temperatura de análisis es alcanzada fácilmente $\mathrm{y}$, a ésta, la adsorción con $\mathrm{N}_{2}$ cubre varios órdenes de presiones relativas (de $10^{-8}$ hasta 1 ), en el cual se produce la adsorción en todo el ámbito de porosidad. Un problema que se presenta con $\mathrm{N}_{2}$ es que la presión de saturación a $77 \mathrm{~K}\left(P_{0}=1\right.$ bar $)$ es algo baja y, por lo tanto, es necesario disponer de un sistema adecuado para alcanzar y medir presiones muy bajas. Se emplean bombas turbomoleculares, transductores de presión de alta sensibilidad, etc. Pero, la principal desventaja de la adsorción de $\mathrm{N}_{2}$ a $77 \mathrm{~K}$ es que cuando se utiliza para la caracterización de sólidos microporosos, se produce la difusión de las moléculas dentro de los microporos estrechos (diámetro $<0,7 \mathrm{~nm}$ ) con una cinética de adsorción muy lenta, y en consecuencia un tiempo de equilibrio que puede ser extremadamente largo. Esta desventaja generalmente es una fuente de error para la evaluación de la microporosidad $\mathrm{y}$, en la mayoría de los casos, el adsorbente no puede ser utilizado para la caracterización de materiales con microporos muy estrechos, como ocurre con los tamices moleculares carbonosos, carbones vegetales, etc. [2-6].

Para solucionar este problema se ha planteado el uso de otros adsorbentes. Así, ha sido propuesta la adsorción de He a 4,2K [7-10] 
como método para realizar una determinación adecuada de la microporosidad. El átomo de $\mathrm{He}$ es el más pequeño de todos los adsorbentes utilizados, tiene una forma esférica e interacciona débilmente con cualquier superficie sólida [7]. Además, requiere menor tiempo para alcanzar el equilibrio y la cantidad adsorbida es mayor que en el caso del $\mathrm{N}_{2}$ a $77 \mathrm{~K}$. En este trabajo, los autores concluyen que el análisis de la microporosidad con $\mathrm{N}_{2}$ puede dar resultados erróneos [7]. A pesar de todos estos resultados interesantes y promisorios obtenidos con adsorción de $\mathrm{He}$, las condiciones experimentales utilizadas $(4,2 \mathrm{~K})$ hacen que esta técnica no pueda ser utilizada para realizar caracterizaciones de rutina.

La adsorción de $\mathrm{CO}_{2}$, tanto a 273 como a 298K [2-4,11-15], es otra alternativa muy útil para el acceso a los microporos más estrechos. Si bien el tamaño de la molécula de $\mathrm{CO}_{2}$ es similar a la de $\mathrm{N}_{2}$, la mayor temperatura de adsorción del $\mathrm{CO}_{2}$ genera mayor energía cinética en las moléculas, las cuales son capaces de acceder a los microporos más estrechos. De esta manera, ha sido demostrado que este gas es un adsorbente que complementa muy bien los resultados obtenidos con $\mathrm{N}_{2}$, debido a que permite un buen análisis de la microporosidad [4,6-16,17]. La principal desventaja de este gas es que $P_{0}$ es algo alta (34,7 y 64,1 bar a 273 y $298 \mathrm{~K}$, respectivamente) y por lo tanto es necesario llevar a cabo la adsorción hasta altas presiones para cubrir todo el ámbito de porosidad.

\subsubsection{Distribución de Tamaño de Poros (DTP)}

Si bien parámetros como el área superficial y el volumen de los poros, entre otros, son importantes, una caracterización completa del adsorbente necesitará del conocimiento de la DTP. La DTP será la que determinará en gran parte las propiedades de adsorción del material estudiado, y así, su desempeño en una aplicación determinada. Hay varios ejemplos en la literatura donde materiales de carbono con similares áreas superficiales y tamaño promedio de poros, presentan diferentes resultados para una aplicación particular. Estos casos son 
usualmente encontrados, por ejemplo, en el almacenamiento de hidrógeno desde fase gaseosa a temperatura ambiente, observándose que carbones activados con diámetro de poro medio alrededor de 0,6nm muestran las mayores capacidades de adsorción de hidrógeno [18,19], mientras que para el desarrollo de supercapacitores SC, la DTP tiene una gran influencia en la accesibilidad de los iones del electrolito a los poros del material y en la optimización de la adsorción de los iones en la DCE [20,21].

No se conoce un método definitivo para determinar la DTP en la región de los microporos, debido a las características especiales de la interacción entre la molécula de adsorbato y el adsorbente en los poros de esos tamaños. El solapamiento de los potenciales de paredes opuestas de los pequeños poros, genera que las moléculas adsorbidas se comporten de manera muy diferente que cuando se encuentran interaccionando en superficies abiertas.

Un método comúnmente utilizado para calcular la DTP es la Teoría Funcional de la Densidad (DFT, del inglés, Density Functional Theory). Éste no puede ser considerado como un método definitivo pero sí muchas veces efectivo para la determinación de la DTP. Esto se explica porque: 1) la forma de los poros se considera como perfectos cilindros o hendiduras; 2) no se tienen en cuenta los defectos en la superficie de los grafenos; 3) se ignora la presencia de grupos funcionales en los carbones; 4) no se considera la conectividad de los poros. Los métodos para el cálculo de la DTP no pueden ser aplicados en condiciones fuera del equilibrio, como ocurre comúnmente para las isotermas de adsorción de $\mathrm{N}_{2}$ en materiales con microporos pequeños.

\subsection{Sistema electroquímico}

En este trabajo de tesis se han utilizado celdas electroquimicas de tres electrodos. Generalmente, interesa la reacción que ocurre en uno de los electrodos, llamado electrodo de trabajo (ET). El potencial al cual se encuentra este electrodo es impuesto por el PotenciostatoGalvanostato y medido con respecto a otro electrodo que se comporta 
como un electrodo no-polarizable ideal, es decir, cuyo potencial no cambia con el pasaje de corriente y se caracteriza por exhibir un potencial fijo y conocido, denominado electrodo de referencia, ER. En el esquema presentado en la Figura 2.2 se ha incluido un voltímetro, V, colocado en paralelo, es decir, entre el ET y el ER. Este posee una resistencia interna muy alta para que la corriente que pase por el dispositivo sea despreciable, generando una perturbación mínima en el sistema. Cuando se trabaja con tres electrodos, la corriente fluye entre el ET y el contraelectrodo (CE), puesto que el PotenciostatoGalvanostato coloca una gran resistencia entre el ET y el ER. El amperimetro, A, mide la corriente que pasa. Para efectuar la medida es necesario que la corriente circule por el amperimetro, por lo que éste debe colocarse en serie. El amperimetro debe poseer una resistencia interna lo más pequeña posible con la finalidad de evitar una caída de tensión apreciable, esto es, al ser muy pequeña permitirá un mayor paso de electrones para su correcta medida. Tanto el voltímetro como el amperimetro fueron colocados en la figura para graficar y comprender el funcionamiento del sistema completo. Los tres electrodos son conectados al equipo electrónico, el cual está acoplado a una computadora que permite tanto programar los experimentos a realizar como obtener las respuestas de éstos.

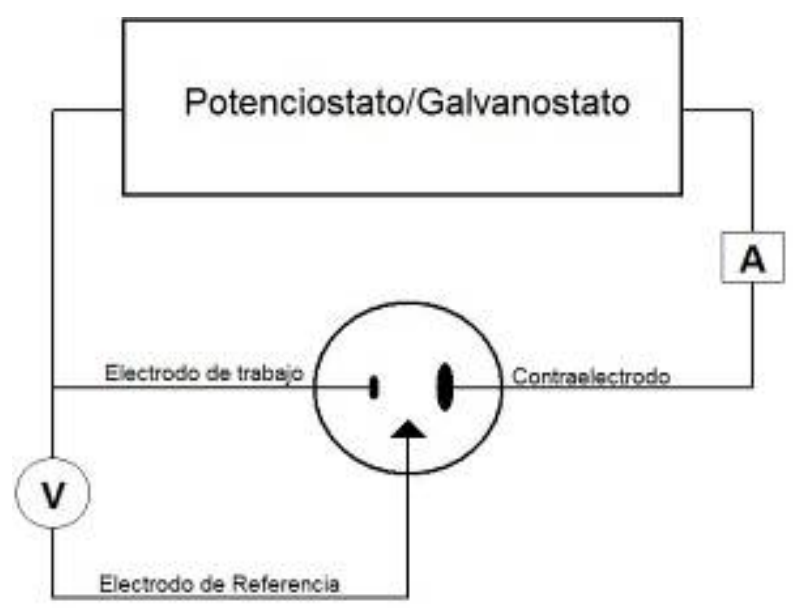

Figura 2.2: Representación esquemática del sistema electroquímico básico utilizado en este trabajo.

La conducción eléctrica entre los electrodos es producida por los iones del electrolito donde están sumergidos. Tanto los electrodos como 
el electrolito y el diseño de la celda variaron en los experimentos presentados en cada sección. En cada una de las secciones se detallan los componentes del sistema electroquímico.

Una mejor comprensión de un sistema electroquímico, es decir, en qué consiste y cómo funciona, se logra representándolo con un circuito eléctrico equivalente (Figura 2.3). En éste se colocaron los electrodos como terminales, observándose asimismo las diferentes variables que están presentes en las medidas electroquímicas cuando se polarizan los electrodos. En este caso simplificado se muestra la capacidad de la doble capa eléctrica (DCE) que se forma en la interfaz electrodo de trabajo / solución electrolítica, $C_{d l}$, la resistencia a la transferencia de carga, $R_{t}$, y la resistencia de la solución electrolítica, $R_{s}$. La solución electrolítica es responsable del transporte de la corriente por los iones que la constituyen.

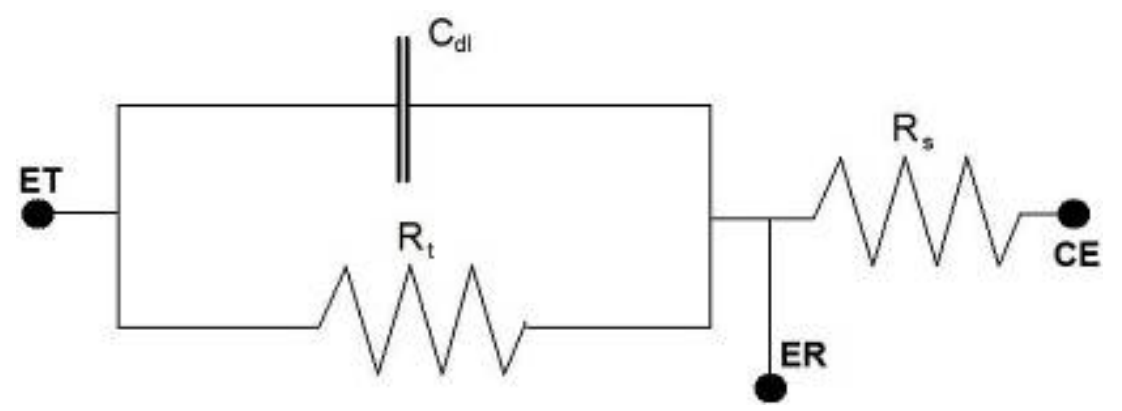

Figura 2.3: Circuito eléctrico equivalente comúnmente utilizado para modelar un sistema electroquímico como el utilizado en este trabajo.

\subsection{Técnicas electroquímicas}

\subsubsection{Cronoamperometria}

Este método consiste en aplicar un escalón de potencial constante durante un tiempo t (Figura 2.4) registrando como respuesta la corriente que cambia con $t$, por lo cual a esta técnica se la conoce como cronoamperometría, CA. Para el tiempo $t_{1}=0$ el electrodo se encuentra a un potencial inicial $\mathrm{E}_{1}$ y a $\mathrm{t}_{2}$ se lo lleva instantáneamente hasta un potencial $\mathrm{E}_{2}$. En ese momento se comienza a medir la corriente como respuesta al escalón de potencial aplicado. Esta corriente contiene la contribución de la DCE y luego, si la energía provista por $\mathrm{E}_{2}$ es suficiente, comenzará a producirse alguna 
transferencia de carga faradaica. Por ejemplo, se presenta el caso en el que una sustancia $A$ se oxida a otra $B$ al potencial $E_{2}$, siendo ésta una reacción rápida y reversible (nernstiana). Al aplicar el escalón de potencial, la corriente alcanza un valor máximo debido a la reorganización de la DCE y al comienzo de la oxidación de A para generar B. A medida que el tiempo avanza ( $t>t_{2}$ ), la concentración de A sobre la superficie del electrodo $\left[\mathrm{C}_{\mathrm{A}}(0, \mathrm{t})\right]$ disminuye hasta alcanzar una concentración cero $\left[\mathrm{C}_{\mathrm{A}}(0, \mathrm{t})=0\right]$. Como consecuencia de esto, siempre que la reacción electroquímica sea más rápida que el flujo de moléculas hacia el electrodo, el sistema está bajo control difusional y la corriente disminuirá con la inversa de $\mathrm{t}^{1 / 2}$.
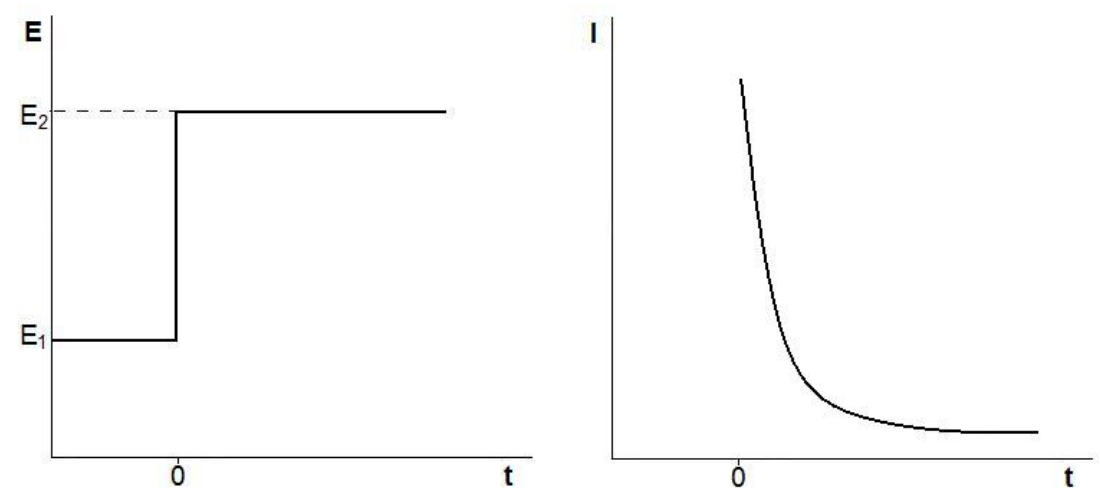

Figura 2.4: Perturbación de potencial aplicada y respuesta típica de I vs. t en una CA.

\subsubsection{Voltamperometria Cíclica (VC)}

En este método se aplica un potencial que cambia en forma lineal con el tiempo, obteniendo como respuesta una corriente resultante definiendo así un método potenciodinámico. Se advierte entonces la diferencia con la CA porque en esta última se fija el ET a un potencial constante durante un cierto tiempo $t$, mientras que en la VC el potencial cambia en forma lineal con $\mathrm{t}$.

La VC es el método más utilizado en experimentación electroquímica porque proporciona datos que permiten tener una idea importante del comportamiento electroquímico del sistema a estudiar. Por lo tanto, es la primera técnica que se emplea al comenzar a trabajar con un sistema desconocido. Ésta consiste en aplicar un barrido lineal de potencial como el que se muestra en la Figura 2.5. Comienza en un 
potencial inicial, $\mathrm{E}_{1}, \mathrm{y}$ avanza hasta un potencial, $\mathrm{E}_{2}$, a una velocidad constante $\mathrm{v}=\mathrm{dE} / \mathrm{dt}$ o velocidad de barrido. En $\mathrm{E}_{2}$ se invierte la dirección del barrido hasta alcanzar el potencial $E_{1}$, a la misma velocidad de barrido con que se cambió de $E_{1}$ a $E_{2}$, definiendo en este caso un barrido simétrico. A medida que se aplica el barrido de potencial, se registra la corriente I obteniendo curvas I vs. E (o I vs. t). Cada barrido triangular realizado $\left(\mathrm{E}_{1}-\mathrm{E}_{2}-\mathrm{E}_{1}\right)$ se lo denomina ciclo voltamperométrico y da como resultado una curva I vs. E denominada voltamperograma. En la Figura 2.5 se muestra un voltamperograma típico.
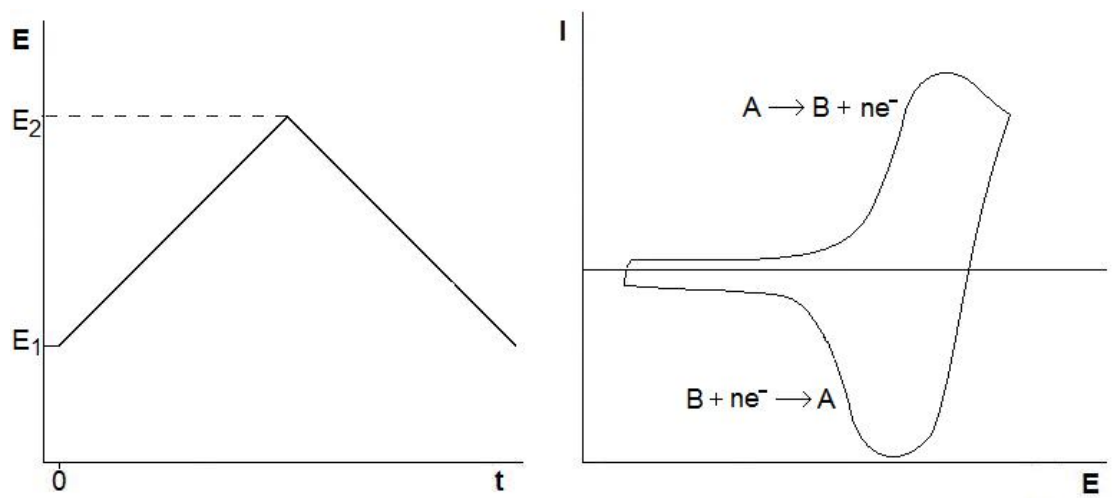

Figura 2.5: Perturbación de $\mathrm{E}$ aplicado y respuesta típica de I vs. E en una VC.

Cuando comienza el barrido al potencial $E_{1}$, es decir, a un potencial más negativo que el potencial formal $\mathrm{E}_{0}$ ' correspondiente a la cupla redox A/B, sólo fluirán corrientes no faradaicas, es decir, se produce el flujo de iones con carga contraria a la del electrodo aumentando la densidad de carga de la DCE como respuesta a un aumento de la densidad de carga en la superficie del electrodo. Cuando se alcanzan valores de potencial en el entorno de $\mathrm{E}_{0^{\prime}}$, comienza el flujo de electrones desde la solución hacia el electrodo, producto de la oxidación de moléculas de A para dar moléculas de B (corriente faradaica). A medida que el potencial se va haciendo más positivo, la corriente aumenta y por lo tanto la velocidad de oxidación, lo cual genera una disminución de la concentración superficial de A. A medida que el potencial se mueve hacia valores más positivos que $E_{0}$ la concentración superficial cae a valores cercanos a cero y la 
transferencia de masa debida a A alcanza su máxima velocidad. Consecuentemente, el proceso total es dominado por la difusión de las moléculas de A desde el seno de la solución hacia la superficie del electrodo, y por lo tanto se llega a un valor máximo de corriente, el cual comienza a decaer conforme la concentración de A continúa disminuyendo. Como resultado de la presencia de dos procesos que generan resultados inversos, el aumento de potencial y la disminución de concentración en la superficie del electrodo, se obtiene una curva que presenta un pico de corriente $\mathrm{I}_{\mathrm{p}}$ a un dado potencial $\mathrm{E}_{\mathrm{p}}$. Por otro lado, si se invierte la dirección del barrido del potencial (desde $\mathrm{E}_{2}$ hasta $E_{1}$ ), se fuerza a los electrones a pasar desde el electrodo hacia la solución obteniendo una respuesta análoga, sólo que ahora, las moléculas de B captarán electrones, reduciéndose para formar A.

\subsubsection{Cronopotenciometria}

Hasta aquí se presentaron dos métodos electroquímicos en los cuales la variable impuesta es el potencial y la respuesta medida es la corriente. En la cronopotenciometría, como su nombre lo indica, se mide el valor del potencial del ET en función del tiempo, mientras que la variable impuesta o que controla es la corriente que pasa entre el ET y el CE.

Existen diferentes tipos de cronopotenciometrias, de acuerdo al modo de aplicación de la corriente. Sin embargo, usualmente se utilizan uno o varios escalones de corriente. En la Figura 2.6 se muestra la perturbación de corriente aplicada y una respuesta típica de potencial, ambos en función del tiempo que dura la perturbación. Este caso puede entenderse volviendo al ejemplo de la sustancia A que se oxida para dar la sustancia B en la superficie del electrodo, ahora a velocidad constante (I=constante). Cuando el proceso comienza, el potencial del electrodo se mueve hacia el valor $\mathrm{E}_{0}$ ', característico de la cupla redox A/B, y varía con el tiempo conforme las concentraciones de estos compuestos cambian. Como se puede observar, el potencial del electrodo aumenta continuamente porque la concentración de A va 
disminuyendo y por lo tanto, se necesita una mayor energía para mantener constante la velocidad del proceso. Cuando la concentración de A es muy baja, el flujo de estas moléculas es insuficiente para captar todos los electrones que son forzados a pasar a través de la interfase electrodo-solución. Debido a este hecho, el potencial del electrodo comienza a aumentar rápidamente hasta alcanzar un valor suficiente como para que comience otro proceso. El tiempo durante el cual el proceso de oxidación de A es el principal contribuyente de electrones a la superficie del electrodo es llamado tiempo de transición $(\tau)$. Este parámetro está relacionado con la concentración y el coeficiente de difusión de las especies A que reaccionan y es el análogo al pico de corriente o a la corriente limite observada en los experimentos realizados a potencial controlado.
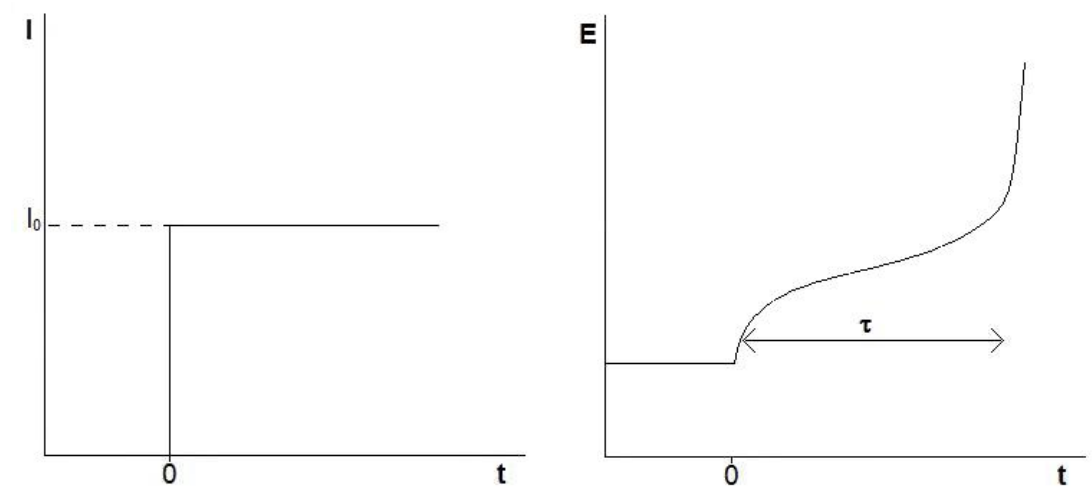

Figura 2.6: Perturbación de E aplicada y respuesta típica de I vs. t en una CP.

\subsubsection{Espectroscopia de Impedancia Electroquímica}

La impedancia es una función particular de una clase más general de las llamadas funciones de transferencia. Esta clase de funciones se define para sistemas lineales e invariantes en el tiempo. Designaremos a este tipo de sistemas como Sistemas LIT.

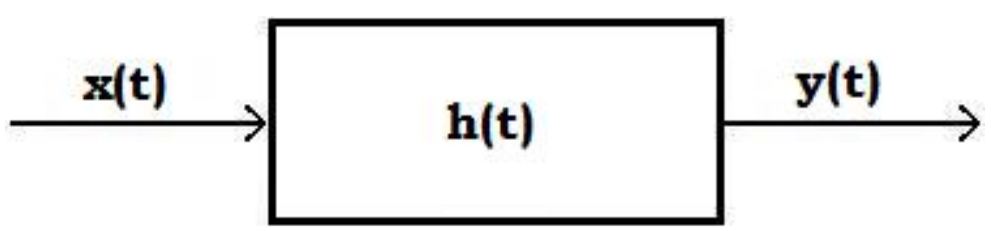

Figura 2.7: Representación esquemática de un sistema LIT. 
En un sistema lineal, para una dada perturbación

$$
\mathrm{x}(\mathrm{t})=\mathrm{x}_{1}(\mathrm{t})+\mathrm{x}_{2}(\mathrm{t})
$$

la respuesta es una suma del tipo

$$
\mathrm{y}(\mathrm{t})=\mathrm{y}_{1}(\mathrm{t})+\mathrm{y}_{2}(\mathrm{t})
$$

Además, si éste es invariante en el tiempo, la respuesta será idéntica para cualquier tiempo de aplicación de $\mathrm{x}(\mathrm{t})$.

Si un sistema es del tipo LIT cumple la siguiente relación entre la perturbación y la respuesta, dada por el Teorema de Convolución:

$$
y(t)=\int_{0}^{t} h(\tau) x(t-\tau) d \tau
$$

donde $h(\tau)$ es llamada función impulso; $x(\mathrm{t})$ es la perturbación; $y(\mathrm{t})$ es la respuesta. De la ecuación (2.1) se desprende que la respuesta del sistema es simplemente la convolución de la perturbación con la función impulso $h$. Este análisis, realizado en el dominio del tiempo, puede ser llevado al campo de las frecuencias realizando las transformadas de Fourier o de Laplace de la ecuación (2.1).

La transformada de Fourier (TF) se define como:

$F(s)=\int_{-\infty}^{\infty} f(t) \exp (-s t) d t$

$s=j \omega$

aplicando las ecuaciones (2.1) y (2.2) se obtiene:

$\mathrm{Y}(j \omega)=\mathrm{H}(j \omega) . \mathrm{X}(j \omega)$,

donde $\mathrm{H}(j \omega)$ es la Función de Transferencia del sistema.

En el Esquema 2.8 se muestra la relación entre el dominio temporal y el dominio de frecuencias para un sistema LIT. Luego, en ese Esquema se indica la integral de convolución como $h(t) * x(t)$, donde $\left({ }^{*}\right)$ se refiere a la convolución. Aplicando la $\mathrm{TF}$ a $x(\mathrm{t})$ se pasa al dominio de las frecuencias dando $\mathrm{X}(j \omega)$, y para $y(t)$ se obtiene $\mathrm{Y}(j \omega)$. Ahora se tiene la relación $\mathrm{Y}(j \omega)=\mathrm{H}(j \omega) . \mathrm{X}(j \omega)$, es decir que $\mathrm{Y}(j \omega)$ es el producto $(\mathrm{X})$ de $\mathrm{H}(j \omega) . \mathrm{X}(j \omega)$, siendo $\mathrm{H}(j \omega)$ la Función de Transferencia del sistema. 


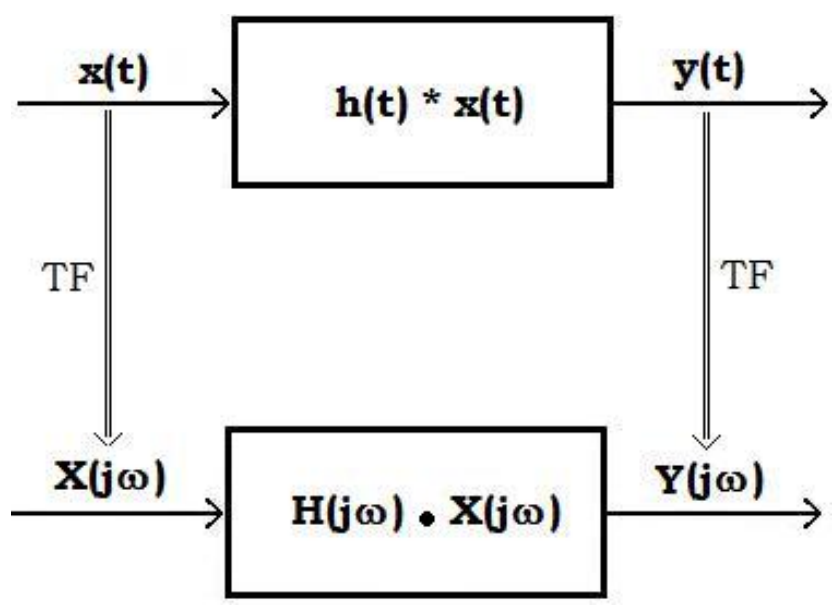

Figura 2.8: Representación esquemática de la $\mathrm{TF}$ aplicada a la integral de convolución.

Por lo tanto, la convolución en el dominio del tiempo es equivalente al producto en el dominio de las frecuencias. Si este sistema lineal es perturbado con una señal periódica $x(t)$, del tipo sinusoidal, cuya frecuencia es $\omega$,

$x(t)=|X| \exp (j \omega t)$

por ser un sistema LIT, la respuesta tendrá la misma frecuencia, pero la amplitud y el ángulo de fase serán diferentes:

$y(t)=|Y| \exp (j(\omega t+\phi))$

Ahora se puede calcular la función de transferencia de la siguiente manera:

$H(\omega)=\frac{|Y|}{|X|} \exp (j \phi)=|H(\omega)| \exp (j \phi)$

De forma tal que la función de transferencia en general es una función compleja que también puede escribirse como:

$H(\omega)=|H(\omega)|(\cos (\phi)+i \operatorname{sen}(\phi))$

Cuando la perturbación es una señal de potencial y la respuesta es una señal de corriente, la inversa de la función de transferencia corresponde a la impedancia del sistema $Z(\omega)$.

Para una mayor claridad de la aplicación de estos conceptos en electroquímica, se muestran a continuación algunos ejemplos con circuitos eléctricos simples. 
En la Figura 2.9 se muestran los tres elementos eléctricos más comunes. El caso más simple es el de una resistencia $(R)$, Figura 2.9 (a). Al aplicar una diferencia de potencial a través de una $R$, la corriente $(I)$ estará dada por la ley de Ohm.

$$
V=I R, \quad \frac{V}{I}=R
$$

Consecuentemente, cualquiera sea la perturbación aplicada, la impedancia $(Z)$ tendrá siempre el mismo valor, será un número real y no dependerá de la frecuencia.

Cuando una diferencia de potencial es aplicada entre los terminales de un capacitor (Figura 2.9 (b)), una cantidad de carga (q) es almacenada en cada una de sus placas y la magnitud de ésta depende de la capacidad $(C)$ del dispositivo. Este sistema está gobernado por las siguientes ecuaciones:

$$
\frac{d q}{d V}=C=i \frac{d t}{d V} \quad i=C \frac{d V}{d t}
$$

aplicando la transformada de Fourier:

$$
I(j \omega)=j \omega C . V(j \omega) \quad \frac{V(j \omega)}{I(j \omega)}=Z(j \omega)=\frac{1}{j \omega C}=-j \frac{1}{\omega C}
$$

Este resultado es totalmente diferente, dado que en este caso la impedancia es siempre un número imaginario que depende de la frecuencia.

Como último ejemplo de un elemento eléctrico aislado, desarrollamos de manera análoga a los anteriores el caso de una inductancia $(L)$ (Figura 2.9 (c)).

$L \frac{d i}{d t}=V(t)$

aplicando la transformada de Fourier:

$$
j \omega L . I(j \omega)=V(j \omega) \quad \frac{V(j \omega)}{I(j \omega)}=Z(j \omega)=j \omega L
$$

nuevamente, la impedancia será un número imaginario que dependerá de la frecuencia de la perturbación.

Por último, vamos a analizar los dos circuitos simples esquematizados en la Figura 2.9 (d) y (e), en los cuales combinamos una 
resistencia $R$ y un capacitor $C$. Para ello, debemos tener en cuenta que las impedancias de elementos en serie se suman mientras que cuando los elementos son conectados en paralelo, la inversa de la impedancia es la suma de las inversas de las impedancias de los elementos. Estos principios resultarán más claros al resolver los ejemplos.

Cuando colocamos una $R$ en serie con un $C$, la impedancia total estará dada por la suma de las impedancias de la resistencia y del capacitor.

$Z_{T}=Z_{R}+Z_{C}$

reemplazando con los resultados obtenidos anteriormente:

$Z_{T}=R+\frac{1}{j \omega C}=R-j \omega C$

por lo tanto, la componente real de la impedancia, $Z_{\text {real, será una }}$ constante, $R$, mientras que la componente imaginaria, $Z_{\text {imag, será }}$ negativa, proporcional a la capacidad y dependerá de la frecuencia de la perturbación.

Pero si ahora colocamos la $R$ y el $C$ en paralelo y operamos de manera análoga tenemos:

$$
\frac{1}{Z_{T}}=\frac{1}{Z_{R}}+\frac{1}{Z_{C}}=\frac{1}{R}+j \omega C \text { y } Z_{T}=\frac{R}{1+j \omega C R}=\frac{R}{1+(\omega C R)^{2}}-j \frac{\omega C R^{2}}{1+(\omega C R)^{2}}
$$

este resultado es claramente más complejo. En este caso ambas componentes dependerán de la frecuencia, de la resistencia y de la capacidad de los elementos.

De esta manera pueden construirse circuitos más complejos y calcular la impedancia total. Si bien el cálculo no genera problemas matemáticos aunque los circuitos sean relativamente complejos, muchas veces las ecuaciones obtenidas pueden llegar a ser dificiles de manejar. 


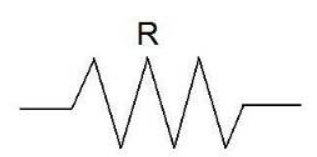

(a)

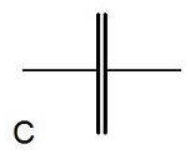

(b)

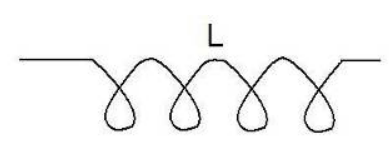

(c)

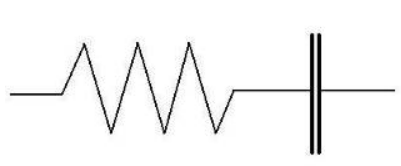

(d)

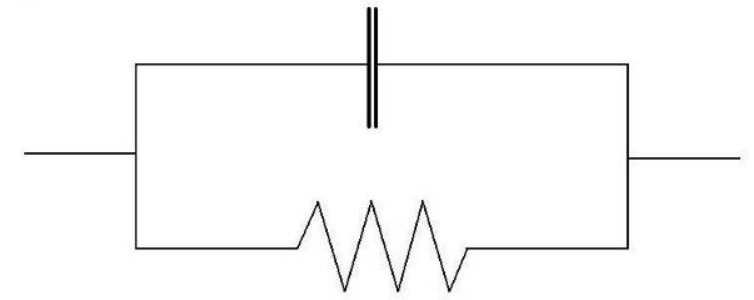

(e)

Figura 2.9: Elementos básicos de un circuito eléctrico (a), (b) y (c) y configuraciones en serie (d) y en paralelo (e) de los elementos básicos mostrados en (a) y (b).

Los resultados obtenidos a través de esta técnica generalmente son representados bajo la forma de Diagramas de Nyquist o de Diagramas de Bode. En los Diagramas de Nyquist se grafica en el eje de las abscisas la parte real de la impedancia y en el de las ordenadas la parte imaginaria. Por otra parte, existen dos tipos de Diagrama de Bode, donde en ambos se grafica en el eje de las abscisas el logaritmo de la frecuencia de la perturbación, pero en uno en el eje de las ordenadas se coloca el logaritmo del módulo de la impedancia, mientras que en el otro se ubica la fase de esta función, la cual es el ángulo que forma el vector impedancia con el eje de las abscisas. En la Figura 2.10 se muestran los Diagramas de Nyquist para los circuitos (d) y (e) de la Figura 2.9.
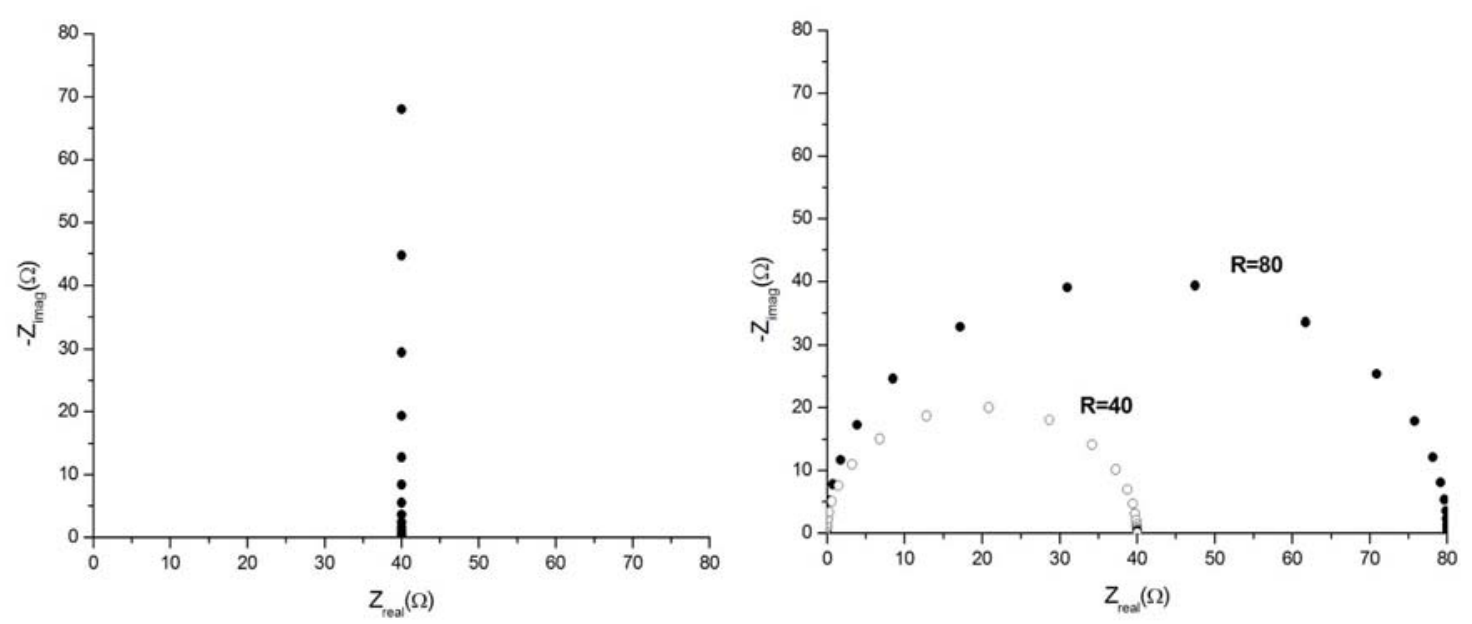
Figura 2.10: Diagramas de Nyquist obtenidos con: (a) $R=40$ y $C=0,0005$; (b) $R=80$ y 40 y $\mathrm{C}=0,0005$.

Los sistemas electroquímicos más simples como por ejemplo una chapa metálica en un electrolito generalmente pueden ser modelados por un circuito como el mostrado en la Figura 2.11. Cuando pasa una corriente por el sistema electroquímico (modelado por el circuito citado), ésta tiene que fluir a través del electrolito, el cual tiene una resistencia asociada que usualmente es llamada resistencia de la solución (modelada como $R_{S}$ ). En la superficie del electrodo, esta corriente participa en dos procesos en paralelo, es decir, la transferencia de carga faradaica, la cual tendrá asociada una impedancia faradaica $\left(Z_{f}\right)$, y la carga de la DCE, que es modelada como un capacitor cuya capacidad es $C$, este proceso está asociado a la impedancia capacitiva, $Z_{d l}$. De manera que la impedancia interfacial, $Z_{i}$, puede modelarse como la conexión en paralelo de $Z_{f}$ y $Z_{d l}$.

Siguiendo el tratamiento matemático aplicado anteriormente, podemos encontrar la impedancia del circuito que modela nuestro sistema electroquímico simple. La impedancia total será igual a la suma de la impedancia de la solución, $R_{s}$, más $Z_{i}$.

$Z_{T}=R_{s}+Z_{i}$

Donde:

$$
\frac{1}{Z_{i}}=\frac{1}{j \omega C_{d l}}+\frac{1}{Z_{F}} \quad Z_{T}=R_{s}+\left[\frac{1}{j \omega C_{d l}}+\frac{1}{Z_{F}}\right]^{-1}
$$

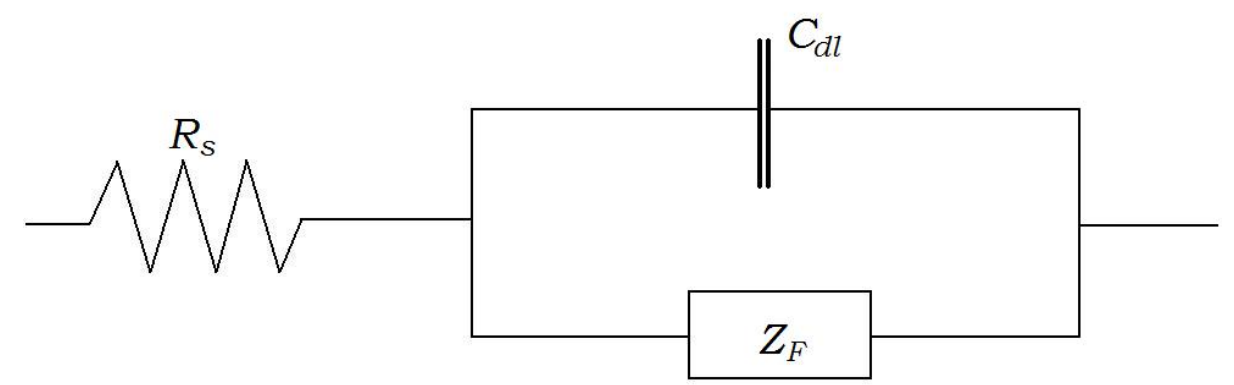

Figura 2.11: Circuito equivalente utilizado para modelar una transferencia de carga en un electrodo plano. 
en el caso en el cual $Z_{F}$ es equivalente a una resistencia $R_{t}$, se obtiene el diagrama que se muestra en la Figura 2.12.

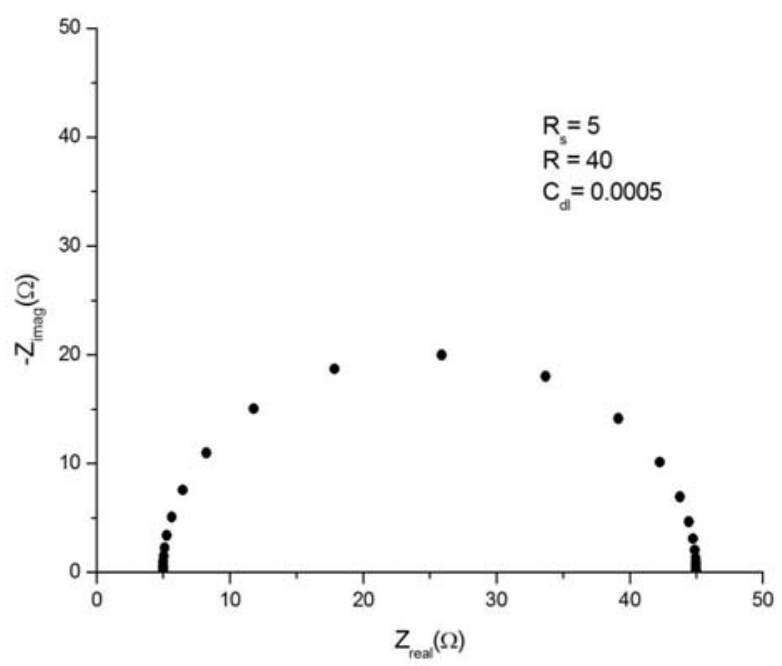

Figura 2.12: Diagrama de Nyquist para un sistema electroquímico simple en el que se produce una transferencia de carga, cuya impedancia puede modelarse con una $R_{t}$ constante.

De la última ecuación se desprende que a bajas frecuencias $Z_{T}=$ $R_{S}$, mientras que a valores altos de $\omega, Z_{T}=R_{S}+R_{t}$

\subsection{Modelo fisicoquimico para electrodos porosos}

El electrodo es modelado como una estructura porosa isotrópica, cuyos intersticios están ocupados por el electrolito. El modelo, basado en la teoría clásica de electrodos porosos inundados [22,23], tiene en cuenta la naturaleza porosa del material, las conductividades del sólido y del líquido y los procesos electroquímicos que tienen lugar en la interfase material sólido/electrolito.

\subsubsection{Ecuaciones involucradas en el modelo.}

Debido a la existencia de una resistencia óhmica se establece una distribución del potencial en ambas fases, sólida y liquida (Figura 2.13). El colector de corriente se localiza en $\mathrm{x}=0$ y la distancia $\mathrm{x}=\mathrm{L}$ corresponde al ancho del electrodo. 


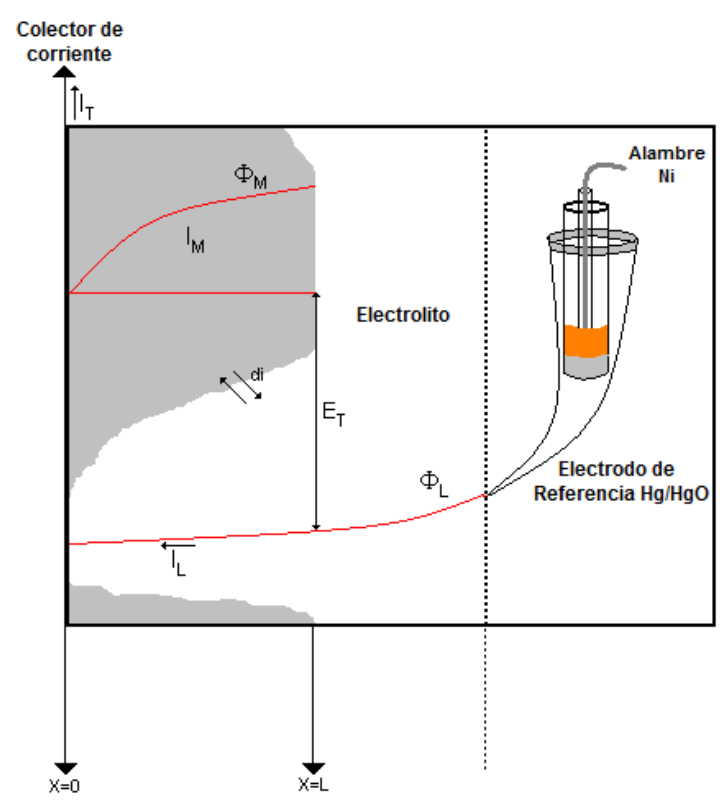

Figura 2.13: Representación esquemática de las distribuciones de potencial involucradas en un sistema compuesto por un electrodo poroso.

La siguiente serie de ecuaciones describe la distribución del potencial en las fases sólida $\left(\Phi_{\mathrm{M}}\right)$ y líquida $\left(\Phi_{\mathrm{L}}\right)$ [23]. En el análisis subsiguiente las concentraciones del electrolito y del agua se consideran constantes.

$$
\begin{aligned}
& \frac{d \Phi_{L}}{d x}=-\frac{I_{L}}{\kappa} \quad \frac{d \Phi_{M}}{d x}=-\frac{I_{M}}{\sigma} \\
& I_{T}=I_{M}+I_{L} \\
& E=\Phi_{M}-\Phi_{L}=-Z_{i} \frac{d I_{M}}{d x}=Z_{i} \frac{d I_{L}}{d x}
\end{aligned}
$$

donde $I_{L}, I_{M}$ y $I_{T}$ son las densidades de corriente de las fases líquida y sólida, y la densidad de corriente total (por unidad de área geométrica del electrodo), respectivamente. Los parámetros $\kappa$ y $\sigma$ corresponden a las conductividades efectivas de las fases líquida y sólida, respectivamente. $Z_{i}$ representa la impedancia de la interfase sólido / líquido por unidad de volumen del electrodo $\left(\Omega \mathrm{cm}^{3}\right)$. 
Si $\kappa, \sigma$ y $Z_{i}$ se consideran independientes de la coordenada $\mathrm{x}$, pueden desarrollarse las siguientes ecuaciones:

$$
\begin{aligned}
& \frac{d^{2}(E)}{d x^{2}}-\left(\frac{1}{\sigma}+\frac{1}{\kappa}\right) \frac{1}{Z_{i}}(E)=0 \\
& \frac{d^{2}\left(I_{L}\right)}{d x^{2}}-\left(\frac{1}{\sigma}+\frac{1}{\kappa}\right) \frac{1}{Z_{i}} I_{L}+\frac{1}{\sigma Z_{i}} I_{T}=0 \\
& \frac{d^{2}\left(I_{M}\right)}{d x^{2}}-\left(\frac{1}{\sigma}+\frac{1}{\kappa}\right) \frac{1}{Z_{i}} I_{M}+\frac{1}{\kappa Z_{i}} I_{T}=0
\end{aligned}
$$

Esta serie de ecuaciones pueden resolverse con las siguientes condiciones de contorno.

$\operatorname{Parax}=\mathrm{L}, I_{L}=I_{T} \quad \mathrm{y}$

$\frac{d E}{d x}=\frac{I_{T}}{\kappa}$

Para $\mathrm{x}=0, I_{M}=I_{T} \quad \mathrm{y}$

$\frac{d E}{d x}=\frac{I_{T}}{\sigma}$

La ecuación (2.6) puede resolverse para calcular $E_{L}=\left(\Phi_{\mathrm{L}}-\Phi_{\mathrm{M}}\right)_{\mathrm{x}}=\mathrm{L}$

$E_{L}=\frac{-I_{T}}{\lambda \sigma} \operatorname{sen}(\lambda L)+\frac{\frac{I_{T}}{\kappa}-\frac{I_{T}}{\sigma} \cos (\lambda L)}{\lambda \operatorname{sen}(\lambda L)} \cos (\lambda L)$

donde

$\lambda^{2}=-\left(\frac{1}{\sigma}+\frac{1}{\kappa}\right) \frac{1}{Z_{i}}$

La diferencia de potencial total $E_{T}=\left(\Phi_{\mathrm{L}}\right)_{\mathrm{x}=\mathrm{L}}-\left(\Phi_{\mathrm{M}}\right)_{\mathrm{x}=0}$ corresponde a: $E_{T}=E_{L}-\int_{L}^{0} \frac{I_{M}}{\sigma} d x$

De esta manera puede calcularse, $Z_{p}$, la impedancia total del electrodo poroso por unidad de área geométrica, 


$$
Z_{p}=\frac{E_{T}}{I_{T}}
$$

y la expresión final para $Z_{p}[22]$, puede escribirse como:

$Z_{p}=\frac{L}{A_{p}(\kappa+\sigma)}\left[1+\frac{2+\left(\frac{\sigma}{\kappa}+\frac{\kappa}{\sigma}\right) \cosh (v)}{v \operatorname{senh}(v)}\right]$

donde $A_{p}$ es el área geométrica transversal del electrodo y $v$ está dado por:

$v=L\left(\frac{\kappa+\sigma}{\kappa \sigma}\right)^{1 / 2} Z_{i}^{-1 / 2}$

\subsubsection{Impedancia interfacial (Zi).}

Para calcular la impedancia total $Z_{p}$ usando la ecuación (2.14), es necesario formular una expresión para $Z_{i}$. La impedancia interfacial involucra la impedancia ligada a la doble capa eléctrica, DCE, $\left(Z_{d l}\right)$ conectada en paralelo con la impedancia de la reacción faradaica $\left(Z_{F}\right)$, es decir,

$Z_{i}^{-1}=Z_{d l}^{-1}+Z_{F}^{-1}$

donde

$$
Z_{d l}=\frac{1}{j \omega C_{d l}}
$$

$C_{d l}$ es la capacidad de la doble capa eléctrica por unidad de volumen $\left(\mathrm{Fcm}^{-3}\right) ; j$ es el número imaginario; $\omega=2 \pi f(\mathrm{f}$, frecuencia de la señal de perturbación) y $Z_{F}$ es la impedancia faradaica por unidad de volumen $\left(\Omega \mathrm{cm}^{3}\right)$.

\subsubsection{Tratamiento general de $Z_{F}$}

En general, en un sistema electroquimico la relación entre la corriente medida, $I$, y el potencial impuesto ( $V$ ), o viceversa, no es lineal. Experimentalmente es posible trabajar en un entorno de potenciales pequeño, donde una relación de linealidad entre la corriente y el potencial sea válida. Para lograr ese objetivo, el sistema es perturbado 
con una señal sinusoidal de muy pequeña amplitud. En la Figura 2.14 se observa una gráfica de $I$ vs. $V$, que muestra una relación claramente no lineal. Asimismo, se observa un entorno pequeño de corrientes y de potenciales donde estas variables se relacionan linealmente.

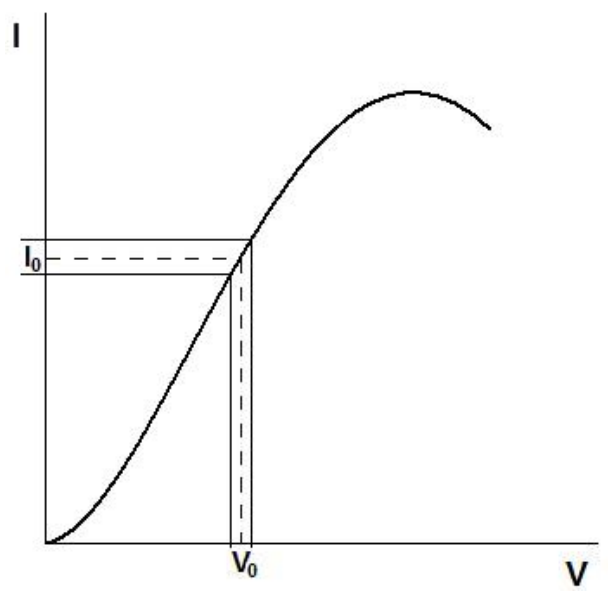

Figura 2.14: Representación arbitraria de una relación no lineal entre I y V. Se muestra el entorno de $\mathrm{I}_{0} \mathrm{y} \mathrm{V}_{0}$ en los que las variables tienen una relación lineal.

Las señales sinusoidales de potenciales y de corrientes pueden ser descritas como:

$$
\begin{aligned}
& \Delta V=|\Delta V| \exp (j \omega t) \\
& \Delta I=|\Delta I| \exp (j(\omega t+\Phi))
\end{aligned}
$$

Usualmente, los experimentos son realizados aplicando una onda sinusoidal de potenciales obteniendo como respuesta otra onda sinusoidal de corrientes. En la Figura 2.15 pueden observarse los parámetros de las ondas mencionadas. 


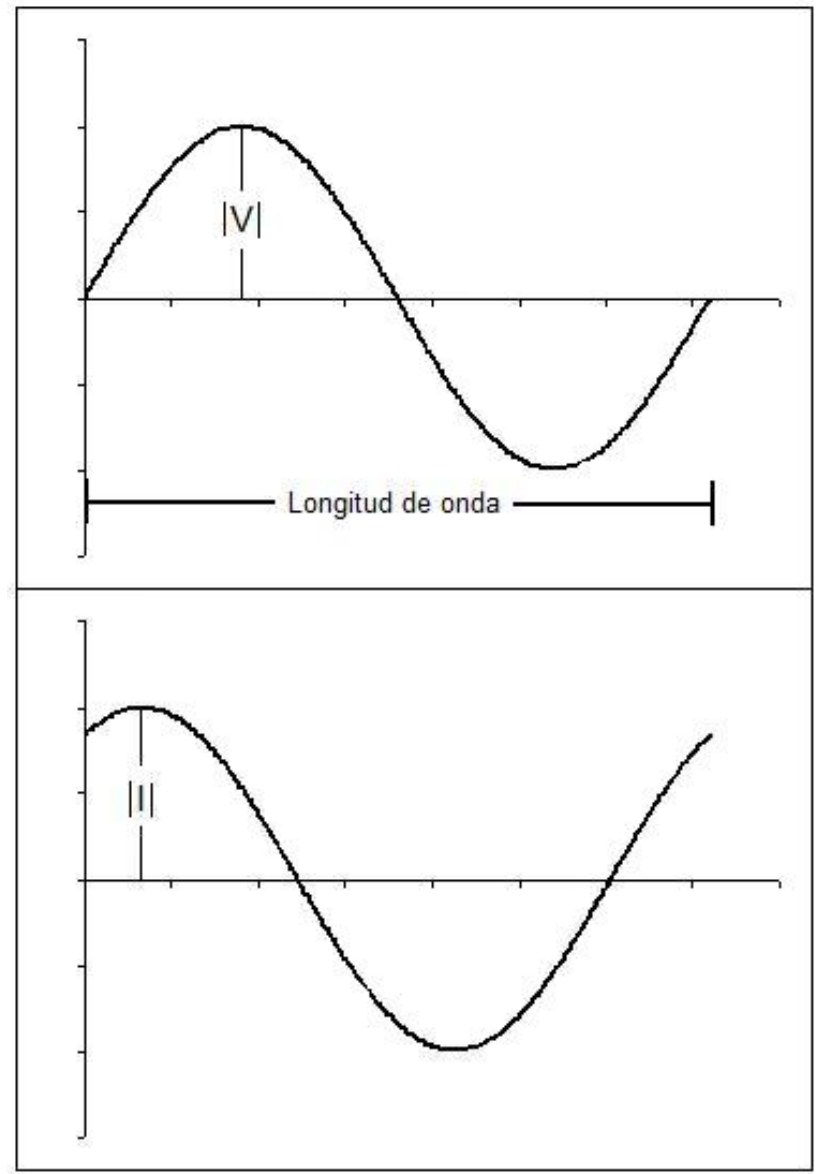

Figura 2.15: Representación esquemática de la señal V impuesta y la de I obtenida.

Como fue explicado antes, la respuesta del sistema LIT (en nuestro caso, I) es una señal del mismo tipo y frecuencia que la perturbación impuesta, pero de diferente amplitud y fase. Una característica importante de estos sistemas es que la variación temporal de las variables de estado también corresponde a una función del mismo tipo con distinta fase y amplitud. En un sistema electroquímico, la corriente (I) puede ser función de variables de estado tales como concentraciones, grados de recubrimiento, temperatura, etc.

Supongamos que la $I$ es función del potencial (V) y de una variable de estado $p$, cuya variación temporal esté dada por:

$\Delta p=|\Delta p| \exp \left(j \omega t+\Phi_{1}\right)$

podemos ahora escribir en forma general las ecuaciones de estado del sistema:

$I=I(V, p)$ 
$\frac{d p}{d t}=g(V, p)$

La ecuación (2.20) corresponde al comportamiento dinámico de $p$, debido a la perturbación de potencial, siendo en general $g$ una función no lineal.

Más arriba escribimos que $I$ es una función no lineal, pero que el sistema opera linealmente en un entorno de potenciales pequeño, de manera que la podemos linealizar expandiendo la función en serie de Taylor y tomando los términos lineales.

$$
I=I^{0}+\left(\frac{\partial I}{\partial V}\right)_{0} \Delta V+\left(\frac{\partial I}{\partial p}\right)_{0} \Delta p
$$

por lo expuesto anteriormente, podemos aplicarlo también para $g$ :

$$
\frac{d p}{d t}=\left(\frac{\partial g}{\partial V}\right)_{0} \Delta V+\left(\frac{\partial g}{\partial p}\right)_{0} \Delta p
$$

La expresión para la impedancia faradaica, $Z_{F}$, puede ser obtenida dividiendo la expresión para $I$ por la de $\Delta V$ :

$$
\frac{1}{Z_{F}}=\left(\frac{\partial I}{\partial V}\right)_{0}+\left(\frac{\partial I}{\partial p}\right)_{0} \frac{\Delta p}{\Delta V}
$$

dividiendo (2.19) por (2.17) se obtiene:

$$
\frac{\Delta p}{\Delta V}=\frac{|\Delta p|}{|\Delta V|} \exp \left(j \Phi_{1}\right)
$$

reemplazando en la expresión para $Z_{F}$ se obtiene:

$$
\frac{1}{Z_{F}}=\left(\frac{\partial I}{\partial V}\right)_{0}+\left(\frac{\partial I}{\partial p}\right)_{0} \frac{|\Delta p|}{|\Delta V|} \exp \left(j \Phi_{1}\right)
$$

Finalmente, conseguimos una expresión general de la impedancia faradaica. En este trabajo de tesis, esta expresión será aplicada para resolver el caso de la reacción de reducción de hidrógeno sobre nanotubos de carbono. 


\subsection{Espectroscopia infrarroja de Transformada de Fourier in situ (FTIR-in situ).}

La técnica de Espectroscopia infrarroja de Transformada de Fourier in situ, conocida como FTIR-in situ del inglés Fourier Transform Infrared Spectroscopy, permite obtener datos de especies neutras o iónicas tanto en solución como adsorbidas en una superficie. El espectro vibracional de las especies refleja el estado de los enlaces, las interacciones laterales de los adsorbatos o de las moléculas en solución, así como también, en nuestro caso, el efecto del campo eléctrico externo sobre la frecuencia e intensidades de las vibraciones de los adsorbatos.

En la Figura 2.16 se muestra un esquema de la celda utilizada en experimentos de FTIR-in situ. Una ventana de IR se sitúa en el fondo de la celda mediante una rosca. En la misma figura se indican los tres electrodos, ET (apoyado sobre la ventana), ER y CE, así como también las entradas y salidas de líquidos y de gases. En las Figuras 2.17 y 2.18 se muestra la celda electroquímica utilizada en este trabajo. En ellas pueden observarse el disco de Au que hace las veces de ET, el CE, constituido por una cinta de platino de forma circular, el ER, que es un electrodo de burbuja de hidrógeno y también la ventana de $\mathrm{CaF}_{2}$ en la parte inferior de la celda.

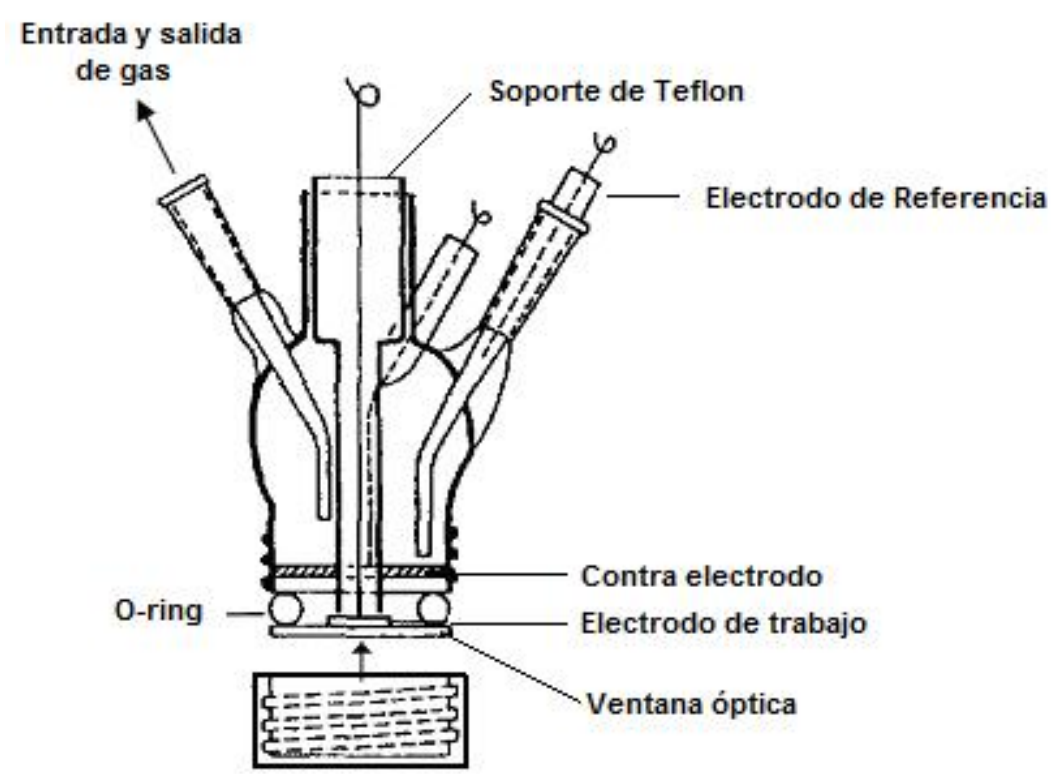

Figura 2.16: Representación esquemática de la celda utilizada para realizar las medidas espectroelectroquímicas. 


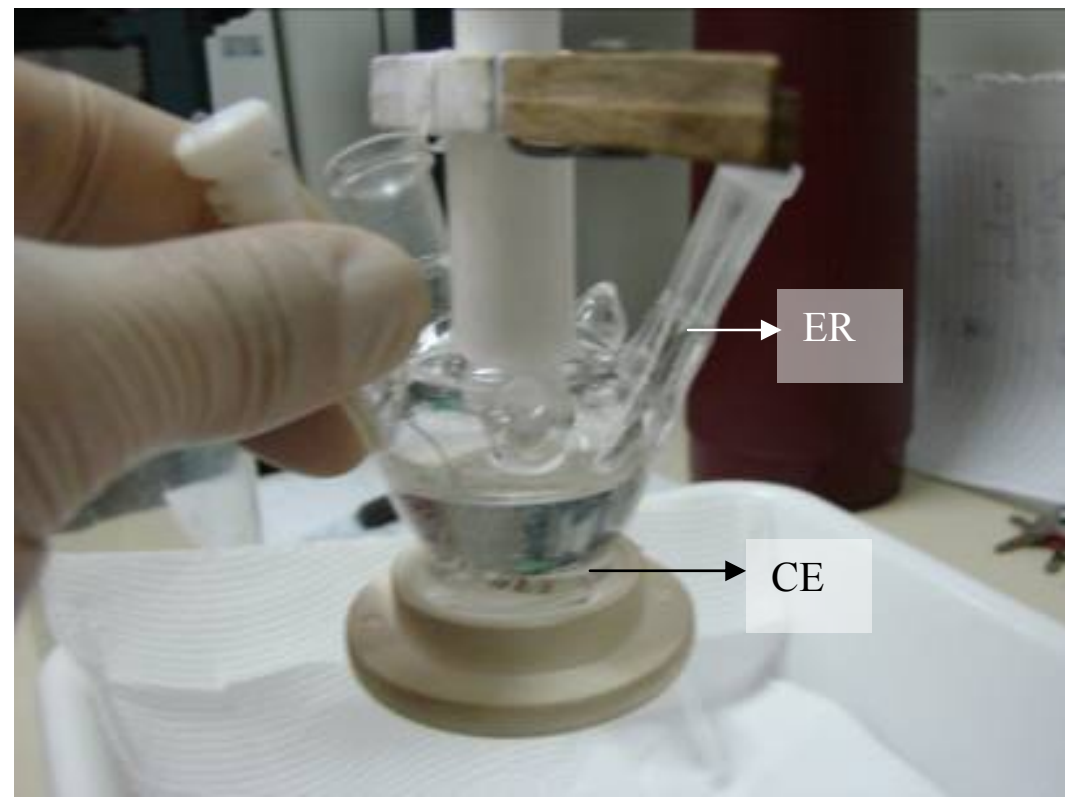

Figura 2.17: Foto de la Celda electroquímica utilizada para realizar los experimentos de FTIR-in situ, donde pueden observarse los ER y CE.

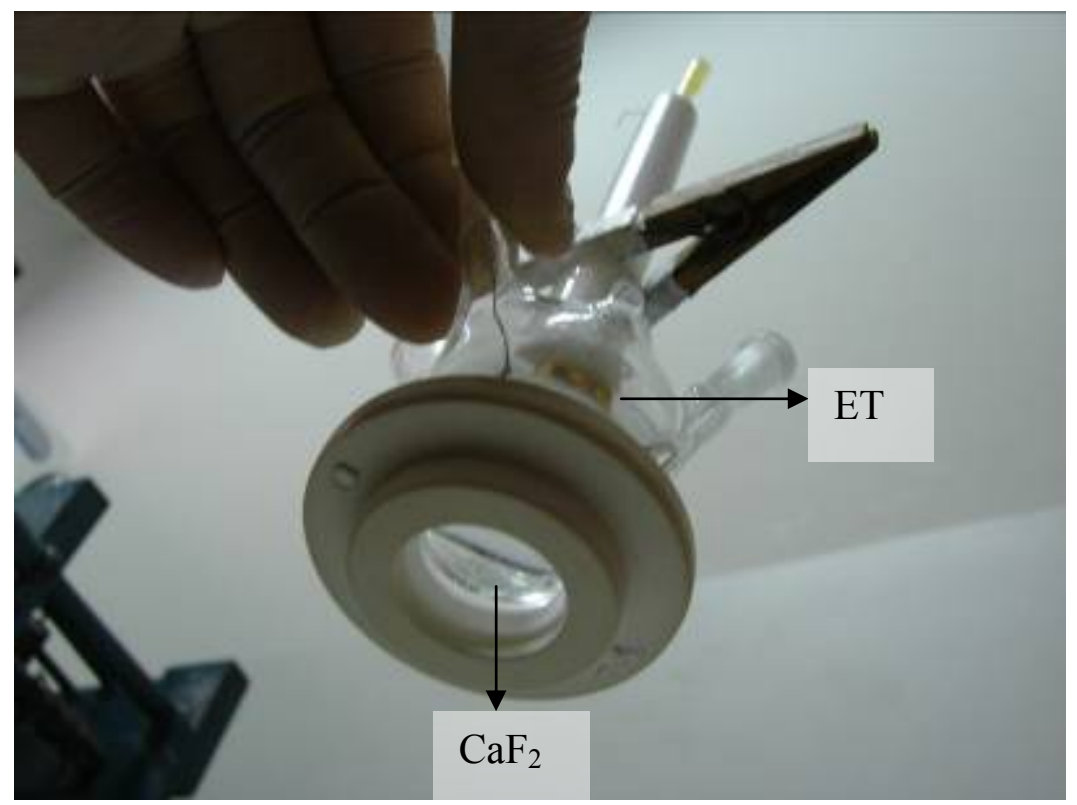

Figura 2.18: Foto de la Celda electroquímica utilizada para realizar los experimentos de FTIR-in situ, donde puede observarse la ventana de $\mathrm{CaF}_{2}$ montada en el fondo de la celda y el disco de oro (ET) en el extremo de la pieza cilíndrica de teflón.

Debido a las propiedades corrosivas de muchas de las soluciones electroliticas que se utilizan (ácidos fuertes, bases, agentes oxidantes, etc.), la elección del tipo de ventana utilizada está muy limitada. La ventana de $\mathrm{CaF}_{2}$ es la más ampliamente empleada. Su rango operativo cubre desde 900 a $77000 \mathrm{~cm}^{-1}$. Otros materiales usados son ZnSe (500 a $\left.20000 \mathrm{~cm}^{-1}\right), \mathrm{BaF}_{2}\left(770\right.$ a $\left.66666 \mathrm{~cm}^{-1}\right), \quad \mathrm{Si}\left(1540\right.$ a $10000 \mathrm{~cm}^{-1}$, no continuo). 
Cuando se mide un espectro de reflectancia de una interfase líquido-sólido, utilizando un líquido que no es transparente, el principal problema con la mayoría de los solventes es su propia absorción. Este problema es particularmente serio en el caso del agua, la cual presenta bandas intensas que cubren un amplio intervalo en la región media del IR. Para superar este problema, Bewick y colaboradores [24,25] sugirieron colocar el electrodo bien cerca de la ventana de IR, formando una capa de electrolito muy fina $(1-10 \mu \mathrm{m})$ entre el electrodo y la ventana. Sin embargo, este arreglo perturba el libre intercambio de iones con el resto de la solución. Este problema ha sido considerado en unas cuantas publicaciones [26-28]. Utilizando esta configuración, el método FTIR-in situ fue desarrollado en los años 70. La compensación de la absorción de fondo que se produce en el paso del rayo (solvente, aire, instrumentos ópticos, etc.) fue obtenida restando dos espectros individuales colectados a dos potenciales diferentes. El hecho de que usualmente el espectro de fondo no varie con el potencial hizo posible la compensación. Así, cualquier banda que aparezca en el espectro luego del cambio de potencial será debida a la aparición o desaparición de una nueva sustancia.

El trabajo que se expone en esta Tesis fue realizado con un equipo de FTIR convencional al cual le fue adaptado un banco óptico (Figuras 2.19, 2.20 y 2.21), especialmente diseñado para el equipo de FTIR utilizado, sobre el cual es posible encallar la celda electroquímica mostrada anteriormente. Éste consta de dos espejos móviles, que pueden ser ajustados para obtener el máximo valor de transmitancia. El rayo de IR sale desde la fuente del equipo y llega a uno de los espejos del banco, que está orientado de modo de reflejar el rayo hacia la ventana de $\mathrm{CaF}_{2}$ y en dirección a la superficie del ET. En este último se producirá una nueva reflexión, en dirección al segundo espejo, para guiar el rayo de luz resultante hacia el detector del espectrómetro. 


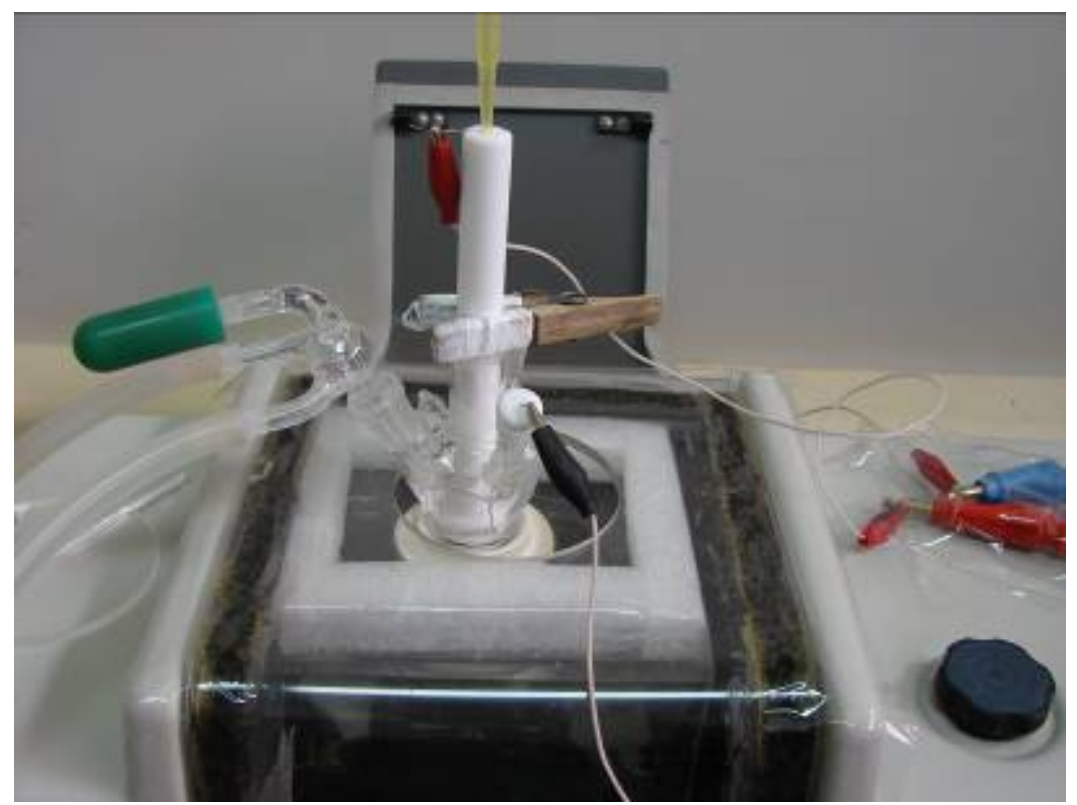

Figura 2.19: Foto de la celda electroquímica montada sobre el banco óptico en el espectrómetro Bomem (Hartmann \& Braun), modelo MB-100.

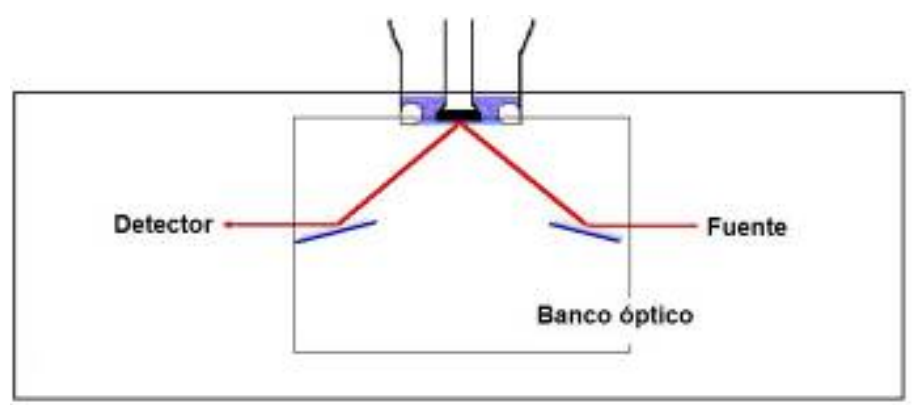

Figura 2.20: Esquema del arreglo experimental utilizado.

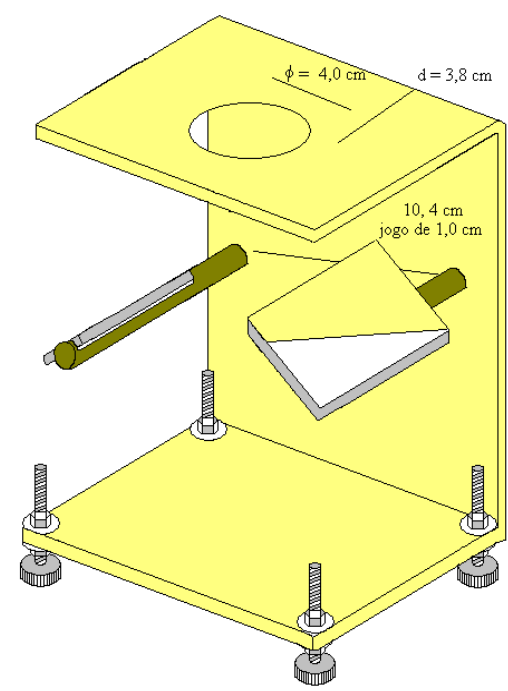

Figura 2.21: Diseño original del banco óptico. 


\subsection{Referencias Bibliográficas}

[1] K. S. W. Sing, D. H. Everett, R. A. W. Haul, L. Moscou, R. A. Pierotti, J. Rouquerol, T. Siemieniewska (Subcommittee on Reporting Gas Adsorption Data). Reporting physisorption data for gas/solid systems with Special Reference to the Determination of Surface Area and Porosity. Pure \& App!. Chem., 57 (1985) 603619.

[2] F. Rodríguez-Reinoso, A. Linares-Solano. Microporous structure of activated carbons as revealed by adsorption methods. En: P. A. Thrower, ed. Chemistry and Physics of Carbon, vol. 28, Marcel Dekker, New York. 1988, pp. 1-146.

[3] D. Cazorla-Amorós, J. Alcañiz-Monge, M. A. Casa-Lillo, A. LinaresSolano. $\mathrm{CO}_{2}$ as an adsorptive to characterize carbon molecular sieves and activated carbons. Langmuir, 14(16) (1998) 4589-4596.

[4] D. Lozano-Castelló, D. Cazorla-Amorós, A. Linares-Solano. Usefulness of $\mathrm{CO}_{2}$ adsorption at $273 \mathrm{~K}$ for the characterization of porous carbons. Carbon, 42(7) (2004) 1233-1242.

[5] S. Villar-Rodil, A. Martínez-Alonso, J. M. D. Tascón. Carbon molecular sieves for air separation from Nomex aramid fibers. J. Colloid Interface Sci., 254(2) (2002) 414-416.

[6] S. Villar-Rodil, R. Denoyel, J. Rouquerol, A. Martínez-Alonso, J. M. D. Tascón. Porous texture evolution in nomex-derived activated carbon fibers. J. Colloid Interface Sci., 252(1) (2002) 169-176.

[7] K. Kaneko, N. Setoyama, T. Suzuki. Ultramicropore characterization by $\mathrm{He}$ adsorption. En: J. Rouquerol et al., eds. Characterization of Porous Solids III. Studies in Surface Science and Catalysis, vol. 87, Elsevier Science, the Netherlands. 1994, pp. 593-602.

[8] N. Setoyama, M. Ruike, T. Kasu, T. Suzuki, K. Kaneko. Surface characterization of microporous solids with He adsorption and small angle x-ray scattering. Langmuir, 9(10) (1993) 2612-2617.

[9] N. Setoyama, S. Inoue, R. W. Pekala, Y. Hanzawa, P. J. Branton, M. S. Dresselhaus, K. S. W. Sing, K. Kaneko. Helium adsorption on mesoporous solids at $4.2 \mathrm{~K}$. (Proc. Characterization of Porous Solids IV). Spec. Publ. R. Soc. Chem., 213 (1997) 118-124.

[10] N. Setoyama, K. Kaneko, F. Rodríguez-Reinoso. Ultramicropore characterization of microporous carbons by low temperature helium adsorption. J. Phys. Chem., 100(24) (1996) 10331-10336. 
[11] D. Cazorla-Amorós, J. Alcañiz-Monge, A. Linares-Solano. Characterization of activated carbon fibers by $\mathrm{CO}_{2}$ adsorption. Langmuir, 12(11) (1996) 2820-2824.

[12] M. B. Sweatman, N. Quirke. Characterization of porous materials by gas adsorption at ambient temperatures and high pressure. J. Phys. Chem. B, 105(7) (2001) 1403-1411.

[13] A. Guillot, F. Stoeckli, Y. Bauguil. The microporosity of activated carbon fiber KF1500 assessed by combined $\mathrm{CO}_{2}$ adsorption and calorimetry techniques and by immersion calorimetry. Adsorpt. Sci. Technol., 18(1) (2000) 1-14.

[14] P. I. Ravikovitch, A. Vishnyakov, R. Russo, A. V. Neimark. Unified approach to pore size characterization of microporous carbonaceous materials from $\mathrm{N}_{2}, \mathrm{Ar}$, and $\mathrm{CO}_{2}$ adsorption isotherms. Langmuir, 16(5) (2000) 2311-2320.

[15] D. Lozano-Castelló, D. Cazorla-Amorós, A. Linares-Solano, D. F. Quinn. Micropore size distributions of activated carbons and carbon molecular sieves assessed by high-pressure methane and carbon dioxide adsorption isotherms. J. Phys. Chem. B, 106(36) (2002) 9372-9379.

[16] A. M. Puziy, O. I. Poddubnaya, A. Martinez-Alonso, F. SuárezGarcía, J. M. D. Tascón. Synthetic carbons activated with phosphoric acid-II. Porous structure. Carbon, 40(9) (2002) 15071519.

[17] A. Linares-Solano, C. Salinas-Martínez de Lecea, J. Alcañiz-Monge, D. Cazorla-Amorós. Further advances in the characterization of microporous carbons by physical adsorption of gases. Tanso., 185 (1998) 316-325.

[18] M. Casa-Lillo, F. Lamari-Darkrim, D. Cazorla-Amorós, A. LinaresSolano. Hydrogen storage in activated carbons and activated carbon fibers. J. Phys. Chem. B, 106(42) (2002) 10930-10934.

[19] M. Jordá-Beneyto, F. Suárez-García, D. Lozano-Castelló, D. Cazorla-Amorós, A. Linares-Solano. Hydrogen storage on chemically activated carbons and carbon nanomaterials at high pressures. Carbon, 45 (2007) 293-303.

[20] D. Lozano-Castelló, D. Cazorla-Amorós, A. Linares-Solano, S. Shiraishi, H. Kurihara, A. Oya. Influence of pore structure and surface chemistry on electric double layer capacitance in nonaqueous electrolyte. Carbon, 41(9) (2003) 1765-1775. 
[21] E. Raymundo-Piñero, K. Kierzek, J. Machnikowski, F. Béguin. Relationship between the nanoporous texture of activated carbons and their capacitance properties in different electrolytes. Carbon, 44(12) (2006) 2498-2507.

[22] E. B. Castro, S. G. Real, A. Bonesi, A. Visintin, W. E. Triaca. Electrochemical impedance characterization of porous metal hydride electrodes. Electrochim. Acta, 49 (2004) 3879-90.

[23] J. P. Meyers, M. Doyle, R. M. Darling, J. J. Newman. The impedance response of a porous electrode composed of intercalation particles. J. Electrochem. Soc., 147 (2000) 2930.

[24] A. Bewick, K. Kunimatsu, B. S. Pons. Infra red spectroscopy of the electrode-electrolyte interphase. Electrochim. Acta, 25 (1980) 465468.

[25] A. Bewick, K. Kunimatsu, B. S. Pons. Infra red spectroscopy of the electrode-electrolyte interphase. Surf. Sci., 101 (1980) 131-138.

[26] T. Iwasita, F. C. Nart en Advances in Electrochemical Sciences and Engineering, H. Gerischer, C. W. Tobias, (Eds.), Verlag Chemie, Weinheim, Vol. 4, pp. 123-216 (1995).

[27] T. Bae, X. Xing, D. Scherson, E. B. Yeager. Infrared spectroscopic determination of $\mathrm{pH}$ changes in diffusionally decoupled thin-layer electrochemical cells. Anal. Chem., 62 (1990) 45-49.

[28] T. Iwasita, F. C. Nart. Bulk effects in external reflection IR spectroscopy: The interpretation of adsorption data for ionic species. J. Electroanal. Chem., 295 (1990) 215-224. 


\section{Capítulo 3}

\section{Supercapacitores Electroquímicos}

\subsection{Introducción}

Los capacitores electroquímicos de doble capa eléctrica (CDC), al igual que las baterías son dispositivos electroquimicos capaces de almacenar energía.

La energía eléctrica puede ser almacenada fundamentalmente de dos maneras diferentes: 1) de manera indirecta en baterias, disponible como energía química. Constan de dos electrodos: i) un ánodo, en el cual un reactivo electroquímicamente activo se oxida; ii) un cátodo, en el cual, otro reactivo capta los electrones que pierde el reactivo oxidado en el ánodo. Estos electrones realizan trabajo al fluir a través de un circuito eléctrico que une los electrodos que están a diferente potencial eléctrico (este tipo de dispositivo será más claramente desarrollado en el Capítulo 5); 2) directamente, en forma electrostática, como cargas eléctricas positivas y negativas en las placas de un capacitor. Este proceso es conocido como almacenamiento de energía eléctrica no faradaico. En la Figura 3.1 se observa un capacitor conteniendo agua entre sus placas metálicas, a las cuales se les ha impuesto una diferencia de potencial, generando que una de ellas posea un exceso de cargas positivas y la otra de cargas negativas, ambas de igual magnitud. Los iones presentes en la solución acuosa, por ejemplo de $\mathrm{KOH}$, son atraídos a una u otra placa, dependiendo del signo de su carga. Así, los 
cationes potasio se acercan a la placa que se encuentra a menor potencial y los aniones hidroxilo a aquélla teniendo un potencial mayor.

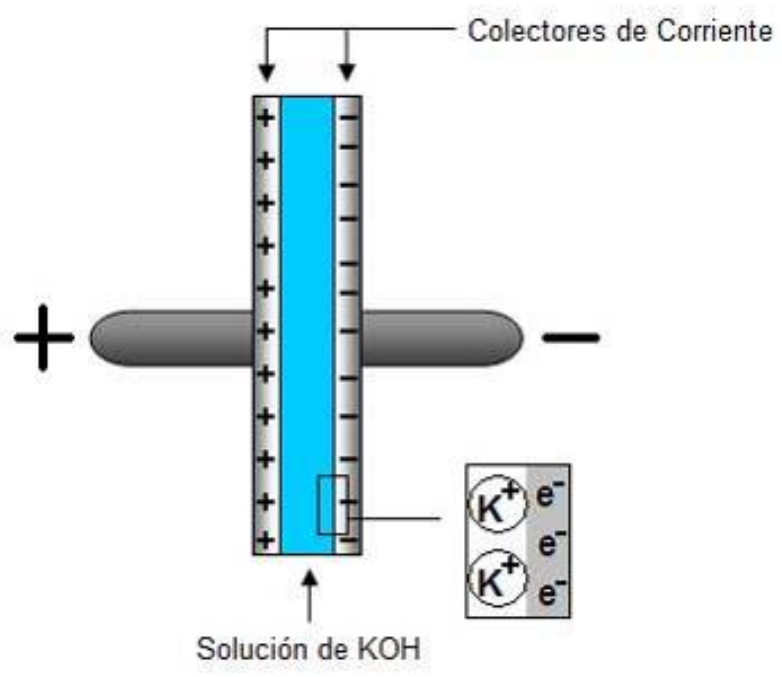

Figura 3.1: Esquema de un capacitor conteniendo una solución acuosa entre sus placas metálicas.

Las baterias y los CDC son dispositivos que poseen características muy diferenciadas, lo cual hace que los mismos sean aptos para distintas aplicaciones o bien que sean complementarios en una misma aplicación. Para comprender esto es necesario que dichas características sean claramente definidas.

Las diferencias observadas en las densidades de almacenamiento de carga son extremadamente grandes. En un electrodo plano, la densidad de almacenamiento de carga en la doble capa eléctrica (DCE) depende básicamente de la diferencia de potencial entre las dos placas del capacitor. Así, en la superficie de un electrodo plano pueden almacenarse entre 16 y $50 \mathrm{\mu Ccm}^{-2}$. Teniendo en cuenta este dato y considerando una densidad superficial atómica de $10^{15}$ at. $\mathrm{cm}^{-2}$ podemos encontrar que este electrodo podrá almacenar en su DCE alrededor de 0,18 electrones por átomo. Por otro lado, en una batería, las reacciones de óxido-reducción suelen involucrar, uno, dos y hasta tres electrones por átomo. Además, en éstas la energía está almacenada no sólo en los átomos superficiales sino también en el seno de la o de las sustancias electroquímicamente activas. Esto hace que las energías almacenadas 
en una batería sean varios órdenes de magnitud mayores que las acumuladas en un capacitor de doble capa plano.

Como puede deducirse de lo expuesto anteriormente, la capacidad de almacenamiento de carga en un CDC es directamente proporcional al área superficial expuesta. Con el objetivo de aumentar el área superficial expuesta se utilizan electrodos porosos, compuestos por diferentes tipos de carbones con áreas superficiales muy altas 1000-2000 $\mathrm{m}^{2} \mathrm{~g}^{-1}$. En la Figura 3.2 se muestra un CDC conteniendo entre los colectores de corriente dos electrodos de carbones porosos embebidos con un electrolito acuoso. A su vez, éstos se encuentran separados por un material poroso no conductor que evita el contacto eléctrico entre los carbones, pero permite el paso de los iones acuosos y del agua. Estos dispositivos poseen capacidades cientos de veces mayores que las que tienen los $\mathrm{CDC}$ convencionales, por lo que usualmente son denominados Supercapacitores electroquímicos (SC).

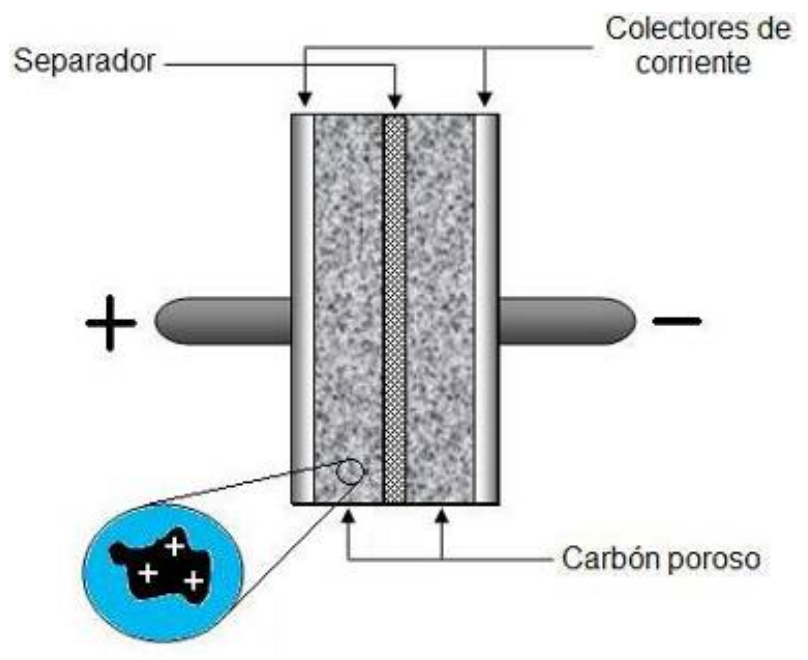

Figura 3.2: Esquema de un Supercapacitor Electroquímico (SC).

Estos materiales hacen posible obtener capacidades teóricas de 300-900 Fg-1 (realizando el cálculo hecho para CDC). Teniendo en cuenta una diferencia de potencial de $1 \mathrm{~V}$, la densidad de energía almacenada será $E=(1 / 2) \mathrm{CV}^{2}=150-450 \mathrm{KJ} \mathrm{Kg}^{-1}$ o $42-126 \mathrm{Wh} \mathrm{Kg}^{-1}$. Sin embargo, los valores obtenidos en la práctica están muy por debajo de los teóricos, principalmente debido a que el electrolito no es capaz de 
acceder a poros excesivamente pequeños. En general, este problema es más grave cuanto mayor área superficial presenta un carbón, debido a que generalmente, este parámetro crece junto con el aumento de la microporosidad del material.

Realizando un cálculo similar para una batería de $\mathrm{Ni}-\mathrm{Cd}$, obtenemos una densidad de energía de $810 \mathrm{KJ} \mathrm{Kg}^{-1}$ o $225 \mathrm{Wh} \mathrm{Kg}^{-1}$. Estos valores teóricos son muy cercanos a los experimentales. Tanto para las cargas y descargas del capacitor como de la batería se consideró que las corrientes son lo suficientemente bajas como para que el dispositivo pueda cargarse o descargarse empleando el máximo de sus capacidades.

Si bien la energía almacenada en una batería es sustancialmente mayor, una comparación adecuada debiera tener en cuenta la energía almacenada en un capacitor completo, esto es, realizar los cálculos considerando la presencia de los dos electrodos del dispositivo, los cuales poseen una diferencia de potencial de 1V. Así, cuando tenemos la formación de dos DCE en serie, la capacidad equivalente será igual a la mitad de la capacidad de una DCE, considerando capacidades similares para ambas DCE. Si además, tenemos en cuenta que la masa de material activo será el doble de la original, entonces la densidad de energía específica teórica calculada será cuatro veces menor, esto es, 10-30 Wh Kg-1.

De la expresión para el cálculo de la energía $\left(1 / 2 \mathrm{CV}^{2}\right)$ se desprende que, luego de haber resuelto cómo aumentar el área superficial de los electrodos, un aumento de la diferencia de potencial entre los electrodos de un capacitor podría generar dispositivos con mayor almacenamiento de energía. Por este motivo, se han estudiado y continúa en estudio el desarrollo de capacitores electroquímicos que utilizan electrolitos no acuosos, algunos de los cuales funcionan con diferencias de potencial de hasta 3,5V. Por otro lado, estos electrolitos introducen otro tipo de dificultades, como por ejemplo: i) poseen menor conductividad que los electrolitos acuosos; ii) las moléculas e iones 
tienen tamaños mayores que los iones acuosos y el agua, agravando aún más los problemas de accesibilidad y de difusión en los microporos.

Otra característica muy importante que diferencia estos dispositivos es la densidad de potencia. Mientras que los capacitores pueden trabajar a densidades de potencia muy altas, limitada en gran parte por la ingeniería del dispositivo electroquímico, cuando las baterías son expuestas a las altas corrientes de carga o de descarga a la que funcionan los capacitores, puede aprovecharse sólo una pequeña fracción de la energía que éstas son capaces de almacenar. Esta gran diferencia se debe a que el proceso de carga y descarga de un capacitor (formación y ruptura de la DCE) tiene una cinética mucho mayor que la carga y descarga de una batería, en la cual generalmente están involucrados procesos de transferencia de carga y de difusión hacia o desde el electrodo o dentro de la matriz sólida de éste.

Otra diferencia importante entre estos dos dispositivos son los ciclos de vida. Ésta surge nuevamente de la disparidad en los mecanismos involucrados. Mientras que en los capacitores se producen cambios totalmente reversibles, formación y ruptura de la DCE, que permiten realizar entre $10^{5}-10^{6}$ ciclos, los componentes de las baterías sufren gradualmente cambios irreversibles que conducen a que su utilidad se prolongue por un número de ciclos 100-1000 veces menor que el de un capacitor.

Un trabajo del año 2008 de Vasile V. N. Obreja [1], muestra que la máxima energía específica almacenada por $\mathrm{SC}$ comerciales es de $5,7 \mathrm{Wh} \mathrm{Kg}^{-1}$ para un $\mathrm{SC}$ construido con un carbón activado de $3000 \mathrm{~m}^{2} \mathrm{~g}^{-1}$ y con solvente orgánico (NESSCAP cell type ESHSP-5000C0002R7) y de $13 \mathrm{Wh} \mathrm{Kg}^{-1}$ para otro $\mathrm{SC}$, pero conteniendo un electrolito acuoso (ESMA cell type EC 353). La minima capacidad para las baterias es de 35-40 Wh Kg-1 para la de $\mathrm{Pb}-\mathrm{H}_{2} \mathrm{SO}_{4}$, mientras que las de ión-litio alcanzan valores de $250 \mathrm{Wh} \mathrm{Kg}^{-1}$ [2]. Las potencias específicas de los SC citados son de 6,4 y 2,3 $\mathrm{kW} \mathrm{Kg}^{-1}$, respectivamente, mientras que las baterías de ión-litio poseen potencias de $0,7 \mathrm{~kW} \mathrm{Kg}-1$. 
Hasta aquí hemos marcado las diferencias entre dos dispositivos que almacenan la energía de maneras totalmente distintas. Por un lado, en los capacitores las cargas son almacenadas en la DCE de forma electrostática, fundamentalmente en un proceso no faradaico. En el caso de las baterías el proceso es esencialmente faradaico, hay una transferencia electrónica que cambia la química de los reactivos. Sin embargo, hay un gran número de capacitores que presentan situaciones intermedias. La gran cantidad de materiales utilizados para construir SC hace difícil una rápida diferenciación de estos dispositivos. Sin embargo, aquellos SC que presentan transferencia de carga, cumplen con condiciones termodinámicas que les permite seguir perteneciendo a ese grupo de dispositivos. En éstos, el potencial del electrodo, $V$, es una función continua de la cantidad de carga almacenada, $q$, de modo que puede escribirse la derivada $d q / d V$, la cual es equivalente a una capacitancia. La capacitancia que exhiben estos sistemas se conoce como pseudocapacitancia. Si bien los materiales más conocidos que muestran comportamientos pseudocapacitivos son algunos óxidos metálicos $\left(\mathrm{RuO}_{\mathrm{x}}, \mathrm{IrO}_{\mathrm{x}}\right.$, etc.) y polímeros conductores como las polianilinas o politiofenos, no existen capacitores ideales y todos tienen alguna componente pseudocapacitiva que puede ser más o menos despreciable. Así, los capacitores construidos con materiales carbonosos, en algunos casos llegan a tener un 5\% de su capacidad debida a procesos faradaicos reversibles, generalmente debido a la reactividad de los átomos de oxígeno que se encuentran en los bordes de las láminas de grafeno. Los mismos pueden ser originados en los procesos de sintesis, purificación y activación de los materiales. Si bien este tema ha sido extensamente estudiado, el desarrollo de nuevos materiales con diferentes áreas específicas y distribuciones de poros mantiene este campo en continuo progreso [3-15]. Estos dispositivos están siendo utilizados en diferentes aplicaciones tecnológicas, sin embargo, las más difundida es el uso de SC como fuentes de potencia en vehículos eléctricos, principalmente en automóviles y en trenes. En estos casos, bancos de SC de alta potencia y baja densidad de energía 
actúan por tiempos cortos en aceleraciones que requieren descargas energéticas altas y rápidas o almacenando energía durante las desaceleraciones. Acoplados a éstos, son utilizadas baterías de alta densidad de energía (ión-litio) luego de una rápida aceleración, para mantener velocidades (corrientes) por largos lapsos de tiempo sin cambios bruscos. Debido a ésto, en el último tiempo se han desarrollado materiales para electrodos de SC muy diversos, en muchos casos haciendo dificil la clasificación de los dispositivos como SC o baterías [16-29]. La gran demanda mundial de nuevos sistemas de almacenamiento de energía obliga a la búsqueda de dispositivos con una potencia especifica superior a $10 \mathrm{kWkg}^{-1}$ y una durabilidad de $10^{6}$ ciclos.

Dentro de este contexto, con el objetivo de realizar una investigación básica, en este trabajo se emplearon varios carbones con características muy variadas, cubriendo un amplio espectro de materiales carbonosos. Por otro lado, se realizaron trabajos conjuntos con un grupo de investigadores del INCAR-CSIC (Instituto Nacional del Carbón-Consejo Superior de Investigaciones Científicas), de Oviedo, España. Este grupo dispone de un laboratorio destinado a la sintesis de Xerogeles de cabono. Nuestro trabajo consistió en realizar las medidas electroquímicas a estos Xerogeles en los laboratorios de INIFTA, identificando los parámetros fisicoquímicos que determinan su funcionamiento. Así, sobre la base de los resultados obtenidos se logró guiar a los investigadores españoles en la sintesis de mejores y más eficientes materiales.

Los geles de carbón son materiales porosos muy interesantes para ser utilizados en esta área, debido a que sus características estructurales pueden ser seleccionadas ajustando las condiciones empleadas en la sintesis y posterior tratamiento de los materiales. Los Xerogeles de carbono son frecuentemente obtenidos utilizando resorcinol y formaldehído $(\mathrm{RF})$ como reactivos; el gel obtenido es subsecuentemente secado por evaporación y finalmente pirolizado. Los geles de carbono sintetizados utilizando RF generalmente poseen áreas 
superficiales medidas por BET de $600-700 \mathrm{~m}^{2} \mathrm{~g}^{-1}$, mientras que cuando son sometidos a procesos de activación pueden alcanzar áreas superiores a $2000 \mathrm{~m}^{2} \mathrm{~g}^{-1}$. La activación química es una de las técnicas más reconocidas para incrementar la microporosidad de un material de carbono. Variando las condiciones de activación, es posible controlar la distribución de tamaños de los microporos, manteniendo constante la estructura meso-macroporosa del gel de carbono [30]. Así, este método permite obtener carbones de muy elevada área específica, aunque la conectividad entre las partículas de carbono es algo baja y consecuentemente, estos materiales poseen importantes resistencias internas.

\subsection{Parte experimental}

\subsubsection{Materiales}

Fueron empleados diferentes materiales de carbono, los cuales cubren un importante rango de características: (I) Vulcan $\mathrm{XC72}{ }^{\circledR}$; (II) nanotubos de carbono de pared simple (NTCS) de Aldrich ${ }^{\circledR}$; (III) nanotubos de carbono de paredes múltiples (NTCM) de Aldrich $^{\circledR}$; (IV) Xerogeles de carbono de alta área específica sintetizados en el Instituto Nacional del Carbón (INCAR-Oviedo, España): i) M0; ii) M1; iii) M2; iv) M3; v) M4.

\subsubsection{Sintesis de Xerogeles de carbono}

M0: fue sintetizado con una relación estequiométrica $R / F$ y una dilución, D (moles de solvente/moles de reactivo), la cual se fijó en 5,7. La solución inicial, de $\mathrm{pH}$ 6,5, fue colocada en un horno a $85{ }^{\circ} \mathrm{C}$ durante 72 horas para permitir la gelificación y el envejecimiento. Una vez obtenido el gel, fue secado por evaporación en el mismo horno a $150{ }^{\circ} \mathrm{C}$. Luego del secado, fue pirolizado a $800^{\circ} \mathrm{C}$ en un horno tubular, bajo flujo de nitrógeno $\mathrm{y}$ utilizando el siguiente programa de calentamiento: (i) rampa a $1,7{ }^{\circ} \mathrm{Cmin}^{-1}$ hasta $150{ }^{\circ} \mathrm{C}$, manteniendo a esa temperatura durante $15 \mathrm{~min}$; (ii) rampa a $5{ }^{\circ} \mathrm{Cmin}^{-1}$ hasta $400{ }^{\circ} \mathrm{C}$, 
manteniendo a esa temperatura durante $60 \mathrm{~min}$; (iii) rampa a $5{ }^{\circ} \mathrm{Cmin}^{-1}$ hasta $800^{\circ} \mathrm{C}$, manteniendo a esa temperatura durante $120 \mathrm{~min}$; (iv) enfriar a temperatura ambiente. Finalmente, el Xerogel de carbono fue activado químicamente con ácido fosfórico, utilizando una razón de masas de agente activante/Xerogel de 3,1. La mezcla fue agitada a $85^{\circ} \mathrm{C}$ durante 2 horas, filtrada y luego secada durante toda la noche en un horno a $110^{\circ} \mathrm{C}$. Posteriormente, las muestras fueron agitadas bajo flujo de $\mathrm{N}_{2}\left(85 \mathrm{~cm}^{3} \mathrm{~min}^{-1}\right)$ a $5{ }^{\circ} \mathrm{Cmin}^{-1}$ hasta alcanzar los $450{ }^{\circ} \mathrm{C} \mathrm{y}$ mantenidas a esta temperatura por 2 horas. Finalmente, fueron lavadas con agua hasta alcanzar un $\mathrm{pH}=6$ y secadas durante toda la noche a $110^{\circ} \mathrm{C}$.

M1: El pH mezcla RF se fijó en 6,5. Una vez preparada la mezcla, se tomaron $30 \mathrm{ml}$ y se vertieron en un recipiente transparente a la radiación microondas, el cual fue introducido en el horno microondas y se fijaron las condiciones de operación. En primer lugar, se colocó una temperatura de $85^{\circ} \mathrm{C}$, es decir, la misma temperatura que en el caso de la sintesis en horno convencional, durante aproximadamente 3 horas, tiempo necesario como para que ocurra la gelación y parte del curado del material. Transcurrido ese tiempo, se eliminó la limitación de temperatura de manera que el horno microondas comenzó a funcionar a la máxima potencia $(700 \mathrm{~W})$. Esta etapa se llevó a cabo durante el tiempo necesario para conseguir el secado completo de los geles, generalmente entre 2 y 2,5 horas. El xerogel orgánico sintetizado, fue activado directamente en un horno microondas, de manera que las etapas de carbonización y activación tuvieron lugar simultáneamente. Para efectuar la activación química, se utilizó $\mathrm{KOH}$ como agente activante, con una relación másica agente activante/precursor de 3,1, colocando en contacto ambos reactivos mediante mezcla física. Esta mezcla fue colocada en una navecilla de alúmina, la que se introdujo en el horno microondas para proceder a su activación bajo las siguientes condiciones: $500 \mathrm{~cm}^{3} \mathrm{~min}^{-1}$ de $\mathrm{N}_{2}$ y a una temperatura de activación de $700{ }^{\circ} \mathrm{C}$ durante un tiempo de 6 minutos. Una vez que se enfrió el 
material, se llevó a cabo el lavado del mismo con agua destilada hasta conseguir que el agua de lavado tuviera un $\mathrm{pH}$ próximo a $6 \mathrm{y}$ posteriormente se introdujo en una estufa a $110^{\circ} \mathrm{C}$ durante una noche para obtener el xerogel activado libre de humedad.

M2: La síntesis del xerogel orgánico fue completamente idéntica a la descrita anteriormente con la única diferencia de que en este caso, la muestra se activa químicamente con hidróxido potásico en un horno horizontal tubular. Las condiciones de activación son: $700{ }^{\circ} \mathrm{C}$ de temperatura durante un tiempo de 2 horas bajo un flujo de $\mathrm{N}_{2}$ de $500 \mathrm{~cm}^{3} \mathrm{~min}^{-1}$. Las etapas posteriores de lavado y secado fueron iguales que en el caso anterior.

M3: Fue obtenido de igual manera que en los casos anteriores, exceptuando que en éste el pH de la mezcla RF se fijó en 5,8. Otra diferencia es que la activación química fue realizada sobre el xerogel de carbono. Por eso, una vez preparado el xerogel orgánico, se carbonizó en un horno horizontal tubular bajo atmósfera de $\mathrm{N}_{2}\left(100 \mathrm{~cm}^{3} \mathrm{~min}^{-1}\right)$, utilizando el siguiente programa de temperaturas: (i) calentamiento de la muestra con una rampa de $1,7^{\circ} \mathrm{Cmin}^{-1}$ hasta $150^{\circ} \mathrm{C}$, con un tiempo de residencia de 15 minutos, (ii) calentamiento hasta $400^{\circ} \mathrm{C}$ con una velocidad de $5{ }^{\circ} \mathrm{Cmin}^{-1}$, manteniendo la muestra a esa temperatura durante 1 hora, (iii) calentamiento con una rampa de $5{ }^{\circ} \mathrm{Cmin}^{-1}$ hasta $800^{\circ} \mathrm{C}$ con un tiempo de permanencia de 2 horas y, finalmente, (iv) enfriamiento de la muestra hasta temperatura ambiente. La muestra carbonizada, se sometió a un proceso de activación química con $\mathrm{KOH}$ siguiendo el mismo procedimiento que en los dos casos descritos anteriormente.

M4: El procedimiento de sintesis es exactamente igual que el aplicado para la muestra M3 salvo que el $\mathrm{pH}$ de la mezcla precursora se fija en 6,5 . 


\subsubsection{Teflonado de los carbones}

Para obtener los electrodos en forma de pastilla es necesario colocar a los carbones una sustancia que actúe como aglomerante. Para ello, cada carbón fue colocado en un frasco, cubierto con etanol y agitado con un buzo magnético sobre una placa calefactora hasta llegar a una temperatura de $50{ }^{\circ} \mathrm{C}$. En otro recipiente se prepara una solución 1/10 de PTFE TE-3893 ${ }^{\circledR}$ (una dispersión acuosa de PTFE) y etanol. La cantidad de esta solución depende de la relación PTFE/Carbón que se desea obtener. Como se conoce la cantidad de PTFE que hay en un volumen dado de la dispersión, es posible tomar la masa del polímero deseada de la dispersión y diluirlo con etanol. Posteriormente, la solución de PTFE TE-3893 ${ }^{\circledR}$ y etanol se agrega gota a gota, muy lentamente, sobre el recipiente conteniendo el carbón, para permitir que el polímero se mezcle de manera homogénea en toda la masa de carbón. Una vez adicionado todo el PTFE, se dejó en agitación durante 30 minutos permitiendo que todo el PTFE se mezcle con las partículas carbonosas. Posteriormente se llevó a estufa a $80^{\circ} \mathrm{C}$ durante 2 días.

\subsubsection{Sistema electroquímico}

Las medidas electroquímicas fueron realizadas empleando una celda de tres electrodos en $\mathrm{KOH}$ acuoso 6M. Como electrodo de trabajo se usaron los carbones teflonados; el contraelectrodo era una malla de níquel y como electrodo de referencia se utilizó $\mathrm{Hg} / \mathrm{HgO} / \mathrm{KOH} 6 \mathrm{M}$ $(+0,098 \mathrm{~V}$ us. NHE). En la Figura 3.3 se observa la celda formada por cuatro compartimentos. En el del centro se encuentra la pastilla conteniendo uno de los carbones evaluados. A sus costados pueden verse claramente las mallas de Ni y por último podemos observar el ER, cuyo color naranja se debe al $\mathrm{HgO}$, en un recipiente conectado al que contiene el ET a través de un capilar de Luggin. En el texto, los potenciales están referidos al electrodo utilizado como referencia. Todos los experimentos se llevaron a cabo a $303 \mathrm{~K}$. 


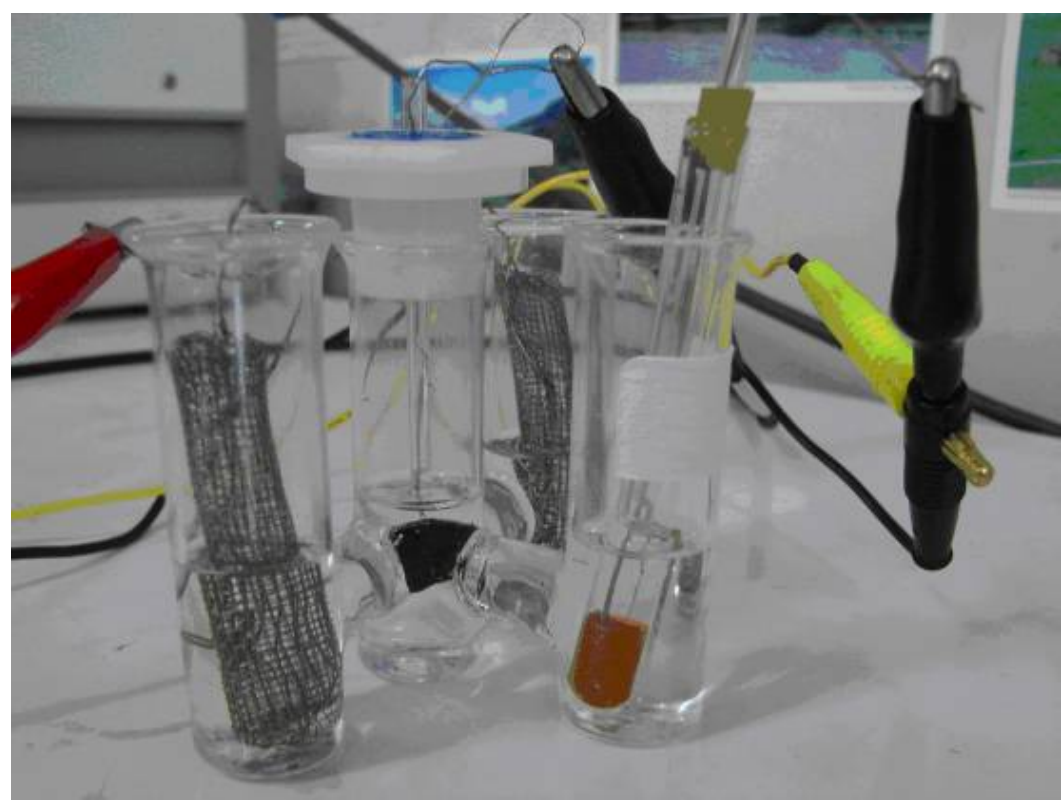

Figura 3.3: Celda electroquímica de tres electrodos.

Los electrodos se prepararon mezclando los componentes, introduciéndolos en un pastillero de acero, en el cual previamente se había colocado un esqueleto de alambre de $\mathrm{Ni}$, aplicando luego una presión de $2100 \mathrm{kgcm}^{-2}$. En la Figura 3.4 se puede observar el electrodo obtenido, una pastilla de color negro conteniendo NTCS, de la cual sale un alambre de Ni (enrollado en forma de espiral dentro de la pastilla de carbón) que hará las veces de colector de corriente.

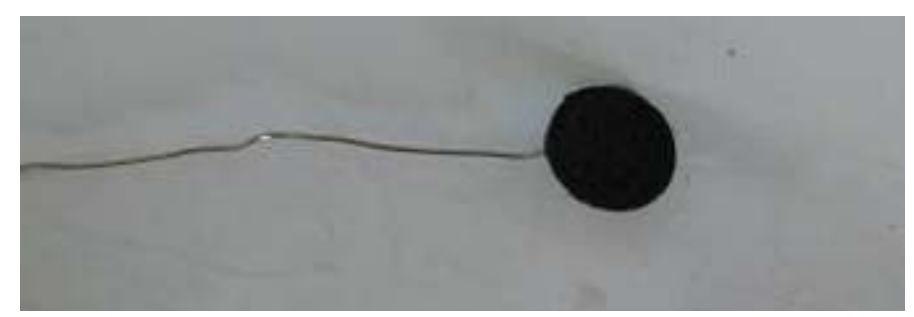

Figura 3.4: Electrodo en forma de pastilla.

\subsubsection{Caracterizaciones}

La caracterización textural de las muestras fue llevada a cabo a través de la adsorción física de $\mathrm{N}_{2}$ a $77 \mathrm{~K}$ en el equipo TriStar II de Micromeritics. El método de Dubinin-Radushkevich (DR) [31] fue aplicado a las isotermas de adsorción de $\mathrm{N}_{2}$ para obtener el volumen de los microporos, VDUB-N2. A partir del volumen de los microporos y el 
tamaño medio de los poros $\left(L_{p}\right)$ y utilizando la ecuación de Stoeckli [32], puede obtenerse el área de la superficie de los microporos $\left(\mathrm{S}_{\text {mic }}=2 \mathrm{~V}_{\text {mic }} / \mathrm{L}_{\mathrm{p}}\right)$. El área BET fue también calculada utilizando las isotermas de adsorción de $\mathrm{N}_{2}$ [33].

La estructura de las muestras fue evaluada con un microscopio de transmisión electrónica (TEM). Las imágenes fueron tomadas con un equipo JEOL JEM-2000 EX II.

Las medidas de conductividad de los carbones fueron realizadas a presión atmosférica, en un equipo construido en el laboratorio, el cual es una modificación del método de cuatro puntas de Van der Pauw [34]. El material es presionado entre dos pistones y se pasa una corriente constante a través de éste. La presión entre los pistones puede ser controlada, lo cual permite obtener medidas de conductividad en un alto rango de presiones. Para estas medidas se construyó una pastilla de la misma manera que se construye el electrodo pero sin utilizar el esqueleto de Ni. Luego se la colocó entre los dos pistones y se midió la conductividad a una presión muy baja, con el objetivo de obtener un valor que sea representativo del electrodo sumergido en la solución, el cual, sufre una presión muy cercana a la atmosférica. De esta manera se obtiene la conductividad efectiva del sólido ( $\sigma)$. Si se aumenta progresivamente la presión aplicada, se llegará a un valor de conductividad constante, el cual será la conductividad del sólido.

\subsection{Resultados y discusión}

\subsubsection{Caracterización de los carbones}

\subsubsection{Microscopía de transmisión electrónica (TEM)}

En las Figuras 3.5-3.9 se muestran imágenes de los distintos carbones utilizados en este trabajo tomadas con un microscopio de transmisión electrónica JEOL JEM-2000 EX II.

Las Figuras 3.5 A y 3.6 A muestran NTCS y NTCM puros. Tanto el diámetro de los NTCS como los diámetros internos y externos de los NTCM pueden ser claramente observados. Por otro lado, no pudieron 
percibirse diferencias entre las imágenes tomadas con muestras teflonadas (Fig. 3.5 A) y sin teflonar (Fig. 3.5 B).

En las Figuras 3.7, 3.8 y 3.9 se observan carbones amorfos, donde, en este caso, pueden advertirse diferencias significativas entre los carbones con y sin PTFE.

La estructura del carbón Chezacarb (Ch) se muestra en la Figura 3.7, en la que no se observa la estructura típica de un carbón amorfo. Pueden distinguirse estructuras de capas con un cierto grado de orden. En la Figura 3.8 se muestra el muy conocido Vulcan $\mathrm{XC} 72^{\circledR}$, el cual posee una estructura típica de un carbón amorfo. Por último, en la Figura 3.9 se muestra la estructura amorfa típica de un Xerogel (en este caso MO).
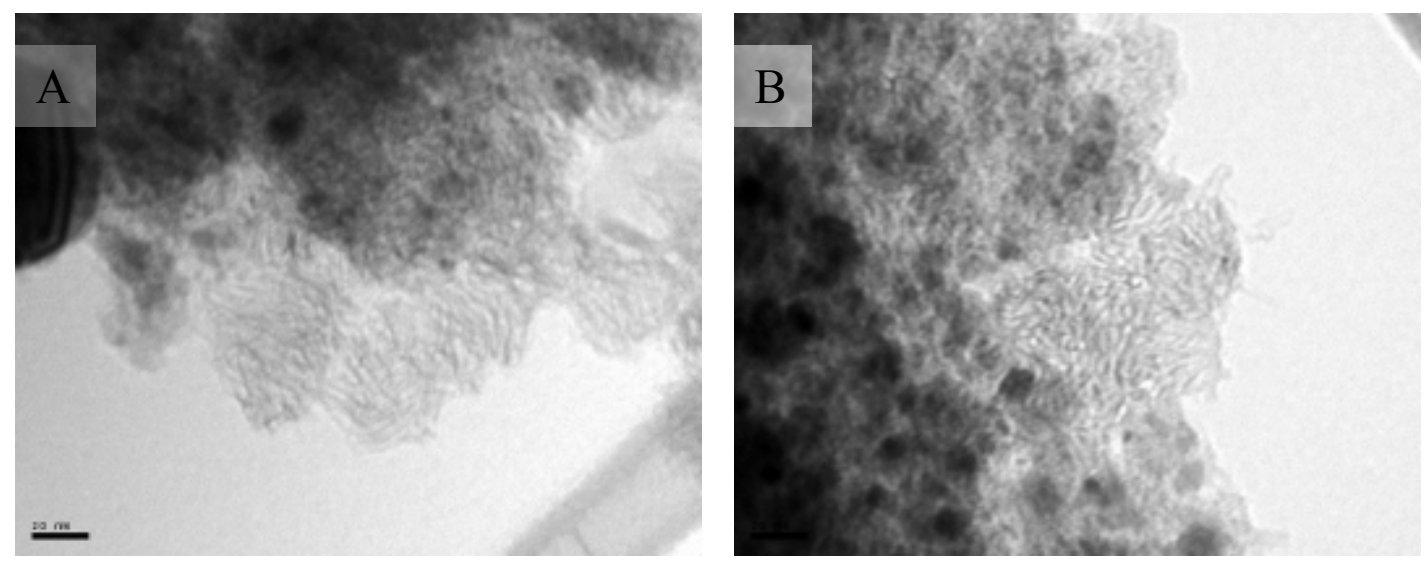

Figura 3.5: NTCS sin PTFE (A) y con PTFE (B)

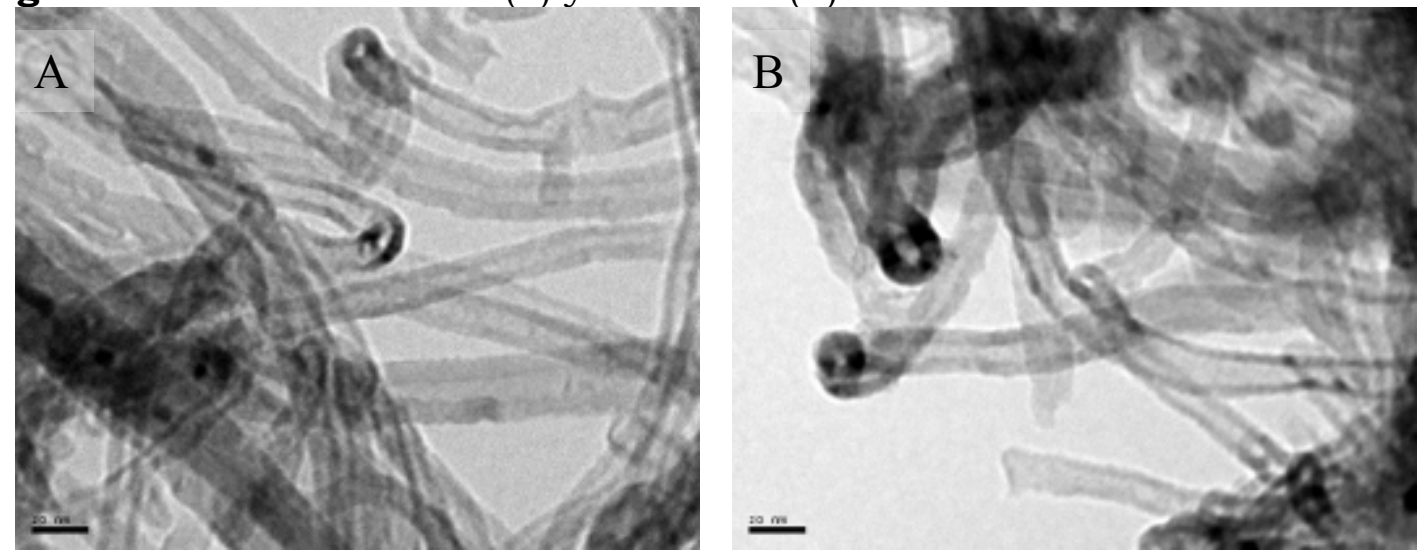

Figura 3.6: (A) NTCM sin PTFE y (B) con PTFE. 

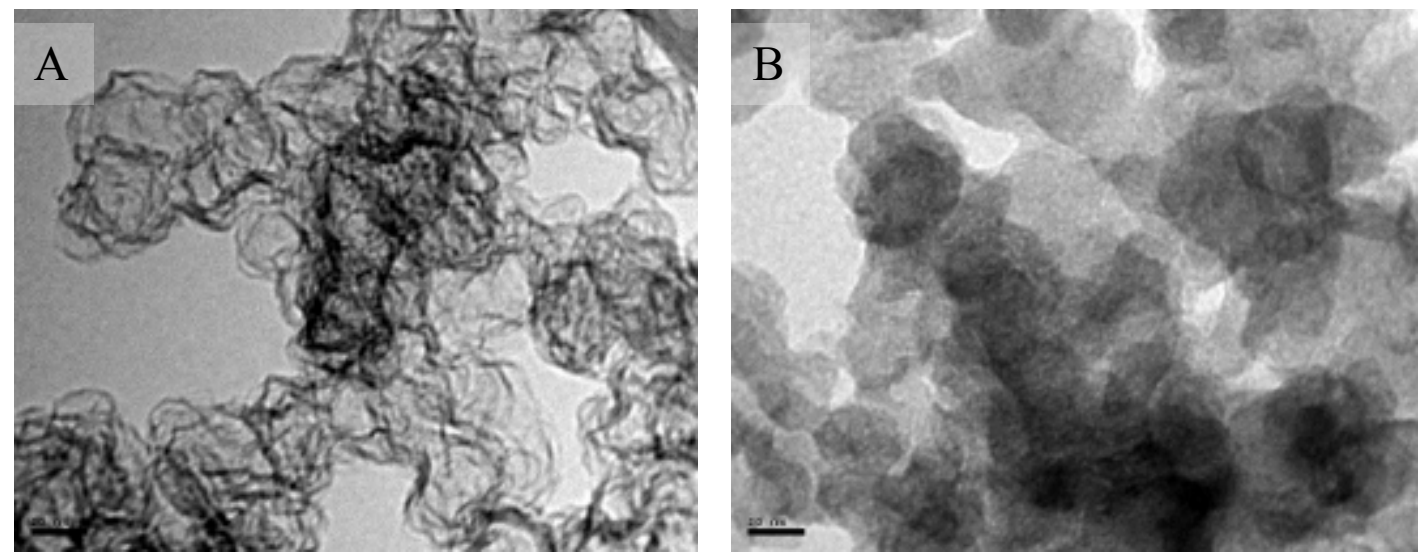

Figura 3.7: (A) Chezacarb sin PTFE y (B) con PTFE.
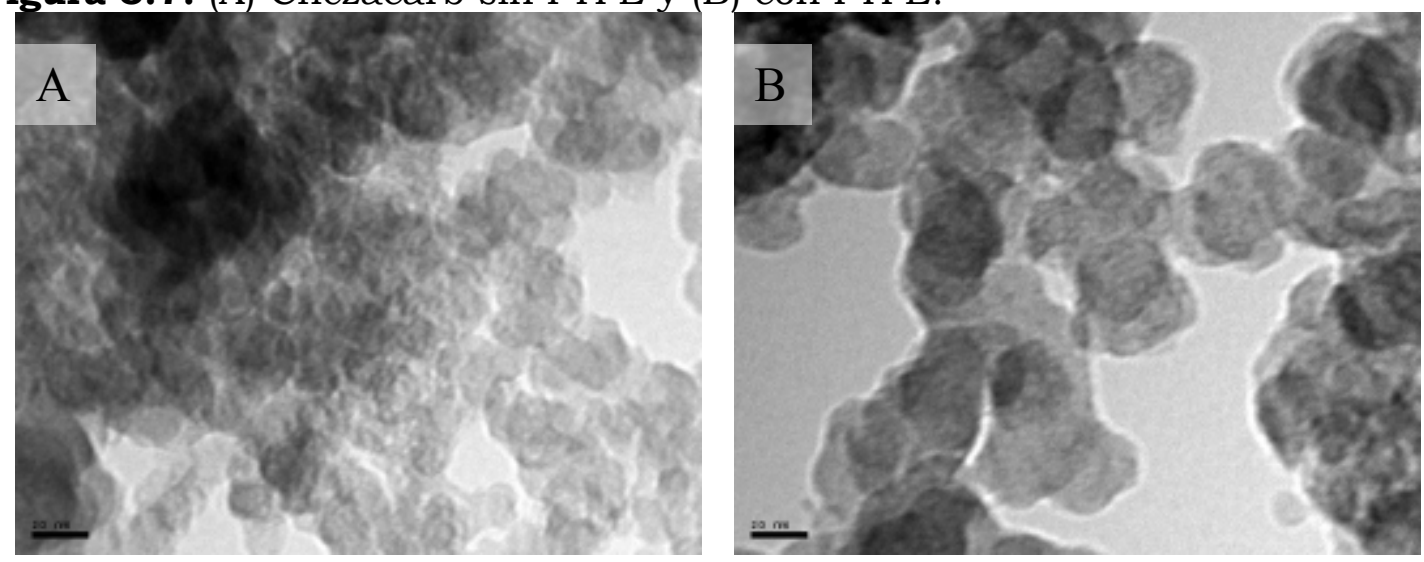

Figura 3.8: (A) Vulcan XC72 sin PTFE y (B) con PTFE.
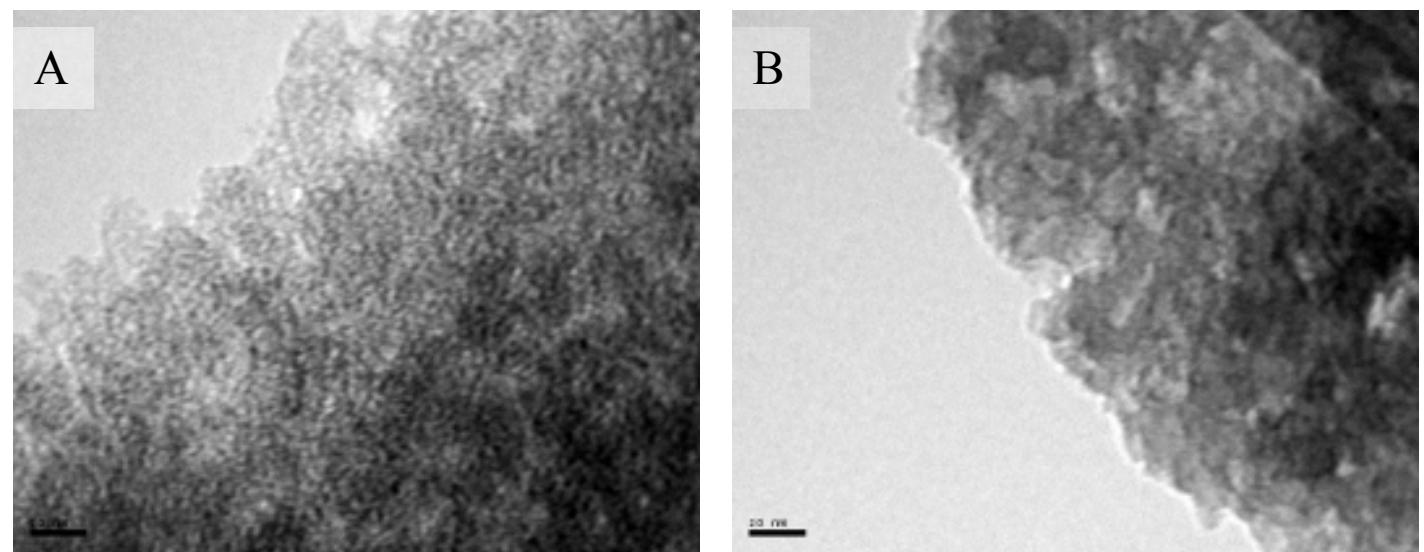

Figura 3.9: (A) Xerogel MO sin PTFE y (B) con PTFE.

\subsubsection{Isotermas de adsorción de gases}

Si bien hasta aquí se presentaron las características de los materiales en forma conjunta, las medidas realizadas con ellos poseen un orden cronológico tal que involucra cambios en la forma de trabajo. Así, en primer lugar se mostrarán las isotermas para NTCS, NTCM, Vulcan, Ch y M0, para luego abordar el estudio de los demás Xerogeles de carbono. 
Las isotermas mostradas en las Figuras 3.10-3.11 presentan un ciclo de histéresis debido a la condensación capilar que ocurre en los mesoporos. Comparando este resultado con la clasificación de isotermas IUPAC [35], surge que estos carbones presentan isotermas del tipo IV.

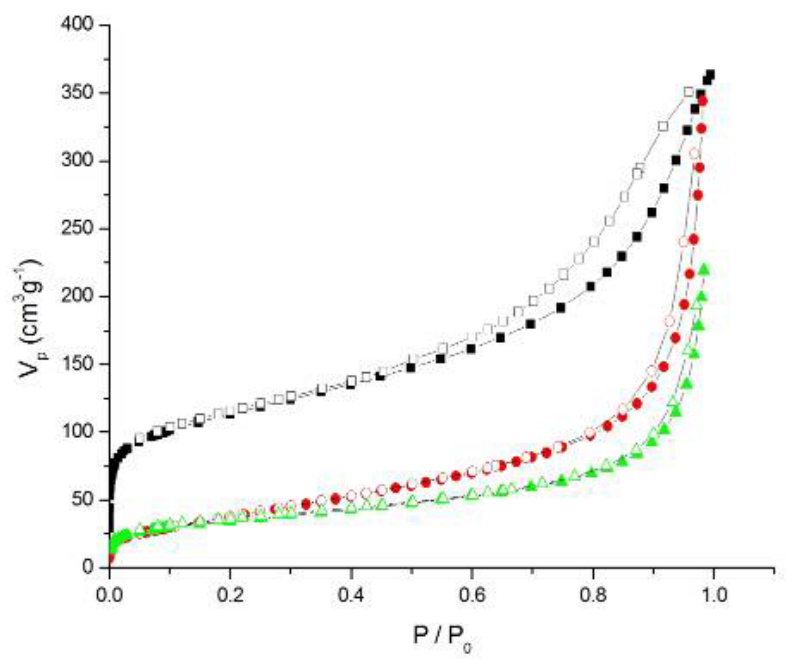

Figura 3.10: Isotermas de adsorción de $\mathrm{N}_{2}$ correspondientes a los adsorbentes NTCS ( $)$ ), NTCM ( $\mathbf{O})$, Vulcan ( $\mathbf{\Delta})$.

Las isotermas mostradas en la Figura 3.10, pertenecen al grupo de carbones que poseen áreas superficiales en el orden de $10 \mathrm{~s} 1000 \mathrm{~m}^{2} \mathrm{~g}^{-1}$ o mayores. Debido a la gran diferencia en las escalas de valores es necesario separar los carbones en dos grupos.

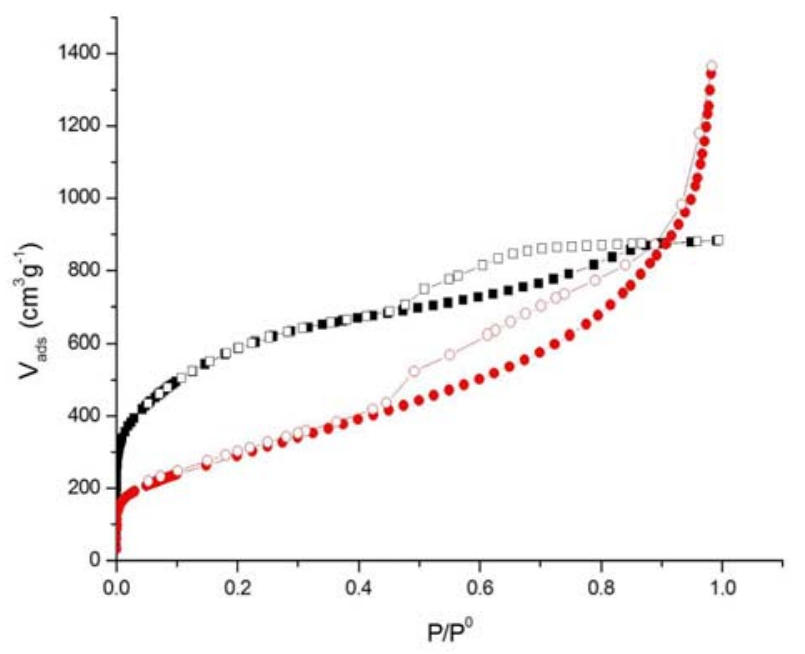

Figura 3.11: Isotermas obtenidas con MO ( $\square)$, Ch (O). 
Tanto el Xerogel MO como el carbon Ch son esencialmente materiales micro-mesoporosos. Esto se deduce porque es característico de las isotermas que muestran grandes volúmenes de adsorción de $\mathrm{N}_{2}$ a bajas presiones relativas. Por otro lado, tanto los NTC como el Vulcan son carbones con una cantidad comparativamente mucho menor de microporos. Además, a bajas presiones relativas el Ch muestra un comportamiento intermedio entre el Xerogel y los carbones con menor área interfacial. En este último grupo, claramente, los NTCS son los que presentan mayor microporosidad.

La región de presiones relativamente altas de las isotermas son las que caracterizan la naturaleza de los mesoporos. Como se desprende de la observación de las Figuras 3.10-3.11, en esta zona se perciben las mayores diferencias de comportamiento. El lazo de histéresis da una idea del tamaño y el volumen de los mesoporos. Así, cuanto menor sea el tamaño de los mesoporos, a menor $\mathrm{p} / \mathrm{p}_{0}$ se encontrará el lazo y cuanto mayor sea el volumen de éstos, estará mejor definido. En la Tabla 3.1 se muestra un resumen de algunos parámetros calculados a través de las isotermas medidas, los cuales están relacionados con la porosidad y las áreas superficiales de los materiales.

\begin{tabular}{|l|c|c|c|c|}
\hline Muestra & $\mathbf{S}_{\text {BET }}\left(\mathbf{m}^{\mathbf{2}} \mathbf{g}-\mathbf{1}\right)$ & $\mathbf{V}_{\text {meso }}\left(\mathbf{c m}^{\mathbf{3}} \mathbf{g}^{-\mathbf{1}}\right)$ & $\mathbf{V}_{\text {micro }}\left(\mathbf{c m}^{\mathbf{3}} \mathbf{g}^{-\mathbf{1}}\right)$ & $\mathbf{L} \mathbf{p ~ ( n m )}$ \\
\hline NTCS & 411 & 0,39 & 0,17 & 2,9 \\
\hline NTCM & 149 & 3,76 & 0,04 & 3,8 \\
\hline Vulcan & 199 & 0,30 & 0,08 & 1,9 \\
\hline Ch & 1360 & 1,94 & 0,48 & 1,9 \\
\hline
\end{tabular}

Tabla 3.1: Caracteristicas texturales de los carbones estudiados, obtenidas a través de las isotermas de adsorción de $\mathrm{N}_{2}$ a $77 \mathrm{~K}$.

Las isotermas mostradas hasta el momento y los resultados derivados de las mismas fueron obtenidos con los carbones sin teflonar, lo cual no genera problema alguno puesto que fue corroborado experimentalmente que el agregado de $10 \%$ de PTFE no varió sensiblemente los resultados texturales de los materiales. Así, la forma de las isotermas de los carbones con y sin teflón es muy similar. Sin 
embargo, aquellas isotermas correspondientes a los carbones teflonados muestran una pequeña disminución de las propiedades texturales de los materiales.

Cuando se comenzó a trabajar con la serie de Xerogeles M1, M2, M3, M4 y el carbón activado S30, se encontró que algunos de estos carbones necesitaron cantidades superiores de PTFE para permitir el armado de los electrodos, lo cual nos obligó a comenzar a medir isotermas de los materiales teflonados. De esta manera, es posible obtener parámetros más representativos del material que forma parte del electrodo de trabajo en las medidas electroquímicas. En el mismo sentido, decidimos medir las isotermas de los carbones teflonados en forma de pastilla, esto es, directamente del electrodo de trabajo (pero sin el colector de corriente de Ni). En la Figura 3.12 pueden observarse claramente los importantes cambios en las propiedades texturales de los diferentes materiales luego de ser teflonados y de haber aplicado presión para formar una pastilla.
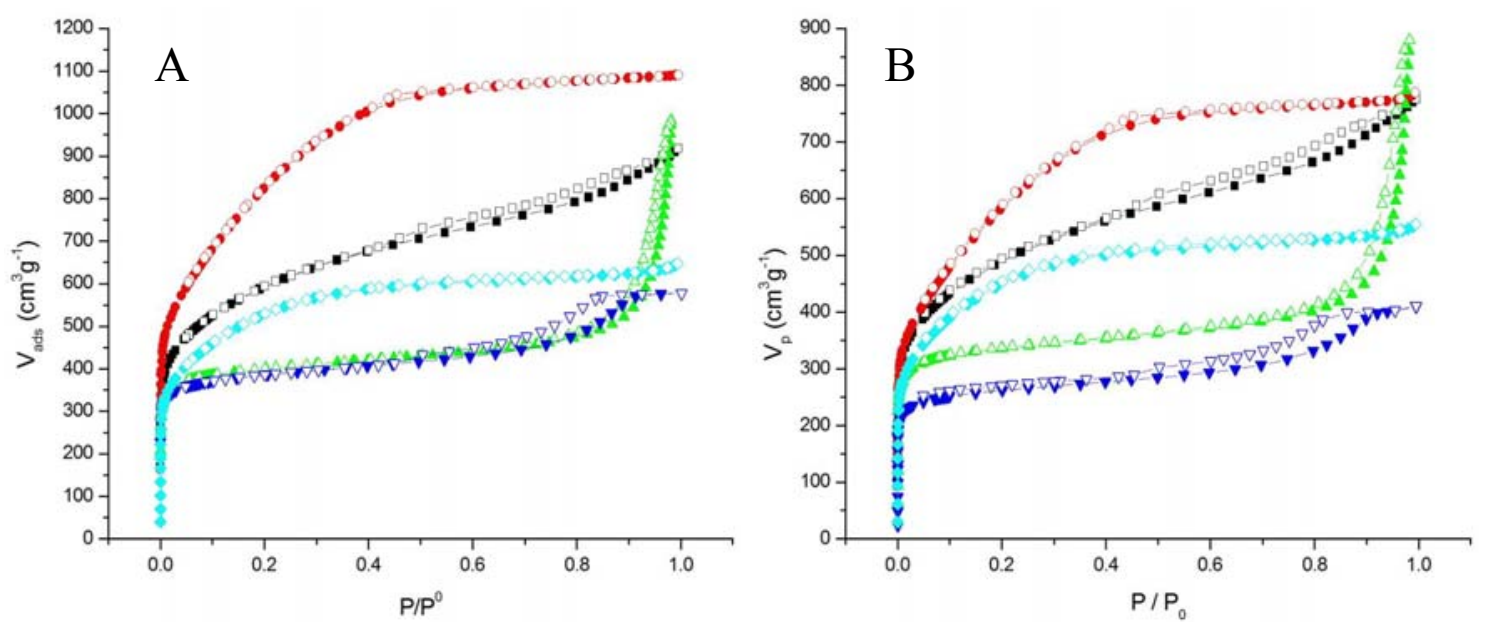

Figura 3.12: Isotermas de adsorción de $N_{2}$ para $M 1(\boldsymbol{\square}), M 2(\boldsymbol{O}), M 3(\bar{\Delta}), M 4(\boldsymbol{\nabla})$, S30 ( )

Las muestras M2 y S30 presentan una isoterma de tipo I, las cuales se corresponden con la presencia de materiales predominantemente microporosos. Sin embargo, una inspección cuidadosa permite advertir la presencia de mesoporos pequeños (adsorción importante a presiones medias-bajas y pequeño ciclo de histéresis), mientras que M1, M3 y M4 poseen un ciclo de histéresis 
mucho más importante, presentando isotermas de tipo I-IV, que son características de materiales micro-mesoporosos.

En la Tabla 3.2 se muestran algunos parámetros calculados para los Xerogeles y para S30.

\begin{tabular}{|l|c|c|c|c|c|}
\hline Muestra & $\mathbf{S}_{\text {BET }}\left(\mathbf{m}^{\mathbf{2}} \mathbf{g}^{-\mathbf{1}}\right)$ & $\mathbf{S}_{\mathbf{m i c}}\left(\mathbf{m}^{\mathbf{2}} \mathbf{g}^{\mathbf{1}}\right)$ & $\mathbf{V}_{\text {meso }}\left(\mathbf{c m}^{\mathbf{3}} \mathbf{g}^{-\mathbf{1}}\right)$ & $\mathbf{V}_{\text {micro }}\left(\mathbf{c m}^{\mathbf{3}} \mathbf{g} \mathbf{- 1}\right)$ & $\mathbf{L} \mathbf{p}(\mathbf{n m})$ \\
\hline M1 & 1786 & 719 & 0,54 & 0,65 & 1,8 \\
\hline M2 & 2089 & 733 & 0,54 & 0,67 & 1,8 \\
\hline M3 & 1316 & 869 & 0,83 & 0,52 & 1,2 \\
\hline M4 & 1020 & 787 & 0,23 & 0,40 & 1,0 \\
\hline S30 & 1664 & 687 & 0,31 & 0,54 & 1,6 \\
\hline
\end{tabular}

Tabla 3.2: Características texturales de los Xerogeles.

\subsubsection{Medidas electroquimicas}

\subsubsection{Voltamperometría Cíclica (VC) y Potenciometría (CD por carga-descarga)}

La VC fue llevada a cabo realizando barridos triangulares de potencial a $\mathrm{v}=1.10^{-3}, 3.10^{-3}, 5.10^{-3}$ y $1.10^{-2} \mathrm{Vs}^{-1}$. Los limites de potencial se fijaron de modo de mostrar solamente la región de comportamiento puramente capacitivo.

En la Figura 3.13 se muestran voltamperogramas realizados a $\mathrm{v}=1.10^{-2} \mathrm{Vs}^{-1}$ para todos los carbones utilizados. Para permitir una visualización más clara, las medidas realizadas con Xerogeles fueron colocadas en un gráfico aparte (Fig. 3.13B). En los electrodos realizados con los materiales de menores áreas interfaciales y mayores conductividades (Fig. 3.13A) puede observarse una clara contribución pseudocapacitiva, teniendo en cuenta que los voltamperogramas no poseen la forma rectangular típica que se observa cuando el comportamiento es el de un capacitor puro. De todos modos, una parte de esta desviación, se debe a la resistencia intrínseca del sistema utilizado para evaluar los materiales. Este hecho aparece mucho más acentuado con los Xerogeles, en cuyas medidas se observan componentes resistivos muy importantes. Esto hace que los parámetros medidos en este tipo de experimentos no puedan ser comparados 
directamente con los obtenidos con materiales utilizando otro sistema o en un capacitor. Por lo tanto, para tener un parámetro directo de comparación, fue adquirido el carbón comercial Supra $30\left(\right.$ Norit $\left.^{\circledR}\right)$, el cual es utilizado en la fabricación de SC. Por esa razón, en ambos gráficos se presenta la respuesta de este carbón comercial, al cual también se le hizo la caracterización textural.
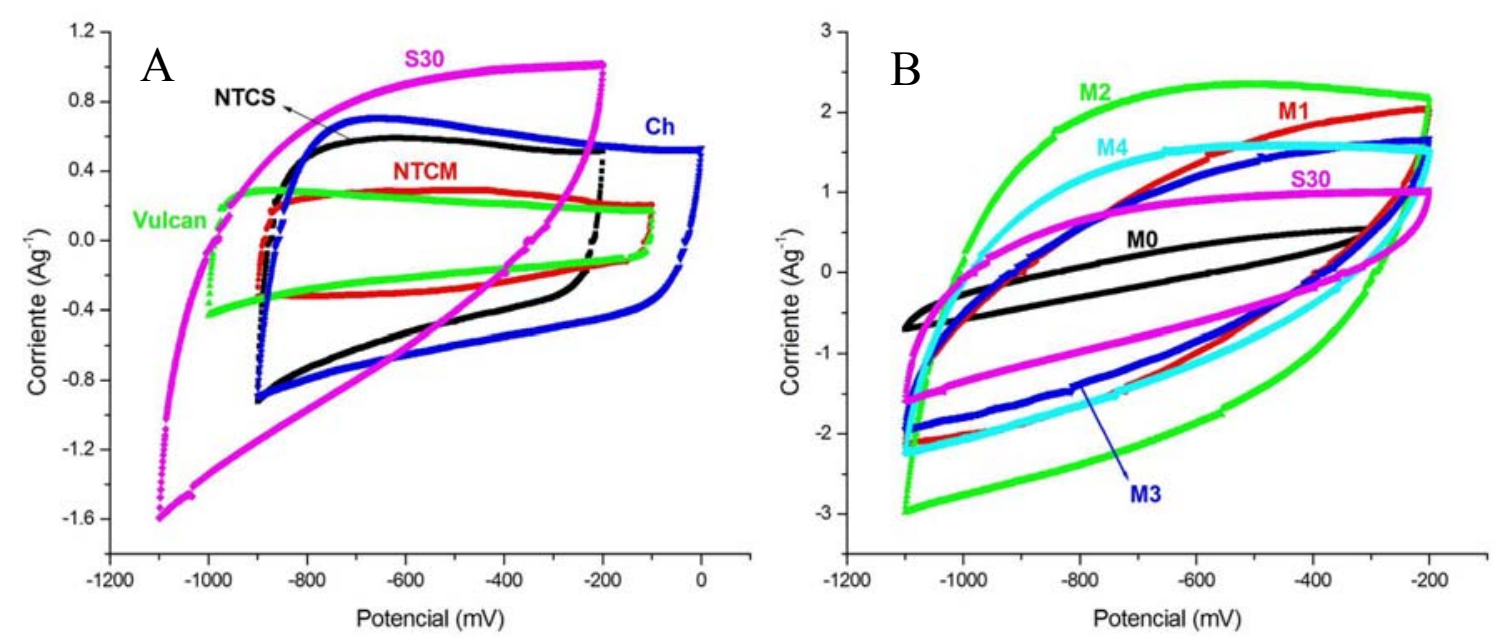

Figura 3.13: Voltamperogramas realizados con todos los materiales utilizados en este trabajo.

Comparando las dos figuras podemos concluir que los Xerogeles muestran corrientes de carga y descarga de la DCE mayores que las observadas para los carbones de la Figura 3.13A, excepto para M0. Además, todos los electrodos permiten visualizar la importante componente resistiva citada anteriormente. Por otro lado, tanto los NTC como el Chezacarb poseen una contribución resistiva muy baja a esta velocidad de barrido y las desviaciones del comportamiento de un capacitor ideal se deben principalmente a la existencia de fenómenos de transferencia de carga. La comparación con la respuesta mostrada por S30 ilustra muy bien lo expuesto.

Las cargas y descargas galvanostáticas para los Xerogeles y S30 fueron realizadas entre los $-0,20$ y $-0,90 \mathrm{~V}$. Los electrodos fueron cargados a $88,6 \mathrm{mAg}^{-1}$ y subsecuentemente descargados a distintas corrientes. 
Las curvas potencial-tiempo poseen pequeñas desviaciones de la linealidad debido a la ocurrencia de reacciones de transferencia de carga. Además, la variación de las capacidades con las diferentes velocidades de descarga da una idea de la resistencia interna del sistema (Figuras 3.14 y 3.15). Debido a que el único cambio que se realiza entre medida y medida es la composición del ET, es válido asignar las diferencias observadas a los distintos componentes resistivos de los carbones. Estos resultados están directamente relacionados con las diferencias de potencia a la que podrán funcionar los SC fabricados con estos materiales.

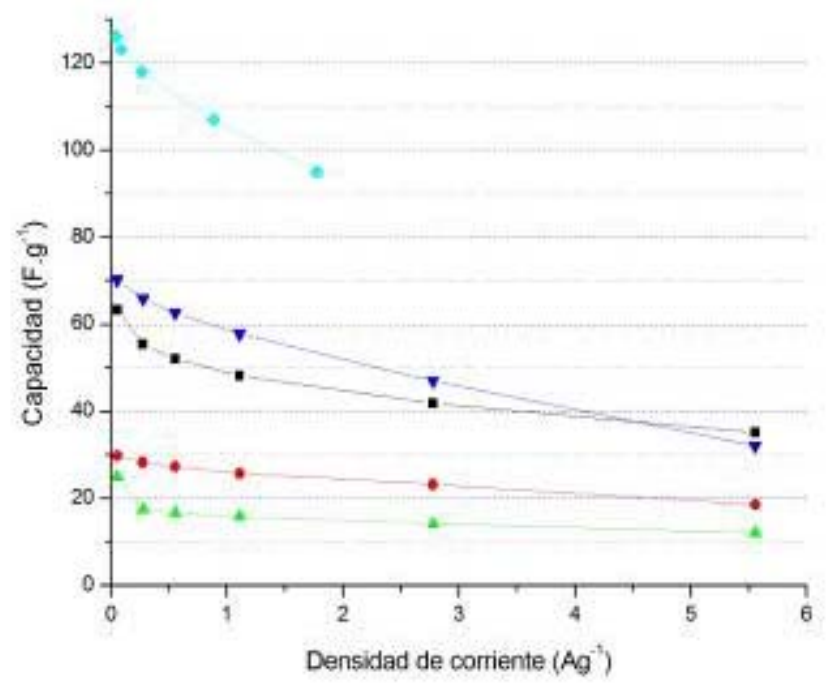

Figura 3.14: Valores de capacidad especifica, $C$, obtenidos a diferentes velocidades de descarga. NTCS ( $\boldsymbol{\square})$, NTCM ( ) , Vulcan ( $\bar{\Delta}$ ), Chezacarb ( $\boldsymbol{\nabla})$, S30 ( ).

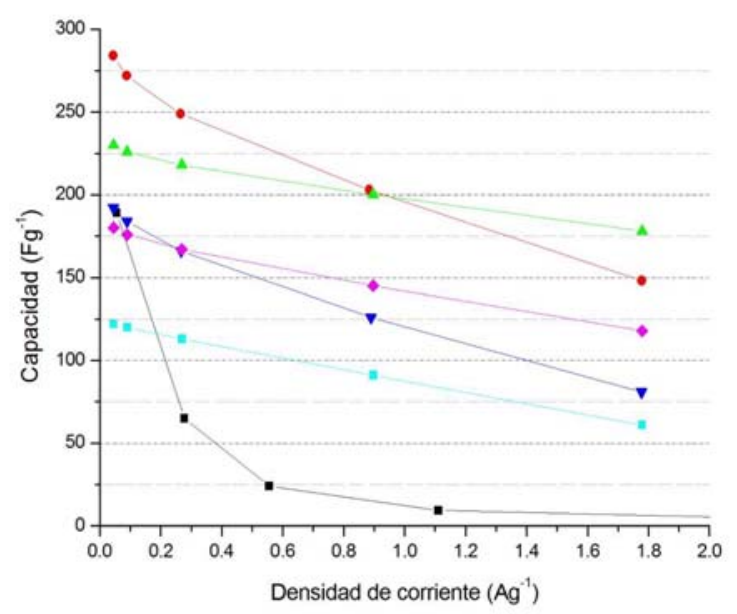

Figura 3.15: Valores de $C$ obtenidos a diferentes velocidades de descarga para: M0 $(\boldsymbol{\square}), \mathrm{M} 1(\mathbf{O}), \mathrm{M} 2(\overline{\mathbf{\Delta}}), \mathrm{M} 3(\boldsymbol{\nabla}), \mathrm{M} 4(\bigcirc)$ y S30 $(\bullet)$ 
Comparando las respuestas de S30 en las dos figuras, donde se muestra la dependencia de la capacidad con la velocidad o corriente de descarga de los electrodos, se deduce que la disminución de este parámetro con el aumento de los valores en el eje de las abscisas es notablemente más marcado para los Xerogeles y para S30 que para los demás carbones (Figuras 3.14 y 3.15). Esta conclusión está de acuerdo con los resultados obtenidos con la técnica VC, donde concluimos que los Xerogeles de Carbono tenian componentes resistivas mayores que las mostradas por los NTC y el Chezacarb.

Por otro lado, los Xerogeles de carbono son los que muestran los valores marcadamente más altos de capacidades a bajas corrientes. Un resultado muy importante desde el punto de vista tecnológico es que todos los materiales obtenidos en el laboratorio del INCAR, excepto MO, exhiben capacidades mayores que el carbón comercial.

\subsubsection{Espectroscopia de Impedancia Electroquimica}

Las medidas de EIS fueron realizadas a un potencial de -0,30V, aplicando una onda sinusoidal de $15 \mathrm{mV}$ de amplitud en el rango de frecuencias de $0.5 \mathrm{mHz} \leq \mathrm{f} \leq 50 \mathrm{kHz}$. El potencial fue elegido con el objetivo de minimizar la contribución de la pseudocapacitancia a la capacidad de DCE del electrodo.

En la Figura 3.16 se muestran los diagramas de Nyquist de los carbones de menor área superficial. Con el propósito de visualizar claramente la respuesta típica de un electrodo poroso, el espectro obtenido para $\mathrm{Ch}$ se muestra sólo e inserto en él se encuentra una ampliación de la zona de altas frecuencias.

A las frecuencias más altas puede observarse un semicírculo que está directamente relacionado con el contacto entre las partículas que forman el carbón y el que se produce entre éstas y el colector de corriente [36]. El radio del semicírculo aumenta cuanto menor es el contacto entre partículas carbonosas y entre éstas y el colector de corriente, generando una menor conductividad efectiva del sólido. 
En el rango de frecuencias medias-altas, se observa un comportamiento lineal con una pendiente aproximada a los $45^{\circ}$, hasta alcanzar una frecuencia característica, a partir de la cual el ángulo aumenta hasta aproximadamente los $90^{\circ}$. Este tipo de respuesta está asociada con la distribución de potencial, debido a las conductividades efectivas finitas de las fases sólidas y del electrolito dentro de la estructura porosa [37].

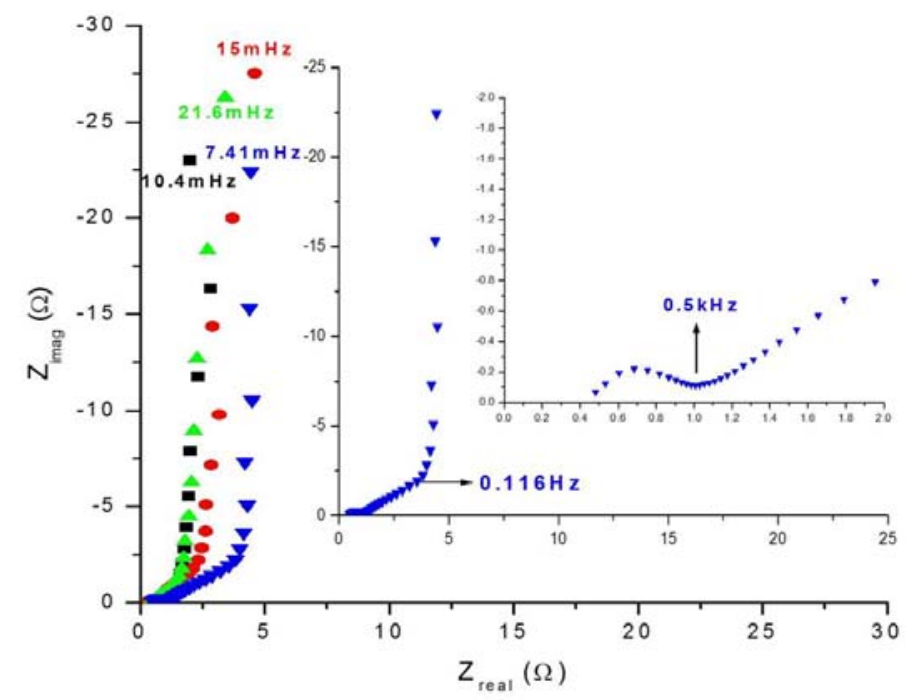

Figura 3.16: Diagramas de Nyquist para $\operatorname{NTCS}(\boldsymbol{\square}), \operatorname{NTCM}(\mathbf{O})$, Vulcan $(\bar{\Delta})$ y $\mathrm{Ch}(\boldsymbol{\nabla})$.

En la Figura 3.17 se muestran los diagramas de Nyquist obtenidos con los Xerogeles (excepto M0 que se discutirá más adelante). Claramente podemos observar que las impedancias involucradas en estos materiales son mucho mayores que las de aquellos presentados en la Figura 3.16, lo cual justifica claramente los resultados obtenidos mediante VC. Además, el semicírculo a altas frecuencias es mucho más significativo para los xerogeles de carbono, lo cual está de acuerdo con las mayores resistencias de estos sólidos.

$\mathrm{Si}$ bien las conclusiones que pueden obtenerse de una simple observación de los diagramas son muy importantes, el desarrollo del modelo fisicoquímico para electrodos porosos presentado en el Capítulo 2 , nos ha permitido obtener información muy valiosa, que se presenta a continuación. 


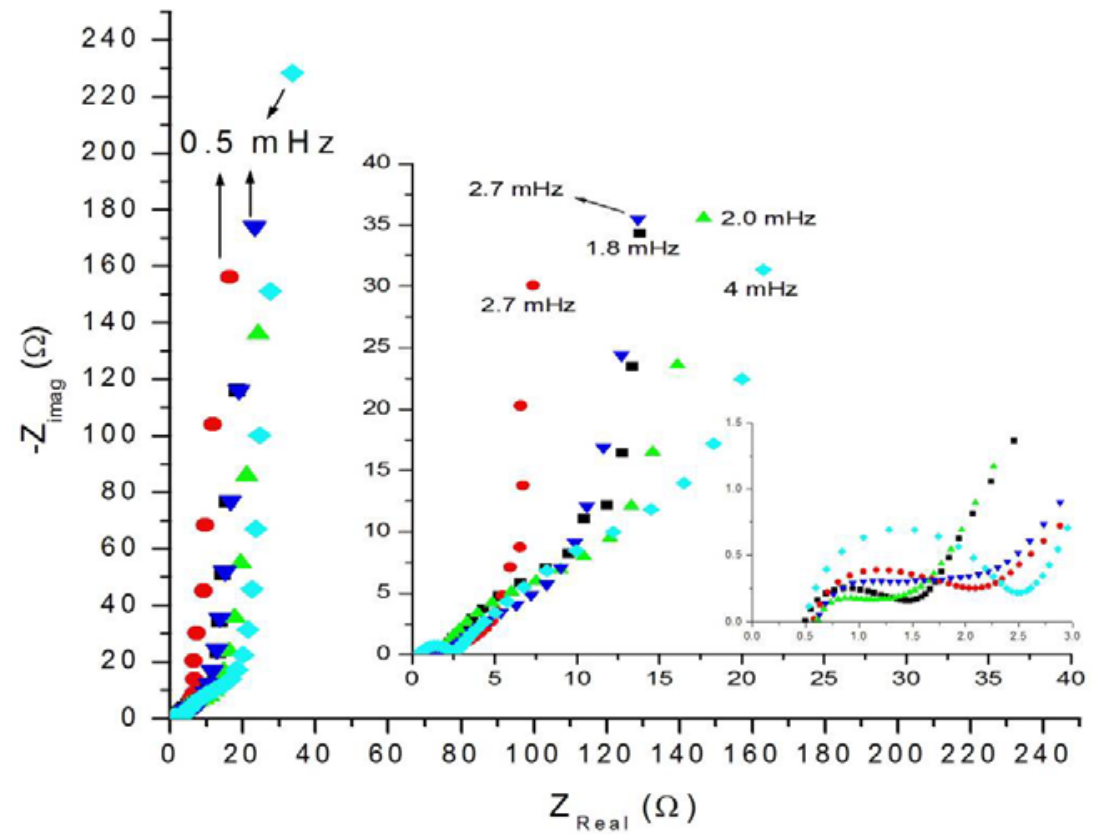

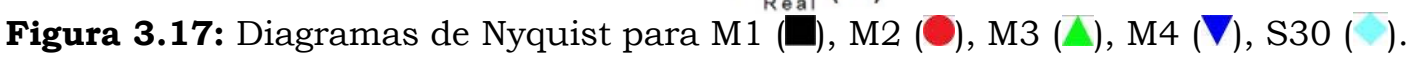

\subsection{Análisis Teórico-Aplicación del modelo fisicoquímico} descrito en el Capítulo 2

Se realizó un análisis teórico de la respuesta dinámica del sistema utilizando el modelo fisicoquímico desarrollado anteriormente. Con el objetivo de identificar parámetros estructurales y cinéticos de los diferentes electrodos estudiados, se realizó un ajuste de la función impedancia derivada del modelo a los datos experimentales.

$Z_{p}=\frac{L}{A_{p}(\kappa+\sigma)}\left[1+\frac{2+\left(\frac{\sigma}{\kappa}+\frac{\kappa}{\sigma}\right) \cosh (v)}{v \operatorname{senh}(v)}\right]$

donde $A_{p}$ es el área geométrica transversal del electrodo y $v$ está dado por:

$v=L\left(\frac{\kappa+\sigma}{\kappa \sigma}\right)^{1 / 2} Z_{i}^{-1 / 2}$

teniendo en cuenta lo expuesto en la sección donde se desarrolló el modelo (Capítulo 2, Sección 2.4), y el tipo de sistema estudiado en ésta, despreciando la pseudocapacitancia del electrodo alrededor de -0,3V, la impedancia interfacial queda resumida a: 


$$
Z_{i}=Z_{d l}=\frac{1}{j \omega C_{d l}}
$$

Cuando se comenzó con esta parte de la tesis se trabajó exclusivamente con el grupo de carbones con áreas interfaciales menores que $1000 \mathrm{~m}^{2} \mathrm{~g}^{-1}$, que fueron medidas empleando el método BET. En el grupo de Conversión y Almacenamiento de Energía (CAE) de INIFTA teníamos experiencia en el uso del carbón Vulcan para la construcción de electrodos almacenadores de energía de hidruros metálicos. Este tipo de carbones porosos poseen conductividades electrónicas relativamente grandes, lo cual genera que $\sigma>>$ y que por lo tanto la impedancia del electrodo poroso no dependa de la conductividad efectiva del sólido. Las expresiones que resultan de esta simplificación son:

$$
\begin{gathered}
Z_{p}=\frac{L}{A_{p} \kappa}\left[\frac{1}{v \tanh v}\right] \quad v=L\left(\frac{1}{\kappa}\right)^{1 / 2} Z_{i}^{-1 / 2} \\
Z_{i}=Z_{d l}=\frac{1}{j \omega C_{d l}}
\end{gathered}
$$

Con el propósito de identificar los parámetros del sistema, se realiza un procedimiento de ajuste de la impedancia experimental en términos de la función de impedancia teórica, $Z_{p}$. Se desarrolla un programa de ajuste basado en el Nelder-Mead simplex search algorithm [38]. El ajuste se considera aceptable cuando $J_{p}$, la función costo, es $J_{p}<5 \times 10^{-3}$.

$J_{p}=\frac{1}{K} \sum_{k}\left|\frac{Z_{e}\left(\omega_{k}\right)-Z_{p}\left(p, \omega_{k}\right)}{Z_{e}\left(\omega_{k}\right)}\right|^{2}$

donde $K$ es número de frecuencias empleadas en los experimentos $(\omega)$; $Z_{e}$ y $Z_{p}$ corresponden a los datos experimentales $\mathrm{y}$ teóricos, respectivamente, correspondiendo a la frecuencia $\omega_{\mathrm{k}}$.

En las Figuras 3.18 y 3.19 se muestran los diagramas de Nyquist y de Bode de los ajustes para los electrodos construidos con NTCS y NTCM, respectivamente. Sólo se muestran los ajustes para estos dos 
electrodos puesto que las gráficas son útiles para corroborar visualmente la calidad de los ajustes, la cual es comprobada matemáticamente a través de los valores de $J_{p}$. Cabe señalar que los ajustes fueron realizados descartando las frecuencias a las cuales aparece el semicírculo debido al contacto entre partículas. Para la serie de carbones de bajas áreas interfaciales este hecho es despreciable, pero los espectros obtenidos con los Xerogeles de carbones muestran que es necesario descartar un número importante de datos que influyen negativamente en la calidad de los resultados finales.
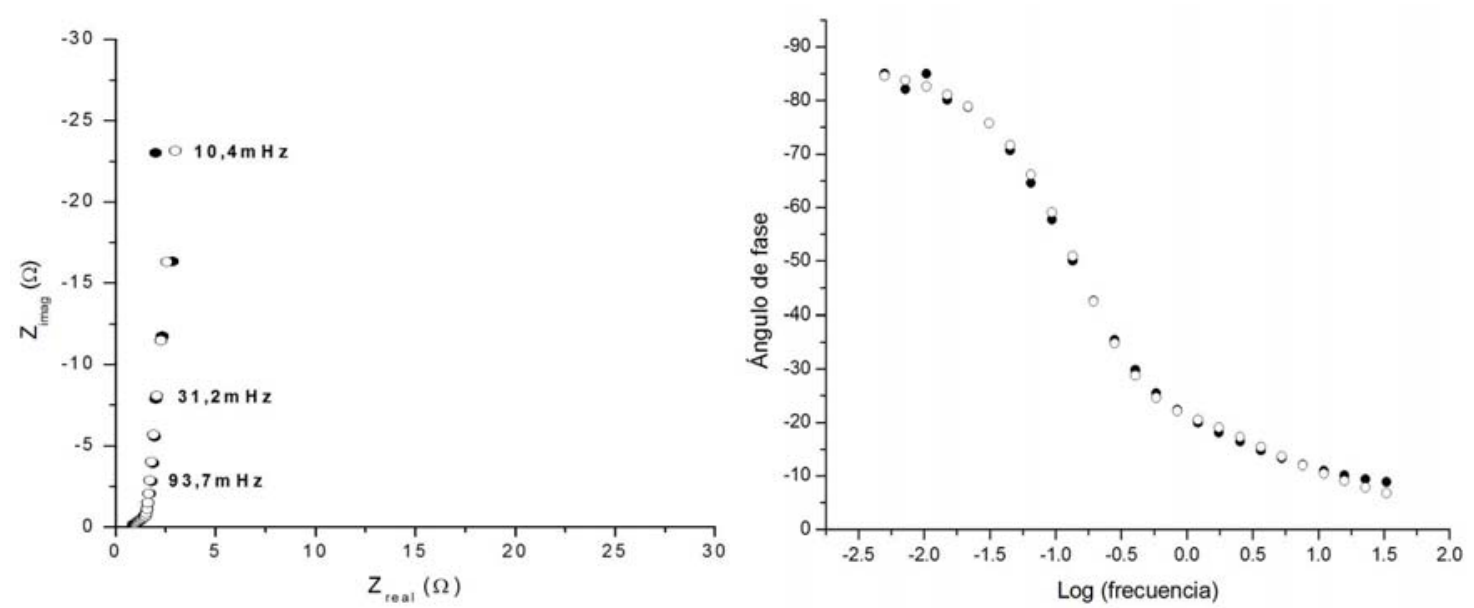

Figura 3.18: Diagramas de Nyquist y de Bode. Datos $(\bullet)$ experimentales y $(\bigcirc)$ teóricos para NTCS.
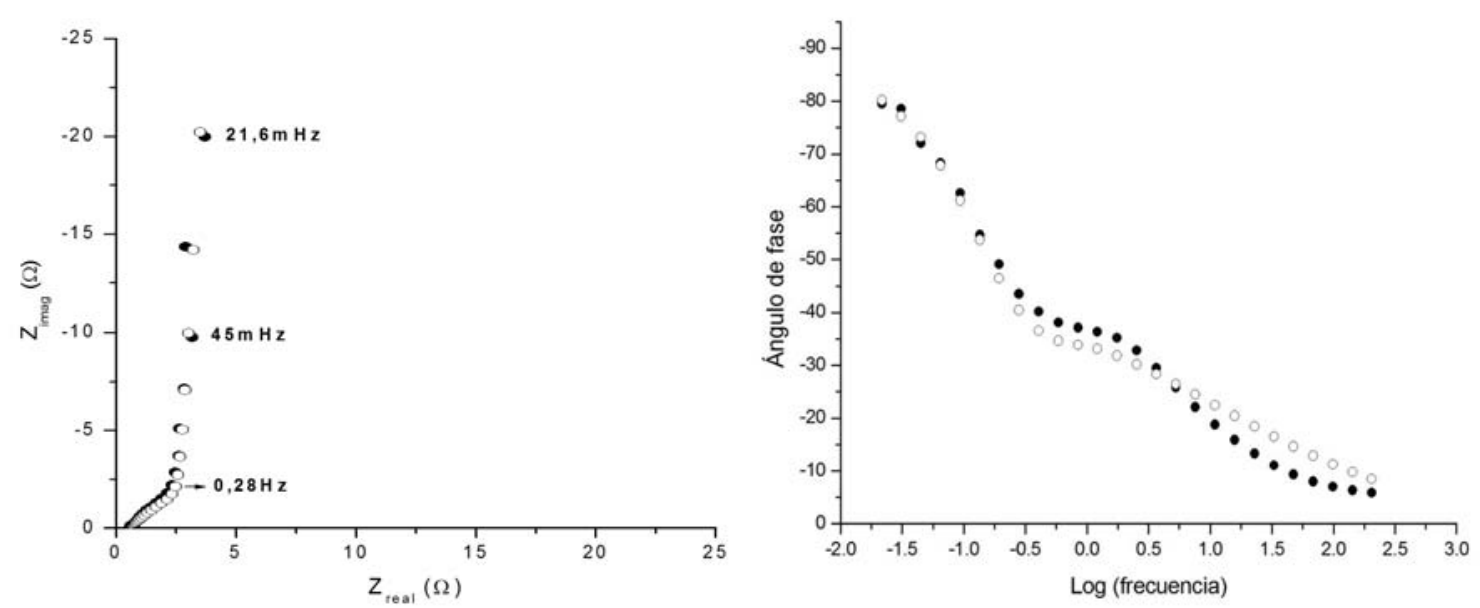

Figura 3.19: Diagramas de Nyquist y de Bode. Datos $(\bullet)$ experimentales y $(\bigcirc)$ teóricos para NTCM.

En la Tabla 3.3 se muestran los parámetros derivados del ajuste. La capacidad de la DCE, $C_{d l} O C_{E I E}$ (dependiendo de las unidades 
utilizadas) y la conductividad efectiva del electrolito son parámetros que nos permiten interpretar los resultados electroquímicos.

\begin{tabular}{|l|c|c|c|}
\hline Electrodo & $\mathbf{C}_{\boldsymbol{d l}} / \mathbf{F c m}^{-3}$ & $\boldsymbol{\kappa}^{*} 10^{2}$ & $\mathbf{C}_{\boldsymbol{E I E}} / \mathbf{F g}^{-1}$ \\
\hline NTCS & 19,5 & 0,9 & 37 \\
\hline NTCM & 4,5 & 1,9 & 20 \\
\hline Vulcan & 3,6 & 3,2 & 15 \\
\hline Ch & 14,5 & 0,8 & 52 \\
\hline
\end{tabular}

Tabla 3.3: Parámetros fisicoquímicos obtenidos del procedimiento de ajuste.

$C_{\mathrm{dl}}$ se obtiene con el procedimiento de ajuste para cada electrodo. Este parámetro puede relacionarse con los valores de $C$ obtenidos de los experimentos de $\mathrm{CD}$, cuando es multiplicado por el volumen de cada uno de los electrodos $\left(L A_{\mathrm{p}}\right)$ y dividido por la masa de éste. Así, en la Tabla 3.4 se presentan los valores de capacidad obtenidos mediante CD y los que resultan del ajuste de las medidas de impedancia. Los valores de $C_{E I S}$ son comparados con aquéllos obtenidos a las menores corrientes empleadas en este trabajo, dado que $C_{d l}$ es obtenido a través de las medidas de EIE, en las cuales se determina el área interfacial total disponible. Como se puede observar, la tendencia de ambos valores coincide muy bien. El hecho de que los valores sean diferentes no debe llamar la atención porque el ajuste proporciona un valor que representa el almacenamiento de carga en la DCE, un proceso enteramente capacitivo, mientras que el obtenido mediante $\mathrm{CD}$ presenta contribuciones de la DCE y de la transferencia de carga faradaica originada por los grupos superficiales de los carbones.

\begin{tabular}{|l|c|c|}
\hline Electrodo & $\boldsymbol{C}_{\boldsymbol{E I E}} / \mathbf{F g}^{-1}$ & $\mathbf{C} / \boldsymbol{F g}^{-1}$ \\
\hline NTCS & 37 & 64 \\
\hline NTCM & 20 & 30 \\
\hline Vulcan & 15 & 25 \\
Ch & 52 & 70 \\
\hline
\end{tabular}

Tabla 3.4: Comparación entre la capacidad teórica (Obtenida mediante el ajuste) y la experimental (Obtenida mediante cronopotenciometría). 
Otro parámetro importante a tener en cuenta es $S_{E I E}$, área interfacial por gramo. Es un parámetro que se deduce luego de los ajustes con los resultados experimentales, y desde el punto de vista electroquímico reviste gran interés porque es una medida del área real que efectivamente participa en la reacción de electrodo. Esto constituye un valioso hallazgo porque los datos de áreas específicas proporcionados por el método BET involucran a toda la superficie a la cual puede acceder el $\mathrm{N}_{2}$, mientras que el área interfacial hallada por EIE es una información de la fracción del material que realmente participa en el proceso que tiene lugar en la interfase electrodo/solución electrolitica. $C_{d l}$ es una medida directa de la interfase sólida puesta en contacto con la solución electrolítica, sin embargo, sus unidades no permiten una comparación directa con las áreas medidas por BET. Corrientemente, se considera que la capacidad de la DCE por unidad de área, $C_{\mathrm{dl}}^{0}$, en electrodos planos es del orden de $1,6.10^{-5}$ a $5,0.10^{-5} \mathrm{Fcm}^{-2}$ [39]. Considerando un valor promedio de $3,0.10^{-5} \mathrm{Fcm}^{-2}$, se obtiene el área interfacial por unidad de volumen $\left(\mathrm{a}_{\mathrm{i}}\right)$ para cada electrodo, $C_{\mathrm{dl}}=C_{\mathrm{dl}}^{0} \mathrm{a}_{\mathrm{i}}$

Por consiguiente, el área electroquímicamente accesible de los carbones, $S_{E I E}$, puede hallarse luego de calcular $\mathrm{a}_{\mathrm{i}}$, teniendo en cuenta que,

$$
S_{E I E}=\frac{\mathrm{a}_{\mathrm{i}} V}{m}
$$

donde $V$ es el volumen del electrodo y $m$ es la masa total del carbón. Luego, a través de este parámetro y comparando con los valores obtenidos de los experimentos BET (empleando $\mathrm{N}_{2}$ ), es posible calcular la fracción del área de carbón total accesible al electrolito. Asimismo, la comparación entre $S_{B E T}$ y $S_{E I E}$ o $C_{d l}$ permite tener una idea de la accesibilidad del electrolito a la matriz porosa del electrodo. Para ello, definimos el parámetro de accesibilidad, $A_{c}$, como:

$A_{c}=S_{E I E} / S_{B E T}$

En la Tabla 3.5 pueden observarse los valores de $A_{c}$ obtenidos. Este parámetro nos indica que, por ejemplo, en el electrodo construido 
con NTCM, el electrolito puede acceder al 44\% del área superficial que fue medida para este material por el método BET. Debe recordarse que $S_{B E T}$ fue obtenida con el material teflonado, pero antes de aplicar presión. Anteriormente fue mencionado que las isotermas realizadas con los Xerogeles fueron obtenidas luego de formar la pastilla (electrodo de trabajo), por lo cual, el parámetro $A_{c}$ será un indicativo del área del electrodo que fue inundada por el electrolito, ahora no con respecto al material original sino con respecto al mismo electrodo.

\begin{tabular}{|l|c|c|c|}
\hline Electrodo & $\boldsymbol{S}_{\boldsymbol{B E T} \boldsymbol{T}} / \boldsymbol{m}^{\mathbf{2}} \boldsymbol{g}^{-1}$ & $\boldsymbol{S}_{\boldsymbol{E I E}} / \boldsymbol{m}^{\mathbf{2}} \boldsymbol{g}^{\mathbf{1}}$ & $\boldsymbol{A}_{\boldsymbol{c}}$ \\
\hline NTCS & 404 & 124 & 0,31 \\
\hline NTCM & 152 & 67 & 0,44 \\
\hline Vulcan & 121 & 31 & 0,26 \\
\hline Ch & 952 & 173 & 0,18 \\
\hline
\end{tabular}

Tabla 3.5: Comparación entre los valores de área electroquímica y aquellos calculados con BET.

Como fue adelantado, el mismo procedimiento fue empleado para los xerogeles de carbono y para el carbón activado comercial S30. La diferencia de estos ajustes radica en que en este caso no podemos realizar la aproximación que $\sigma \gg>\kappa$, por lo cual se hace necesario utilizar la expresión para la impedancia del electrodo deducida originalmente.

En la Tabla 3.6 se muestran los resultados del ajuste junto a la capacidad de almacenamiento de carga, $C$, obtenida en los experimentos cronopotenciométricos y $\sigma\left(\mathrm{Scm}^{-1}\right)$ medida con el método de Van der Pauw.

\begin{tabular}{|c|c|c|c|c|c|c|c|c|}
\hline & $\boldsymbol{\sigma . 1 0 ^ { 2 }}$ & $\sigma_{\mathrm{EIE}} \mathbf{1 0}^{2}$ & $\boldsymbol{\kappa}_{\mathrm{EIE}} \mathbf{1 0}^{\mathbf{2}}$ & $\boldsymbol{C}_{\text {EIE }} / \mathbf{F g}^{-1}$ & $\mathbf{C} / \mathbf{F g}^{-1}$ & $\mathbf{S}_{\boldsymbol{B E T}} / \mathbf{m}^{\mathbf{2}} \boldsymbol{g}^{-1}$ & $\mathbf{S}_{E I E} / \mathbf{m}^{\mathbf{2}} \boldsymbol{g}^{-1}$ & $\boldsymbol{A}_{\boldsymbol{c}}$ \\
\hline M1 & 0.42 & 0.8 & 0.68 & 197 & 284 & 1786 & 657 & 0.37 \\
\hline M2 & 0.66 & 1.7 & 0.65 & 174 & 230 & 2089 & 581 & 0.28 \\
\hline M3 & 0.08 & 0.7 & 2.25 & 139 & 192 & 1316 & 464 & 0.35 \\
\hline M4 & 0.09 & 0.5 & 0.13 & 133 & 180 & 1020 & 422 & 0.41 \\
\hline S30 & 0.12 & 0.04 & 0.38 & 98 & 126 & 1664 & 345 & 0.21 \\
\hline
\end{tabular}

Tabla 3.6: Parámetros fisicoquímicos teóricos y experimentales para los xerogeles M1, M2, M3, M4 y S30. 
Nuevamente, la tendencia entre $C_{E I E}$ y $C$ coinciden, lo cual es una clara muestra que los procesos capacitivos son los dominantes del sistema electroquímico. El resultado más interesante en este caso es el que se deriva al obtener $S_{E I E}$ o $A_{c}$. Este parámetro permite esclarecer las diferencias encontradas en los valores de las capacidades a bajas corrientes de los electrodos empleados. El hecho que $C$ para M1 sea mayor que para M2, que posee un área interfacial medida por BET marcadamente superior que $M 1$, se debe a que el electrolito puede acceder a una fracción mucho mayor de la matriz porosa de M1 que de M2 (37\% frente a 28\%, respectivamente). S30 posee un área BET superior a las medidas para M3 y M4, sin embargo la accesibilidad del electrolito a su matriz porosa es mucho menor, lo cual genera que éste sea el carbón con menor $C$ a bajas corrientes. De la misma forma pueden explicarse los resultados para M3 y M4. Aunque este último presenta una $S_{B E T}$ sensiblemente menor, el mayor valor de $A_{c}$ genera capacidades similares.

Podemos observar que los resultados obtenidos para la conductividad del sólido, tanto de los ajustes electroquímicos como de las medidas realizadas con el método de Van der Pauw, siguen una tendencia aceptable. Sin embargo, para poder realizar una comparación entre las conductividades obtenidas de los ajustes y los resultados obtenidos midiendo $C$ de cada uno de los electrodos a diferentes velocidades es necesario multiplicar los valores de $\sigma_{E I E}$ y $\kappa_{E I E}$ por el espesor de los electrodos. Lamentablemente, la forma de fabricación del electrodo hace que su espesor, $L$, no pueda ser medido con una precisión tal que permita realizar comparaciones entre carbones de conductividades similares.

\subsubsection{Efecto de la adición de NTCM a un material altamente resistivo}

En esta sección se describirán los experimentos realizados al obtener mezclas entre el xerogel MO y NTCM. Este xerogel fue con el que se comenzaron a realizar una serie de medidas electroquímicas que 
involucrarian varios xerogeles de carbono, encontrándose que M0 exhibía resultados negativos. Incluso a bajas corrientes se observó una gran disminución de la capacidad de almacenamiento de carga con el aumento de la corriente. Los grandes componentes resistivos observados en los experimentos empleando la técnica VC y que se manifiestan asimismo en los experimentos cronopotenciométricos a distintas corrientes, dieron motivo para pensar en mezclar este xerogel con un material que tuviese muy buenos valores de conductividad. En ese contexto, se eligieron los NTCM, porque poseen buenos valores de $\sigma$ y $\kappa$, asociado al hecho que se trata de estructuras extendidas, lo cual genera que cada nanotubo entre en contacto con una parte importante de la estructura del xerogel.

El sistema electroquímico en el cual fueron realizados estos experimentos y la simplicidad de la forma en la que fue obtenido el nanocompuesto hacen que este no sea un trabajo diseñado para obtener un material novel o revolucionario, sino que el propósito del mismo es que se discutan aspectos básicos que en muchos de los trabajos en esta área son pasados por alto, muchas veces asignando erróneamente comportamientos experimentales a parámetros que no determinan el funcionamiento del sistema.

\subsubsection{Obtención del nanocompuesto y preparación de los electrodos}

Para obtener el nanocompuesto se procedió a teflonar ambos carbones con $10 \%$ de PTFE. Luego se los mezcló en diferentes proporciones, se los cubrió con etanol y se los llevó al ultrasonicador por 15 minutos. Los electrodos fueron preparados como fue descrito anteriormente. Se utilizaron $15 \mathrm{mg}$ de MO/NTCM en diferentes proporciones: MO sólo (E0), MO con 9\% p/p de NTCM (E9) y MO con $18 \% \mathrm{p} / \mathrm{p}$ de NTCM (E18). 


\subsubsection{Caracterización de los materiales}

Anteriormente se presentaron las isotermas de los materiales utilizados. Como fue antes descrito, ambos presentan propiedades texturales totalmente diferentes. MO es un material microporoso, mientras que los NTCM poseen una adsorción muy baja a bajas presiones. El ciclo de histéresis muestra que M0 posee mesoporos de menor tamaño, pero un mayor volumen acumulado de mesoporos. E1 parámetro $L_{p}$ muestra que el tamaño medio de los microporos en los $\operatorname{NTCM}(4,3 \mathrm{~nm})$ es marcadamente superior que los de M0 (1,9 nm).

Las imágenes de TEM (Figura 3.20) muestran que el material obtenido no es totalmente homogéneo. Así, pueden observarse partes de la muestra conteniendo solamente NTCM, otras con sólo MO, nanotubos "decorados" con MO y regiones donde se logró un nanocompuesto homogéneo.
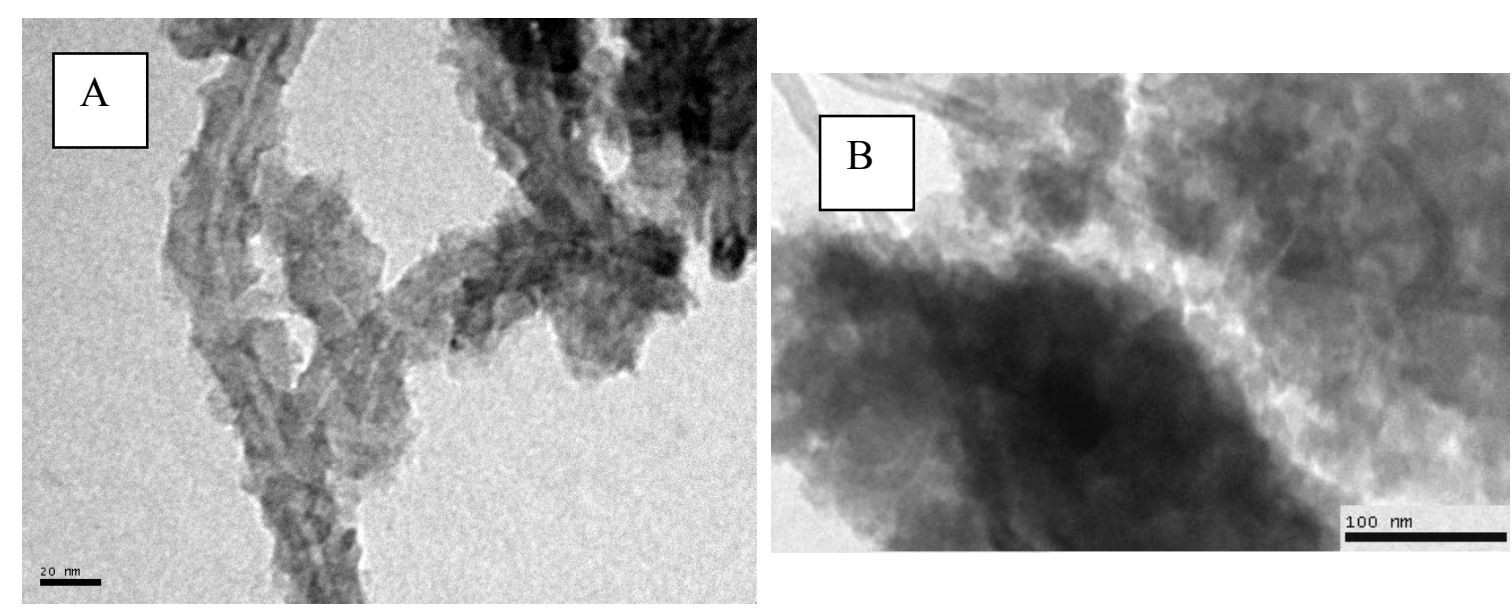

Figura 3.20: Imágenes de TEM de: (A) NTCM decorados con MO y (B) NTCM insertos en la estructura del xerogel de carbono.

\subsubsection{Resultados electroquimicos}

A continuación se muestran los resultados obtenidos con las técnicas VC (Figura 3.21) y $\mathrm{CD}$ (Figura 3.22) para las tres composiciones estudiadas. Los experimentos fueron llevados a cabo de la misma manera que fueron realizados con los otros materiales. 


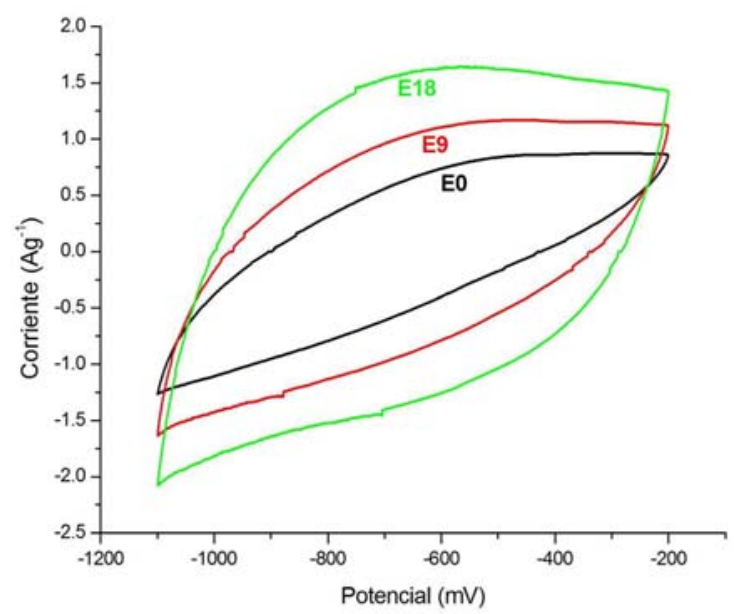

Figura 3.21: Voltamperogramas obtenidos con todos los electrodos utilizados en este trabajo. $\mathrm{v}=1.10^{-1} \mathrm{Vs}^{-1}$.
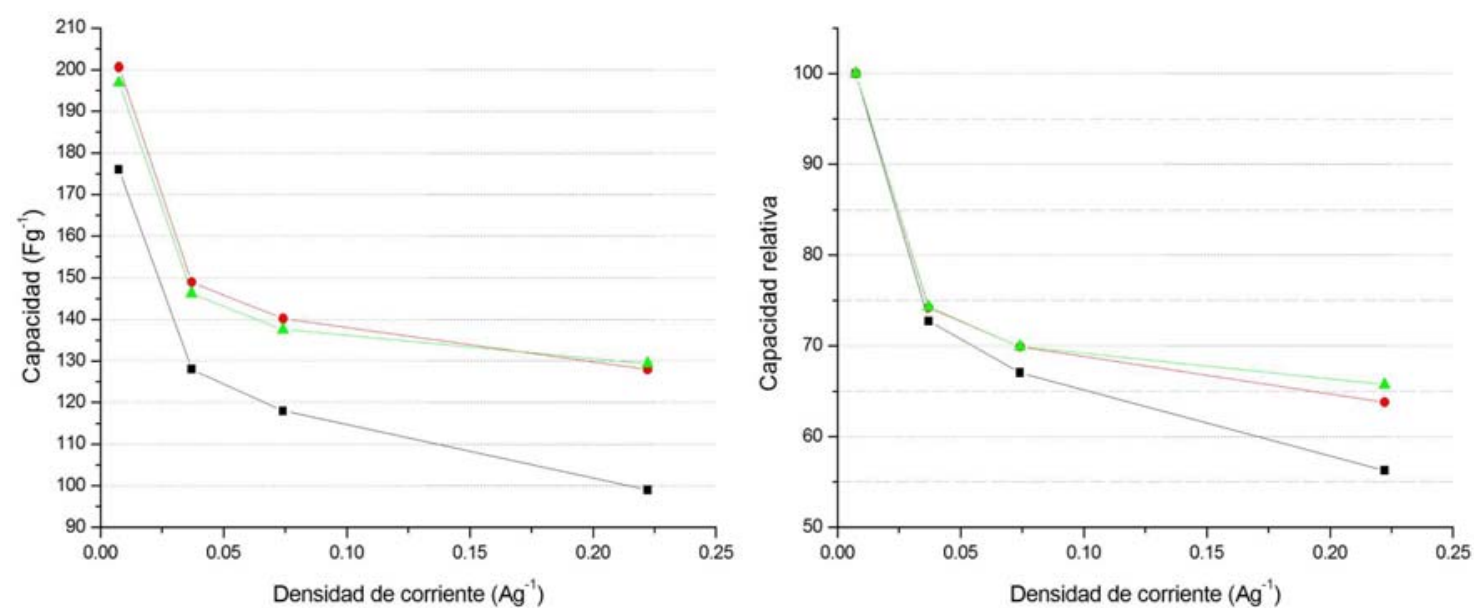

Figura 3.22: $C$ (A) y $C$ relativa (B) a diferentes velocidades de descarga para E0 ( $\square$ ), E9 (O) y E18 ( $\mathbf{\Delta})$.

Los voltamperogramas obtenidos poseen las mismas características generales que las descritas para los demás xerogeles. Como puede observarse en la Figura 3.21, el agregado de NTCM genera una mayor velocidad en la respuesta del electrodo y un aumento significativo en la capacidad de la DCE. Claramente, esto es debido a que los NTCM aumentan la conductividad del electrodo, puesto que poseen un área interfacial marcadamente menor que la de M0. Si bien esta conclusión se basa en las isotermas medidas, la gran diferencia en los valores que presentan ambos carbones hace que sea prácticamente imposible que el área electroquímicamente activa de los nanotubos sea superior a la del xerogel. Esta presunción quedará corroborada luego de analizar las medidas de EIE. 
En una parte importante de la literatura se menciona a la conductividad como un término global. Sin embargo, desde el punto de vista básico, es interesante conocer si el proceso de carga-descarga de la DCE está gobernado por $\sigma, \kappa$, o ambas variables.

Los resultados obtenidos con VC se confirman al realizar medidas de CD. En la Figura 3.22 se observa cómo la $C$ de los electrodos conteniendo nanotubos se incrementa sensiblemente. No se observan diferencias importantes entre E9 y E18. Sin embargo, una inspección cuidadosa de los resultados (sumado a lo discutido sobre VC) nos permite concluir que a medida que incrementamos la corriente de descarga, aumentan las diferencias de $C$ de los electrodos y podemos predecir diferencias mayores para E18 con respecto a E9 a corrientes mayores que las utilizadas.

En la Figura 3.23 se muestran los resultados obtenidos con EIE. La forma de todos los diagramas es muy similar y no tiene diferencias cualitativas con lo mostrado anteriormente. Sin embargo, se observan claras diferencias entre los electrodos. A altas frecuencias podemos advertir la presencia de un semicírculo, cuyo diámetro decrece con el aumento de la cantidad de NTCM. Si bien la diferencia entre E9 y E18 es pequeña, los electrodos conteniendo nanotubos muestran una conductividad eléctrica muy superior que aquél construido solamente con M0. Este resultado es esperable por las características de los materiales que constituyen los electrodos. Por otra parte, este resultado está de acuerdo con las conductividades, $\sigma$, medidas para cada uno de los electrodos utilizando el método de Van der Pauw, las cuales se muestran en la Tabla 3.7. A frecuencias medias-altas se observa nuevamente el comportamiento debido a la distribución de resistencias y capacidades dentro de los poros del electrodo. El hecho que esta región finalice a frecuencias más altas en el orden E18>E9>E0 es indicativo que la conductividad del electrolito dentro de la matriz porosa aumenta con la cantidad de NTCM que posee el electrodo. Por último, vemos que a bajas frecuencias, los valores que toma la parte imaginaria de la impedancia a cada frecuencia para E18 y E9 son similares, lo cual 
indica que tienen áreas interfaciales muy similares. El hecho de que E0 tome valores algo superiores está directamente relacionado con una menor área interfacial.

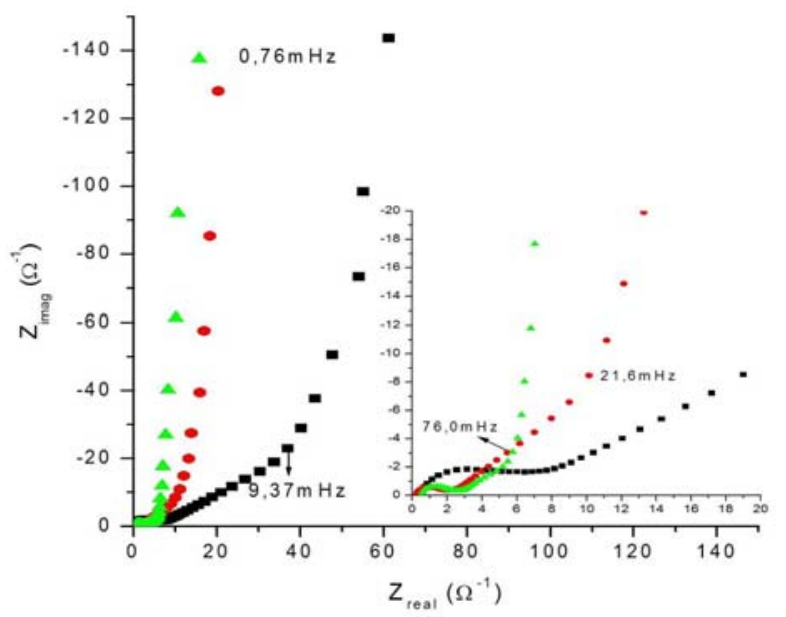

Figura 3.23: Diagramas de Nyquist obtenidos con E0 ( $\boldsymbol{\square})$, E9 () y E18 ( $\overline{\mathbf{A}}$ ).

Utilizando los valores experimentales de las conductividades efectivas de los electrodos, se realizó nuevamente el ajuste del modelo teórico a los resultados electroquímicos obteniéndose los parámetros fisicoquímicos mostrados en la Tabla 3.7.

\begin{tabular}{|c|c|c|c|c|c|}
\hline & $\boldsymbol{\sigma . 1 0 ^ { 2 }}$ & $\boldsymbol{\kappa}^{*} \mathbf{1 0}^{\mathbf{2}}$ & $\mathbf{C}_{\boldsymbol{E I E}} / \mathbf{F g}^{\mathbf{1}}$ & $\mathbf{C} / \mathbf{F g}^{-1}$ & $\mathbf{S}_{E I E} / \mathbf{m}^{\mathbf{2}} \boldsymbol{g}^{-1}$ \\
\hline E0 & 0,25 & 0,019 & 99 & 176 & 328 \\
\hline E9 & 0,49 & 0,066 & 110 & 201 & 366 \\
\hline E18 & 1,15 & 0,260 & 110 & 197 & 366 \\
\hline
\end{tabular}

Tabla 3.7: Parámetros teóricos y experimentales para E0, E9 y E18.

Las áreas electroquímicamente activas obtenidas explican las diferencias de capacidades de los electrodos. El agregado de NTCM no puede causar un aumento del área interfacial del electrodo puesto que MO tiene una $S_{E I E}$ de 328 frente a 67 de los NTCM. Claramente, el agregado de NTCM genera un aumento de la accesibilidad del electrolito a la matriz porosa de los electrodos. Sin embargo, el aumento de la cantidad de NTCM de 9\% a 18\% no genera un aumento extra del área interfacial medida. Probablemente, el aumento de $A_{c}$ se vea compensado 
por el agregado de una cantidad importante de un material como los NTCM, los cuales poseen un área interfacial accesible marcadamente menor que MO.

La conclusión más interesante de estos ajustes surge al observar los valores de conductividades obtenidos. El agregado de NTCM aumenta las conductividades efectivas tanto del sólido como del electrolito dentro de la matriz porosa de los electrodos. Sin embargo, el hecho que $\sigma$ sea un orden de magnitud mayor que $\kappa$ en todos los casos, hace que la conductividad efectiva del electrolito sea la variable que domina las componentes resistivas del electrodo. De este análisis se concluye que la mejora en el comportamiento de los electrodos conteniendo NTCM no se debe al aumento de la conductividad del sólido sino al aumento de la conductividad efectiva del electrolito dentro de los poros. Esta conclusión surge al observar en la Tabla 3.7 que $\kappa$ alcanza a ser del orden de $\sigma$ para cantidades de NTCM por lo menos iguales a $18 \%$. Este análisis básico demuestra que la idea inicial que se tuvo de buscar un material altamente conductor para formar el nanocompuesto y que llevó a obtener buenos resultados era errónea. La mejora de las propiedades del material para actuar como SC se obtiene, por un lado, al generar una mayor accesibilidad del electrolito a la matriz porosa y por otro, a través de una mejora de $\kappa$. El aumento de la conductividad electrónica del sólido no es necesario puesto que este factor no limita el funcionamiento del material. 


\subsection{Referencias Bibliográficas}

[1] V. V. N. Obreja. On the performance of supercapacitors with electrodes based on carbon nanotubes and carbon activated material-A review. Physica E, 40 (2008) 2596-2605.

[2] R. A. Huggins. Advanced Batteries Materials Science Aspects, New York, NY (USA), Springer Science, 2009.

[3] E. Frackowiak, F. Béguin. Carbon materials for the electrochemical storage of energy in capacitors. Carbon, 39 (2001) 937-950.

[4] F. Béguin. Application of nanotextured carbons for electrochemical energy storage in aqueous medium. J. Braz. Chem. Soc., 17 (2006) 1083-1089.

[5] D. Qu, H. Shi. Studies of activated carbons used in double-layer capacitors. J. Power Sources, 74 (1998) 99-107.

[6] B. E. Conway, V. Birss, J. Wojtowicz. The role and utilization of pseudocapacitance for energy storage by supercapacitors. J. Power Sources, 66 (1997) 1-14.

[7] Q. Cheng , J. Tang, J. Ma, H. Zhang, N. Shinya, L. C. Qin. Graphene and carbon nanotube composite electrodes for supercapacitors with ultra-high energy density. Phys. Chem. Chem. Phys., 21;13(39) (2011) 17615-24.

[8] P. Björnbom. Charge/discharge of an electrochemical supercapacitor electrode pore; non-uniqueness of mathematical models. Electrochem. Commun., 9 (2007) 211-215.

[9] E. Frackowiak, K. Jurewicz, K. Szostak, S. Delpeux, F. Béguin. Nanotubular materials as electrodes for supercapacitors. Fuel Processing Technology 77-78 (2002) 213-219.

[10] D. Qu, H. Shi. Studies of activated carbons used in double-layer capacitors. J. Power Sources, 74 (1998) 99-107.

[11] Y. Sun, Q. Wu, G. Shi. Supercapacitors based on self-assembled graphene organogel. Phys. Chem. Chem. Phys., 14;13(38) (2011) 17249-54.

[12] Q. Wu, Y. Sun, H. Bai, G. Shi. High-performance supercapacitor electrodes based on graphene hydrogels modified with 2aminoanthraquinone moieties. Phys. Chem. Chem. Phys. 21;13(23) (2011) 11193-8. 
[13] P. Björnbom. Charge/discharge of an electrochemical supercapacitor electrode pore; non-uniqueness of mathematical models. Electrochem. Commun., 9 (2007) 211-215.

[14] K. Jurewicz, C. Vix-Guterl, E. Frackowiak, S. Saadallah, M. Reda, J. Parmentier, J. Patarin, F. Béguin. Capacitance properties of ordered porous carbon materials prepared by a templating procedure. J. Phys. Chem. of Solids., 65 (2004) 287-293.

[15] M. G. Sullivan, B. Schnyder, M. Bärtsch, D. Alliata, C. Barbero, R. Imhof, R. Kötzz. Electrochemically Modified Glassy Carbon for Capacitor Electrodes. Characterization of Thick Anodic Layers by Cyclic Voltammetry, Differential Electrochemical Mass Spectrometry, Spectroscopic Ellipsometry, X-Ray Photoelectron Spectroscopy, FTIR, and AFM. J. Electrochem. Soc., 147 (2000) 2636-2643.

[16] C. Vix-Guterl, E. Frackowiak, K. Jurewicz, M. Friebe, J. Parmentier, F. Béguin. Electrochemical energy storage in ordered porous carbon materials. Carbon, 43 (2005) 1293-1302.

[17] J. Hou, Y. Shao, M. W. Ellis, R. B. Moore, B. Yi. Graphene-based electrochemical energy conversion and storage: fuel cells, supercapacitors and lithium ion batteries. Phys. Chem. Chem. Phys., 14;13(34) (2011) 15384-402.

[18] D. S. Su, R. Schlögl. Chem. Nanostructured carbon and carbon nanocomposites for electrochemical energy storage applications. Sus. Chem., 22;3(2) (2010) 136-68.

[19] O. Barbieri, V. Hahn, A. Herzog, R. Kötz. Capacitance limits of high surface area activated carbons for double layer capacitors. Carbon, 43 (2005) 1303-1310.

[20] G. Lota, B. Grzyb, H. Machnikowska, J. Machnikowski, E. Frackowiak. Effect of nitrogen in carbon electrode on the supercapacitor performance. Chem. Phys. Lett., 404 (2005) 53-58.

[21] G. A. Planes, M. C. Miras, C. A. Barbero. Double layer properties of carbon aerogel electrodes measured by probe beam deflection and AC impedance techniques. Chem. Commun., 16 (2005) 2146-2148.

[22] E. Raymundo-Piñero, F. Leroux, F. Béguin. A High-Performance Carbon for Supercapacitors Obtained by Carbonization of a Seaweed Biopolymer. Adv. Mater., 18 (2006) 1877-1882.

[23] J. H. Kim, K-W. Nam, S. B. Ma, K. B. Kim. Fabrication and electrochemical properties of carbon nanotube film electrodes. Carbon, 44 (2006) 1963-1968. 
[24] F. Ç. Cebeci, E. Sezer, A. S. Sarac. A novel EDOT-nonylbithiazoleEDOT based comonomer as an active electrode material for supercapacitor applications. Electrochim. Acta., 54 (2009) 63546360.

[25] C. Niu, E. K. Sichel, R. Hoch, D. Moy, H. Tennent. High power electrochemical capacitors based on carbon nanotube electrodes. Appl. Phys. Lett., 70 (1997) 1480-1482.

[26] C. Vix-Guterl, S. Saadallah, K. Jurewicz, E. Frackowiak, M. Reda, J. Parmentier, et al. Supercapacitor electrodes from new ordered porous carbon materials obtained by a templating procedure. Mat. Sci. Eng. B., 108 (2004) 148-55.

[27] A. Malak, K. Fic, G. Lota, C. Vix-Guterl, E. Frackowiak. Hybrid materials for supercapacitor application. J. Solid State Electrochem., 14 (2010) 811-816.

[28] L. Zhongxue, C. Jie. An impedance-based approach to predict the state-of-charge for carbon-based supercapacitors. Microelectronic Engineering., 85 (2008) 1549-1554.

[29] P. Simon, Y. Gogotsi. Materials for electrochemical capacitors. Nature Materials., 7 (2008) 845-854.

[30] L. Zubizarreta, A. Arenillas, J. J. Pis, J. P. Pirard, N. Job. Studying chemical activation in carbon xerogels. J. Mater. Sci., 44 (2009) 6583-6590.

[31] M. M. Dubinin, en: Danielli J. F., M. D. Rosenberg, D. Cadenhead. (Editores), "Progress in Surface and Membrane Science", vol. 9, Academic Press, New York, 1975.

[32] H. F. Stoeckli, L. Ballerini. Evolution of Microporosity during Activation of Carbon. Fuel, 70 (1991) 557-560.

[33] J. B. Parra, J. C. de Sousa, R. C. Bansal, J. J. Pis, J. A. Pajares. Characterization of activated carbons by the BET equation-an alternative approach. Adsorpt. Sci. Technol., 12 (1995) 51-66.

[34] L. J. van der Pauw. A Method of Measuring the Resistivity and Hall Coefficient of Discs of Arbitrary Shape. J. Philips Res. Repts., 13 (1958), 1-9.

[35] K. S. W. Sing, D. H. Everett, R. A. W. Haul, L. Moscou, R. A. Pierotti, J. Rouquerol, T. Siemieniewska (Subcommittee on Reporting Gas Adsorption Data). Reporting physisorption data for gas/solid systems with Special Reference to the Determination of 
Surface Area and Porosity. Pure \& App!. Chem., 57 (1985) 603619.

[36] A. Lundqvist, G. Lindbergh. Kinetic study of a porous metal hydride electrode. Electrochim. Acta., 44 (1999) 2523-2542.

[37] R. de Levie. On porous electrodes in electrolyte solutions. Electrochim. Acta., 8 (1963) 751-80.

[38] A. Visintin, E. B. Castro, S. Real, W. E. Triaca, C. Wang, M. P. Soriaga. Electrochemical activation and electrocatalytic enhancement of a hydride-forming metal alloy modified with palladium, platinum and nickel. Electrochim. Acta., 51 (2006) 3658-67.

[39] B. E. Conway. Electrochemical Supercapacitors. Scientific Fundamentals and Technological Applications, Kluwer Academic/Plenum Publishers, New York, 1999. 


\section{Capitulo 4}

\section{Almacenamiento electroquímico de hidrógeno en nanotubos de carbono - Reacción de evolución de hidrógeno (REH)}

\subsection{Introducción}

En este trabajo de tesis fue comentado previamente que los nanotubos de carbono (NTC) poseen características peculiares en las que se combinan propiedades físicas y químicas que despiertan el interés de numerosos investigadores para aplicaciones como supercapacitores [1-5], sensores químicos [6], dispositivos para el almacenamiento de energía [6-9], entre muchas otras. Para el almacenamiento de energía, la generación y el almacenamiento de hidrógeno se ha constituido en un área promisoria para ser explorada. En la actualidad el hidrógeno reviste gran interés porque es el vector de energía más limpio que se conoce. Más precisamente, el hidrógeno es apto para contribuir a resolver el problema de la contaminación urbana, proveyendo a dispositivos que posibilitan la emisión nula de gases contaminantes en vehículos provistos de motores eléctricos alimentados con celdas de combustible de hidrógeno. Así, el almacenamiento de este gas para ser empleado en la industria automotriz, es un problema que aún no ha terminado de resolverse y constituye un tema importante que forma parte de varias investigaciones tanto de índole básica como aplicada. 
El almacenamiento de hidrógeno es realizado mediante dos clases de métodos experimentales. Uno de ellos involucra la aplicación de altas presiones que conduce a la fisisorción [10,11] de las moléculas de hidrógeno dentro de un conjunto de nanotubos ampliando la distancia entre los mismos [12-14]. La máxima capacidad de almacenamiento de hidrógeno informada bajo esas condiciones varía entre 3 y $6 \%$ en peso [12,14]. Sin embargo, para lograr una manipulación provechosa, es conveniente almacenar hidrógeno gaseoso a temperatura ambiente y a presiones menores que 10 atmósferas. Un inconveniente serio ha sido la pobre reproducibilidad de los experimentos porque dependen estrechamente de las condiciones de preparación de las muestras [15].

Dillon et al. [12], para poder evaluar la cantidad de hidrógeno adsorbido en NTC, midieron su desorción empleando el método de Desorción a Temperatura Programada (DTP). Maddox y Gubbins [16,17] evaluaron la adsorción de gases en poros cilindricos aplicando el método de simulación de Monte Carlo en un conjunto de gran canónico. Darkrim y Levesque [18,19] fueron los primeros en computar la adsorción de hidrógeno en NTC abiertos en un dominio amplio de presión y de temperatura. Estos investigadores, para diferentes condiciones termodinámicas, optimizaron la estructura del adsorbente que conduciría a estados altamente favorables de adsorción modificando el diámetro de los tubos y el espaciado entre los mismos. Estos resultados condujeron a estudiar experimentalmente la adsorción de hidrógeno en NTC y también teóricamente empleando simulaciones de dinámica molecular.

Los abordajes teóricos han dado resultados más coherentes que los experimentales, cuyos datos se observaron a menudo dispersos y asimismo contradictorios [20,21]. La explicación se encuentra en el tipo de material empleado en ambos casos. Así, en las simulaciones moleculares los nanotubos poseen sus extremos abiertos, están bien estructurados, desprovistos de carbono amorfo y de impurezas, disponiendo de diámetros bien determinados y elegidos, y una correcta localización geométrica en el conjunto de nanotubos. En contraste, las 
muestras de nanotubos empleadas en las investigaciones experimentales, a menudo poseían impurezas, entre ellas carbono amorfo y residuos catalíticos que provienen de los procesos de síntesis [22].

Otra forma de abordar el almacenamiento de hidrógeno es utilizando procedimientos electroquímicos [23-26], que pueden ser aplicados a baterías secundarias de hidrógeno. A través de esta vía, la capacidad de almacenamiento de hidrógeno no excede $1 \%$ en peso. Este valor se aparta considerablemente de $6,5 \%$ en peso, establecido por el Departamento de Energía de Estados Unidos como punto de referencia para que pueda ser utilizado para almacenamiento de energía en vehículos [27].

Los valores de capacidad de almacenamiento de hidrógeno que se encuentran en la literatura para ambos tipos de NTC difieren según los autores, observándose capacidades que cubren entre 0,2 \% y 3,7\% en peso [23,28-31]. Nuevamente, las razones de estas fluctuaciones se deben principalmente a un contenido importante de impurezas en las muestras, principalmente carbono microporoso; y en algunos casos al uso de aditivos empleados para mejorar la conductividad de los electrodos. Sin embargo, hoy en día, los métodos de purificación de NTC están bien establecidos y los resultados experimentales obtenidos en la segunda parte de la década pasada son mucho más coherentes y se ha alcanzado un acuerdo. En este sentido, cuando se emplean NTC de muy alta pureza, la capacidad de almacenamiento no excede de $0,2-0,4 \%$ en peso [32,33].

Con el propósito de mejorar la capacidad de almacenamiento de hidrógeno, algunos investigadores desarrollan estudios teóricos para dilucidar y comprender el mecanismo involucrado en la formación de hidrógeno molecular en nanotubos de carbono [34]. Así, surgen varios interrogantes que se relacionan con diferentes etapas, que comienzan con la descomposición electroquímica del agua hasta alcanzar el producto final. Asimismo, debe tenerse en cuenta el tipo de adsorción, es decir, si se trata de una fisisorción o de una quimisorción; el sitio en 
el cual se produce la adsorción, sea entre los nanotubos o en el interior de los mismos; la capacidad máxima de almacenamiento; el mecanismo de la inserción del hidrógeno y de su extracción, incluyendo el grado de reversibilidad del proceso [35-39].

Debe ponerse énfasis en el hecho de que varios artículos afirman que en los NTC no es posible almacenar grandes cantidades de hidrógeno; en aquellos casos en que se logra almacenar, los valores reportados son insignificantes [23,28-31]. Por otra parte, se observan resultados de estudios voltamperométricos, en los cuales los picos de corriente registrados obedecen a la oxidación de impurezas metálicas provenientes de los catalizadores empleados para la fabricación de los NTC y no deben ser atribuidos a la oxidación de hidrógeno. El empleo de estos materiales impuros son responsables de los altos valores de almacenamiento de hidrógeno reportados por algunos investigadores $[40,41]$.

El propósito de esta investigación estuvo centrado en la determinación de la capacidad de almacenamiento de hidrógeno de los NTC de pared simple (NTCS) y en la dilucidación y en la comprensión del mecanismo involucrado en la reacción de evolución de hidrógeno (REH) en NTCS. El estudio se realiza aplicando técnicas electroquímicas y espectroscópicas. Es importante destacar que durante los últimos años han sido publicados varios artículos dedicados a investigar el rol de los NTCS en el almacenamiento de hidrógeno. Hoy en día, este tipo de trabajos se centran principalmente en el dopado de los NTCS con diferentes materiales (NPs metálicas, $\mathrm{TiO}_{2}$, etc.) o, en menor grado, en realizar tratamientos sobre los NTCS para mejorar su capacidad de almacenamiento, obteniendo resultados que están lejos de satisfacer los requerimientos de la aplicación $[42,43]$.

\subsection{Parte Experimental}

\subsubsection{Materiales y métodos}

Se emplearon NTCS, CarboLex AP-grade. La pureza, del 50-70 vol. \%, se determinó con espectroscopia Raman y SEM, encontrándose 
impurezas residuales $(\mathrm{Ni}, \mathrm{Y})$ provenientes del catalizador usado para su preparación, dado que se empleó el método de descarga de arco. Los nanotubos se presentan en atados con una longitud aproximada de $20 \mu \mathrm{m}$. Las dimensiones de los tubos son: $1,2-1,5 \mathrm{~nm}$ de diámetro y $2-$ $5 \mu \mathrm{m}$ de longitud. Los NTCS fueron rigurosamente purificados antes de ser usados. Para ello se los colocó en $\mathrm{HNO}_{3}$ concentrado y se los mantuvo a reflujo durante dos horas, para luego filtrar y lavar hasta $\mathrm{pH}$ neutro. Además de los NTCS se empleó el carbono amorfo Vulcan $\mathrm{XC}{ }^{\circledR}$, cuyas características fueron descritas en el Capítulo 3.

El área superficial específica de los NTCS y del Vulcan $\mathrm{XC} 72^{\circledR}$ fueron determinadas empleando el método de Brunauer-Emmett-Teller (BET) usando nitrógeno gaseoso como adsorbato. Se determinaron isotermas para la adsorción y desorción de nitrógeno a $77 \mathrm{~K}$, empleando un aparato de medida volumétrica convencional. Las presiones se midieron con un manómetro capacitivo Baratron y la temperatura con un termómetro digital provisto de sensores de Pt-100 (DIN). El error experimental máximo del volumen adsorbido fue $0,3 \%$. Los resultados obtenidos del área superficial específica fueron $316 \mathrm{~m}^{2} \mathrm{~g}^{-1}$ para NTCS y $234 \mathrm{~m}^{2} \mathrm{~g}^{-1}$ para Vulcan $\mathrm{XC} 72^{\circledR}$.

El sistema electroquímico fue el mismo que se describió en forma completa en el Capítulo 3 que trata el tema "Supercapacitores Electroquímicos". En el tema que se desarrolla en este Capítulo se utilizaron como materiales de electrodo NTCS y Vulcan XC72 ${ }^{\circledR}$.

Con el propósito de investigar la REH y de evaluar la eficiencia de los NTCS en el almacenamiento de hidrógeno, se emplearon electrodos conteniendo Vulcan $\mathrm{XC} 72^{\circledR}$ teflonado (VT); y VT con cantidades variables de NTCS purificados (designados en el texto como EX-Y, donde E representa al "Electrodo"; la letra (X) se refiere a la masa de NTCS y la (Y) a la masa de VT. La masa de ambos componentes, NTCS y VT, está expresada en mg.

Se emplearon técnicas electroquímicas como $\mathrm{VC}$ y la voltamperometria combinada con escalones de potencial; experimentos de carga y descarga galvanostáticos (CP) y EIE. 


\subsection{Resultados y discusión}

\subsubsection{Caracterización}

\subsubsection{Espectroscopia Raman}

La espectroscopia Raman se utilizó con el propósito de estudiar la naturaleza de los nanotubos purificados. La caracterización se realizó con un equipo Jobin-Yvon XY-800, usando un láser de Ar con una longitud de onda de $514 \mathrm{~nm}$ y una potencia de $310 \mathrm{~mW}$.

La Figura 1(a) exhibe el espectro Raman de los NTCS purificados usados en los experimentos. Generalmente, las características sobresalientes en los espectros Raman de los NTCS, modos Raman de primer orden, es la banda G del espectro, que se desdobla en rasgos distintivos en alrededor de $1580 \mathrm{~cm}^{-1}$, y el modo de frecuencia radial más bajo (radial breathing mode, RBM). El RBM es una característica muy importante del espectro para la caracterización de los NTCS, teniendo en cuenta que esta banda se presenta solamente en los NTCS y en consecuencia, esta manifestación en el espectro Raman provee una evidencia directa de que una muestra contiene NTCS. En este sentido, RBM se empleó para estudiar el diámetro del nanotubo $\left(d_{t}\right)$ a través de su frecuencia ( $\left.\omega_{\mathrm{RBM}}\right)$. La frecuencia RBM depende linealmente de la inversa del diámetro del nanotubo de acuerdo a: $\omega_{\mathrm{RBM}}=\mathrm{A} / \mathrm{d}_{\mathrm{t}}+\mathrm{B}$, donde A y B se determinan experimentalmente; luego, es posible establecer el diámetro medio del nanotubo en las muestras [44]. Para conjuntos (bundles) de nanotubos típicos para diámetros del orden de $\mathrm{d}_{\mathrm{t}}=1,5 \pm 0,2 \mathrm{~nm}$, se encontró que $\mathrm{A}=234 \mathrm{~cm}^{-1} \mathrm{~nm}$ y $B=10 \mathrm{~cm}^{-1}$ (donde $\mathrm{B}$ es un corrimiento en $\omega_{\mathrm{RBM}}$ asignado a las interacciones tubotubo). Se conoce que el rasgo típico del RBM Raman usualmente no se detecta en muestras de NTC con paredes múltiples (NTCM), porque esta señal para diámetros de nanotubos grandes es muy débil y un diámetro interno normal ensancha la señal. Por lo tanto, considerando que los diámetros de los NTCS empleados en este trabajo se encuentran entre 1,2 y 1,6 nm, la expresión escrita más arriba usando los datos experimentales de los espectros Raman de los NTCS purificados que 
dan un valor de $\omega_{\mathrm{RBM}}=165 \mathrm{~cm}^{-1}$, resulta un diámetro $\mathrm{d}_{\mathrm{t}}=1,5 \mathrm{~nm}$. Asimismo, la banda G de los NTCS está compuesta por varios picos. La Figura 1(b) indica que la de la banda G característica de los NTCS consiste de dos componentes principales, uno con un pico en $1590 \mathrm{~cm}^{-1}$ $\left(\mathrm{G}^{+}\right)$y el otro pico en $1570 \mathrm{~cm}^{-1}\left(\mathrm{G}^{-}\right) . \mathrm{G}^{+}$se relaciona con vibraciones de los átomos de carbono a lo largo del eje del nanotubo (LO phonon mode). Por el contrario, $\mathrm{G}^{-}$se asocia con vibraciones de los átomos de carbono a lo largo de la dirección de la circunferencia de los NTCS (TO phonon mode).
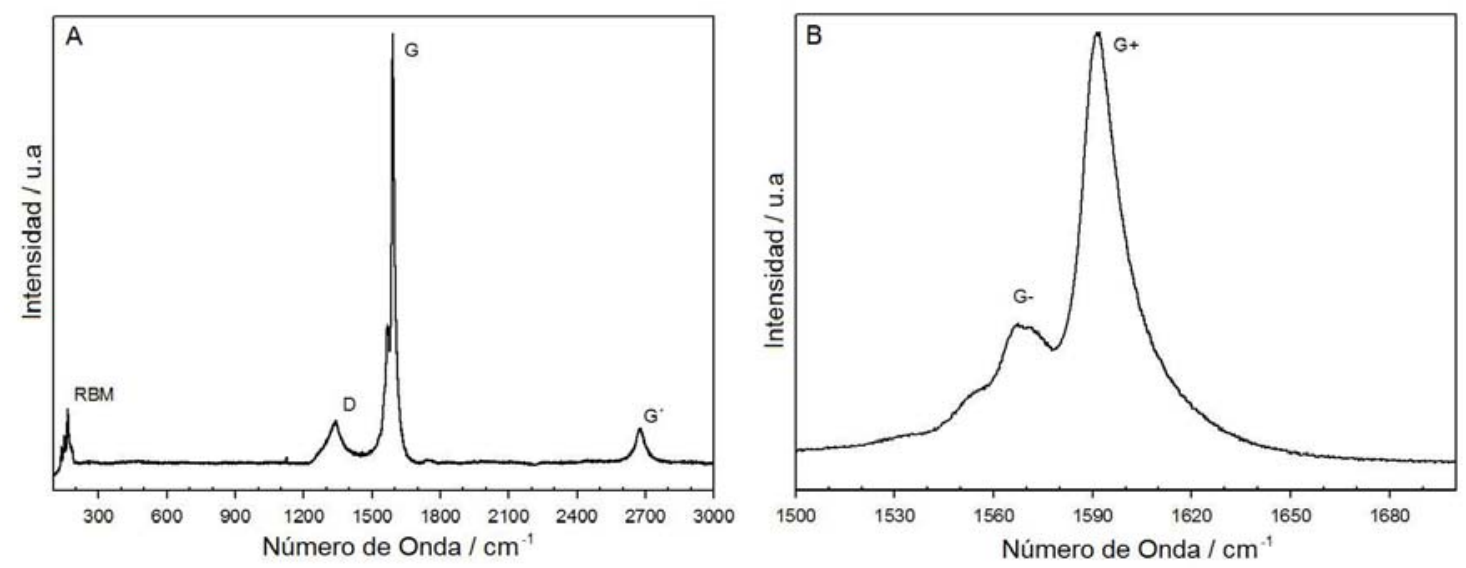

Figura 1. (A) Espectro Raman de NTCS purificados; (B) Ampliación de la banda G.

\subsubsection{Experimentos electroquímicos}

\subsubsection{Voltamperometría cíclica}

Los experimentos de VC fueron realizados empleando un Potenciostato/Galvanostato Princeton Applied Research (PAR) modelo 273. Se realizaron barridos triangulares de potencial entre, $E_{s a} y E_{s c}$, limite superior e inferior, respectivamente. Para caracterizar y estudiar el comportamiento de los NTCS se aplicaron varias rutinas de potencial. La rutina I involucra barridos de potencial triangulares repetitivos (BPTR) a una velocidad $\mathrm{v}=5.10^{-3} \mathrm{Vs}^{-1}$ comenzando desde $\mathrm{E}_{\mathrm{sa}}=0 \mathrm{~V}$, cambiando $\mathrm{E}_{\mathrm{sc}}$ en forma gradual en pasos de $-0,15 \mathrm{~V}$ hacia potenciales negativos hasta alcanzar a $E_{\mathrm{sc}}=-1,60 \mathrm{~V}$ (Figuras 2 y 3). La rutina II consiste también en BPTR a v=5.10-3 $\mathrm{Vs}^{-1}$ desde $\mathrm{E}_{\mathrm{sa}}=0 \mathrm{~V}$ hasta $\mathrm{E}_{\mathrm{sc}}=$ $-1,50 \mathrm{~V}$, pero antes de invertir la dirección del barrido se aplica un 
escalón de potencial en $\mathrm{E}_{\mathrm{sc}}$ durante distintos tiempos $\mathrm{t}=1$, 3, y 6 horas (Figura 4).

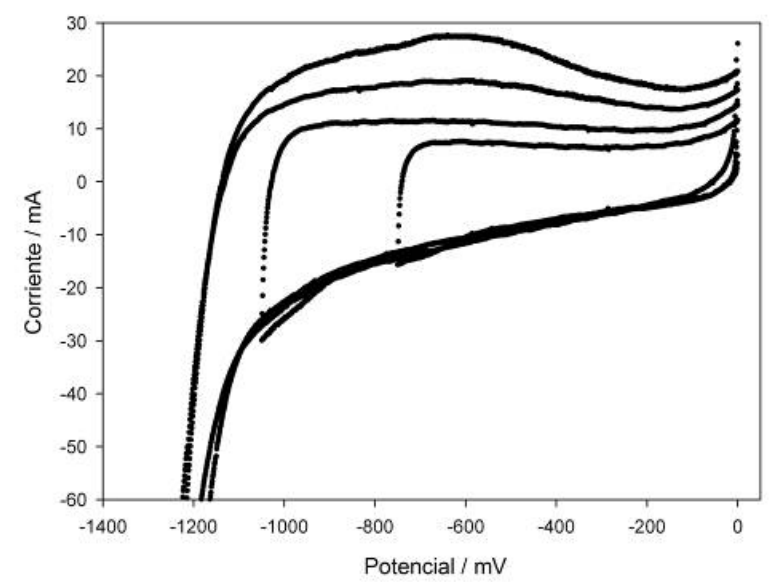

Figura 2. Voltamperogramas para E10-75 mostrando el efecto del aumento gradual de $\mathrm{E}_{\mathrm{sc}}=-0,75,-1,05,-1,30,-1,45 \mathrm{~V} ; \mathrm{E}_{\mathrm{sa}}=0 \mathrm{~V} . \mathrm{v}=0,005 \mathrm{Vs}^{-1} ; 6 \mathrm{M} \mathrm{KOH} . \mathrm{T}=303 \mathrm{~K}$.

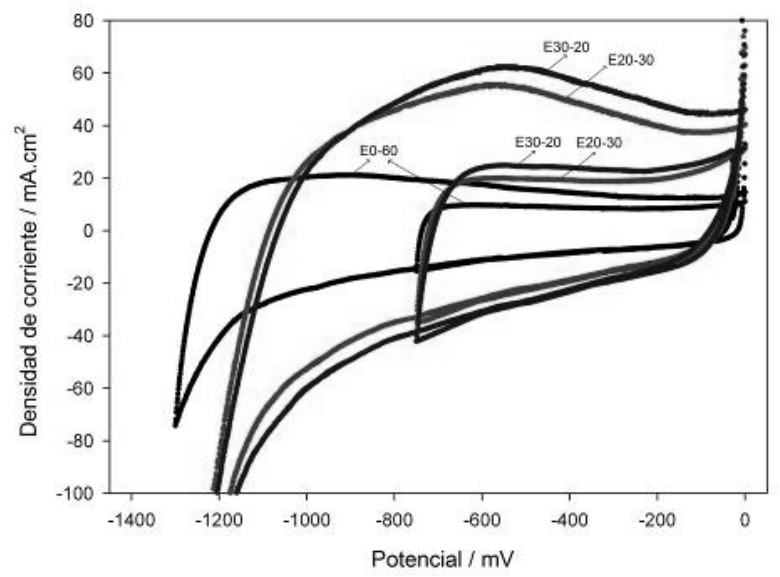

Figura 3. Voltamperogramas para electrodos conteniendo VT y NTCS-VT. $\mathrm{E}_{\mathrm{sa}}=0 \mathrm{~V}$, $E_{\mathrm{sc}}=-0,75 \mathrm{y}-1,45 \mathrm{~V} . \mathrm{v}=0,005 \mathrm{Vs}^{-1} ; 6 \mathrm{M} \mathrm{KOH} . \mathrm{T}=303 \mathrm{~K}$.

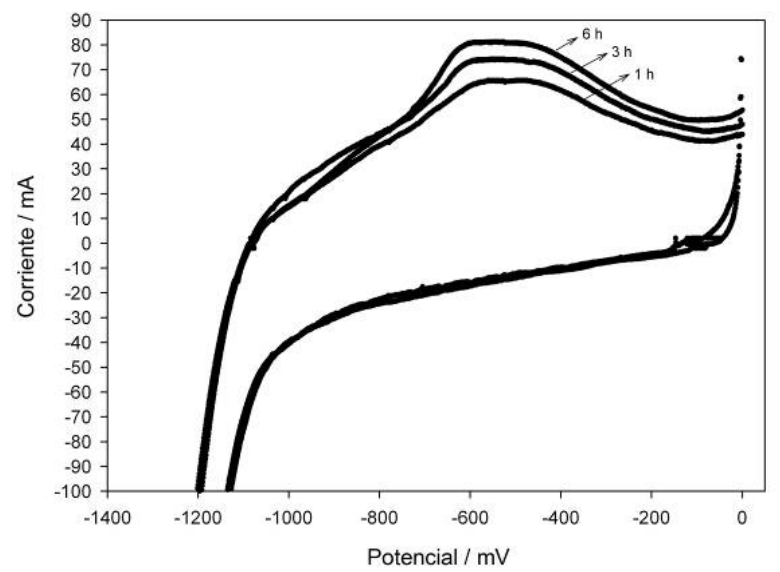

Figura 4. Voltamperogramas para E25-60 que muestran el efecto de la aplicación de escalones de potencial en $\mathrm{E}_{\mathrm{sc}}=-1,50 \mathrm{~V}$ durante $\mathrm{t}=1,3$ y $6 \mathrm{~h} . \mathrm{E}_{\mathrm{sa}}=0 \mathrm{~V}, \mathrm{E}_{\mathrm{sc}}=-1,50 \mathrm{~V}$. $\mathrm{v}=0,005 \mathrm{Vs}^{-1} ; 6 \mathrm{M} \mathrm{KOH} . \mathrm{T}=303 \mathrm{~K}$. 
Una inspección cuidadosa de los voltamperogramas de la Figura 2 permite concluir que se definen dos dominios de potencial. El primero, entre $0,00 \mathrm{~V}$ y $-0,90 \mathrm{~V}$, en el cual tiene lugar principalmente la carga y descarga de la DCE, sumada a la pseudocapacitancia y también a la resistencia interna del sistema electroquímico. El segundo, a potenciales menores que $-0,90 \mathrm{~V}$, donde ocurre la $\mathrm{REH}$, que involucra la electrosorción de átomos de hidrógeno $\mathrm{H}$ seguida por la formación y el desprendimiento de hidrógeno molecular $\mathrm{H}_{2}$. Finalmente, invirtiendo la dirección del barrido de potencial desde $E_{\mathrm{sa}}=-1,30$ hasta $\mathrm{E}_{\mathrm{sc}}=0 \mathrm{~V}$, se produce la oxidación de hidrógeno en prácticamente todo el rango de potenciales. Este hecho se observa a través de un ancho pico centrado en $-0,60 \mathrm{~V}$, donde se produce la máxima desorción de hidrógeno. Este sobrepotencial requerido para la oxidación de hidrógeno es relativamente grande $\mathrm{y}$ es asimismo una clara evidencia que el hidrógeno producido y almacenado a potenciales muy negativos se adsorbe fuertemente dentro de la estructura porosa de los NTCS. Por otro lado, el ancho del pico puede deberse a la gran cantidad de heterogeneidades que presentan los electrodos, conteniendo así varios sitios de adsorción con diferentes energías.

La Figura 3 exhibe las características voltamperométricas que resultan al aplicar la rutina I para los tres tipos de electrodos, pero para una mejor comprensión de los voltamperogramas se muestran solamente dos valores de $\mathrm{E}_{\mathrm{sc}}$, es decir, -0,75 V y -1,45 V. El primer ciclo fue barrido en una región de potencial estrecha que comprende desde $\mathrm{E}_{\mathrm{sa}}=0 \mathrm{~V}$ hasta $\mathrm{E}_{\mathrm{sc}}=-0,75 \mathrm{~V}$. La forma aproximadamente rectangular de las curvas hasta este potencial de corte, en las que se observa valores comparables de las corrientes positivas y negativas, prueba en forma concluyente el comportamiento puramente capacitivo y asimismo reversible de los electrodos fabricados con carbono, sea el VT como también el VT con NTCS. Sin embargo, el dominio de potenciales que exhibe comportamiento capacitivo es mayor para los electrodos de VT pues se extiende hasta cerca de -1,0V. Además, puede observarse que en aquellos electrodos que contienen NTCS, la contribución de corriente 
correspondiente a la DCE aumenta a medida que la cantidad de NTCS en los electrodos crece, lo cual es esperable teniendo en cuenta que, como se determinó en el capítulo 3, éstos tienen un área interfacial superior a la del Vulcan. Por otro lado, se observa que al agregar cantidades crecientes de NTCS, los voltamperogramas se apartan más de aquellos que muestran un comportamiento capacitivo puro. Seguramente esto se debe a un aumento de la pseudocapacitancia debida a las reacciones faradaicas de los grupos superficiales creados en los NTCS en el proceso de purificación. A medida que $E_{s c}$ se desplaza hacia valores de potencial más negativos, paulatinamente comienzan las contribuciones de corriente faradaica relacionadas con la REH.

Posteriormente, el barrido de potencial en sentido positivo exhibe un pico de corriente centrado en $-0,60 \mathrm{~V}$, claramente definido desde $\mathrm{E}=-1,15 \mathrm{~V}$. Este pico está vinculado a la oxidación de hidrógeno formado durante los barridos en sentido negativo. Es importante señalar que este pico se incrementa cuando se aplican escalones de potencial en $E_{s c}=-1,50 \mathrm{~V}$ durante $1 \leq t \leq 6$ horas (Figura 4), siendo observado solamente para aquellos electrodos que contienen NTCS. Para los electrodos construidos exclusivamente con VT este pico está ausente (Figura 3).

Con los resultados obtenidos en los experimentos voltamperométricos es posible calcular la capacidad de la DCE $\left(C_{d l}\right)$ evaluando la carga (q) acumulada en el dominio de potencial involucrado en la perturbación del potencial $(\Delta V)$. Esto se expresa a través de la siguiente ecuación,

$C_{d l}=q / \Delta V ;$ donde $q=I t$

$\mathrm{y}$

$\Delta V=v t$

$v$ es la velocidad del barrido de potencial y $t$ es el tiempo durante el cual la perturbación es aplicada.

El cálculo de $C_{d l}$ se realizó con los datos de los voltamperogramas realizados entre $E_{\mathrm{sa}}=0,00 \mathrm{~V}$ y $\mathrm{E}_{\mathrm{sc}}=-0,75 \mathrm{~V}$, que exhiben el comportamiento típico de un capacitor puro. Para llevar a cabo este 
cálculo debe tenerse en cuenta la corriente medida y la cantidad de carga acumulada en el dominio de potencial correspondiente. Estos parámetros están relacionados a través de la ecuación,

$C_{d l}=I / v$

donde $I$ es la corriente y $v$ es la velocidad del barrido de potencial.

En la Tabla 1 se muestran los resultados obtenidos para $C_{d l}$ empleando los datos voltamperométricos. Se calculó la $C_{d l}$ por gramo de NTCS para un gran número de electrodos utilizados en VC. Los valores obtenidos permiten concluir que el comportamiento de aquellos electrodos conteniendo porcentajes de NTCS mayores que $50 \%$ es similar al obtenido por otros métodos, como se observa en la Tabla 1.

\begin{tabular}{|c|c|}
\hline Electrodo & $\boldsymbol{C}_{\boldsymbol{d l}}$ \\
\hline $\mathrm{E} 0-60$ & $11 \mathrm{Fg}^{-1}$ \\
\hline $\mathrm{E} 20-30$ & $57 \mathrm{Fg}_{\mathrm{NTCS}^{-1}}$ \\
\hline $\mathrm{E} 30-20$ & $53 \mathrm{Fg}_{\mathrm{NTCS}^{-1}}$ \\
\hline
\end{tabular}

Tabla 1. Resultados obtenidos para $C_{d l}$ utilizando VC.

\subsubsection{Experimentos de carga y descarga galvanostáticos}

Las investigaciones relacionadas con la carga y descarga galvanostática se llevaron a cabo empleando el mismo equipo utilizado para realizar la VC. Los resultados se presentan en gráficos donde se observa la respuesta del potencial en función del tiempo de aplicación de la corriente. Los procesos de carga se realizaron aplicando una densidad de corriente de $-50 \mathrm{mAcm}^{-2}$ durante 4 horas. Para el proceso de descarga las densidades de corriente fueron $0,5,1,2$, y $5 \mathrm{mAcm}^{-2}$; éstas se aplicaron durante el tiempo requerido para alcanzar un potencial de corte de $-0,2 \mathrm{~V}$. Se observa que para todas las densidades de corriente de descarga, los valores calculados de la capacidad de descarga y las características de las curvas son similares. La Figura 5 exhibe la capacidad de descarga de hidrógeno de dos electrodos que contienen distinto porcentaje de NTCS. Los gráficos correspondientes a los experimentos de carga y descarga presentan un pequeño punto de 
inflexión; luego, considerando este comportamiento, la relación hallada potencial versus tiempo podría considerarse aproximadamente lineal como ocurre para la descarga de un capacitor. Sin embargo, teniendo en cuenta la capacidad de la DCE de cada electrodo, esta contribución alcanza valores iguales a 7\%, 10\%, y 63\%, para los electrodos E30-20, E20-30 y E0-60, respectivamente. Restando estos valores se puede calcular la corriente debida a la reacción de oxidación de hidrógeno y en consecuencia, calcular la capacidad de almacenamiento de todos los electrodos empleados en los experimentos. Así, la corriente de descarga medida en aquellos electrodos que contienen NTCS proviene de la oxidación del hidrógeno almacenado dentro de los nanotubos, mientras que para los electrodos conteniendo solamente VT la corriente de descarga tiene su origen principalmente en la descarga de la DCE.

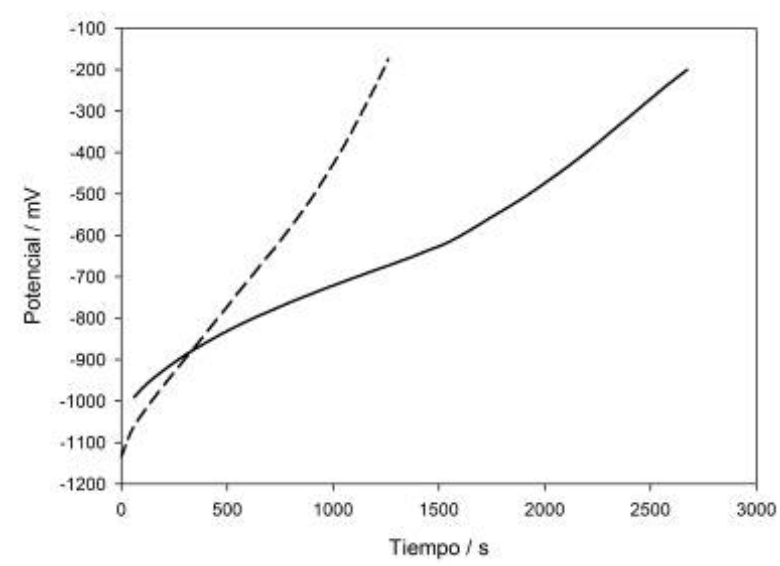

Figura 5. Capacidad de descarga de hidrógeno para los electrodos (- - ) E0-60 y $(\longrightarrow$ E20-30 realizada a una corriente de $2 \mathrm{~mA}$, luego de cargar los electrodos a $-15 \mathrm{~mA}$ durante $4 \mathrm{~h}$.

\begin{tabular}{|c|c|c|}
\hline Electrodo & $\mathbf{C}\left(\mathbf{m A h} / \mathbf{g}_{\mathbf{m}}\right)$ & \% de NTCS \\
\hline E0-60 & 6.5 & 0 \\
\hline E20-30 & 49.5 & 40 \\
\hline E30-20 & 45.2 & 60 \\
\hline
\end{tabular}

Tabla 2. Capacidad de almacenamiento de Hidrógeno por gramo de Vulcan $\mathrm{XC} 72^{\circledR}$ y NTCS.

El porcentaje en peso de almacenamiento de hidrógeno por gramo de NTCS es igual a 0,17 \% p/p para E30-20 y 0,18 \% p/p para E20-30. 
Estos valores concuerdan con algunos reportados en la literatura para el almacenamiento electroquímico de hidrógeno en NTCS [23-27,32,33]. Precisamente, se encuentra que existe un acuerdo implícito que este valor es cercano al $0,2 \%$ p/p, el cual está aún muy por debajo del requerido para ser empleado en aplicaciones tecnológicas.

\subsubsection{Espectroscopia de impedancia electroquimica}

Los experimentos de espectroscopia de impedancia electroquímica (EIE) se realizaron a diferentes potenciales predeterminados, aplicando una señal sinusoidal de pequeña amplitud $(5 \mathrm{mV})$ en el rango de frecuencias, $\mathrm{f}, 1 \mathrm{mHz} \leq \mathrm{f} \leq 50 \mathrm{kHz}$, donde $\mathrm{f}=\omega / 2 \pi$. Se empleó un generador/analizador de funciones (frequency response analyser, FRA) Solartron 1250 y un Potentiostato Princeton Applied Research (PAR) modelo 273, acoplado a un sistema de adquisición de datos.

Los ensayos se efectuaron a potencial constante, cubriendo un dominio de potenciales $\mathrm{E}, 0 \mathrm{~V} \leq \mathrm{E} \leq-1,2 \mathrm{~V}$. Se colocó el electrodo a un potencial negativo correspondiente a la formación de hidrógeno molecular y una vez que se alcanzaba el estado estacionario (la corriente se mantiene constante) se comenzó con la medida (barrido de frecuencias). Una vez finalizada, se cambió el potencial en sentido positivo y se repitió la secuencia. Nuevamente se realizaron las medidas con electrodos de composición variable.

Los resultados de EIE para aquellos electrodos conteniendo solamente VT indican que para $0 \mathrm{~V} \leq \mathrm{E} \leq-0,9 \mathrm{~V}$, la respuesta de la impedancia corresponde a la de un proceso capacitivo puro, es decir, la corriente se debe a la carga de la DCE y no se detecta contribución de corriente faradaica. El diagrama de Nyquist, en el dominio de frecuencias altas, exhibe claramente un comportamiento lineal con una pendiente de $45^{\circ}$, una respuesta que se asocia con la naturaleza porosa del electrodo. Sin embargo, cuando la frecuencia disminuye, la pendiente aumenta, alcanzando a una frecuencia característica un valor de $90^{\circ}[28,45-52]$. Para un dominio de potencial comprendido en el entorno de -1.0 y $-1.2 \mathrm{~V}$ los diagramas comienzan a curvarse $\mathrm{y}$ 
finalmente adoptan la forma de un semicírculo que esta ligado a un proceso de transferencia de carga, esto es, a la REH (Figuras 6a-c).
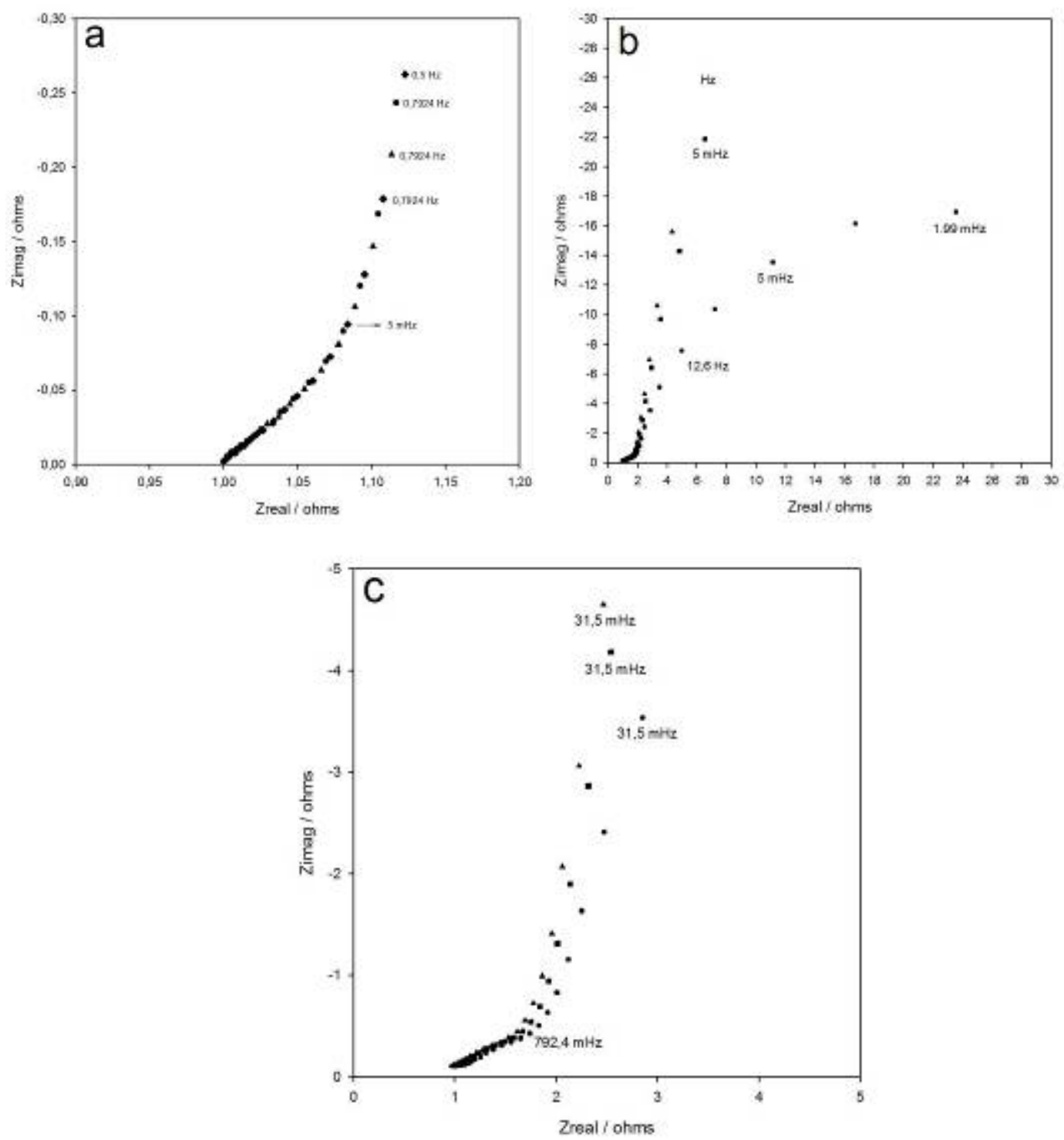

Figura 6. Diagramas de Nyquist correspondientes al electrodo E0-60. (a) $E=(\boldsymbol{\bullet})-0,4$; (घ) -0,6; ( $\mathbf{\Delta})-0,8 \mathrm{~V}$. Los valores de frecuencia están indicados para el espectro realizado a $\mathrm{E}=-0,8 \mathrm{~V}$; (b) $\mathrm{E}=(\mathbf{\Delta})-1,0$; (घ) $-1,1 ;(\boldsymbol{\bullet})-1,2 \mathrm{~V}$. Se indican valores de frecuencias; (c) $\mathrm{E}$ $=(\mathbf{\Lambda})-1,0 ;(\boldsymbol{\bullet})-1,1 ;(\mathbf{\square})-1,2 \mathrm{~V}$. En este último gráfico se muestra sólo el dominio de altas frecuencias.

Cuando los electrodos fueron elaborados con VT y NTCS, se obtuvieron resultados similares con respecto a los electrodos compuestos por VT solamente. No obstante, cuando se adicionan NTCS se perciben algunas diferencias. Así, en los experimentos en los que involucran la $\mathrm{VC}$, curvas de polarización corriente/potencial y en los espectros de impedancia, para un potencial constante, la densidad de corriente aumenta cuando se incrementa el porcentaje de NTCS en los electrodos y, 
consecuentemente, los radios de curvatura correspondientes a los semicírculos en los diagramas de Nyquist comienzan a definirse a potenciales más positivos. Por otra parte, el dominio de potencial correspondiente a la carga de la DCE se extiende desde 0,00 hasta $-0,75 \mathrm{~V}$, como puede percibirse en los voltamperogramas y en los diagramas de Nyquist. Para $\mathrm{E}<-0,90 \mathrm{~V}$ tienen lugar las primeras etapas de la electro-reducción de hidrógeno; este hecho puede apreciarse en los diagramas de Nyquist como una pequeña inclinación en los espectros a bajas frecuencias. Para potenciales más negativos y para valores de frecuencia intermedias y bajas, se define abiertamente el clásico semicírculo correspondiente al proceso de transferencia de carga, mientras que en el ámbito de las altas frecuencias se exhibe un comportamiento lineal con una pendiente de $45^{\circ}$, inherente a la estructura porosa del electrodo (Figuras 7 y 8 ). Además, para un valor fijo predeterminado de potencial, la densidad de corriente aumenta con el contenido de NTCS en los electrodos y, consecuentemente, la resistencia vinculada al proceso de transferencia de carga disminuye. Este hecho se percibe nítidamente en los diagramas de Nyquist (Figura 9), en los cuales disminuyen los radios de curvatura de los semicírculos correspondientes a medida que se incrementa el porcentaje de NTCS en los electrodos.
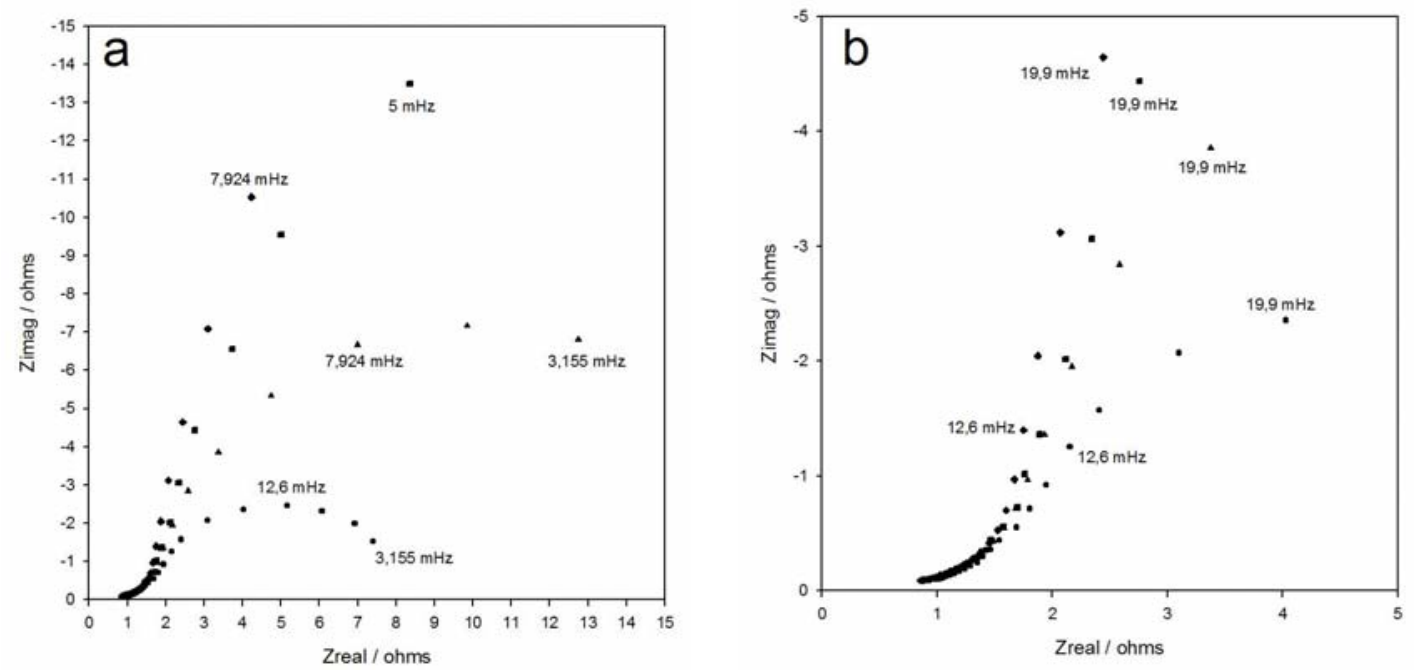

Figura 7. Diagramas de Nyquist correspondientes al electrodo E20-30. (a) $E=(-)-0,95$;

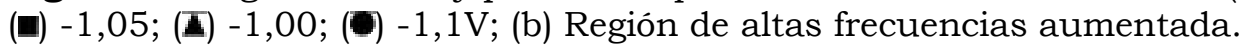



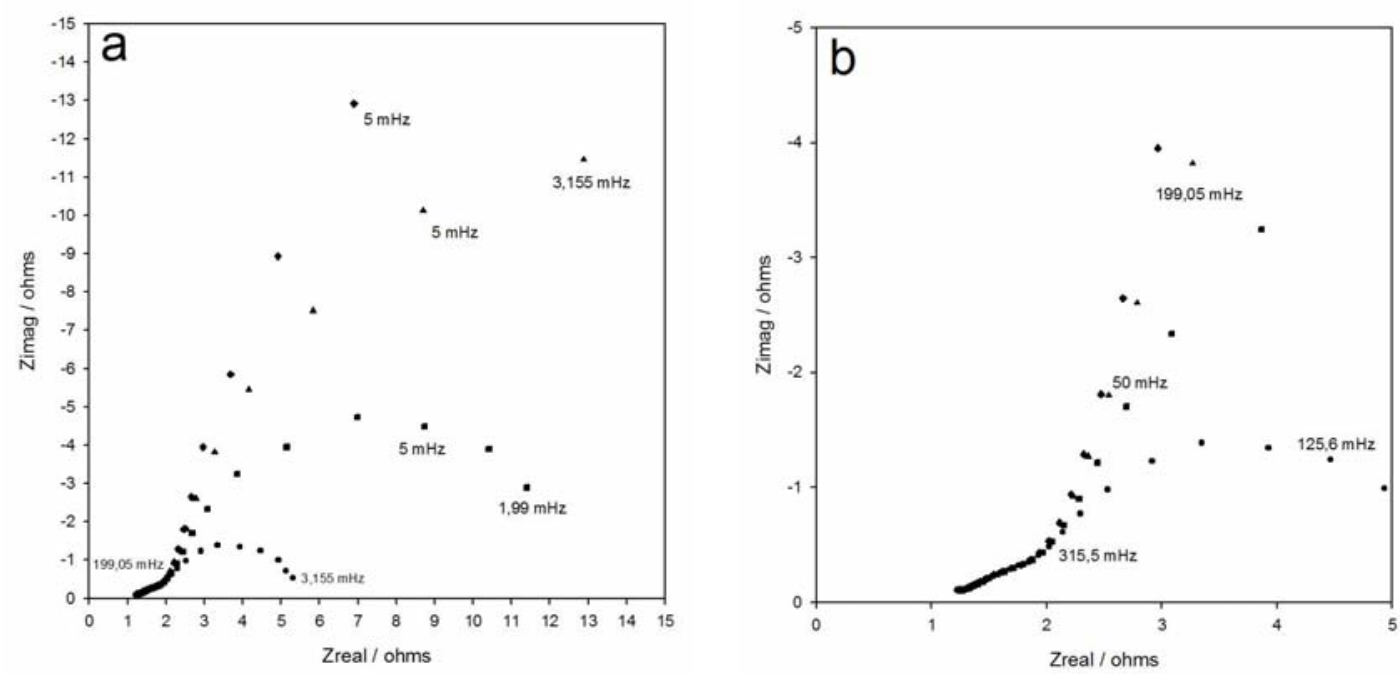

Figure 8. (a) Diagramas de Nyquist correspondientes al electrodo E30-20. $E=(-)-0,95$;

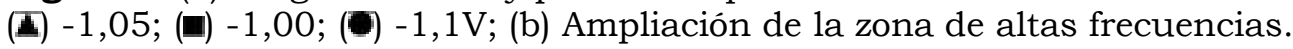

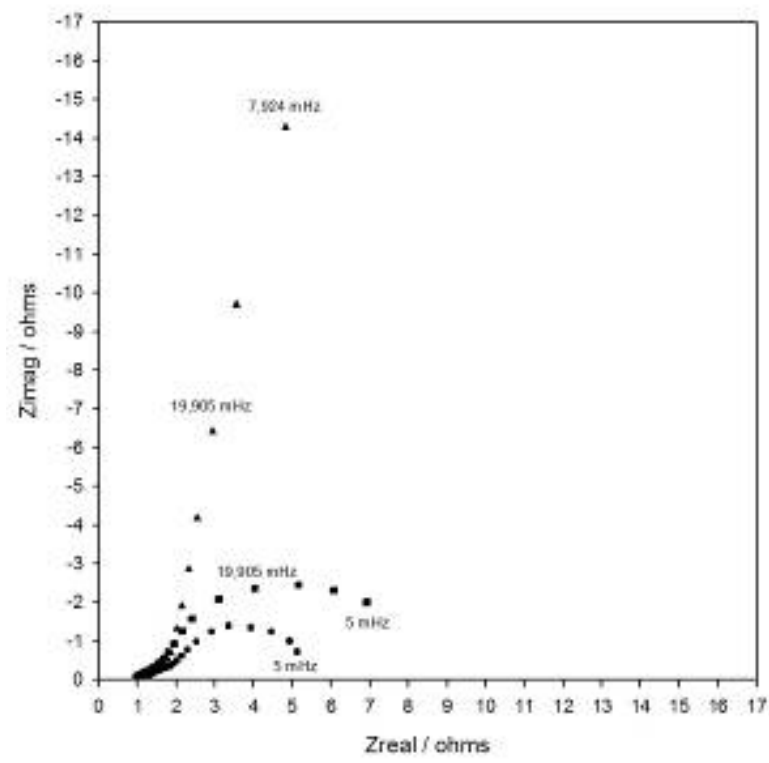

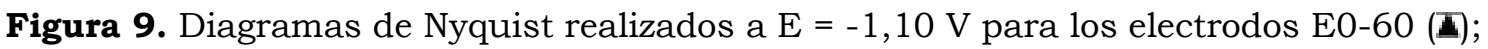
E20-30 (घ); E30-20 (•).

\subsection{Análisis teórico}

En el Capítulo 2 se desarrolló un modelo fisicoquímico para electrodos porosos y se obtuvo una expresión para la impedancia del sistema. De ese análisis se desprende que es fundamental obtener una expresión para la impedancia faradaica. A continuación se realizará la deducción de la ecuación matemática que modela el parámetro buscado. 
Deducción de la expresión para $Z_{F}$.

El proceso faradaico que tiene lugar en el área interfacial $\left(a_{i}\right)$, sólido/electrolito acuoso está relacionado con la $\mathrm{REH}$ :

$\mathrm{H}_{2} \mathrm{O}+\mathrm{e}^{-} \rightarrow 1 / 2 \mathrm{H}_{2}+\mathrm{HO}^{-}$

Considerando constante las concentraciones de $\mathrm{H}_{2} \mathrm{O}$ y de $\mathrm{HO}^{-}$, y también constante la presión de $\mathrm{H}_{2}$, la densidad de corriente faradaica relacionada a la $\mathrm{REH}$ puede ser escrita como:

$i_{f}=i_{f}^{0}\left(\exp \left(\frac{\alpha_{a} F \eta}{R T}\right)-\exp \left(\frac{\alpha_{c} F \eta}{R T}\right)\right)$

Siendo:

$i_{f}^{0}=$ la densidad de corriente de intercambio $\left(\mathrm{Acm}^{-2}\right)$

$\eta=E-E_{E q}$

$E=$ potencial interfacial; $E_{E q}=$ potencial de equilibrio para la $\mathrm{REH}$ vs. $\mathrm{Hg} / \mathrm{HgO}$ ss.

Bajo estas condiciones, considerando que la densidad de corriente depende solo del potencial del electrodo, puede deducirse la impedancia faradaica empleando la ecuación (4.4), luego de linealizar y aplicar la transformada de Fourier:

$$
\frac{1}{Z_{f}}=\frac{\Delta i_{f}(\omega)}{\Delta \eta(\omega)}=\left(\frac{\partial i}{\partial \eta}\right)
$$

Para sobrepotenciales catódicos grandes solamente se considera la rama catódica de la ecuación (4.4) y, consecuentemente,

$$
\frac{1}{Z_{f}}=\frac{1}{R_{t}}=\frac{i_{f} F\left(-\alpha_{c}\right)}{R T}
$$

Finalmente podemos escribir,

$$
Z_{F}=R_{T}=R_{t} / \mathrm{a}_{i}
$$

donde $R_{t}$ es la resistencia a la transferencia de carga $\left(0 h m \mathrm{~cm}^{2}\right), \mathrm{y} \mathrm{a}_{i}$, el área interfacial por unidad de volumen $\left(\mathrm{cm}^{-1}\right)$.

La función de impedancia teórica, $Z_{p}$, se puede calcular en términos de las ecuaciones deducidas en el Capítulo 2 y de las ecuaciones (4.6) y (4.7) recientemente obtenidas: 


$$
\begin{array}{ccc}
Z_{p}=\frac{L}{A_{p}(\kappa+\sigma)}\left[1+\frac{2+\left(\frac{\sigma}{\kappa}+\frac{\kappa}{\sigma}\right) \cosh (v)}{v \operatorname{senh}(v)}\right] \quad v=L\left(\frac{\kappa+\sigma}{\kappa \sigma}\right)^{1 / 2} Z_{i}^{-1 / 2} \\
Z_{i}^{-1}=Z_{d l}^{-1}+Z_{F}^{-1} & Z_{d l}=\frac{1}{j \omega C_{d l}}
\end{array}
$$

Resultados derivados de los procedimientos de ajuste.

La comparación de los resultados experimentales con los diagramas teóricos de Nyquist que resultan del proceso de ajuste para electrodos construidos con VT solamente (E0-60) (Figura 10 A) y electrodos con VT y NTCS (E30-20) (Figura 10 B) constituyen una evidencia de un buen ajuste. Resultados similares se obtienen para electrodos que contienen cantidades diferentes de NTCS y para el dominio total de potenciales cubiertos por los experimentos. Sin embargo, aquellos valores correspondientes a las frecuencias más bajas exhiben un cierto desacuerdo que se atribuye a la existencia de ruido en los resultados experimentales. 

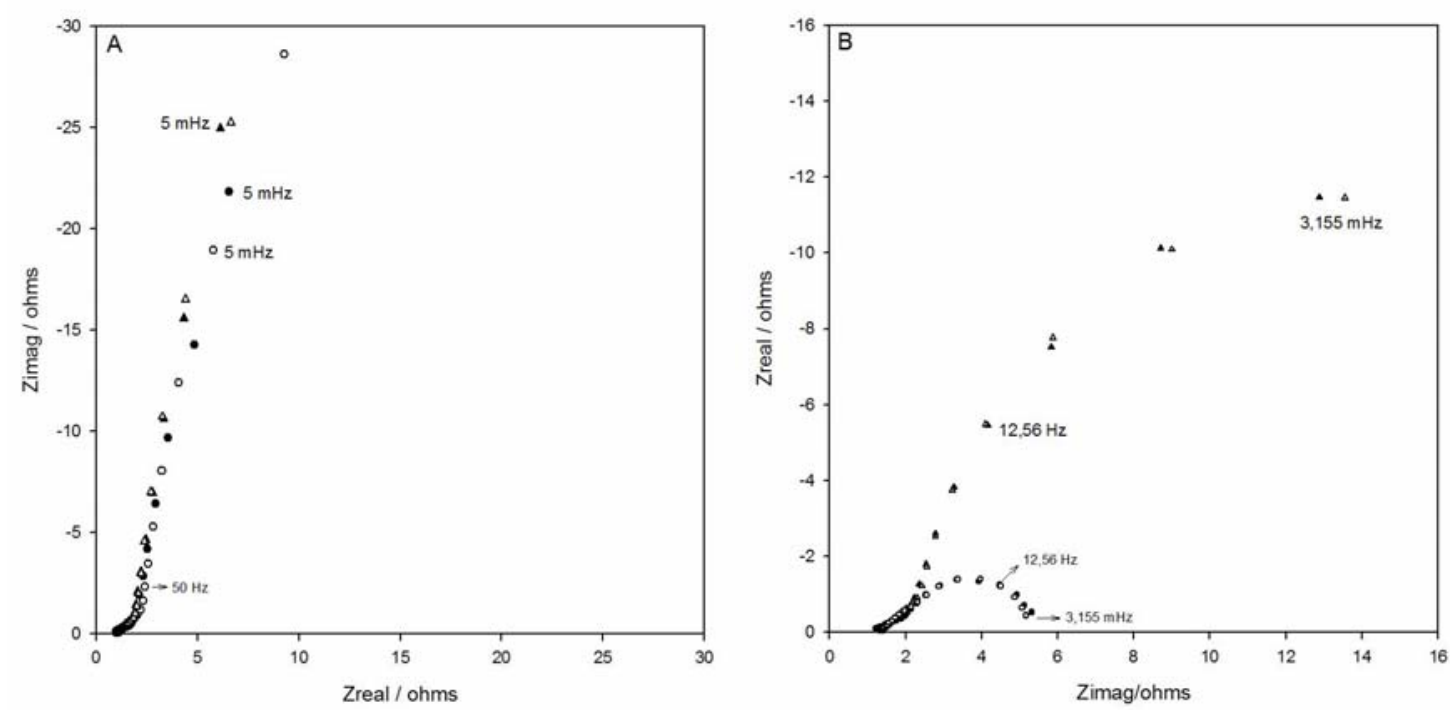

Figure 10. Diagramas de Nyquist realizados a $E=-1,1 \mathrm{~V}(\bullet)$ experimental; $(\varnothing)$ Teórico; y a $\mathrm{E}=-1 \mathrm{~V}(\mathbf{\Lambda})$ experimental; $(\triangle)$ Teórico, para E0-60 (A) y E30-20 (B).

Cálculo de los parámetros electroquímicos.

i) Área interfacial electródica por unidad de volumen ( $\left.\mathrm{a}_{i}\right)$

Como fue discutido detalladamente en el Capítulo 3, a $i$, el área interfacial por unidad de volumen es un parámetro que se deduce luego de los ajustes con los resultados experimentales y es una medida relacionada con la fracción del material que realmente participa en la interfase electrodo/solución electrolítica. Este parámetro se obtiene empleando el mismo procedimiento discutido en el Capítulo anterior, nuevamente considerando que la capacidad de la DCE por unidad de área, $C_{d l}^{0}$, es igual a $3.10^{-5} \mathrm{Fcm}^{-2}$.

ii) Coeficiente de transferencia catódico $\left(\alpha_{c}\right)$

A partir de los ajustes realizados para cada electrodo se obtiene la resistencia a la transferencia de carga multiplicada por el volumen del electrodo $\left(R_{T}\right)\left(\mathrm{ohm} \mathrm{cm}^{3}\right)$. Empleando las ecuaciones (4.5) y (4.6) resulta una expresión para $\alpha_{\mathrm{c}}$,

$\alpha_{c}=-\frac{R T}{R_{T} i_{f} \mathrm{a}_{i} F}$ 
Debe tenerse en cuenta que para hallar $i_{f}$, la corriente medida $i_{m}$ se divide por el área real interfacial del electrodo, la cual se expresa multiplicando $\mathrm{a}_{i}\left(\mathrm{~cm}^{2} \mathrm{~cm}^{-3}\right)$ por $V_{e}\left(V_{e}=A_{p} L\right)$, luego, $i_{f}=i_{m} /\left(\mathrm{a}_{i} V_{e}\right)$. Reemplazando en (4.8) se deduce que $\alpha_{\mathrm{c}}$ es,

$\alpha_{c}=-\frac{R T V_{e}}{R_{T} i_{m} F}$

Siendo $A_{p}=0.38 \mathrm{~cm}^{2}$ y $L=0,17 ; 0,17$ y $0,16 \mathrm{~cm}$ para E0-60, E20-30 y E30-20 respectivamente.

iii) Densidad de corriente de intercambio

La densidad de corriente de intercambio, $i_{f}^{0}$, puede hallarse fácilmente considerando la rama catódica de la ecuación de Tafel, $i_{f}=-i_{f}^{0}\left(\exp \left(\frac{\alpha_{c} F \eta}{R T}\right)\right)$

Es decir, después de calcular $\alpha_{\mathrm{c}}$ se determina $i_{f}$ para distintos valores de potencial, teniendo en cuenta que el sobrepotencial aplicado al electrodo es,

$\eta=E-E_{E q}$

$E_{E q}$ es el potencial de equilibrio para la $\mathrm{REH} v$ s. $\mathrm{Hg} / \mathrm{HgO}$ ss (-0.928V).

La Tabla 3 incluye parámetros derivados del procedimiento de ajuste y del modelo, correspondiendo a electrodos de diferente composición, esto es, E0-60, E20-30 y E30-20. Como puede percibirse, $\mathrm{a}_{i}$, el área interfacial por unidad de volumen, aumenta con el contenido de NTCS en los electrodos. Este es un resultado esperado porque la disminución del contenido de VT en el electrodo (que tiene un 33\% de Teflón) implica un incremento de NTCS, los cuales no sólo poseen un área específica medida por BET mayor sino que también tienen microporos de mayor tamaño, lo cual, favorece la accesibilidad del electrolito a la estructura porosa. Por otra parte, $R_{T}$ decrece con el aumento de NTCS, en total acuerdo con el aumento de la densidad de corriente $i_{f}$, determinada en condiciones de estado estacionario. El motivo que explica el cambio de $i_{f}$ con el contenido de NTCS en los 
electrodos se encuentra en las propiedades electrocatalíticas de este material para la REH. Esta conclusión se advierte a través del incremento de los valores de las densidades de corriente, porque en ausencia de un efecto electrocatalítico un aumento del área interfacial resultaría en valores constantes de $i_{f}$. La misma conclusión puede ser utilizada para explicar el aumento de la densidad de la corriente de intercambio, $i_{f}^{0}$, con el aumento del contenido de NTCS.

\begin{tabular}{|c|cc|c|c|c|c|c|c|}
\hline & $E / V$ & $i / m A$ & $R_{T} / \mathrm{ohmcm}^{3}$ & $C_{d l} / F_{c m}-3$ & $a_{\mathrm{i}} \cdot 10^{-5}$ & $i_{f} / \mathrm{Acm}^{-2}$ & $\alpha_{c}$ & $i_{f}^{0} / \mathrm{Acm}^{-2}$ \\
\hline E0-60 & $-1,1$ & 0,13 & 11,9 & 20,6 & 6,9 & $4.10^{-6}$ & 1,1 & $3,0.10^{-6}$ \\
\hline E20-30 & $-1,1$ & 5,20 & 0,37 & 31,6 & 10,5 & $2,7.10^{-6}$ & 0,9 & $7,7.10^{-5}$ \\
\hline E30-20 & $-1,1$ & 8,30 & 0,19 & 42,1 & 14,0 & $8,3.10^{-6}$ & 1,0 & $9,8.10^{-5}$ \\
\hline
\end{tabular}

Tabla 3. Parámetros del modelo derivados del proceso de ajuste.

Los valores de corriente de intercambio obtenidos para los electrodos conteniendo nanotubos de carbono están en el orden de los reportados para los mejores catalizadores de la REH. Algunos valores reportados en la literatura son: i) $1,02.10^{-6}$ para $\mathbf{C u}(\mathbf{H g})$ en $0,15 \mathrm{M} \mathrm{NaOH}$ [53], ii) 10-7.04 para $\mathbf{A u}$ en $0,1 \mathrm{~N} \mathrm{NaOH}$ [54], iii) $10^{-6.06}$ para $\mathbf{F e}$ en $0,1 \mathrm{~N}$ $\mathrm{NaOH}$ [54], iv) $10^{-6.1}$ para $\mathbf{N i}$ en $0,5 \mathrm{~N} \mathrm{NaOH}$ [55], v) 10-5,01 para $\mathbf{P d}$ en $0,1 \mathrm{~N} \mathrm{NaOH}[54]$ y vi) $10^{-4,06}$ para $\mathbf{P t}$ en $0,5 \mathrm{~N} \mathrm{NaOH}$ [56].

Como puede ser observado en la tabla 3 , los valores obtenidos para el coeficiente de transferencia catódico están alrededor de 1, lo cual es una confirmación de la validez del modelo empleado. El hecho de que los electrodos estén compuestos por materiales semiconductores (Carbon Vulcan XC72 y NTCS purificados químicamente) hace que, en este caso, el coeficiente de transferencia tome valores cercanos a 1 para la reacción catódica cuando se aplica la teoría de semiconductores en la ecuación de Butler-Volmer [57].

\subsection{Conclusiones}

En solución acuosa alcalina el agua es la fuente de protones, y luego de la transferencia de electrones se produce HO-. Numerosas 
investigaciones de la REH sobre carbones y metales indican que ésta se produce primero por una etapa electroquímica,

$$
\mathrm{H}_{2} \mathrm{O}+\mathrm{C}+\mathrm{e}^{-} \leftrightarrow \mathrm{CH}_{\mathrm{ad}}+\mathrm{HO}^{-} \quad \text { Etapa de Volmer }
$$

para luego continuar a través de otra etapa electroquímica o química respectivamente:

$$
\begin{array}{ll}
\mathrm{CH}_{\mathrm{ad}}+\mathrm{H}_{2} \mathrm{O}+\mathrm{e}^{-} \rightarrow \mathrm{H}_{2}+\mathrm{C}+\mathrm{HO}^{-} & \text {Etapa de Heyrovsky } \\
\mathrm{CH}_{\mathrm{ad}}+\mathrm{CH}_{\mathrm{ad}} \rightarrow \mathrm{H}_{2}+2 \mathrm{C} & \text { Etapa de Tafel }
\end{array}
$$

Los resultados de los experimentos de carga y descarga galvanostáticos indican que los valores para el almacenamiento de hidrógeno en NTCS son del $0,18 \%$ en peso. Este hecho confirma las conclusiones voltamperométricas que se relacionan con el pico de corriente anódico en $0,6 \mathrm{~V}$ para todos los electrodos estudiados, prescindiendo que este pico pudiera ser atribuido a impurezas metálicas.

Los resultados de le espectroscopia de impedancia electroquímica indican que la resistencia a la transferencia de carga disminuye a medida que el contenido de NTCS en los electrodos aumenta, en total acuerdo con el incremento de la corriente medida en condiciones de estado estacionario. El hecho que explica el cambio de la corriente faradaica con el contenido de NTCS en los electrodos se encuentra en las propiedades electrocataliticas de este material para la REH. Esta conclusión es claramente percibida a través del incremento de los valores de las densidades de corriente, porque en ausencia de estos efectos electrocatalíticos un aumento del área interfacial conduciría a valores constantes de las densidades de corriente faradaicas. Así también se explica el aumento de la densidad de corriente de intercambio con el aumento del porcentaje de nanotubos de carbono en los electrodos. Además, los valores de corrientes de intercambio obtenido a través de las medidas de EIE indican que los NTCS son muy buenos catalizadores para la REH. 


\subsection{Referencias Bibliográficas}

[1] C. Niu, E. K. Sichel, R. Hoch, D. Moy, H. Tennent. High power electrochemical capacitors based on carbon nanotube electrodes. Appl. Phys. Lett., 70 (1997) 1480-1482.

[2] C. Liu, A. J. Bard, F. Wudl, I. Weitz, J. R. Heath. Electrochemical characterization of films of single-walled carbon nanotubes and their possible application in supercapacitors. Electrochem. SolidState Lett., 2 (1999) 577-578.

[3] E. Frackowiak, F. Béguin. Electrochemical storage of energy in carbon nanotubes and nanostructured carbons. Carbon, 40 (2002) 1775-1787.

[4] K. Jurewicz, S. Delpeux, V. Vertagna, F. Béguin, E. Frackowiak. Supercapacitors from nanotubes/polypyrrole composites. Chem. Phys. Lett., 347 (2001) 36-40.

[5] B. P. Bakhmatyuk, B. Ya. Venhryn, I. I. Grygorchak, M. M. Micov, Yu. O. Kulyk. On the hierarchy of the influences of porous and electronic structures of carbonaceous materials on parameters of molecular storage devices. Electrochim. Acta, 52 (2007) 66046610.

[6] P. J. Britto, K. S. V. Santhanam, P. M. Ajayan. Carbon nanotube electrode for oxidation of dopamine. Bioelectrochem. Bioenerg., 41 (1996) 121-125.

[7] E. Frackowiak, S. Gatier, H. Gaucher, H. Bonnay, F. Béguin. Electrochemical storage of lithium multiwalled carbon nanotubes. Carbon, 37 (1999) 61-69.

[8] P. P. Prosini, A. Pozio, S. Botti, R. Ciardi. Electrochemical studies of hydrogen evolution, storage and oxidation on carbon nanotube electrodes. J. Power Sources, 118 (2003) 265-269.

[9] H. Dai. Carbon nanotubes: opportunities and challenges. Surf. Sci., 500 (2002) 218-241.

[10] W. Pan, X. Zhang, S. Li, D. Wu, Z. Mao. Measuring hydrogen storage capacity of carbon nanotubes by high-pressure microbalance. Int. J. Hydrogen Energy, 30 (2005) 719-722.

[11] L. Zhou, Y. Zhou, Y. Sun. Studies on the mechanism and capacity of hydrogen uptake by physisorption-based materials. Int. J. Hydrogen Energy, 31 (2006) 259-264. 
[12] A. C. Dillon, K. M. Jones, T. A. Bekkedahl, C. H. Kiang, D. S. Bethune, M. J. Heben. Storage of hydrogen in single-walled carbon nanotubes. Nature, 386 (27) (1997) 377-379.

[13] Y. Ye, C. C. Ahn, C. Witham, B. Fultz, J. Liu, A. G. Rinzler, et al. Hydrogen adsorption and cohesive energy of single-walled carbon nanotubes. Appl. Phys. Lett., 74 (16) (1999) 2307-2309.

[14] C. Liu, Y. Y. Fan, M. Liu, H. T. Cong, H. M. Cheng, M. S. Dresselhaus. Hydrogen storage in single-walled carbon nanotubes at room temperature. Science, 286 (1999) 1127-1129.

[15] F. L. Darkrim, P. Malbrunot, G. P. Tartaglia. Review of hydrogen storage by adsorption in carbon nanotubes. Int. J. Hydrogen Energy, 27 (2002) 193-202.

[16] M. W. Maddox, K. E. Gubbins. Molecular simulation of fluid adsorption in buckytubes. Langmuir, 11 (1995) 3988-3996.

[17] M. W. Maddox, S. L. Sowers, K. E. Gubbins. Molecular simulation of binary mixture adsorption in buckytubes and MCM-41. Adsorption, 2 (1996) 23-32.

[18] F. L. Darkrim, D. Levesque. Environmental application of surface reactivity analysis. Surf. Interface Anal., 34 (2002) 97-99.

[19] F. L. Darkrim, D. Levesque. High adsorptive property of opened carbon nanotubes at $77 \mathrm{~K}$. J. Phys. Chem. B, 104 (2000) 67736776.

[20] M. Dresselhaus, K. Williams, P. Eklund. Hydrogen adsorption in carbon materials. MRS Bull., 1 (1999) 45-50.

[21] F. E. Pinkerton, B. G. Wicke, C. H. Olk, G. G. Tibbetts, G. P. Meisner, M. S. Meyer, et al. Thermogravimetric measurement of hydrogen absorption in alkali-modified carbon materials. J. Phys. Chem. B, 104(40) (2000) 9460-9467.

[22] A. C. Dillon, M. J. Heben. Hydrogen storage using carbon adsorbents: past, present and future. Appl. Phys. A, 72 (2001) 133142.

[23] C. Nützenadel, A. Züttel, D. Chartouni, L. Schlapbach. Electrochemical storage of hydrogen in nanotube materials. Electrochem. Solid-State Lett., 2 (1999) 30-32. 
[24] C. Vix-Guterl, E. Frackowiak, K. Jurewicz, M. Friebe, J. Parmentier, F. Béguin. Electrochemical energy storage in ordered porous carbon materials. Carbon, 43 (2005) 1293-1302.

[25] H. Zhang, X. Fu, Y. Chen, S. Yi, S. Li, Y. Zhu, et al. The electrochemical hydrogen storage of multi-walled carbon nanotubes synthesized by chemical vapor deposition using a lanthanum nickel hydrogen storage alloy as catalyst. Physica B, 352 (2004) 66-72.

[26] X. Chen, Y. Zhang, X. P. Gao, G. L. Pan, X. Y. Jiang, J. Q. Qu, et al. Electrochemical hydrogen storage of carbon nanotubes and carbon nanofibers. Int. J. Hydrogen Energy, 29 (2004) 743-748.

[27] S. Hynek, W. Fuller, J. Bentley. Hydrogen storage by carbon sorption. Int. J. Hydrogen Energy, 22 (1997) 601-610.

[28] X. Qin, X. P. Gao, H. Liu, H. T. Yuan, D. Y. Yan, W. L. Gong, et al. Electrochemical hydrogen storage of multiwalled carbon nanotubes. Electrochem Solid-State Lett., 3 (2000) 532-535.

[29] N. Rajalakshmi, K. S. Dhathathreyan, A. Govindaraj, B. C. Satishkumar. Electrochemical investigation of single-walled carbon nanotubes for hydrogen storage. Electrochim. Acta, 45 (2000) 4511-4515.

[30] A. K. M. Fazle Kibria, Y. H. Mo, K. S. Park, K. S. Nahm, M. Y. Yun. Electrochemical hydrogen storage behaviors of CVD, AD and LA grown carbon nanotubes in $\mathrm{KOH}$ medium. Int. J. Hydrogen Energy, 26 (2001) 823-829.

[31] G. Gundiah, A. Govindaraj, N. Rajalakshmi, K. S. Dhathathreyan, C. N. R. Rao. Hydrogen storage in carbon nanotubes and related materials. J. Mater. Chem., 13 (2003) 209-13.

[32] S. M. Lee, K. S. Park, Y. C. Choi, Y. S. Park, J. M. Bok, D. J. Bae, et al. Hydrogen adsorption and storage in carbon nanotubes. Synth. Met., 113 (2000) 209-216.

[33] A. Züttel, P. Sudan, P. Mauron, T. Kioyobayashi, C. Emmenegger, L. Schlapbach. Hydrogen storage in carbon nanostructures. Int. J. Hydrogen Energy, 27 (2002) 203-212.

[34] M. L. Seung, H. A. Kay, H. L. Young, G. Seifert, T. Frauenheim. Novel mechanism of hydrogen storage in carbon nanotubes. J. Korean Phys. Soc., 38 (2001) 686-691. 
[35] M. L. Seung, H. L. Young. Hydrogen storage in single-walled carbon nanotubes. Appl. Phys. Lett., 76(20) (2000) 2877-2879.

[36] G. Mpourmpakis, G. E. Froudakis, G. P. Lithoxoos, J. Samios. Effect of curvature and chirality for hydrogen storage in singlewalled carbon nanotubes: a combined ab initio and Monte Carlo investigation. J. Chem. Phys., 126 (2007) 04-144714.

[37] X. Zhang, W. Wang, J. Chen, Z. Shen. Characterization of a sample of single-walled carbon nanotube array by nitrogen adsorption isotherm and density functional theory. Langmuir, 19 (2003) 60886096.

[38] M. Volpe, F. Cleri. Role of surface chemistry in hydrogen adsorption in single-wall carbon nanotubes. Chem. Phys. Lett., 371 (2003) 476-482.

[39] D. Cao, W. Wang. Storage of hydrogen in single-walled carbon nanotube bundles with optimized parameters: effect of external surfaces. Int. J. Hydrogen Energy, 32 (2007) 1939-1942.

[40] C. P. Jones, K. Jurkschat, A. Crossley, R. G. Compton, B. L. Riehl, C. E. Banks. Use of high-purity metal-catalyst-free multiwalled carbon nanotubes to avoid potential experimental misinterpretations. Langmuir, 23 (2007) 9501-9504.

[41] R. A. H. Niessen, J. de Jonge, P. H. L. Nottena. The electrochemistry of carbon nanotubes. I. Aqueous electrolyte. J. Electrochem. Soc., 153 (2006) A1484-1491.

[42] E. Liu, J. Wang, J. Li, C. Shi, C. He, X. Du, N. Zhao. Enhanced electrochemical hydrogen storage capacity of multi-walled carbon nanotubes by $\mathrm{TiO}_{2}$ decoration. Int. J. Hydrogen Energy, 36 (2011) 6739-6743.

[43] K. Y. Lina, W. T. Tsai, T. J. Yang. Effect of Ni nanoparticle distribution on hydrogen uptake in carbon nanotubes. J. Power Sources, 196 (2011) 3389-3394.

[44] A. M. Rao, J. Chen, E. Richter, U. Schlecht, P. C. Eklund, R. C. Haddon, et al. Effect of van der Waals interactions on the Raman modes in single walled carbon nanotubes. Phys. Rev. Lett., 86 (2001) 3895-3898.

[45] A. Lasia. In: B. E. Conway, J. Bockris, R. E. White, editores. Electrochemical impedance spectroscopy and its applications in modern aspects of electrochemistry, vol. 32. New York: Kluwer Academic/Plenum Publishers. (1999). pp. 143-248. 
[46] R. De Levie. On porous electrodes in electrolyte solutions. Electrochim. Acta, 8 (1963) 751-780.

[47] R. De Levie. On porous electrodes in electrolyte solutions-iv. Electrochim. Acta, 9 (1964) 1231-1245.

[48] R. De Levie. The influence of surface roughness of solid electrodes on electrochemical measurements. Electrochim. Acta, 10 (1965) 113-130.

[49] R. De Levie, A. Vogt. On the electrochemical response of rough electrodes. Part I. The current transient following a voltage step in the absence of faradaic processes. J. Electroanal. Chem., 278 (1990) 25-34.

[50] R. De Levie, A. Vogt. On the electrochemical response of rough electrodes. Part II. The transient response in the presence of slow faradaic processes. J. Electroanal. Chem., 281 (1990) 23-28.

[51] E. B. Castro, S. G. Real, A. Bonesi, A. Visintin, W. E. Triaca. Electrochemical impedance characterization of porous metal hydride electrodes. Electrochim. Acta, 49 (2004) 3879-3890.

[52] A. Visintin, E. B. Castro, S. G. Real, W. E. Triaca, C. Wang, M. P. Soriaga. Electrochemical activation and electrocatalytic enhancement of a hydride-forming metal alloy modified with palladium, platinum and nickel. Electrochim. Acta, 51 (2006) 3658-3667.

[53] J. O'M. Bockris, N. Pentland. The mechanism of hydrogen evolution at copper cathodes in aqueous Solutions. Trans. Faraday Soc. 48 (1952) 833-839.

[54] N. Pentland, J. O'M. Bockris, E. Sheldon. Hydrogen Evolution Reaction on Copper, Gold, Molybdenum, Palladium, Rhodium, and Iron Mechanism and Measurement Technique under High Purity Conditions. J. Electrochem. Soc. 104 (1957) 182-194.

[55] J. O'M. Bockris, S. Srinivasan. Elucidation of the mechanism of electrolytic hydrogen evolution by the use of $\mathrm{H}-\mathrm{T}$ separation factors. Electrochim. Acta 9 (1964) 31-44.

[56] J. O'M. Bockris, S. Srinivasan. Electrochim. Elucidation of the mechanism of electrolytic hydrogen evolution by the use of $\mathrm{H}-\mathrm{T}$ separation factors. Electrochim. Acta 9 (1964) 31-44. 
[57] J. O'M. Bockris, A. K. N. Reddy. Modern Electrochemistry: Fundamentals of Electrodics. Kluwer Academic Publishers New York, Boston, Dordrecht, London, Moscow. 2002. 


\section{Capitulo 5}

\section{Primeros estudios de las vias de electrooxidación de Glicerol sobre nanoparticulas basadas en Pt soportadas sobre diferentes carbones.}

\subsection{Introducción}

\subsubsection{Biodiesel y glicerol en la Argentina}

El Biodiesel es un combustible renovable y biodegradable que se obtiene a partir de la transesterificación de aceites y grasas de origen vegetal y animal. Esto es, la reacción entre un triglicérido (en general con cadenas de carbonos, $\mathrm{R}$, diferentes) y un alcohol (generalmente metanol) para dar un éster del o de los ácidos grasos correspondientes, el cual es conocido como biodiesel (Figura 5.1). Este combustible sustituye total o parcialmente al gas oil en motores diesel móviles o estacionarios. Esta sustancia es utilizada en todo el mundo y la Argentina es un actor muy importante debido a que solamente nuestro país y Alemania sustituyen los combustibles diesel con un $7 \%$ de biodiesel (B7) desde el año 2010 [1]. A mediados del año 2011, la ley de Biocombustibles obliga a las petroleras a aumentar el porcentaje de la mezcla a $10 \%$, convirtiendo a nuestro país en aquél que utiliza combustibles diesel con mayor cantidad de biocombustibles.

La producción de biodiesel genera Propano-1,2,3-triol (Glicerol o Glicerina) como subproducto. Este compuesto constituye un 10\% de la masa total de Biodiesel obtenido. Puesto que la gran producción 
mundial de glicerol no alcanza a ser utilizada por las diferentes industrias a las cuales esta sustancia sirve de materia prima, es muy importante encontrarle nuevos usos y así agregar valor a la cadena de producción de biodiesel. De lo expuesto en los párrafos anteriores se desprende que el aprovechamiento del excedente de glicerol es de interés estratégico para nuestro país.

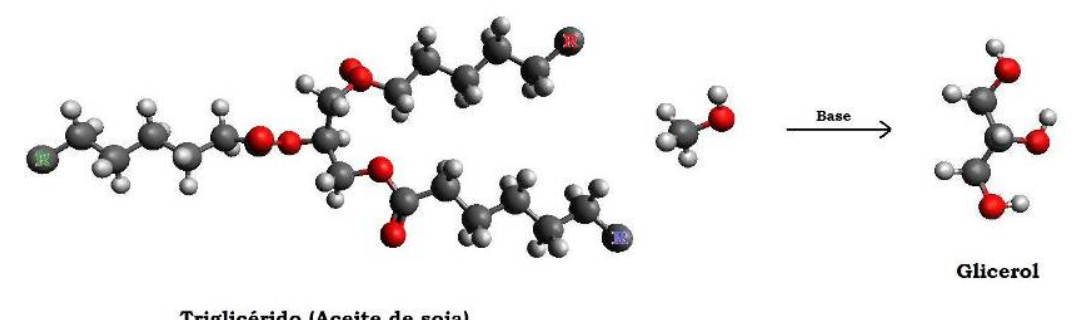

Triglicérido (Aceite de soja)
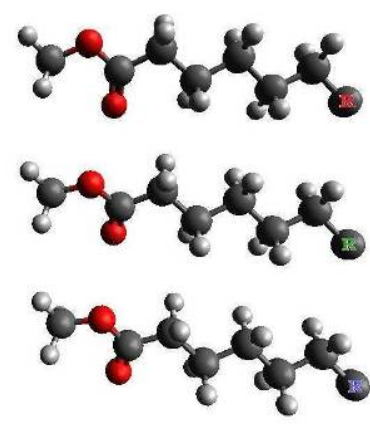

Biodiese1

Figura 5.1: Reacción de transesterificación de grasas y aceites.

Dentro de este contexto, proyectamos investigaciones con el propósito de comprender lo que ocurre en la superficie de catalizadores nanoestructurados basados en $\mathrm{Pt}$, con el objetivo de que el conocimiento adquirido permita el desarrollo de catalizadores efectivos y la posterior utilización en celdas de combustible de glicerol.

\subsubsection{Celdas de combustible}

En el año 1839, William Grove [2] descubrió el principio de funcionamiento básico de una celda de combustible, el cual consiste en invertir la reacción de electrólisis de agua para generar electricidad utilizando $\mathrm{H}_{2} \mathrm{y} \mathrm{O}_{2}$ como reactivos. Este principio descubierto por Grove hace más de 170 años se mantiene inalterado en nuestros días.

Una celda de combustible es un dispositivo electroquimico que convierte energía química en energía eléctrica de forma continua, siempre y cuando el combustible, en principio $\mathrm{H}_{2}$, y el oxidante, $\mathrm{O}_{2}$, sean adicionados (Figura 5.2). Esta conversión ocurre a través de dos hemirreacciones (5.1) y (5.2) que se producen en dos compartimentos 
que alojan a los electrodos, separados por un electrolito apropiado. Así, los electrones producidos en el ánodo se dirigen hacia el cátodo a través de un circuito eléctrico externo. Esta circulación de electrones es aprovechada para hacer funcionar diferentes dispositivos, esto es, bombas de luz, motores eléctricos, etc.

Ánodo:

$$
\mathrm{H}_{2} \longrightarrow 2 \mathrm{H}^{+}+2 \mathrm{e}^{-} \quad \mathrm{E}_{0}=0,000 \mathrm{~V}, \mathrm{pH}=0
$$

Cátodo

$$
\mathrm{O}_{2}+4 \mathrm{H}^{+}+4 \mathrm{e}^{-} \longrightarrow 2 \mathrm{H}_{2} \mathrm{O} \quad \mathrm{E}_{0}=1,229 \mathrm{~V} \text { vs. ERH }
$$

Y la reacción total es:

$$
2 \mathrm{H}_{2}+\mathrm{O}_{2} \longrightarrow 2 \mathrm{H}_{2} \mathrm{O}+\text { calor + electricidad }
$$

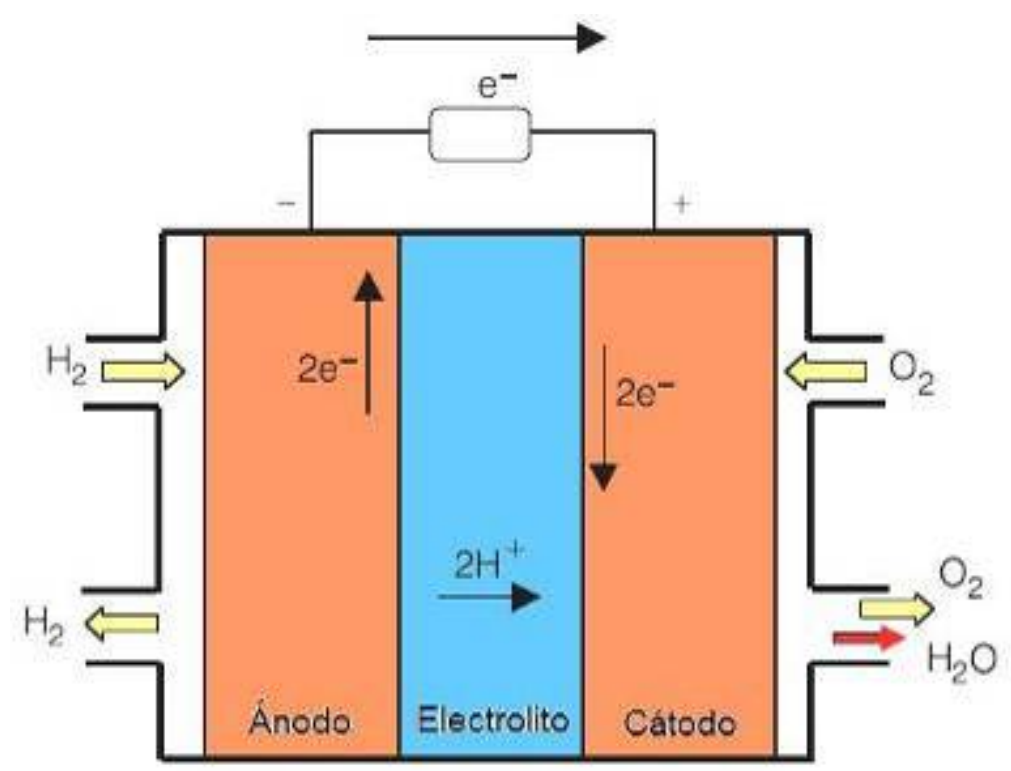

Figura 5.2: Representación esquemática de una celda de combustible de hidrógeno

Las celdas de combustible tienen algunas similitudes con las baterias, con las que comparten la naturaleza electroquímica, y con los motores, los cuales, a diferencia de las baterias, pueden trabajar de forma continua. Resumiendo, una celda de combustible no necesita ser recargada, opera de manera eficiente y silenciosa y lo que es más importante, cuando utiliza hidrógeno como combustible, produce 
energía y agua pura, constituyendo en consecuencia un dispositivo con “emisión cero" de gases contaminantes.

La celda de Grove era un equipo frágil conteniendo ácido sulfúrico diluido, en el cual se sumergieron dos electrodos de Pt. Este fue el dispositivo a partir del cual se han realizado numerosos desarrollos en todos los componentes de las celdas hasta llegar a las modernas, las cuales pueden encontrarse tanto en aplicaciones móviles como estacionarias.

Existen varios tipos de celdas. Éstas se clasifican según el tipo de electrolito que utilizan y la temperatura de operación. En la Tabla 5.1 pueden observarse los desarrollos más importantes junto con algunas de sus características.

\begin{tabular}{|c|c|c|c|c|c|}
\hline Tipo de Celda & Electrolito & Transportador & $\begin{array}{l}\text { Temp. de } \\
\text { operación }\end{array}$ & Combustible & Eficiencia \\
\hline Alcalina & $\mathrm{KOH}$ & $\mathrm{HO}^{-}$ & $60-120^{\circ} \mathrm{C}$ & $\mathrm{H}_{2}$ puro & $35-55 \%$ \\
\hline $\begin{array}{c}\text { Intercambiadora } \\
\text { de Protones }\end{array}$ & $\begin{array}{l}\text { Polímero } \\
\text { sólido }\end{array}$ & $\mathrm{H}^{+}$ & $50-100^{\circ} \mathrm{C}$ & $\begin{array}{c}\mathrm{H}_{2} \text { puro } \\
\text { (Tolera } \mathrm{CO}_{2} \text { ) }\end{array}$ & $35-45 \%$ \\
\hline $\begin{array}{l}\text { de Ácido } \\
\text { Fosfórico }\end{array}$ & $\begin{array}{c}\text { Ácido } \\
\text { Fosfórico }\end{array}$ & $\mathrm{H}^{+}$ & $\sim 220^{\circ} \mathrm{C}$ & $\begin{array}{c}\mathrm{H}_{2} \text { puro } \\
\text { (Tolera } \mathrm{CO}_{2}, \\
1 \% \mathrm{CO} \\
\text { aprox.) }\end{array}$ & $40 \%$ \\
\hline $\begin{array}{l}\text { de Carbonatos } \\
\text { Fundidos }\end{array}$ & $\begin{array}{l}\text { Carbonatos } \\
\text { de Li y de } \\
\text { K }\end{array}$ & $\mathrm{CO}_{3}^{2-}$ & $\sim 650^{\circ} \mathrm{C}$ & $\begin{array}{l}\mathrm{H}_{2}, \mathrm{CO}, \mathrm{CH}_{4} \mathrm{y} \\
\text { otros } \\
\text { hidrocarburos }\end{array}$ & $>50 \%$ \\
\hline $\begin{array}{l}\text { de Óxidos } \\
\text { Sólidos }\end{array}$ & $\begin{array}{l}\text { Óxidos } \\
\text { sólidos de } \\
\text { Itrio y de } \\
\text { Zirconio }\end{array}$ & $\mathrm{O}^{2-}$ & $\sim 1000^{\circ} \mathrm{C}$ & $\begin{array}{l}\mathrm{H}_{2}, \mathrm{CO}, \mathrm{CH}_{4} \mathrm{y} \\
\text { otros } \\
\text { hidrocarburos }\end{array}$ & $>50 \%$ \\
\hline
\end{tabular}

Tabla 5.1: Resumen de los tipos de celdas existentes y sus principales características.

Un tipo de celdas muy interesantes son aquellas que pueden funcionar utilizando combustibles líquidos. Esto es particularmente importante para la aplicación en medios de transporte y en dispositivos portátiles. En este contexto, las celdas de alcohol directo (DAFC, Direct Alcohol Fuel Cells) son una alternativa que ha concentrado una gran 
cantidad de esfuerzos para su desarrollo tecnológico. Existen prototipos de celdas que utilizan como combustible tanto metanol como etanol. Con la finalidad de aumentar las posibilidades de estas tecnologias, las principales problemáticas a abordar son, por una parte, la obtención de mejores catalizadores para los ánodos con el objetivo de reducir los sobrepotenciales de oxidación del alcohol. Por otra parte, deben optimizarse las membranas que separan los electrodos, de modo de minimizar la migración de las moléculas de alcohol desde el ánodo hacia el cátodo.

\subsubsection{Reacción de electrooxidación de glicerol (REG)}

La reacción de electrooxidación de esta molécula ha sido muy poco estudiada [3-6]. En 1994 Roquet y colaboradores estudiaron la electrooxidación de glicerol en electrodos de platino con el propósito de optimizar la obtención de gliceraldehído e identificaron algunos productos utilizando cromatografia líquida [3]. En 1997, Avramov-Ivic y colaboradores realizaron un estudio voltamperométrico de la electrooxidación de glicerol en electrodos de plata y carbón vítreo recubierto con plata [4]. Los autores concluyeron que los materiales estudiados sólo presentan actividad catalítica luego de la formación de óxidos superficiales. En este estudio preliminar no se identificaron productos de oxidación. Venancio y colaboradores estudiaron la misma reacción en matrices de polianilina recubierta con nanopartículas (NPs) de platino [5]. Se observó que las NPs de platino aumentan la densidad de corriente de oxidación de glicerol.

En un artículo reciente, Jeffery y Câmara demostraron que la electrooxidación de glicerol sobre oro en medio alcalino ocurre a través de un mecanismo complejo que tiene varias etapas [7]. Los productos de oxidación fueron detectados por la técnica FTIR-in situ. Se observaron: dióxido de carbono, gliceraldehído, glicerato, carbonato, glicolato e hidroxipiruvato. Aún más recientemente Martins, Giz y Câmara [8] estudiaron la electrooxidación de glicerol en un electrodo de platino policristalino y en medio ácido. A través de la utilización de la técnica 
FTIR-in situ acoplada a la voltamperometría cíclica los autores concluyen que el glicerol se oxida principalmente a $\mathrm{CO}_{2}$, lo que coloca al glicerol como un buen candidato para ser usado como combustible en DGFC (Direct Glycerol Fuel Cell).

En la literatura relacionada con la electrooxidación de glicerol son muy pocos y recientes los trabajos que traten de las rutas de reacción a través de las cuales tiene lugar esa reacción [7-10]. Por lo tanto, son necesarios estudios más profundos del tema.

Desde el punto de vista energético, la electrooxidación total de 1 mol de glicerol a $\mathrm{CO}_{2}$ generaría una carga teórica de $14 \mathrm{~F}$ :

$\mathrm{C}_{3} \mathrm{H}_{5}(\mathrm{OH})_{3}+3 \mathrm{H}_{2} \mathrm{O} \rightarrow 3 \mathrm{CO}_{2}+14 \mathrm{H}^{+}+14 \mathrm{e}^{-}$

Sin embargo, los estudios realizados con alcoholes que poseen enlaces C-C como los del glicerol, por ejemplo, etanol [11,12] e isopropanol [13-16] revelan que uno de los grandes obstáculos para la oxidación de estas moléculas orgánicas es la dificultad de la ruptura del o de los enlaces $\mathrm{C}-\mathrm{C}$ que forman el esqueleto de la molécula. La electrooxidación incompleta de una sustancia genera productos parcialmente oxidados que comprometen el rendimiento energético de la reacción. Si bien prácticamente no se han desarrollado catalizadores que permitan romper la cadena de carbonos del glicerol, investigaciones previas realizadas con etanol y etilenglicol [17,18] muestran catalizadores efectivos, construidos con varios metales, cada uno de ellos cumpliendo diferentes funciones. Uno de los papeles de estos componentes radica en oxidar completamente el reactivo a potenciales inferiores que aquellos medidos para platino puro. Esta función es cumplida por metales que forman especies oxigenadas en su superficie (como el $\mathrm{Sn}$ o $\mathrm{Ru}$ ) [19], las cuales son necesarias para la oxidación de las moléculas orgánicas mencionadas. Paralelamente, se buscan catalizadores capaces de facilitar la ruptura de la cadena de carbonos, de modo que oxidaciones posteriores de átomos de carbono parcialmente oxidados lleven a la generación de $\mathrm{CO}_{2}$. Con este objetivo se forman aleaciones de platino con metales de tamaño menor que éste, los cuales generan una compresión en la red metálica, acercando las 
distancias interatómicas a aquélla que tienen los enlaces $\mathrm{C}-\mathrm{C} \mathrm{sp}^{3}$. El metal más comúnmente escogido para tal fin es el Rh. Estudios recientes de electrooxidación de acetaldehído utilizando catalizadores de $\mathrm{Pt}_{\mathrm{x}} \mathrm{Rh}_{\mathrm{y}}$ [20] muestran que este metal tiene un doble rol durante la oxidación de la molécula orgánica. Por un lado, favorece la ruptura de los enlaces $\mathrm{C}-\mathrm{C}$ mientras que por el otro, disminuye la formación de especies oxigenadas, inhibiendo así los procesos de oxidación. Por lo tanto, esto genera que el agregado de pequeñas cantidades de $\mathrm{Rh}$ produzca una mejora en el catalizador, favoreciendo la ruptura y oxidación de la molécula orgánica. Sin embargo, un exceso de éste origina una carencia de especies oxigenadas y como consecuencia una pérdida de la capacidad de oxidación del material.

\subsection{Parte Experimental}

\subsubsection{Sintesis de los catalizadores}

En este trabajo se han sintetizado diferentes catalizadores empleando el método típico de los polioles [21]. La síntesis de NPs de platino soportadas sobre diferentes carbones se realizó como se describe a continuación. En un balón se colocó una mezcla de: i) carbón de alta área específica que sirve como soporte de las nanopartículas de $\mathrm{Pt}$, en este caso fueron utilizados los carbones Vulcan $\mathrm{XC}{ }^{\circledR}(\mathrm{V})$, Nanotubos de carbono de paredes múltiples (NTCM) y Chezacarb (Ch); ii) Mezcla de Etilenglicol (EG)-Agua (3:1). El EG es el compuesto que actúa como reductor de la sal de Pt; iii) Polivinilpirrolidona (PVP), que es un polimero soluble en agua y se coordina con las NPs formadas, impidiendo que se aglomeren. Para obtener una dispersión homogénea se colocó la mezcla dentro de un sonicador durante veinte minutos. Luego se agregó el precursor de $\mathrm{Pt}\left(\mathrm{PtCl}_{6} \mathrm{H}_{2} \cdot 6 \mathrm{H}_{2} \mathrm{O}\right)$, el cual es reducido por el EG. Se llevó nuevamente al sonicador durante diez minutos y luego, con agitación magnética se lo colocó a $140^{\circ} \mathrm{C}$ y se lo dejó 1hora para permitir la nucleación y el crecimiento de las NPs de Pt sobre el soporte de carbono. Todo el proceso efectuado a $140{ }^{\circ} \mathrm{C}$ se realizó con la ayuda de un condensador. Luego se dejó enfriar a temperatura 
ambiente para después lavar el catalizador utilizando una centrifuga. Así, la solución obtenida fue puesta en tubos de centrífuga, se centrifugó unos minutos para favorecer la decantación del catalizador, apartando luego el sobrenadante. Posteriormente se agregó agua milli-Q agitando el tubo para permitir el contacto entre el agua ultrapura y el catalizador y se procedió a centrifugar nuevamente. Este proceso se repitió cinco veces, hasta lograr reunir todo el sólido en un sólo tubo. Por último, se llevó a una estufa a $70{ }^{\circ} \mathrm{C}$ durante dos días.

Debido a que los catalizadores están compuestos sólo de carbón y Pt, y que nuestro objetivo fue preparar catalizadores con un $20 \%$ en peso del metal, esto es, masa $\mathrm{Pt} /$ masa $\mathrm{C}=0,2$, la cantidad de carbón utilizada se determinó teniendo en cuenta la cantidad de Pt predeterminada. La concentración de ácido cloroplatínico en la mezcla se mantuvo constante a $0,002 \mathrm{M}$, lo cual permite calcular fácilmente la cantidad de solvente (EG-Agua) a utilizar. Por último, la cantidad de PVP empleada se calcula teniendo en cuenta que la cantidad de monómeros del polímero presentes en la solución, dividida por la cantidad de átomos de Pt adicionados debe ser 0,3.

Además de los catalizadores conteniendo sólo NPs de Pt, también se sintetizaron catalizadores trimetálicos sobre carbono Vulcan $\mathrm{XC} 72^{\circledR}$, para lo cual se empleó un procedimiento análogo al descrito anteriormente con algunas diferencias que se detallan a continuación. Se obtuvieron NPs con las siguientes composiciones nominales: i) $\mathrm{Pt}_{61} \mathrm{Sn}_{32} \mathrm{Rh}_{7}$; ii) $\mathrm{Pt}_{61,5} \mathrm{Ru}_{20,2} \mathrm{Rh}_{18,3}$. En el momento de agregar los precursores metálicos, se debieron utilizar tres sales diferentes para cada síntesis. Para Pt se continuó con el $\mathrm{PtCl}_{6} \mathrm{H}_{2} \cdot 6 \mathrm{H}_{2} \mathrm{O}$; para $\mathrm{Sn}$ se utilizó $\mathrm{SnCl}_{2} .2 \mathrm{H}_{2} \mathrm{O}$, mientras que para $\mathrm{Ru}$ se eligió $\mathrm{RuCl}_{3} .3\left(\mathrm{H}_{2} \mathrm{O}\right)$ y para $\mathrm{Rh}, \mathrm{RhCl}_{3} .3\left(\mathrm{H}_{2} \mathrm{O}\right)$. Las cantidades a agregar de cada precursor se calculan teniendo en cuenta las relaciones atómicas de las fórmulas atómicas de las NPs que se espera conseguir. Las cantidades para pesar de carbón y PVP se calculan teniendo en cuenta no sólo los átomos de Pt sino la suma de átomos de todos los metales. 


\subsubsection{Sistema electroquímico}

Tanto para los experimentos electroquímicos tradicionales (VC y CA) como para los de FTIR - in situ se utilizaron celdas electroquímicas de tres electrodos. Como ET se empleó un disco de $\mathrm{Au}$ policristalino $\left(0,78 \mathrm{~cm}^{2}\right.$ de área geométrica) conteniendo en su superficie un depósito de alguno de los catalizadores mencionados. $\mathrm{El} \mathrm{CE}$ fue una chapa de $\mathrm{Pt}$ de alta área o una malla de Pt con negro de Pt en su superficie, pero para los experimentos de FTIR se utilizó una cinta de Pt en forma de anillo. Los potenciales eléctricos fueron medidos contra un electrodo de referencia reversible hidrógeno (RHE) en soluciones de $\mathrm{HClO}_{4}$ 0,01M. Todas las medidas fueron realizadas a temperatura ambiente, burbujeando $\mathrm{N}_{2}$ antes de cada medida para asegurarse trabajar con una solución libre de oxígeno.

Se emplearon técnicas electroquímicas como la VC y la CA. La VC fue realizada en un dominio de potenciales comprendidos entre 0,05 y $1,45 \mathrm{~V}$. Las velocidades de barrido aplicadas fueron $5 \cdot 10^{-3} \mathrm{Vs}^{-1}$ para evaluar el desempeño de los catalizadores y $1.10^{-3} \mathrm{Vs}^{-1}$ para realizar los experimentos de FTIR. Para las medidas cronoamperométricas se eligió un potencial de $0,60 \mathrm{~V}$ respecto al electrodo de hidrógeno $\left(\mathrm{HClO}_{4} \mathrm{0}, 01 \mathrm{M}\right)$, el cual fue impuesto durante un tiempo de 1200 segundos.

\subsubsection{Preparación del electrodo de trabajo}

Como fue informado anteriormente, el ET está formado por el catalizador que se deposita sobre un disco de oro. En primer término el disco fue pulido con un polvo de alúmina de $3 \mu \mathrm{m}$. Luego, se lo lavó con agua Milli-Q y fue sonicado en solución básica de permanganato de potasio durante 20 minutos. El disco fue retirado y lavado con peróxido de hidrógeno y luego colocado en agua y llevado a ebullición. Este último paso se repitió tres veces. Sobre el disco de Au se colocó una tinta del catalizador (Figura 5.3), que se realizó como se describe a continuación. Se colocó $1 \mathrm{mg}$ del catalizador en un pequeño vaso de precipitados con $25 \mu \mathrm{l}$ de Nafion ( $5 \%$ p/p) y $2 \mathrm{ml}$ de agua Milli-Q. Se llevó 
al sonicador durante 20 minutos para luego tomar una alícuota de $50 \mu \mathrm{l}$ y aplicarla sobre el disco de Au, el cual fue calentado previamente sobre una placa calefactora. Una vez que el solvente se evaporó completamente, se colocó sobre el catalizador $95 \mu 1$ de una solución diluida de Nafion (la solución $5 \%$ p/p comercial se diluyó en $20 \mathrm{ml}$ de metanol). La razón de efectuar este último paso se basa en que luego de la evaporación del solvente se forma una película de Nafion sobre el catalizador que le confiere resistencia mecánica al electrodo. Este es un paso muy importante, especialmente cuando se realizan los experimentos de FTIR, porque la superficie del electrodo se coloca en contacto con la ventana óptica de $\mathrm{CaF}_{2}$ y el rozamiento entre estos elementos, a la hora de elegir la mejor posición del ET, podría llegar a desprender parte del catalizador.

Es importante señalar que finalizando los experimentos se encontró una manera de obtener mejores depósitos del catalizador sobre el disco de Au. Ésta consiste en formar la tinta de catalizador, colocando las NPs soportadas en un vaso conteniendo solamente isopropanol. Como se mencionó antes, en este trabajo se utilizó una mezcla de agua y Nafion, pero se encontró que con el empleo de isopropanol se logra una mejor dispersión de los diferentes catalizadores, tanto en la tinta como sobre el disco. El agregado de Nafion al agua se realizó para facilitar la formación de la tinta, puesto que utilizando sólo agua, con algunos catalizadores no se lograba romper aglomerados de carbón, principalmente con NTCM. Por otro lado, el isopropanol es mucho más volátil que el agua, lo cual facilita su evaporación originando mayor agitación térmica en la superficie del disco y por lo tanto una mejor dispersión del catalizador en toda la superficie del disco de Au. 


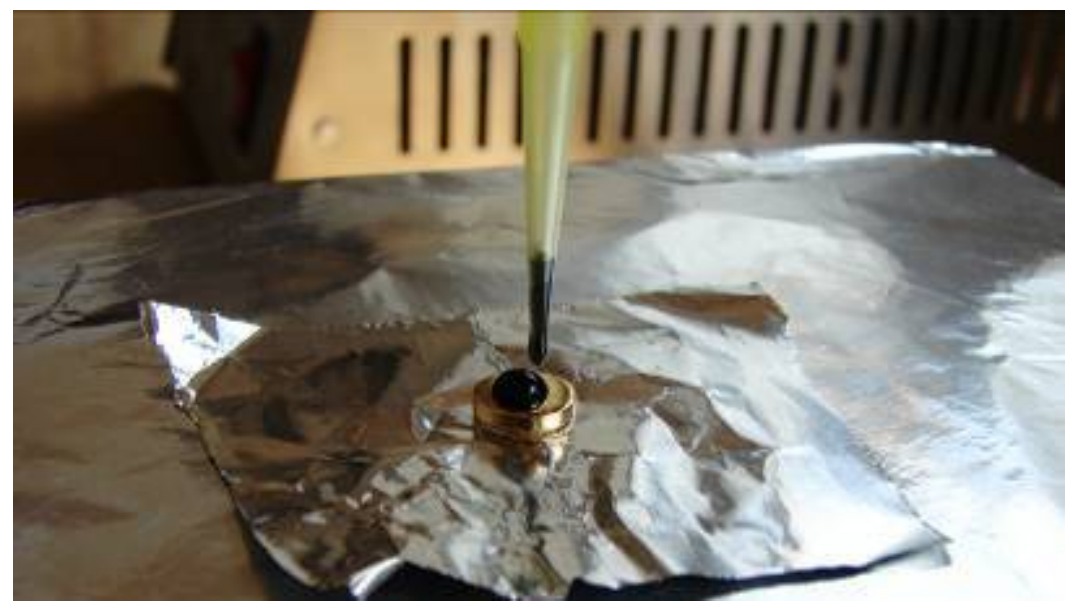

Figura 5.3: Depósito de la tinta de catalizador sobre un electrodo de disco de Au.

\subsubsection{Experimentos de FTIR-in situ}

Los experimentos fueron llevados a cabo con un potenciostato AUTOLAB (Modelo PGSTAT 128N) acoplado a un espectrómetro BOMEM, Modelo 100, con un banco óptico especialmente diseñado para esta aplicación. La celda utilizada para estos experimentos se muestra en la Figura 5.4. Es una celda convencional de tres electrodos, que no tiene fondo pero en su parte inferior posee una rosca en la que se coloca una pieza de plástico que contiene una ventana de $\mathrm{CaF}_{2}$ a través de la cual pasa el rayo de luz IR.

Los espectros de reflectancia fueron calculados como el cociente $\left(R / R_{0}\right)$, donde $R$ es el espectro de la muestra y $R_{0}$ es el espectro de referencia. Las bandas positivas (hacia abajo) y las negativas (hacia arriba) representan la generación y el consumo de las especies al potencial aplicado. Cada espectro es obtenido tomando un promedio de 50 interferogramas, es decir, 50 barridos de longitudes de onda. La resolución espectral elegida fue de $8 \mathrm{~cm}^{-1}$. 


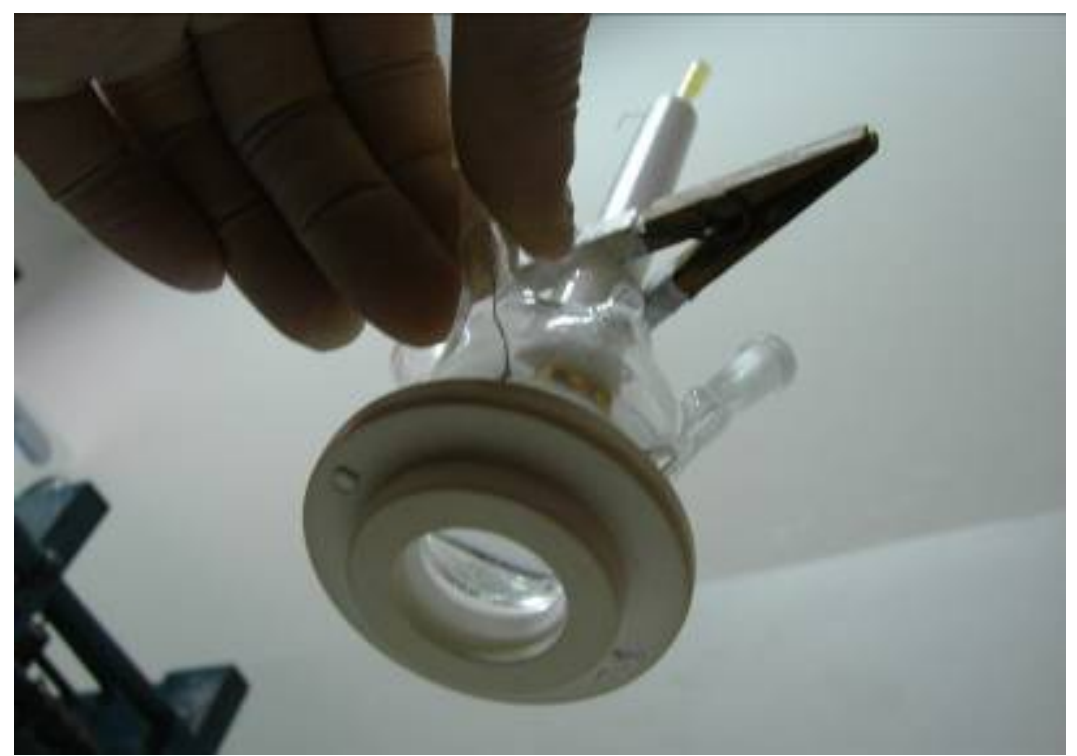

Figura 5.4: Celda electroquímica utilizada para realizar los experimentos de FTIR-in situ, donde puede observarse la ventana de $\mathrm{CaF}_{2}$ montada en el fondo de la celda y el disco de oro en el extremo de la pieza cilindrica de teflón.

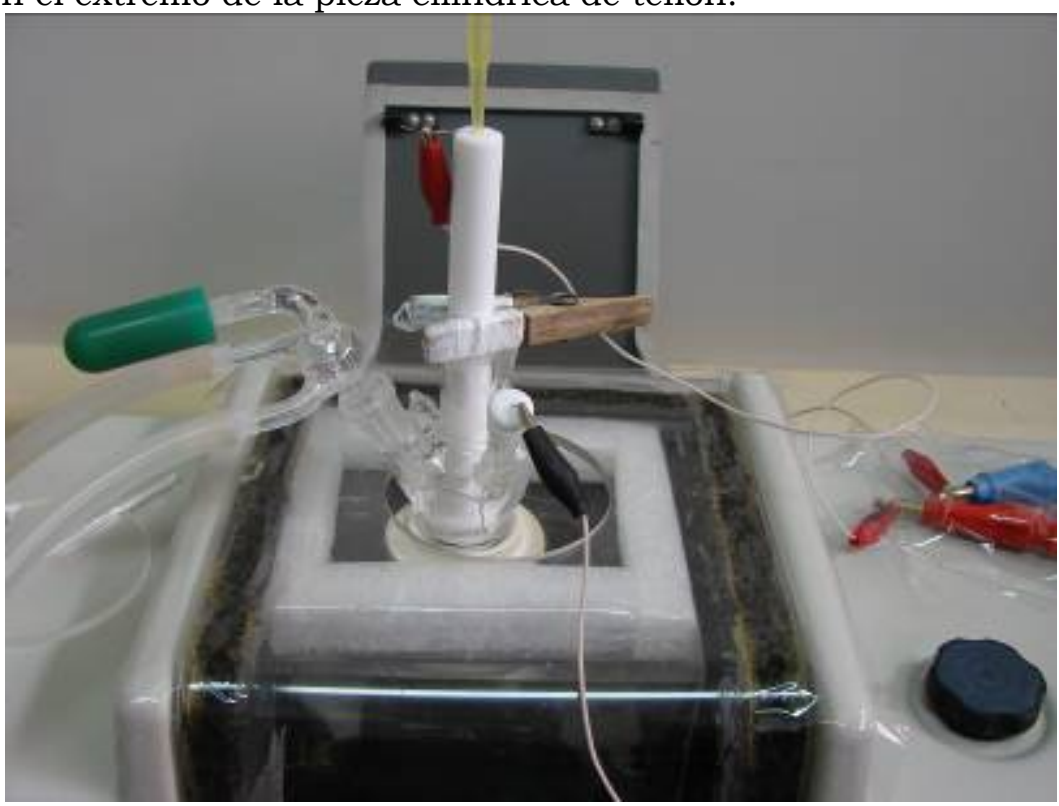

Figura 5.5: Celda electroquímica montada sobre el banco óptico en el espectrómetro Bomem (Hartmann \& Braun), modelo MB-100.

\subsubsection{Caracterización de los materiales}

Con el objetivo de determinar la relación atómica entre los metales de las NPs trimetálicas fueron realizadas medidas de EDX con un espectrómetro THERMO Noran (system six) con detector de SiLi y un barrido de energías desde 0,1 hasta $20 \mathrm{KeV}$.

Se utilizó la técnica de difracción de rayos X (DRX). Los espectros de difracción fueron obtenidos con un difractómetro Miniflex II modelo Rigaku, usando $\mathrm{Cu} \mathrm{K}_{\alpha}(\lambda=0,15406 \mathrm{~nm})$. La resolución angular en 
barridos de $2 \theta$ fue $0,05^{\circ}$. El barrido angular comprendió desde $20^{\circ}$ hasta $90^{\circ}$ y la velocidad de barrido fue de $1,5^{\circ} \mathrm{min}^{-1}$.

Las imágenes de los catalizadores fueron obtenidas con un Microscopio de Trasmisión Electrónica (TEM) Carl Zeiss CEM 902 con una cámara Proscan high-speed slow-scan CCD. La distribución de tamaño de partículas fue determinada con el programa AxioVs40 V 4.8.2.0 Software. 


\subsection{Resultados y Discusión}

\subsubsection{Caracterización física y electrocatálisis}

Fueron obtenidos espectros de EDX utilizando tres regiones diferentes de cada muestra (Catalizadores 1 y 2). Los resultados se encuentran resumidos en la Tabla 5.2. Como puede ser observado, las incertidumbres en las medidas son muy pequeñas, a excepción de la medida en el porcentaje de $\mathrm{Rh}$ en el Catalizador 1 donde el error cuadrático de Gauss alcanza un 14\% del valor medido.

\begin{tabular}{|l|c|c|c|c|}
\hline & Pt & Sn & Ru & Rh \\
\hline Catalizador 1 & $61+/-1$ & $32+/-1$ & & $7+/-1$ \\
\hline Catalizador 2 & $61,5+/-0,4$ & & $20,2+/-0,4$ & $18,3+/-0,7$ \\
\hline
\end{tabular}

Tabla 5.2: Composiciones atómicas porcentuales para los diferentes metales que componen los dos tipos de NPs trimetálicas obtenidas en este trabajo.

En la Figura 5.6 se muestran los difractogramas de los catalizadores Pt-V, $\mathrm{Pt}_{61} \mathrm{Sn}_{32} \mathrm{Rh}_{7}-\mathrm{V}$ y $\mathrm{Pt}_{61,5} \mathrm{Ru}_{20,2} \mathrm{Rh}_{18,3}-\mathrm{V}$. Los resultados obtenidos para Pt-Ch y Pt-NTCM son similares a los de Pt-V. En todos los difractogramas el pico ancho observado entre $20-30^{\circ}$ es debido al plano (002) de la estructura hexagonal del carbón. Los picos de difracción a $39^{\circ}, 46^{\circ}, 67^{\circ}$ y $82^{\circ}$ son debidos a los planos (111), (200), (220) y (311), respectivamente, de la estructura típica cúbica centrada en las caras (fcc) del Pt. Para el catalizador conteniendo Sn, es posible observar los picos (101) y (211) correspondientes al $\mathrm{SnO}_{2}$. 


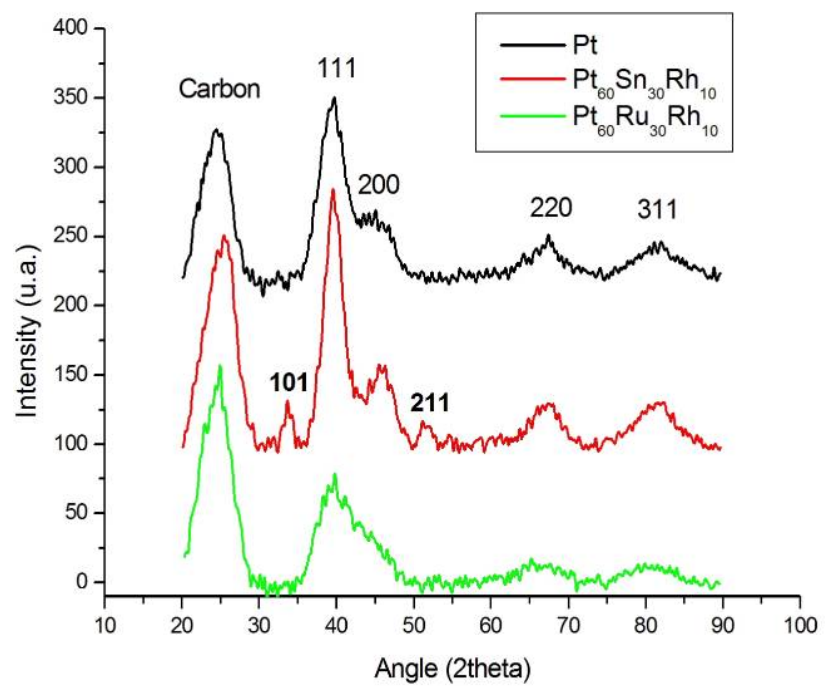

Figura 5.6: Espectro de DRX.

Las imágenes obtenidas con TEM son las típicas para estos catalizadores formados por NPs soportadas. Las de alta magnificación permiten concluir que se obtuvieron NPs bien dispersas sobre la superficie de los carbones, con sectores de mínima aglomeración. En la Figura 5.7 se muestran los catalizadores Pt-V (A), Pt-NTCM (B, C y D) y $\mathrm{Pt}-\mathrm{Ch}(\mathrm{E})$. Las imágenes obtenidas con las aleaciones son idénticas a las de Pt-V.
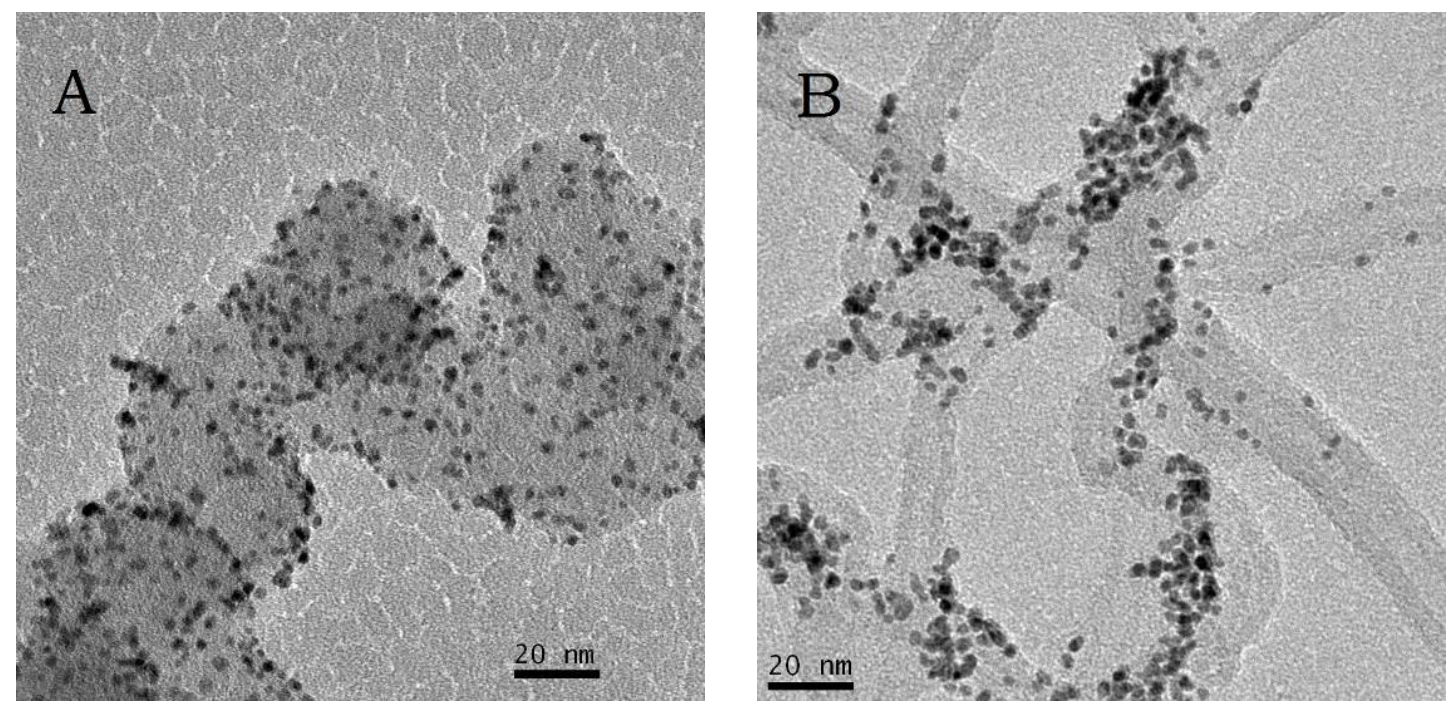


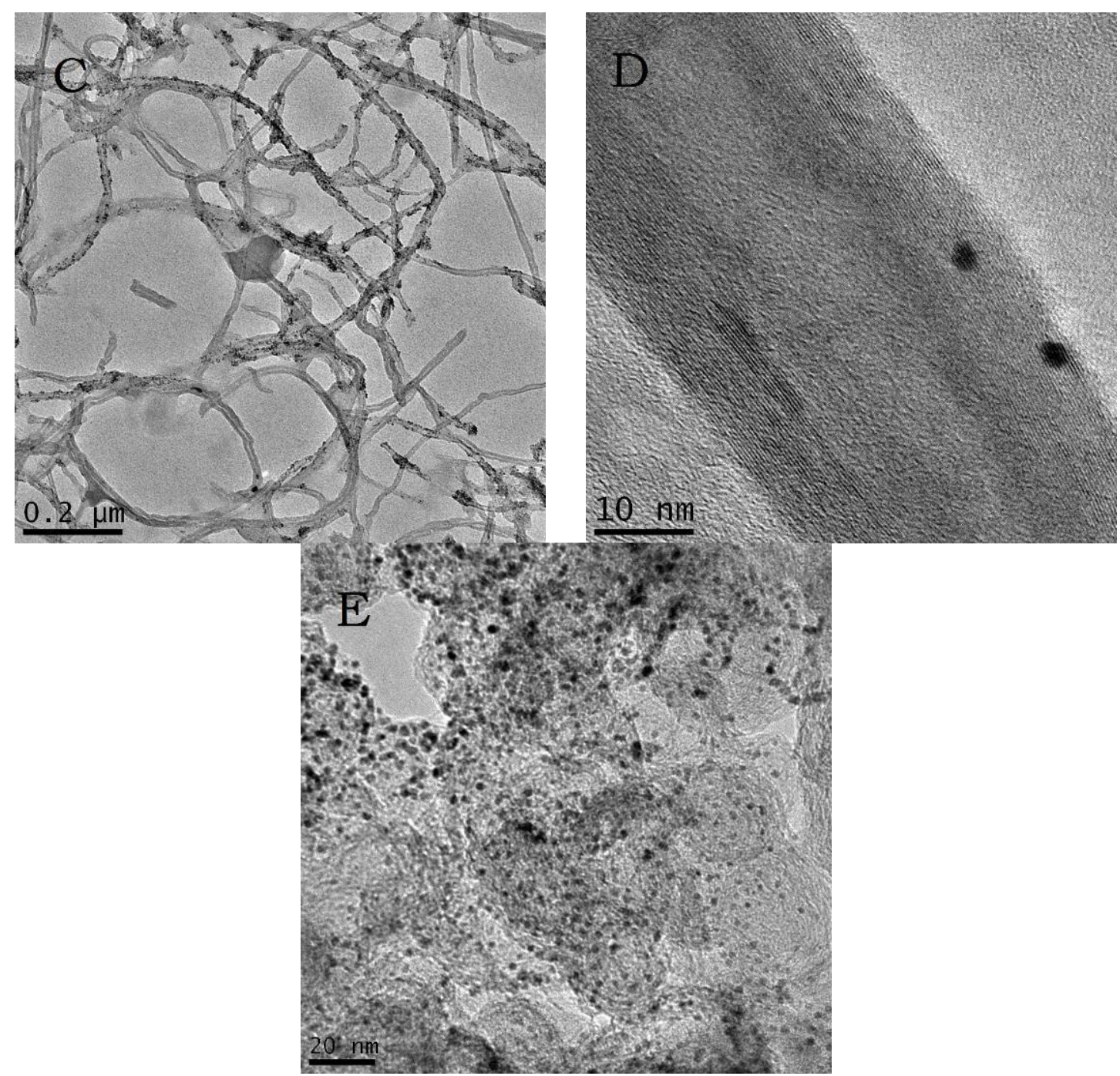

Figura 5.7: Imágenes de TEM para: (A) Pt-V; (B), (C) y (D) Pt-NTCM; (E) Pt-Ch.

Si bien la calidad de las imágenes es muy buena, se hace dificil obtener la distribución de tamaños de forma automática utilizando el software sin tener que medir las NPs una por una.

En la Tabla 5.3 se muestra el tamaño medio de las NPs determinado utilizando las imágenes de TEM, midiendo alrededor de 50 NPs una por una. Las pequeñas desviaciones estándar permiten concluir que las NPs son monodispersas, es decir, todas tienen un tamaño que se desvía muy poco del valor medio medido. Asimismo, en la Figura 5.8 se muestra la distribución de tamaño de partículas para Pt-NT obtenida contando 223 NPs. 


\begin{tabular}{|c|r|}
\hline NPs & TEM $(\mathbf{n} \boldsymbol{m})$ \\
\hline $\mathrm{Pt}-\mathrm{V}$ & $2,7+/-0,1$ \\
\hline $\mathrm{Pt}-\mathrm{NT}$ & $2,7+/-0,1$ \\
\hline $\mathrm{Pt}-\mathrm{Ch}$ & $2,33+/-0,07$ \\
\hline $\mathrm{Pt}_{61} \mathrm{Sn}_{32} \mathrm{Rh}_{7}-\mathrm{V}$ & $2,77+/-0,04$ \\
\hline $\mathrm{Pt}_{61,5} \mathrm{Ru}_{20,2} \mathrm{Rh}_{18,3}-\mathrm{V}$ & $2,33+/-0,03$ \\
\hline
\end{tabular}

Tabla 5.3: Tamaño de NPs medidas utilizando imágenes de TEM

El tamaño de los dominios cristalinos obtenidos utilizando la fórmula de Scherrer no es informado en este trabajo debido a que la calidad de los espectros no permite realizar ajustes suficientemente buenos. Además, la realización de los cálculos utilizando diferentes picos del difractograma arroja resultados muy disímiles, lo cual es otro indicativo del problema mencionado. Los cálculos obtenidos mediante el ajuste del pico (220) genera valores marcadamente inferiores que los obtenidos por TEM, por lo cual, si los resultados fuesen confiables, nos llevarian a concluir que podemos estar en presencia de policristales, hecho que no es esperable para NPs de Pt sintetizadas mediante esta técnica.

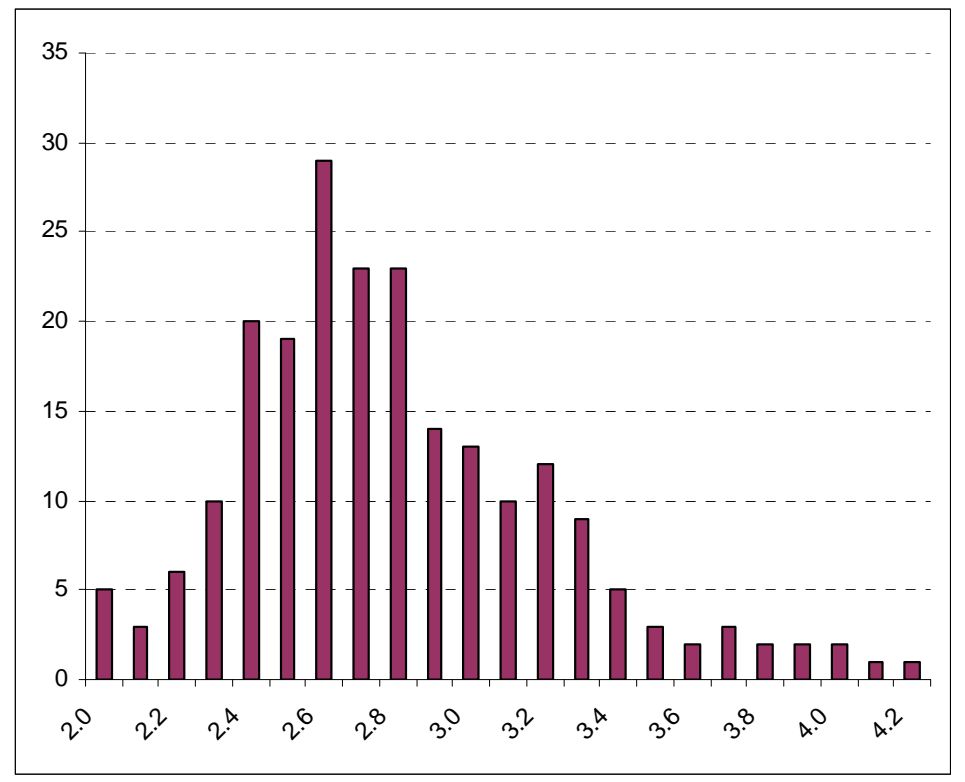

Figura 5.8: Distribución de tamaños para las NPs de Pt-NT. 


\subsubsection{Resultados electroquímicos}

Todos los voltamperogramas fueron realizados a una velocidad de barrido de $5.10^{-3} \mathrm{Vs}^{-1}$. En primera instancia se realizaron voltamperogramas en solución $0,01 \mathrm{M}$ de $\mathrm{HClO}_{4}(\mathrm{pH}=2)$ para verificar el buen estado del sistema (Figuras 5.9 y 5.10), en especial del electrodo de trabajo. El potencial de comienzo de los barridos fue 0,05V. El ET se mantuvo a este potencial mientras se burbujeó la solución con $\mathrm{N}_{2}$. El límite superior de potencial, $\mathrm{E}_{\mathrm{s}}$, se varió según la composición de los catalizadores utilizados, de modo de prevenir la disolución del Sn y el $\mathrm{Ru}$. Así, $\mathrm{E}_{\mathrm{s}}$, se fijó en 1,50V para el catalizador conteniendo sólo Pt; en $1,10 \mathrm{~V}$ para el de Sn y en 1,00V para el de Ru.

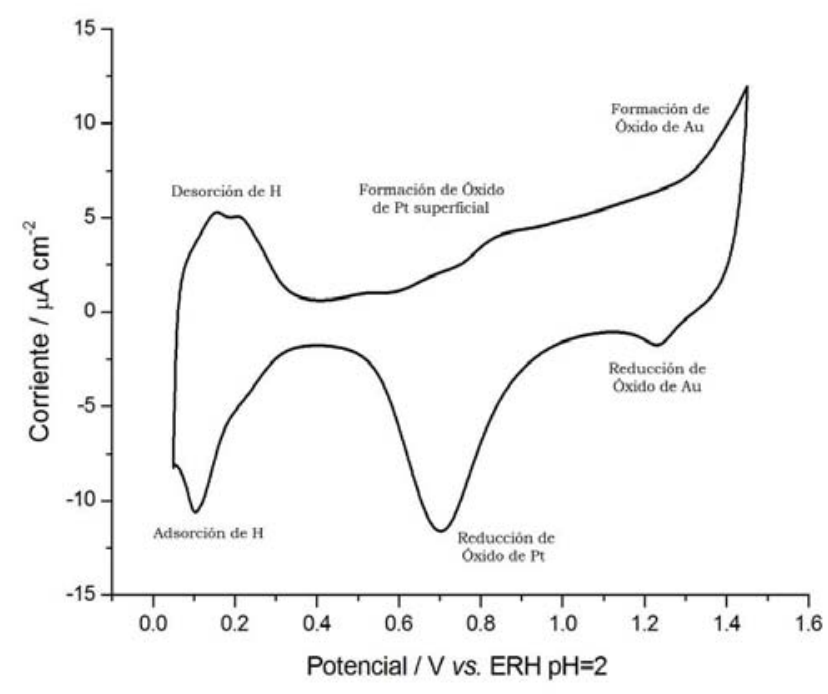

Figura 5.9: Voltamperograma realizado con $\mathrm{Pt}-\mathrm{V} . \mathrm{HClO}_{4}$ 0,01M. v=5.10-3 $\mathrm{Vs}^{-1}$.

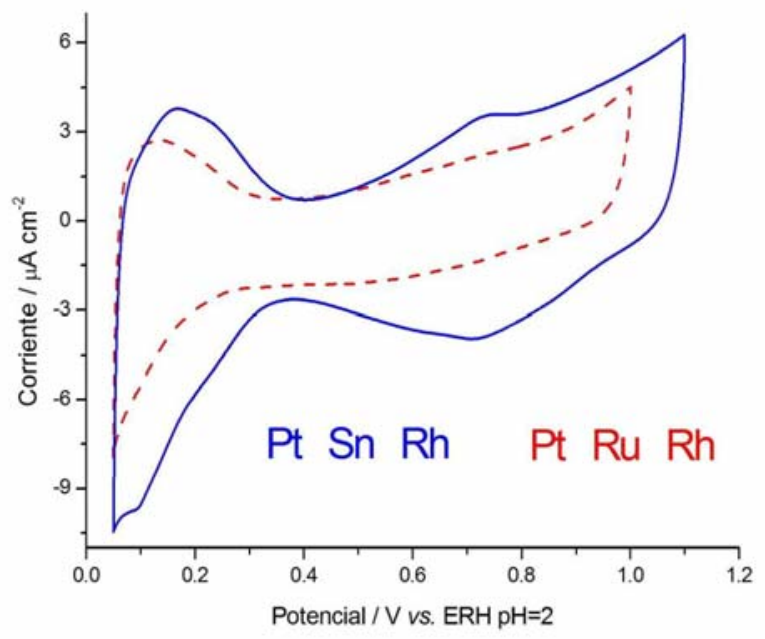

Figura 5.10: Voltamperogramas realizados en solución $0,01 \mathrm{M}$ de $\mathrm{HClO}_{4}$. v=5.10-3 $\mathrm{Vs}^{-1}$. 
Luego de haber obtenido el voltamperograma de cada electrodo estudiado se realizaba el cálculo de su área efectiva, esto es, el área del electrodo sobre la cual el glicerol puede ser oxidado. La cantidad de catalizador que se colocaba sobre el electrodo de $\mathrm{Au}$, no pudo ser controlada de una manera como para que las medidas electroquímicas pudieran ser comparadas directamente teniendo en cuenta las corrientes observadas. Este hecho determina que sea necesario tener una medida de la cantidad de material activo agregado. En electrocatálisis, generalmente se mide el área activa del catalizador.

Un método muy utilizado para algunas NPs metálicas consiste en exponer el electrodo a monóxido de carbono durante un tiempo suficiente como para saturar la superficie metálica con ese gas; luego se realiza la oxidación de $\mathrm{CO}$ a $\mathrm{CO}_{2}$ y se mide la carga que circuló entre los electrodos. La carga está relacionada con los moles de CO que se oxidaron; como se conoce el área que ocupa $1 \mathrm{~mol}$ de $\mathrm{CO}$ en la superficie de dicho material, es posible determinar el área total del catalizador.

Para realizar esta medida se colocó el ET a 0,05V y se burbujeó la solución con $\mathrm{N}_{2}$ durante 15 minutos, luego se introdujo CO durante 5 minutos para permitir la adsorción de esta molécula en todos los sitios activos del catalizador. Posteriormente se volvió a burbujear $\mathrm{N}_{2}$ durante 8 minutos para retirar el exceso de $\mathrm{CO}$ de la solución. Por último se retiró el $\mathrm{N}_{2}$ y se realizaron dos voltamperogramas sucesivos entre $0,05 \mathrm{~V}<\mathrm{E}<\mathrm{E}_{\mathrm{s}}$. Como fuera señalado anteriormente, el valor de $\mathrm{E}_{\mathrm{s}}$ varía con la naturaleza de los metales utilizados. En la Figura 5.11 se observa una de estas medidas. El área rayada muestra la diferencia entre el primero y el segundo barrido debida a la oxidación de CO; ésta es igual a la carga de electrones involucrada en la reacción electroquímica. Luego, sabiendo que el paso de $420 \mu \mathrm{C}$ de carga equivale a una cantidad de $\mathrm{CO}$ que ocupa una superficie de $1 \mathrm{~cm}^{2}$, es posible obtener el área activa del electrodo. 


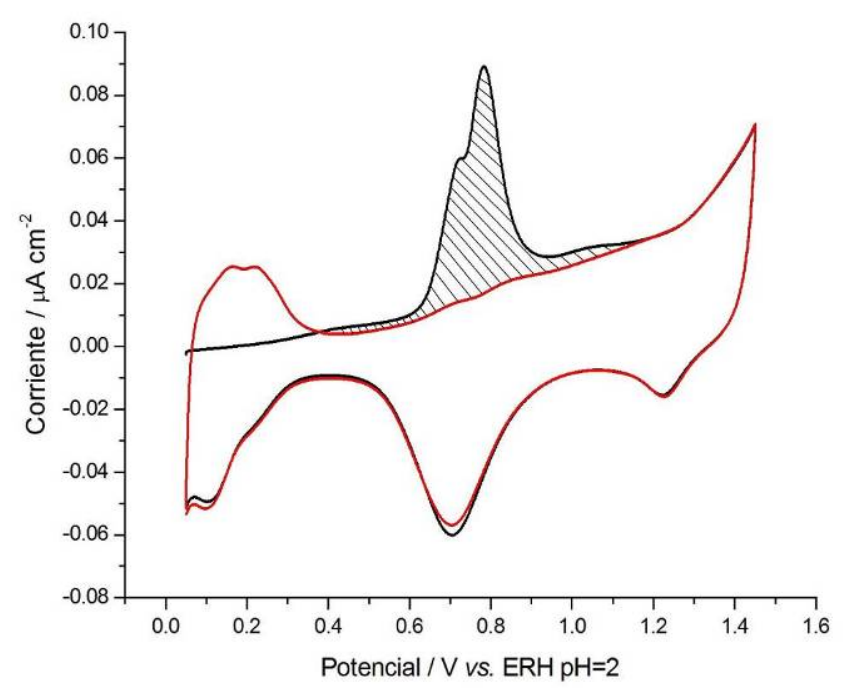

Figura 5.11: Stripping de $\mathrm{CO}$ en solución $0,01 \mathrm{M}$ de $\mathrm{HClO}_{4} \cdot \mathrm{v}=5 \cdot 10^{-3} \mathrm{Vs}^{-1}$.

Una diferencia interesante entre el primero (negro) y el segundo (rojo) ciclo es la región de desorción de $\mathrm{H}(0,05 \mathrm{~V}<\mathrm{E}<0,35 \mathrm{~V})$. Como podemos percibir, en el primer ciclo no se observan los picos de desorción del $\mathrm{H}$ que debió adsorberse cuando el electrodo se mantuvo a 0,05V, lo cual se debe a que la superficie de Pt estaba bloqueada por la adsorción de CO. En cambio, en el segundo ciclo, cuando el $\mathrm{CO}$ fue oxidado completamente, al final del barrido negativo se produce la adsorción de $\mathrm{H}$ con la correspondiente desorción reversible al comienzo del barrido positivo.

En la Figura 5.12 se muestran voltamperogramas realizados con Pt-V, $\mathrm{Pt}_{61} \mathrm{Sn}_{32} \mathrm{Rh}_{7}-\mathrm{V}$ y $\mathrm{Pt}_{61,5} \mathrm{Ru}_{20,2} \mathrm{Rh}_{18,3}-\mathrm{V}$ realizados en solución de glicerol $1 \mathrm{M}$ y $\mathrm{HClO}_{4}$ 0,01M. El efecto del soporte de carbono es despreciable en el perfil observado, por consiguiente, los voltamperogramas obtenidos con Pt-NTCM y Pt-Ch son similares a los de Pt-V. 


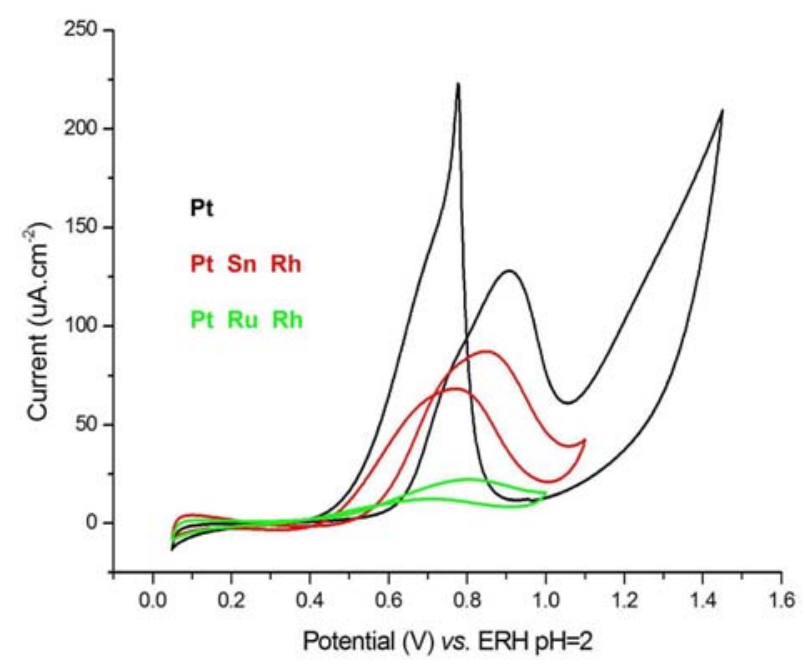

Figura 5.12: Voltamperogramas en solución de $\mathrm{HClO}_{4} 0,01 \mathrm{M}+$ glicerol $1 \mathrm{M}$. $\mathrm{v}=5.10^{-3} \mathrm{Vs}^{-1}$.

A continuación se describe el voltamperograma realizado sólo con NPs de Pt. El barrido de potencial en sentido positivo muestra un pico de oxidación muy pequeño en $0,30 \mathrm{~V}$ en el primer ciclo, pero el voltamperograma que se muestra en la figura corresponde al tercero. En estas condiciones es imposible observarlo pues el electrodo posee adsorbatos en su superficie y por lo tanto la adsorción disociativa del alcohol es muy baja. Por otra parte, se definen dos picos solapados mucho mayores que este último. La corriente comienza a incrementarse muy lentamente a potenciales mayores que $0,30 \mathrm{~V}$; desde $0,50 \mathrm{~V}$ se incrementa un poco más notoriamente para dispararse definitivamente en los 0,60V, alcanzando el máximo de corriente en 0,90V. Luego comienza a caer hasta llegar a $1,00 \mathrm{~V}$, potencial en el cual se produce un abrupto y continuo incremento de corriente hasta el final del barrido en sentido positivo. En $\mathrm{E}_{\mathrm{s}}=1,45 \mathrm{~V}$ se invierte la dirección del barrido. Durante este paso, en alrededor de $0,90 \mathrm{~V}$ se observa un pico de oxidación típico debido a la reactivación de la superficie del electrodo. Por encima de este potencial, la competencia por la superficie de Pt entre el alcohol y el agua es totalmente favorable a esta última. A potenciales por debajo de $0,9 \mathrm{~V}$, el glicerol puede ser readsorbido sobre los sitios activos del Pt generando el pico de oxidación que se observa en el barrido hacia potenciales negativos. 
Una cuidadosa inspección del barrido positivo nos permite concluir que existen al menos cuatro vías de reacción en la ventana de potenciales explorada. La menos importante en términos de cantidad de carga aportada está relacionada al pequeño pico de oxidación alrededor de los 0,30V; las otras dos se deducen de la presencia de los picos solapados a 0,90V y la última surge del aumento continuo de la corriente a potenciales mayores que 1,00V.

En cuanto a las diferencias entre los catalizadores preparados cabe señalar que todos los experimentos realizados con aquellos conteniendo sólo Pt dan resultados muy similares en la localización de los picos, pero con diferencias en las corrientes observadas. Así, los picos de corriente son mayores para el catalizador fabricado con NTCM que para el construido con V. Por su parte, el catalizador construido con Ch mostró corrientes sustancialmente inferiores.

El hecho de que el electrodo conteniendo NTCM sea el que mostró el mejor comportamiento puede ser justificado con los resultados obtenidos en el Capítulo 3, donde se muestra que este material presenta mayor conductividad específica tanto del sólido como del electrolito dentro de sus poros con respecto a V y Ch. Sin embargo, sólo puede ser realizada una comparación estricta únicamente entre los NTCM y V puesto que las NPs de Pt obtenidas sobre Ch poseen una distribución de tamaño un tanto diferente, lo cual puede no afectar los resultados o bien hacerlo en forma positiva o negativa. Como queda claro en un artículo publicado en 2011 por Gilliam y colaboradores [22], los motivos de cómo el tamaño, la forma, los planos cristalinos expuestos en la superficie de las NPs, etc., afectan el desempeño electrocatalítico de éstas, se encuentran muy lejos de ser comprendidos.

Asimismo, al utilizar las aleaciones $\mathrm{Pt}_{61,5} \mathrm{Ru}_{20,2} \mathrm{Rh}_{18,3} \quad \mathrm{y}$ $\mathrm{Pt}_{61} \mathrm{Sn}_{32} \mathrm{Rh}_{7}$ fueron encontrados resultados marcadamente diferentes. Como se observa en el voltamperograma de la Figura 5.12, tanto los picos de corriente como los potenciales en los que éstos se definen, son muy diferentes a los medidos sólo con Pt. El mayor pico de oxidación en el barrido en sentido positivo comienza en $0,20 \mathrm{~V}$ y $0,34 \mathrm{~V}$ para las 
aleaciones conteniendo $\mathrm{Ru}$ y $\mathrm{Sn}$, respectivamente, mientras que la corriente comienza a incrementarse hasta el final del barrido positivo en 0,90V para ambos catalizadores. Este corrimiento de los picos de oxidación muestra cómo las oxidaciones son cinéticamente favorecidas en las aleaciones con respecto al comportamiento exhibido en Pt puro. Sin embargo, la cantidad de carga involucrada en los voltamperogramas es completamente diferente. Así, como puede observarse en la Figura 5.12, la oxidación de glicerol ocurre en una extensión mucho mayor con el catalizador conteniendo NPs de Pt. Las corrientes registradas cuando se utilizaron NPs conteniendo Sn son menores que las registradas para Pt a potenciales mayores que $0,75 \mathrm{~V}$. Por último, las corrientes medidas en presencia de Ru son muy bajas en toda la ventana de potencial, por lo cual, la carga y por lo tanto la extensión de la reacción de oxidación es baja para este material.

Estos resultados concuerdan al menos cualitativamente con los obtenidos con otros alcoholes, como fue señalado en la introducción de este capítulo. Tanto el $\mathrm{Sn}$ como el $\mathrm{Ru}$ generan especies oxigenadas a menores potenciales que el $\mathrm{Pt}$, produciendo un adelanto en los potenciales de oxidación de los alcoholes. Además, el catalizador conteniendo $\mathrm{Ru}$ presenta una proporción de $\mathrm{Rh}$ similar a la de $\mathrm{Ru}$, y del orden del $20 \%$, lo cual, como fue adelantado anteriormente genera un efecto negativo en la electrocatálisis de este tipo de NPs.

En la Figura 5.13 se muestran las densidades de corriente obtenidas luego de fijar el potencial del electrodo en 0,60V durante 1200 seg. Cuando se comparan los valores de corriente registrados para glicerol con los medidos para la oxidación de etanol o de metanol, debe tenerse en cuenta que en nuestro sistema, estableciendo el potencial en $0,60 \mathrm{~V}$ y la concentración de protones a $0,01 \mathrm{M}(\mathrm{pH}=2)$, se deduce que estas cronoamperometrías fueron realizadas a $0,54 \mathrm{~V} v \mathrm{~s}$. ENH.

Por otra parte, los errores en las medidas se deben a que se emplearon sólo dos electrodos. Fueron hechas una cantidad muy grande de medidas, pero en un comienzo, luego de realizar los experimentos de $\mathrm{VC}$ el electrodo se lavaba con ácido sulfúrico caliente 
para eliminar las sustancias orgánicas que pudieran haber quedado adheridas en la superficie del electrodo luego de la VC. Lamentablemente, se detectó que este proceso dañaba el electrodo, disminuyendo el contacto entre el carbón y el disco de Au y por lo tanto afectando negativamente en su rendimiento. Todo esto generó que debieran ser descartadas un número importante de medidas, afectando seriamente la desviación estándar de los valores de corriente obtenidos.

Estas medidas permiten concluir que el catalizador construido con NPs de $\mathrm{Pt}_{61} \mathrm{Sn}_{32} \mathrm{Rh}_{7}$ es el que muestra un mejor comportamiento, lo cual, como fue adelantado, coincide cualitativamente con resultados previos. Sin embargo, por tratarse de un alcohol diferente a los estudiados anteriormente, se requieren estudios sistemáticos en los que se varie tanto la composición, es decir, el tipo y la proporción de átomos en las NPs, así como la distribución de tamaños de las NPs para obtener el catalizador más optimizado para la REG.

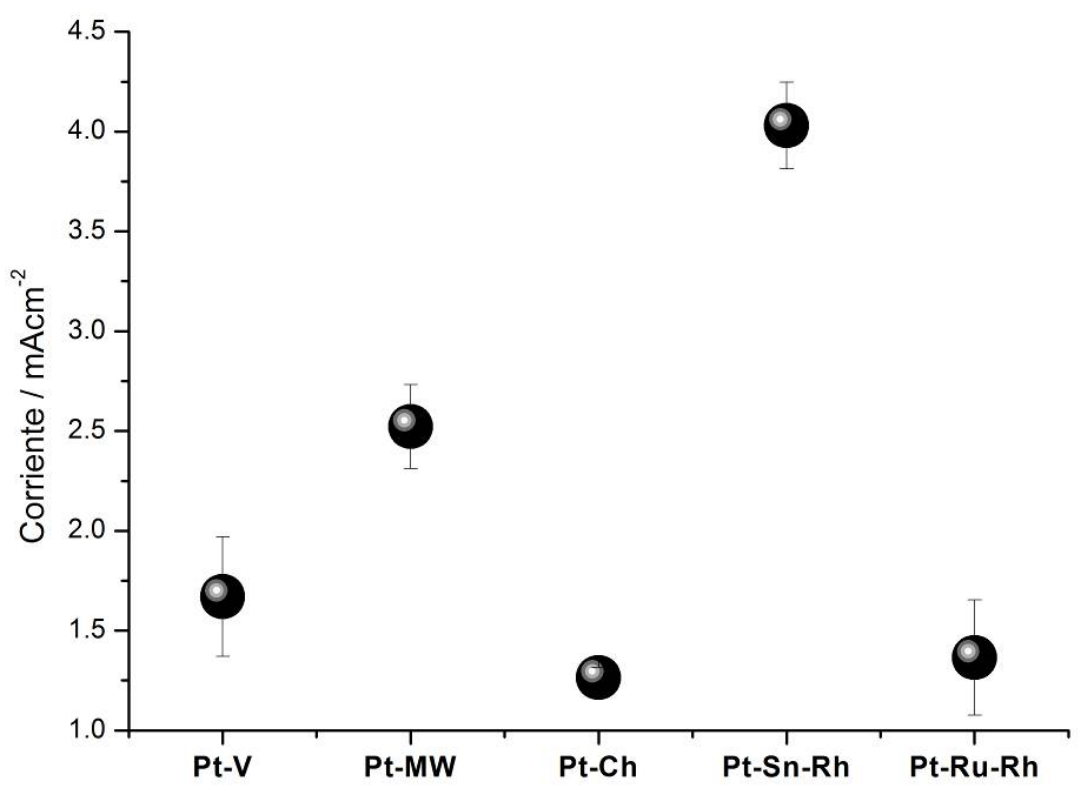

Figura 5.13: Resultados cronoamperométricos para todos los catalizadores ensayados.

\subsubsection{Resultados espectroelectroquímicos}

\subsubsection{Reacción de electrooxidación de CO}

Antes de realizar el análisis de los espectros de FTIR de la REG, es interesante examinar los resultados obtenidos cuando se estudió la oxidación de CO. Esto permitirá entender las características principales 
de los resultados de los catalizadores, así como también determinar la tolerancia a CO. Es conocido que $\mathrm{CO}$ se liga fuertemente al $\mathrm{Pt}$ envenenando el electrodo, por lo cual es un tema muy estudiado en todo el mundo. Así, el objetivo es desarrollar materiales eficientes para ánodos de celdas de combustible tipo PEM que funcionan con $\mathrm{H}_{2}$, el cual habitualmente es generado a partir de sustancias orgánicas y por ende contiene a CO como principal contaminante [23,24].

Para medir el área de los catalizadores se aplicó el procedimiento descrito en la sección anterior (Resultados electroquímicos) con la diferencia que el barrido de potencial en sentido positivo se realizó a $1.10^{-3} \mathrm{Vs}^{-1}$ y además se fueron tomando espectros de IR. El experimento comienza colocando el ET a un potencial de referencia $\mathrm{E}_{\mathrm{r}}=0,05 \mathrm{~V}$ para luego ir tomando espectros a este potencial hasta no registrar variación en los mismos, hecho que indica que el sistema está estabilizado. Este último espectro es tomado como referencia, por lo tanto, aquellos obtenidos en todo el dominio de potenciales seleccionado $\left(E_{n}\right)$ serán resultado de la resta entre el espectro medido y el de referencia. Por lo tanto, la estabilidad requerida no sólo involucra al sistema electroquímico sino que también al interior del banco óptico, el cual debe contener una cantidad constante tanto de $\mathrm{CO}_{2}$ como de $\mathrm{H}_{2} \mathrm{O}$ de la atmósfera. Es aceptado que la oxidación de CO ocurre a través del mecanismo de Langmuir-Hinshelwood (Figura 5.14).

$$
\begin{gathered}
\mathrm{Pt}+\mathrm{H}_{2} \mathrm{O} \rightarrow \mathrm{Pt}-\mathrm{OH}+\mathrm{H}^{+}+\mathrm{e}^{-} \\
\mathrm{Pt}-\mathrm{CO}+\mathrm{Pt}-\mathrm{OH} \rightarrow 2 \mathrm{Pt}+\mathrm{CO}_{2}+\mathrm{H}^{+}+\mathrm{e}^{-}
\end{gathered}
$$
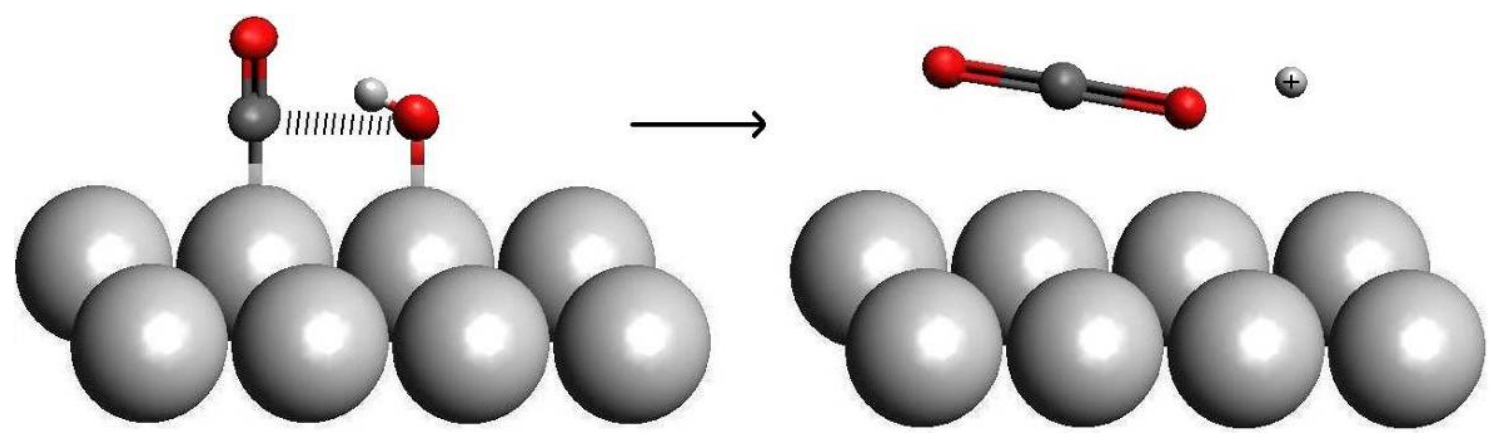

Figura 5.14: Reacción entre especies $\mathrm{Pt}-\mathrm{CO}$ y $\mathrm{Pt}-\mathrm{OH}$. 
En la Figura 5.15 A se muestran los espectros obtenidos para el catalizador Pt-V mientras se varió el potencial del electrodo de trabajo desde $0,05 \mathrm{~V}$ hasta $1,45 \mathrm{~V}$ a una velocidad de barrido de $1.10^{-3} \mathrm{Vs}^{-1}$. En la Figura $5.15 \mathrm{~B}$ se muestra en detalle el desarrollo de la banda de $\mathrm{CO}_{2}$.

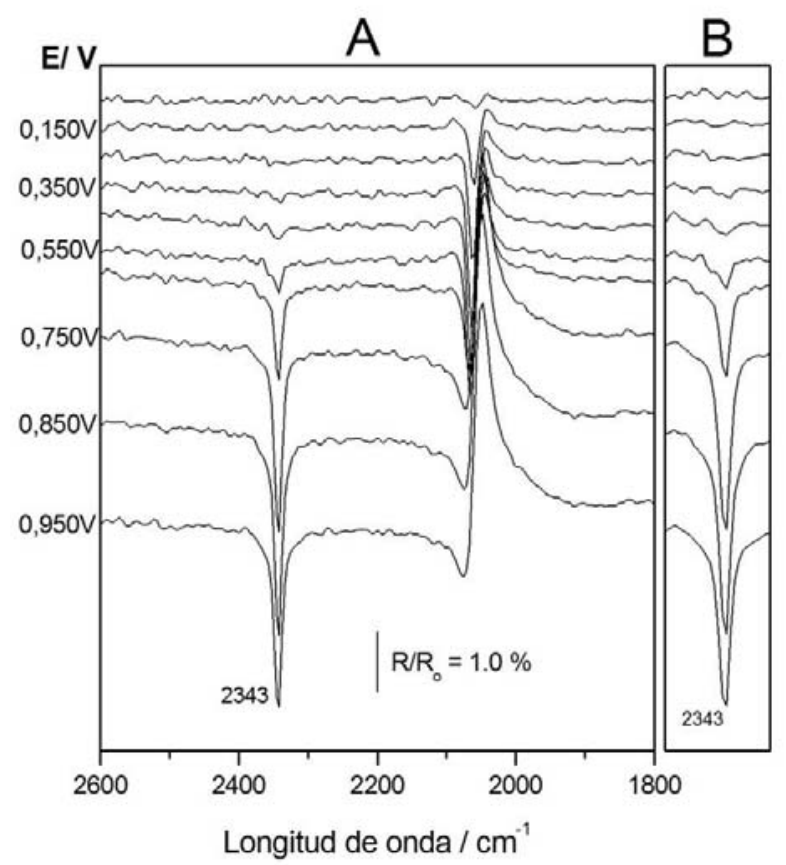

Figura 5.15: (A) Espectros tomados durante el barrido anódico de un experimento de VC a diferentes potenciales; (B) Detalle de la banda de $\mathrm{CO}_{2}$.

Una mirada rápida de la figura muestra que los espectros son bastante más complejos que lo esperado. Sin embargo, cuando a continuación se realiza la asignación de bandas, queda en evidencia la simpleza de estos espectros. Es fundamental tener en cuenta que la banda de CO linealmente adsorbido aparece alrededor de 2040-2060 $\mathrm{cm}^{-1}$, dependiendo, entre otras variables, del tamaño de las NPs [22], mientras que la de $\mathrm{CO}_{2}$ en solución está centrada en $2343 \mathrm{~cm}^{-1}$.

Para $E_{n}=0,10 V$ se observa una banda en alrededor de $2050 \mathrm{~cm}^{-1}$, la cual no se corresponde con la formación de ninguna sustancia porque a este potencial el CO no se desorbe del Pt. Esta banda se debe a que la frecuencia a la cual vibran los adsorbatos en una superficie depende del potencial al que se encuentre la misma. Por lo tanto, a medida que variamos el potencial del electrodo, modificamos la frecuencia a la cual vibran las moléculas de CO. Este efecto, conocido 
como "Efecto Stark", genera la banda de $\mathrm{CO}$ a $0,10 \mathrm{~V}$ que no coincide con la del espectro de referencia y por lo tanto aparece. A medida que el potencial $\mathrm{E}_{\mathrm{n}}$ continúa aumentando, es posible observar una mayor fracción de la banda, lo cual hace que la señal aumente. Por otro lado, puede percibirse cómo, al mismo tiempo, se va generando una banda negativa a $2040 \mathrm{~cm}^{-1}$, que se corresponde con la "desaparición" del CO linealmente adsorbido que vibraba a esta frecuencia a $E_{r}=0,05 \mathrm{~V}$. Alrededor de $0,50 \mathrm{~V}$ puede observarse cómo comienza a crecer la banda de $\mathrm{CO}_{2}$, que se debe claramente a la oxidación de CO. Ésta crece continuamente hasta los $0,80 \mathrm{~V}$, cuando se mantiene constante hasta los $0,90 \mathrm{~V}$ para comenzar a decaer. Debe tenerse en cuenta que el $\mathrm{CO}_{2}$ detectado, es aquél que se mantiene entre la ventana óptica y el electrodo (en realidad, sólo la fracción que se encuentra en el paso del rayo de luz), por lo tanto, a medida que se van generando moléculas, parte de éstas van difundiendo hacia el seno de la solución, no pudiendo ser detectadas. A potenciales mayores que $0,80 \mathrm{~V}$, todo el $\mathrm{CO}$ ha sido oxidado y la disminución de la señal de $\mathrm{CO}_{2}$ se debe a la difusión de éste hacia el seno de la solución. Todos estos resultados espectroscópicos están de acuerdo con el voltamperograma mostrado en la Figura 5.12, esto es, tanto el potencial al cual comienza como al que termina la reacción.

El potencial al cual comienza la oxidación de $\mathrm{CO}$ no debe sorprender, puesto que es necesaria la presencia de especies $\mathrm{Pt}-\mathrm{OH}$ y a potenciales mayores que $0,55 \mathrm{~V}$ comienza la adsorción de agua sobre la superficie de Pt para formar especies $\mathrm{Pt}-\mathrm{OH}$, alcanzando aproximadamente en 1,00V la formación de una monocapa de Pt-OH.

Hasta aquí se presentó una descripción cualitativa de los resultados. Una manera de tratar los datos para obtener información más precisa consiste en integrar las bandas observadas, de modo de conocer los valores de absorbancia y graficarlos en función del potencial. En la Figura 5.16 se muestran las absorbancias relativas para $\mathrm{CO}$ y $\mathrm{CO}_{2}$ en función del potencial del ET, donde se puede apreciar 
que estos resultados muestran más claramente la descripción cualitativa de los espectros.

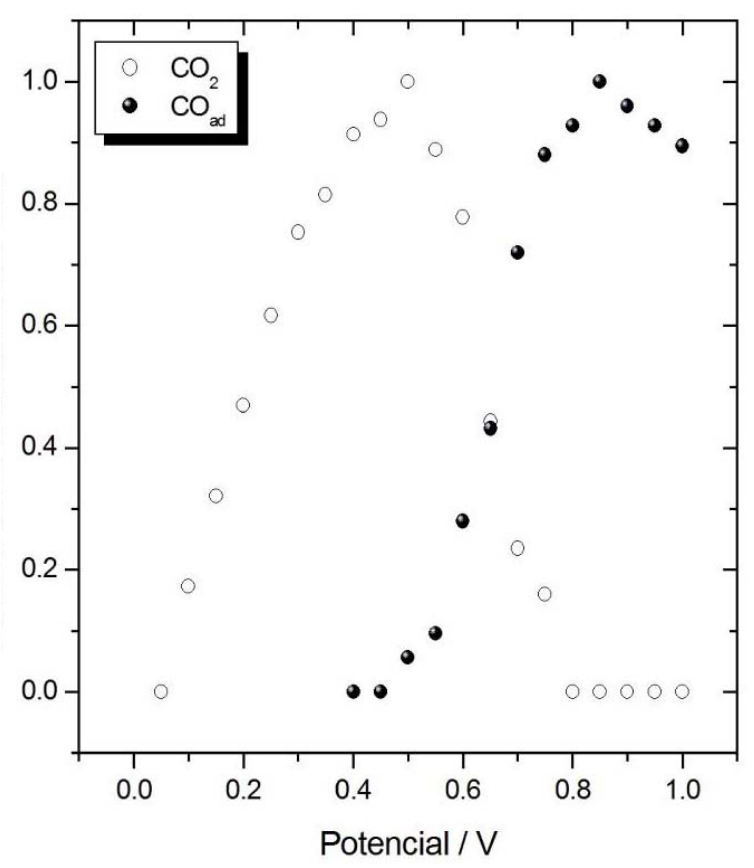

Figura 5.16: Absorbancias integradas para Pt-V.

Los resultados obtenidos con las aleaciones son similares. La diferencia mayor radica en que la oxidación de CO comienza a menores potenciales, debido a que tanto el $\mathrm{Sn}$ como el $\mathrm{Ru}$ consiguen formar especies $\mathrm{M}-\mathrm{OH}$ a potenciales menores que el Pt. De hecho, esta es la característica por la cual fueron escogidos estos metales. En las Figuras 5.17 y 5.18 se muestran cómo varian las absorbancias de las bandas de $\mathrm{CO}$ y $\mathrm{CO}_{2}$ para las dos aleaciones. 


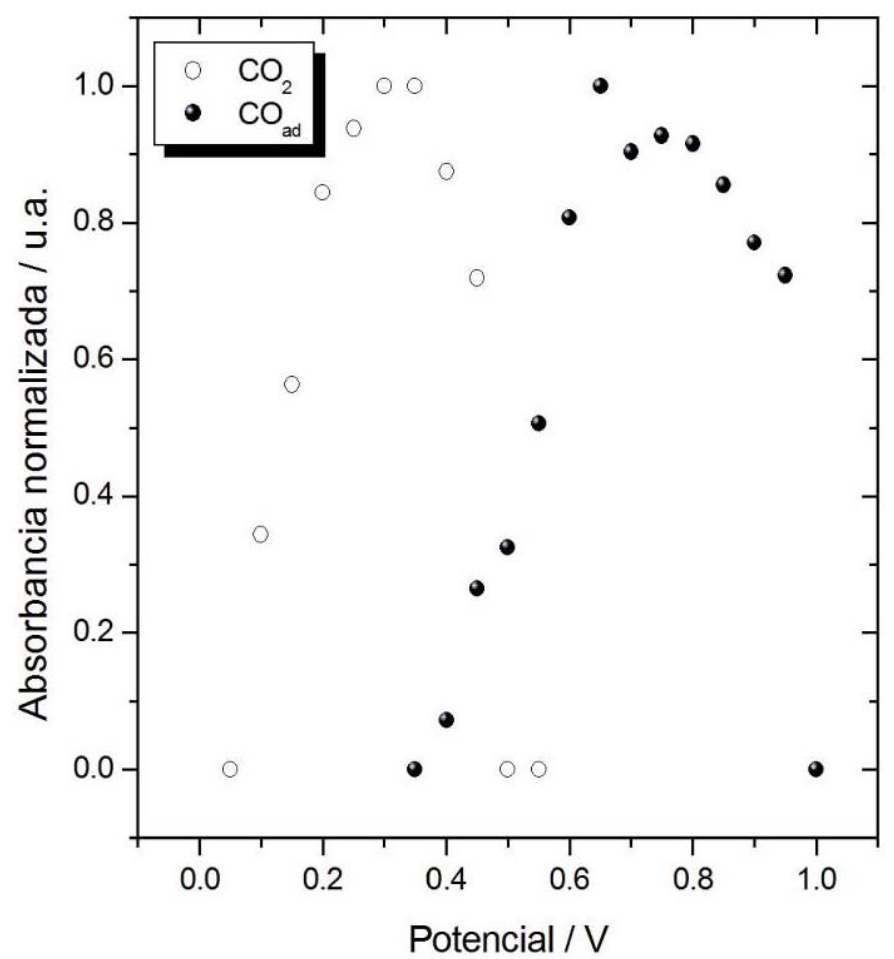

Figura 5.17: Absorbancias integradas para $\mathrm{Pt}_{61,5} \mathrm{Ru}_{20,2} \mathrm{Rh}_{18,3}-\mathrm{V}$.

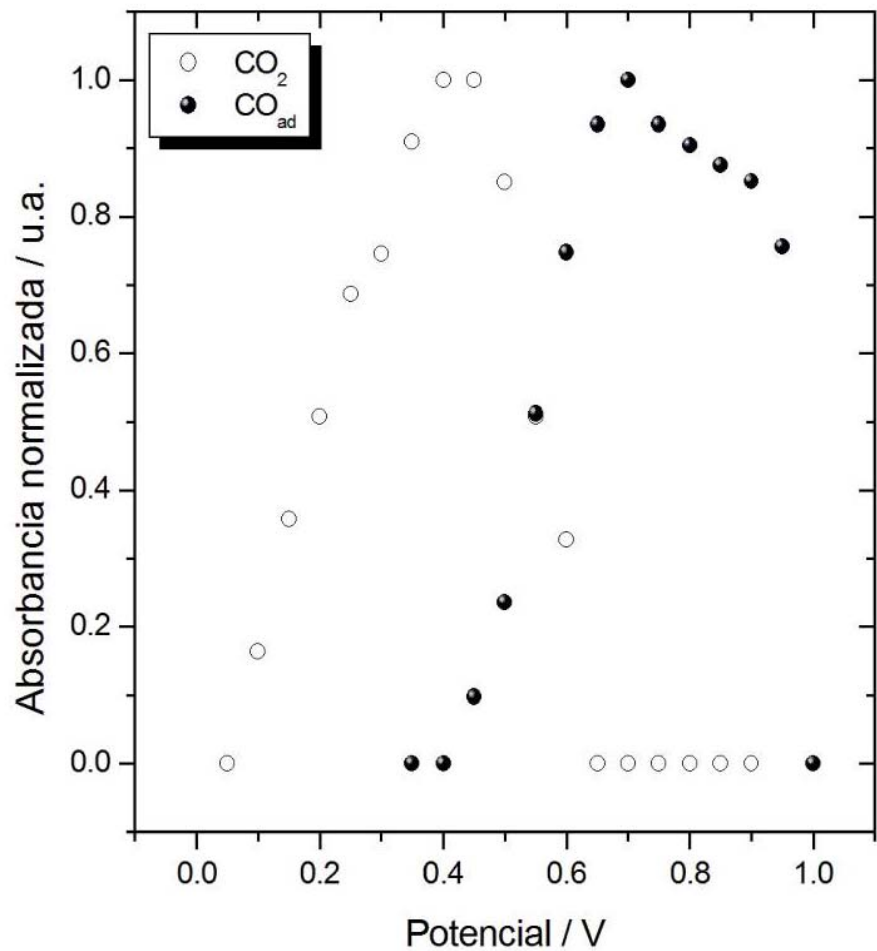

Figura 5.18: Absorbancias integradas para $\mathrm{Pt}_{61} \mathrm{Sn}_{32} \mathrm{Rh}_{7}-\mathrm{V}$. 


\subsubsection{Vías de electrooxidación de glicerol}

La Figura 5.19 A muestra espectros obtenidos durante el barrido de potencial en sentido positivo realizado a $10^{-3} \mathrm{Vs}^{-1}$ en presencia de glicerol y $\mathrm{HClO}_{4}(0,05 \mathrm{~V}<\mathrm{E}<1,45 \mathrm{~V})$, mientras que la Figura $5.19 \mathrm{~B}$ muestra en detalle el desarrollo de la banda de $\mathrm{CO}$, la cual comienza a crecer en $0,30 \mathrm{~V}$ debido a la presencia de $\mathrm{CO}$ linealmente adsorbido $\left(\mathrm{CO}_{\mathrm{ads}}\right)$. El espectro obtenido al final del barrido $\left(\mathrm{E}_{\mathrm{s}}=1,45 \mathrm{~V}\right)$ muestra bandas múltiples centradas en 2343, 2060, 1736, 1630 y $1012 \mathrm{~cm}^{-1}$, y grupos de bandas entre $1200-1400 \mathrm{~cm}^{-1}$ y $1050-1150 \mathrm{~cm}^{-1}$. La relación entre el potencial al cual aparecen las bandas y las sustancias que las generan serán discutidas más adelante.

A

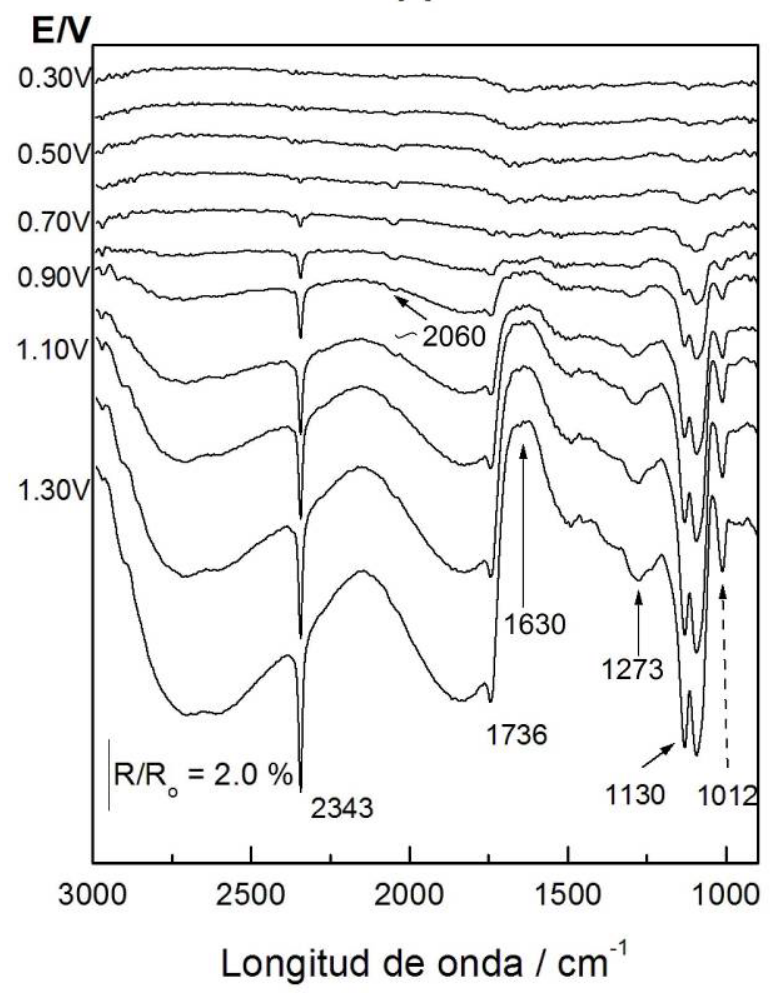

B

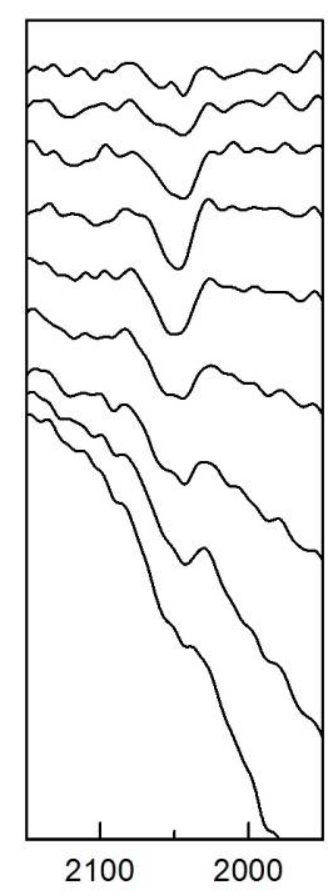

Figura 5.19: Espectros de electrooxidación de glicerol (A) y detalle de la banda de CO (B) para Pt-V.

Con el objetivo de dilucidar las principales vías de reacción y su relación con el potencial aplicado se realiza un examen de la frecuencia, la intensidad y la dependencia de las bandas con el potencial. 


\subsection{La generación de $\mathrm{H}^{+}$}

Durante el barrido de potencial en sentido positivo, se observa un continuo y gran incremento en la intensidad de la banda situada a $1100 \mathrm{~cm}^{-1}$, principalmente a partir de los $0,55 \mathrm{~V}$ y hasta el final del barrido. Esto es debido a que en la superficie del electrodo existe una generación continua de protones como producto de la oxidación total o parcial de glicerol, lo cual genera la migración de iones perclorato (responsable de esta banda) desde el seno de la solución hacia la capa fina ubicada entre la ventana óptica de $\mathrm{CaF}_{2}$ y la superficie del electrodo.

\subsection{La formación de $\mathrm{CO}_{2}$}

Pueden observarse claramente bandas bien establecidas a 2050 y $2343 \mathrm{~cm}^{-1}$, que como fuera antes mencionado, se asocian a la presencia de $\mathrm{CO}_{\text {ads }}$ y $\mathrm{CO}_{2}$ respectivamente. La Figura 5.20 muestra las señales de absorbancia integradas en función del potencial para ambas especies. $\mathrm{El} \mathrm{CO}_{\text {ads }}$ comienza a aparecer en $0,25 \mathrm{~V}$ y la señal crece hasta $0,7 \mathrm{~V}$, coincidiendo con el potencial al cual el $\mathrm{CO}_{2}$ empieza a ser producido. Precisamente en ese potencial el $\mathrm{CO}_{a d s}$ comienza a decrecer abruptamente, como fue observado para otras reacciones de oxidación de compuestos orgánicos $[8,26,27]$. Este comportamiento sugiere que el glicerol se adsorbe sobre la superficie de Pt a través de sus átomos de carbono para producir $\mathrm{CO}_{\text {ads, }}$, el cual se mantiene en la superficie del electrodo hasta que en $0,55 \mathrm{~V}$ se forman especies $\mathrm{Pt}-\mathrm{OH}$, con las cuales se combina para formar $\mathrm{CO}_{2} \mathrm{y} \mathrm{H}^{+}$(Figura 5.14), como fue reportado, entre otros, en los tres trabajos citados anteriormente. Así, el comienzo del pico de corriente percibido en el voltamperograma en $0,55 \mathrm{~V}$ puede ser principalmente atribuido a la generación de $\mathrm{CO}_{2} \mathrm{y} \mathrm{H}^{+}$.

A potenciales mayores, la banda de $\mathrm{CO}_{\text {ads }}$ decrece hasta valores muy bajos en $1,10 \mathrm{~V}$, mientras que la producción de $\mathrm{CO}_{2}$ continúa aumentando de manera persistente hasta convertirse en la banda más importante del espectro. A potenciales superiores que $1,10 \mathrm{~V}$, la superficie de Pt está totalmente cubierta de especies $\mathrm{OH}$ y por ende el 
cubrimiento por $\mathrm{CO}$ es despreciable [28]. Debido a esto, la producción de $\mathrm{CO}_{2}$ no puede ser justificada por la reacción que tiene como intermediario $\mathrm{CO}_{\text {ads }}$.

No obstante, a través del análisis de espectros estándar de productos de oxidación de glicerol en fase líquida, Gomes y TremiliosiFilho sugieren que el $\mathrm{CO}_{a d s}$ no es el único intermediario para la producción de $\mathrm{CO}_{2}$ [10]. Esta proposición podría explicar por qué, el crecimiento de la señal de $\mathrm{CO}_{2}$ no es proporcional en todo el rango de potenciales al decrecimiento de la banda de $\mathrm{CO}_{\text {ads. }}$. Así, es muy posible que el $\mathrm{CO}_{2}$ sea producido, al menos, a través de dos vías diferentes de reacción. La primera, como fue adelantado, previa disociación del glicerol para formar $\mathrm{CO}_{\text {ads }} \mathrm{y}$ otra en la cual el $\mathrm{CO}_{2}$ se produce a través de la ruptura de los enlaces $\mathrm{C}-\mathrm{C}$ del glicerol, pero sin previa formación de $\mathrm{CO}_{a d s}$. Esta segunda vía será discutida más adelante.

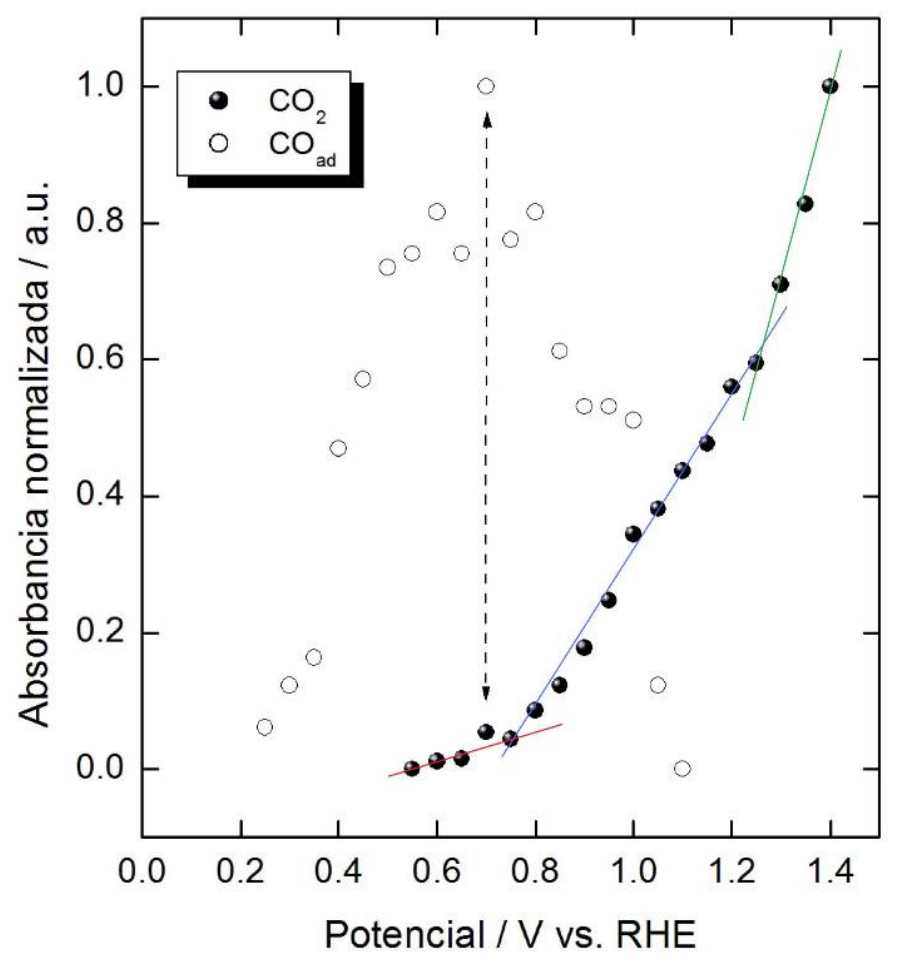

Figura 5.20: Absorbancias integradas para Pt-V en la electrooxidación de glicerol.

\subsection{Las vías de reacción paralelas}

Con el objetivo de facilitar la identificación de los productos de la REG realizamos una comparación entre el espectro que obtuvimos a 
1,3V (a este potencial el glicerol está siendo oxidado a altas velocidades, como puede verse en la Figura 5.12) con espectros correspondientes a los productos de oxidación parcial más probables. En este caso fueron consideradas las sustancias: gliceraldehído, ácido glicérico y ácido tartrónico (Figura 5.21). Los espectros para las sustancias elegidas fueron obtenidos del programa Essential FTIR, version v1.50.282C.

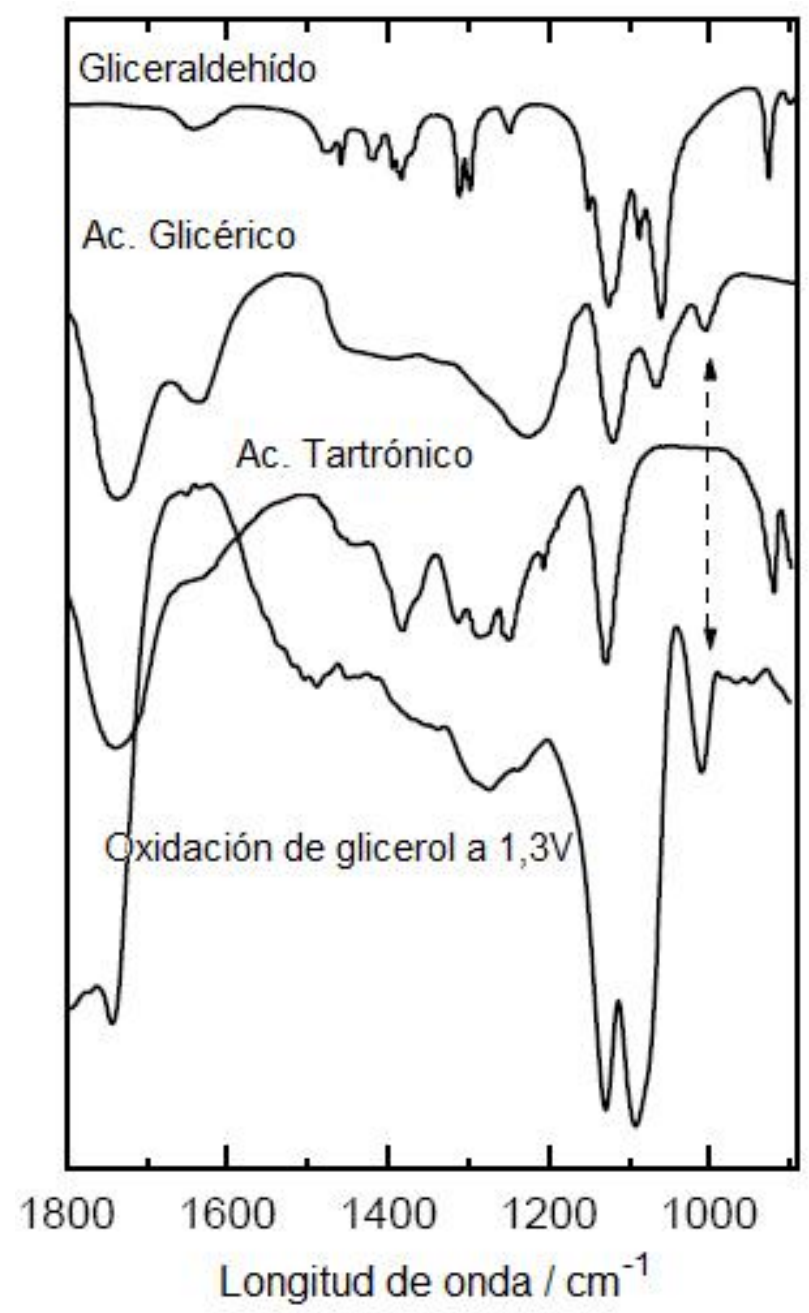

Figura 5.21: Comparación entre uno de los espectros obtenidos para la REG sobre Pt a $1,3 \mathrm{~V}$ y los espectros estándar de algunos de los posibles productos de oxidación incompleta.

La elección de estas sustancias se basó en estudios previos realizados con esta reacción [8-10,29]. Según Kwon y Koper [30], la REG produce ácido fórmico, por lo que inicialmente fue considerado en el análisis. Sin embargo, no encontramos ninguna coincidencia entre las bandas del espectro estándar de esta sustancia con los obtenidos en 
nuestros experimentos, por lo cual, éste fue descartado en nuestro análisis final.

En la Figura 5.21 puede observarse que al menos dos sustancias presentan bandas en la misma región del espectro, lo cual dificulta la discriminación de las bandas producidas durante la REG. Una excepción es la banda centrada en $1012 \mathrm{~cm}^{-1}$, la cual es propiedad única del ácido glicérico.

La banda localizada alrededor de $1740 \mathrm{~cm}^{-1}$ aparece alrededor de $0,8 \mathrm{~V}$ (ver Figura 5.19) y puede ser atribuida al estiramiento del enlace $\mathrm{C}=\mathrm{O}$ debido a la presencia de ácidos carboxílicos, aldehídos y cetonas [10]. Debido al hecho de que el glicerol puede oxidarse a diversos compuestos conteniendo grupos $\mathrm{C}=\mathrm{O}$, probablemente esta banda surja como resultado de la superposición de más de una señal, no pudiendo brindar información mecanística. Por este motivo, el desarrollo de esta banda no será analizado en detalle en este trabajo.

Como fue mencionado, la banda a $1130 \mathrm{~cm}^{-1}$ es difícil de cuantificar debido a que se encuentra en una región en la cual su magnitud es fuertemente influenciada por la presencia de la banda correspondiente al estiramiento $\mathrm{Cl}-\mathrm{O}$ del ión $\mathrm{ClO}_{4}^{-}$[31]. Esta banda podría indicar la presencia de cualquiera de los productos propuestos anteriormente. Sin embargo, una inspección más cercana de esta región (Figura 5.21) demuestra que esta banda aparece a 0,3V y se mantiene durante todo el barrido de potenciales. Este comportamiento sugiere que esta banda es generada por una sustancia que no requiere de la presencia de especie donoras de $\mathrm{O}$ para ser formada. Por lo tanto, podemos suponer que la sustancia se forma a través de un mecanismo de deshidrogenación de glicerol. Por lo tanto, en principio, es razonable esperar que las especies responsables de esta señal sean gliceraldehído o 1,3-dihidroxi-2-propanona, debido a que ambas sustancias son generadas a través de la pérdida de átomos de $\mathrm{H}$ de la molécula de glicerol. Sin embargo, la formación de la cetona posee una señal intensa en $1335 \mathrm{~cm}^{-1}$ [9], que en este caso no fue observada. 


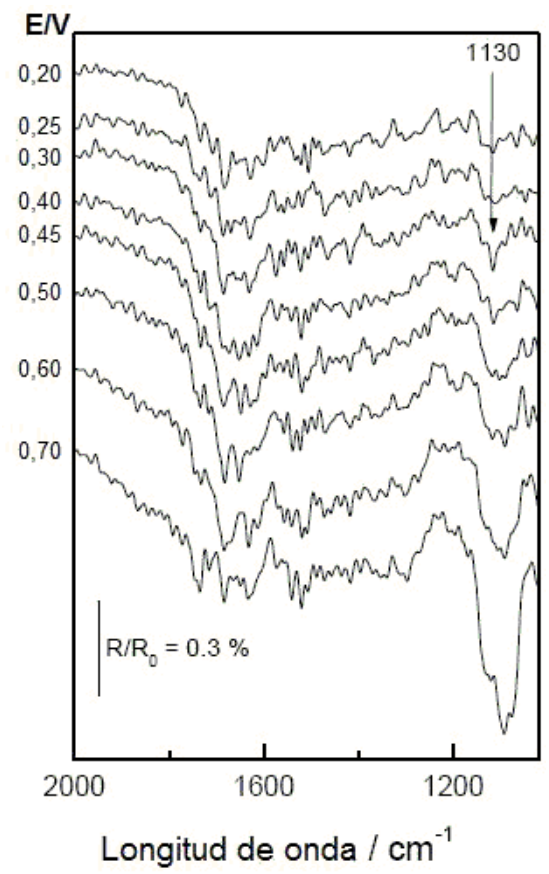

Figura 5.22: Algunos de los espectros de la Figura 5.19 en una escala tal que permite la observación de la banda localizada a $1130 \mathrm{~cm}^{-1}$.

Teniendo en cuenta las observaciones experimentales, sugerimos que a bajos potenciales, el glicerol puede adsorberse a través de uno de sus carbonos terminales, eliminando un $\mathrm{H}$, para luego eliminar un segundo átomo de $\mathrm{H}$ en forma de protón y formar gliceraldehído (Figura 5.23). La propuesta de unión C-Pt se basa en que en este tipo de compuestos hidroxilados, los átomos de $\mathrm{C}$ poseen densidad de carga positiva, lo cual genera que interaccionen favorablemente con la superficie de Pt a potenciales menores que su potencial de carga cero, donde el metal se encuentra con un exceso electrónico. El hecho de que al comienzo del barrido de potencial en sentido positivo, la corriente de desorción de $\mathrm{H}$ se vea muy disminuida por la presencia de glicerol es un indicativo directo que a estos potenciales el alcohol se encuentra adsorbido sobre la superficie del electrodo. Por otro lado, este hecho queda confirmado por la presencia de adsorbatos y la producción de propano a potenciales menores que 0,3V [29]. Para potenciales mayores no es posible realizar un análisis detallado de esta banda, puesto que 
tanto el ácido glicérico como el tartrónico presentan bandas en la misma región del espectro.
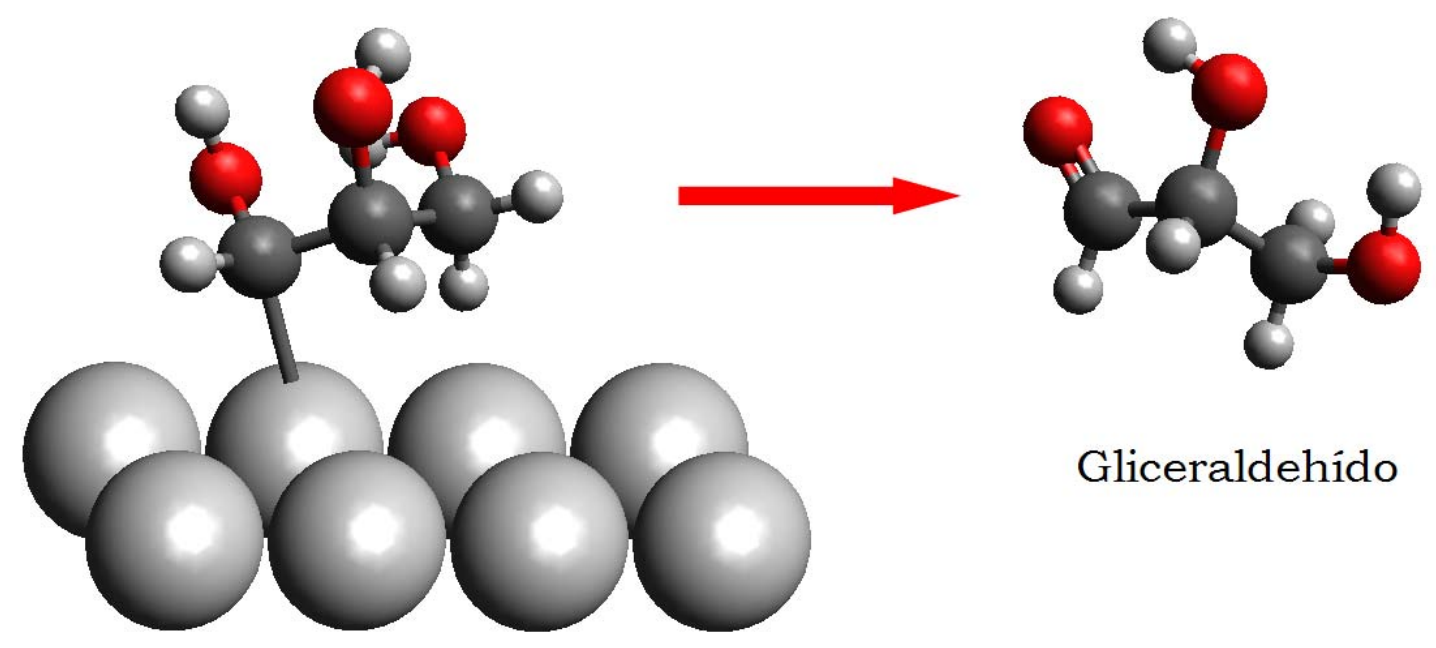

Gliceraldehído

Figura 5.23: Dibujo de bastones y bolas para la transformación de glicerol adsorbido sobre Pt en gliceraldehído.

\subsection{La formación de ácidos carboxílicos}

Resultados previos para las reacciones de electrooxidación de metanol [32] y etanol [11] sugieren que la producción de ácidos carboxilicos ocurre probablemente a través de un mecanismo de EleyRideal, en el cual un intermediario, I, reacciona con especies $\mathrm{OH}$ adsorbidas para generar el ácido correspondiente, sin necesidad de la adsorción previa de $\boldsymbol{I}[32,11]$. Este mecanismo se contrapone al de Langmuir-Hinshelwood, el cual justifica la presencia de $\mathrm{CO}_{2}$ a través de la reacción entre especies $\mathrm{CO}_{\text {ads }}$ y $\mathrm{HO}_{\text {ads }}$ (Figura 5.14) y explica por qué la producción de $\mathrm{CO}_{2}$ se ve negativamente afectada por la presencia de otros adsorbatos que $\mathrm{CO}$ (como aniones $\mathrm{SO}_{4}{ }^{2-}$ o un exceso de $\mathrm{HO}_{\text {ads, }}$, como ocurre a altos potenciales) mientras que la producción de ácidos carboxílicos es mucho menos afectada [32,11].

En este contexto, en la presente discusión se considerará que la formación de un ácido carboxílico depende de la reacción del glicerol con una especie $\mathrm{Pt}-\mathrm{OH}$ previamente adsorbida, mediante el mecanismo de Eley-Rideal. Consecuentemente, la probabilidad de la reacción y la naturaleza del ácido formado dependerán del potencial del electrodo. 
Así, a potenciales menores que $0,55 \mathrm{~V}$, la probabilidad de que uno de los carbones terminales de la molécula de glicerol se encuentre con una especie Pt-OH es cercana a cero, dado que estos potenciales son demasiado bajos como para que se produzca la adsorción disociativa de la molécula de agua sobre Pt [28]. Esta falta de oxígenos reactivos en la superficie del electrodo lleva a que se produzca la adsorción disociativa de glicerol para generar $\mathrm{CO}_{\text {ads }} \mathrm{o}$ no disociativa para producir gliceraldehído mediante dos deshidrogenaciones sucesivas. Sin embargo, la poca intensidad de estas bandas indica que estos compuestos son generados en una extensión relativamente baja.

Para potenciales mayores que $0,55 \mathrm{~V}$, el aumento de $\mathrm{Pt}-\mathrm{OH}$ en la superficie del electrodo genera la producción de $\mathrm{CO}_{2}$, dejando sitios activos de Pt libres. Como consecuencia, estos sitios quedan disponibles para la adsorción competitiva de agua y glicerol. Como fue argumentado anteriormente, el incremento del potencial favorece las interacciones $\mathrm{H}_{2} \mathrm{O}-\mathrm{Pt}$, aumentando el cubrimiento de la superficie por especies $\mathrm{Pt}-\mathrm{OH}$. Estos argumentos, permiten considerar que a potenciales suficientemente altos, la adsorción de glicerol será despreciable y este deberá interactuar directamente con las especies oxigenadas previamente adsorbidas. Así, estas consideraciones explican por qué las bandas relacionadas con los ácidos carboxílicos (a 1380, 1273 y $1012 \mathrm{~cm}^{-1}$ ) pueden ser visualizadas luego de los 0,60V.

Como fuera adelantado, a medida que el potencial del electrodo crece, el cubrimiento superficial por especies oxigenadas aumenta, favoreciendo la reacción de glicerol con múltiples especies Pt-OH. Así, es posible observar productos mas oxidados cuanto mayor sea el potencial del electrodo.

Basándonos en estos argumentos y considerando los productos de electrooxidación previamente identificados en la literatura [8-10,29] hemos sugerido las siguientes vías de reacción:

1. A potenciales alrededor de $0,60 \mathrm{~V}$, el glicerol interactúa con una sola especie Pt-OH, produciendo ácido glicérico (Figura 5.25 A). La banda correspondiente a este ácido comienza a crecer a menores potenciales 
que los requeridos para la formación de ácido tartrónico. Una producción conjunta de estos ácidos generaría un desarrollo mucho más marcado de las bandas en alrededor de $1130 \mathrm{~cm}^{-1}$ y también en la región de frecuencias 1200-1400 $\mathrm{cm}^{-1}$ (Figura 5.25), donde ambos ácidos presentan señales que son más intensas que la de ácido glicérico a $1012 \mathrm{~cm}^{-1}$.

2. A potenciales mayores, el glicerol reacciona a través de sus carbonos terminales con dos especies Pt-OH, generando ácido tartrónico (Figura 5.25 B). Consecuentemente, una nueva banda asignada a ácido tartrónico puede ser visualizada a ca. $1274 \mathrm{~cm}^{-1}$ por encima de $0.7 \mathrm{~V}$ (ver el espectro mostrado en la Figura 5.24).

3. Por último, cuando los 3 átomos de $\mathrm{C}$ del glicerol interactúan con especies oxigenadas, solamente se genera $\mathrm{CO}_{2}$ (Figura $5.25 \mathrm{C}$ ), acelerando sensiblemente su producción, como pudo visualizarse en las Figuras 5.19 y 5.20. Para una mejor apreciación, en la Figura 5.20 fueron trazadas rectas que permiten observar claramente las diferencias en las velocidades de producción de $\mathrm{CO}_{2}$ en tres regiones de potencial diferentes.

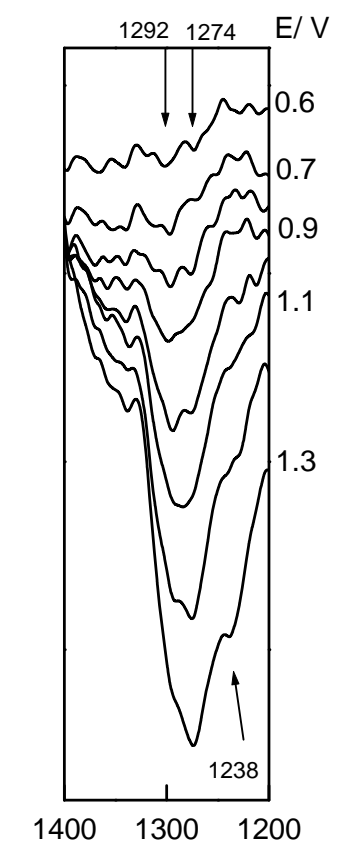

Wavenumber/ $\mathrm{cm}^{-1}$

Figura 5.24: Desarrollo de bandas en la zona 1200-1400 $\mathrm{cm}^{-1}$ correspondientes a los ácidos glicérico y tartrónico. 


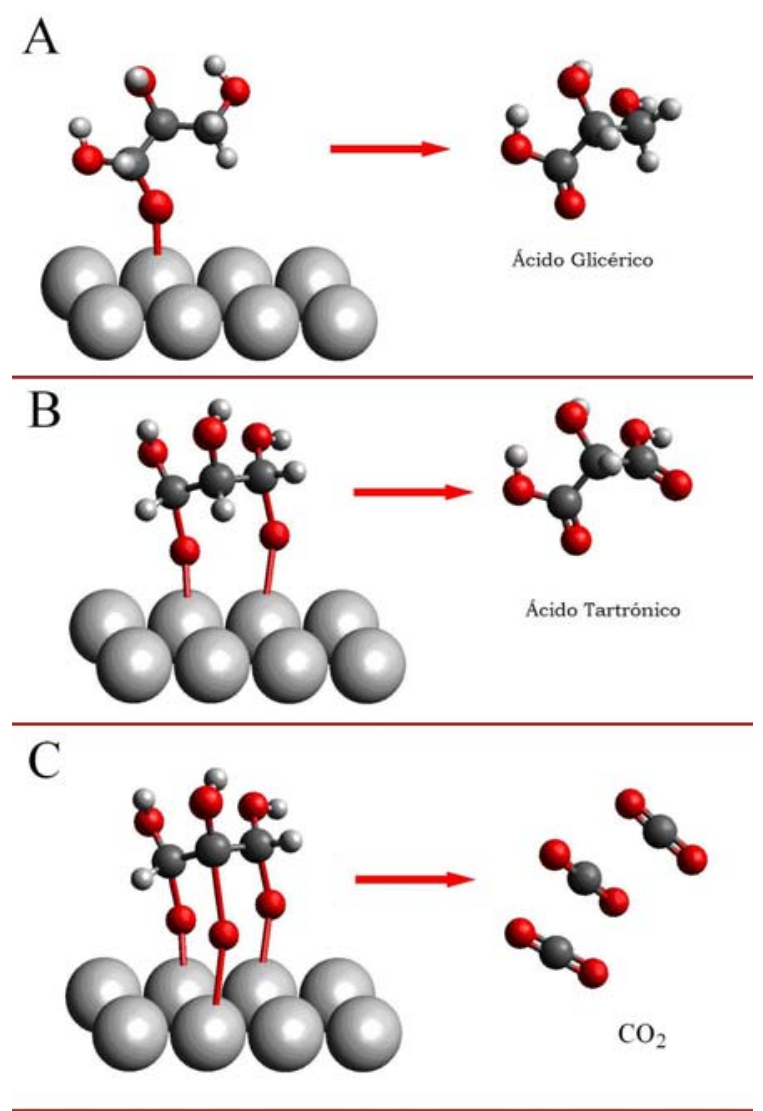

Figura 5.25: Dibujo de bastones y bolas para las vías de formación de ácidos carboxílicos y $\mathrm{CO}_{2}$ a altos potenciales propuestas en esta tesis.

En la Figura 5.26 se muestra una representación de un NTC decorado con NPs de Pt y los diversos productos de oxidación de glicerol. Asimismo, se resume la dependencia entre el potencial electroquímico y los diferentes productos de reacción de la REG. 


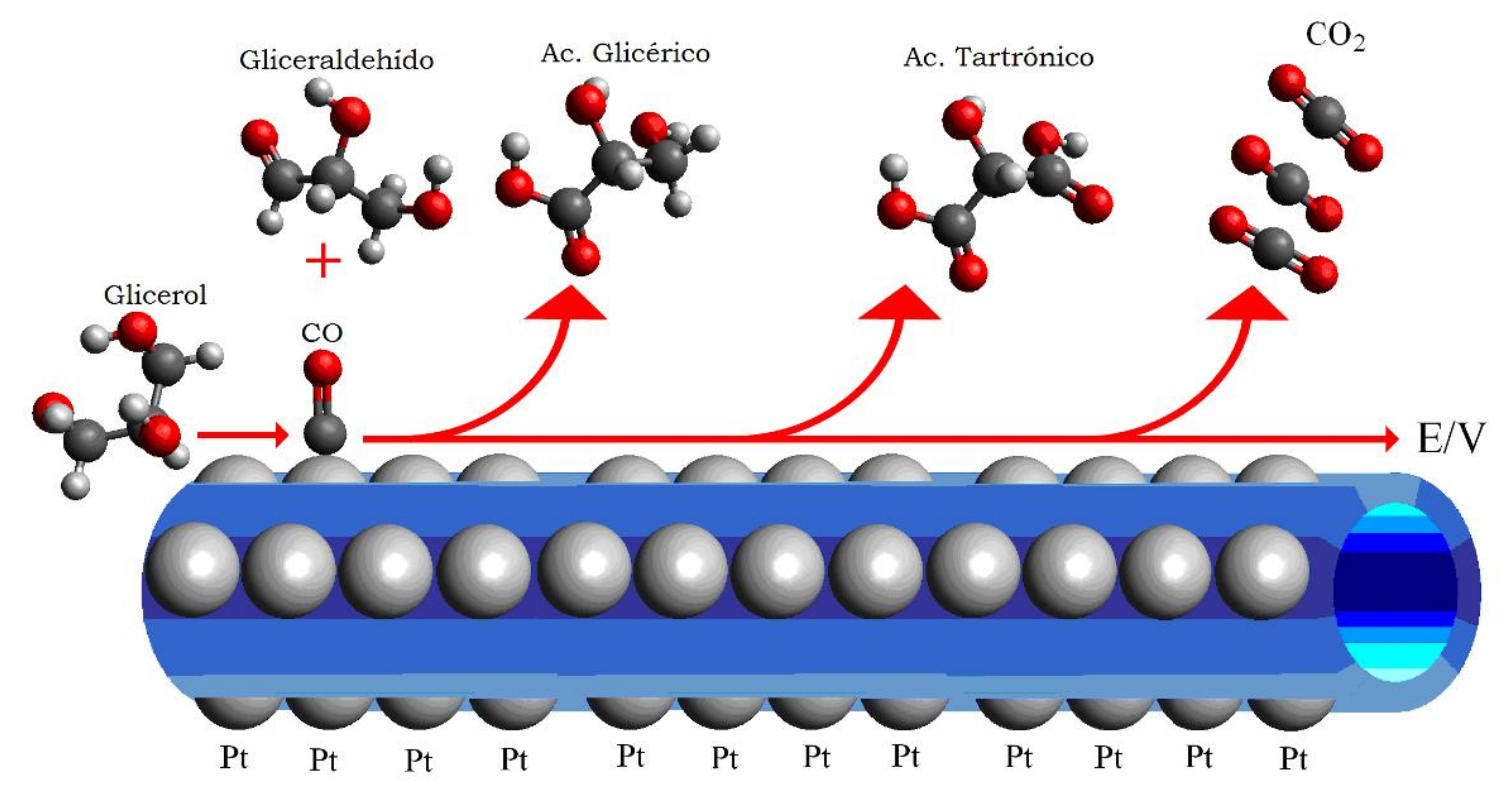

Figura 5.26: Resumen de la dependencia entre los productos formados y el potencial de electrodo.

\subsection{Conclusiones}

Las NPs preparadas por el método de los polioles muestran dispersiones de tamaño pequeñas. Los diámetros de las NPs de Pt soportadas sobre NTCM y V y los de las de $\mathrm{Pt}_{61} \mathrm{Sn}_{32} \mathrm{Rh}_{7}$ son similares, mientras que las NPs de Pt soportadas sobre $\mathrm{Ch} y$ las de $\mathrm{Pt}_{61,5} \mathrm{Ru}_{20,2} \mathrm{Rh}_{18,3}$ son marcadamente menores, hecho que puede influir en su comportamiento electrocatalítico. Sin embargo, se desconocen trabajos que estudien la electrocatálisis de alcoholes en los cuales una diferencia de distribución de tamaños de las NPs trimetálicas como las presentadas en este trabajo logre explicar comportamientos tan disímiles.

La diferencia en la composición de las NPs trimetálicas influye marcadamente en el comportamiento electroquímico de éstas. Se está realizando un análisis de las medidas de FTIR-in situ realizadas con estos catalizadores, el cual indica que cada una de las NPs preparadas en este trabajo generan efectos diferentes sobre las distintas vías de reacción.

Probablemente, la alta cantidad de Rh en las NPs conteniendo $\mathrm{Ru}$ genere un efecto negativo en su comportamiento electrocatalítico. Sin 
embargo, para confirmar esta presunción, se necesita de estudios sistemáticos relacionados con el efecto de la composición de las NPs sobre las vías de electrooxidación de glicerol.

Los soportes de carbono influyen en la electrocatálisis de las NPs metálicas. Así, los experimentos cronoamperométricos muestran corrientes superiores para Pt-NTCM, que para Pt-V.

Las NPs formadas por $\mathrm{Pt}_{61} \mathrm{Sn}_{32} \mathrm{Rh}_{7}$ y $\mathrm{Pt}_{61,5} \mathrm{Ru}_{20,2} \mathrm{Rh}_{18,3}$ logran producir la oxidación de $\mathrm{CO}_{\text {ads }}$ y de glicerol a potenciales considerablemente menores que aquellas de Pt puro. Sin embargo, teniendo en cuenta todo el barrido de potenciales, vemos que las NPs de Pt logran una carga mucho mayor de oxidación. Siendo ésta menor para las NPs conteniendo Sn y muy baja para aquellas conteniendo $\mathrm{Ru}$.

Teniendo en cuenta que el potencial del ánodo de una celda de combustible se localiza en alrededor de los 0,5-0,6V respecto del ERH, podemos concluir que las NPs conteniendo Sn son las más promisorias para el uso en celdas de combustible.

Los productos de electrooxidación de glicerol parecen ser los mismos con todos los catalizadores utilizados. Sin embargo, se producen claras variaciones en la dependencia de las vías de la REG con el potencial de electrodo. No obstante, estamos en proceso de un análisis detallado de los resultados de FTIR-in situ obtenidos con las NPs trimetálicas como para poder explicar minuciosamente estas dependencias.

El $\mathrm{CO}_{2}$ parece formarse a través de dos vías de electrooxidación. Una de ellas ocurre a bajos potenciales e involucra la co-adsorción de glicerol y de especies Pt-OH. La vía a altos potenciales ocurre a través de la reacción entre el glicerol u otras especies en solución con especies Pt-OH.

El aumento del grado de cubrimiento de la superficie de Pt por especies oxigenadas permite explicar todos los productos de electrooxidación identificados por FTIR-in situ. 
A bajos potenciales se produce $\mathrm{CO}_{\text {ads }}$ por ruptura de los enlaces C-C del glicerol; gliceraldehído, por deshidrogenación; y ácido glicérico por reacción con una especie $\mathrm{Pt}-\mathrm{OH}$.

A altos potenciales, el aumento del grado de cubrimiento de la superficie por especies oxigenadas favorece la formación de especies más oxigenadas como el ácido tartrónico por reacción del glicerol con dos especies Pt-OH.

Finalmente, por encima de $1,1 \mathrm{~V}$, el glicerol reacciona con tres especies Pt-OH, generando grandes cantidades de $\mathrm{CO}_{2}$. 


\subsection{Referencias Bibliográficas}

[1] Régimen de regulación y promoción para la producción y uso sustentables de biocombustibles. Ley 26.093. Sancionada el 19 de abril de 2006 y promulgada de hecho el 12 de mayo de 2006.

[2] W. R. Grove. On a new voltaic combination. Philosophical Magazine and Journal of Science, 13 (1838) 430.

[3] L. Roquet, E. M. Belgsir, J. M. Léger, C. Lamy. Kinetics and mechanisms of the electrocatalytic oxidation of glycerol as investigated by chromatographic analysis of the reaction products: Potential and pH effects. Electrochim. Acta, 39 (1994) 2387-2394.

[4] M. Avramov-Ivic, V. Jovanovic, G. Vlajnic, J. Popic. The electrocatalytic properties of the oxides of noble metals in the electrooxidation of some organic molecules. J. Electroanal. Chem., 423 (1997) 119-124.

[5] E. Venancio, W. T. Napporn, A. J. Motheo. Electro-oxidation of glycerol on platinum dispersed in polyaniline matrices Electrochim. Acta, 47 (2002) 1495-1501.

[6] M. G. Hosseini, S. A. S. Sajjadi, M. M. Momeni. Electrodeposition of platinum metal on titanium and anodized titanium from $\mathrm{P}$ salt: application to electro-oxidation of glycerol. Surf. Eng., 23 (2007) 419-424.

[7] D. Z. Jeffery, G. A. Câmara. The formation of carbon dioxide during glycerol electrooxidation in alkaline media: First spectroscopic evidences. Electrochem. Commun, 12 (2010) 1129-1132.

[8] C. A. Martins, M. J. Giz, G. A. Câmara. Generation of carbon dioxide from glycerol: Evidences of massive production on polycrystalline platinum Electrochim. Acta, 56 (2011) 4549-4553.

[9] M. Simões, S. Baranton, C. Coutanceau. Electro-oxidation of glycerol at Pd based nano-catalysts for an application in alkaline fuel cells for chemicals and energy cogeneration. App. Cat. B: Environ., 93 (2010) 354-362.

[10] J. F. Gomes, G. Tremiliosi-Filho. Spectroscopic Studies of the Glycerol Electro-Oxidation on Polycrystalline Au and Pt Surfaces in Acidic and Alkaline Media. Electrocatal., 2 (2011) 96-105.

[11] G. A. Câmara, T. Iwasita. Parallel Pathways of methanol Oxidation: The effect of ethanol concentration. J. Electroanal. Chem., 578 (2005) 315-321. 
[12] M. J. S. Farias, G. A. Câmara, A. A. Tanaka. Electrooxidation of isotope-labeled ethanol: a FTIRS study. J. Solid State Electrochem., 11 (2007) 1465-1469.

[13] E. Pastor, S. González, A. J. Arvia. Electroreactivity of isopropanol on platinum in acids studied by DEMS and FTIRS. J. Electroanal. Chem., 395 (1995) 233-242.

[14] I. A. Rodrigues, F. C. Nart. 2-Propanol oxidation on platinum and platinum-rhodium electrodeposits. J. Electroanal. Chem., 590 (2006) 145-151.

[15] I. A. Rodrigues, J. P. I. de Souza, E. Pastor, F. C. Nart. Cleavage of the $\mathrm{C}-\mathrm{C}$ Bond during the Electrooxidation of 1-Propanol and 2Propanol: Effect of the Pt Morphology and of Codeposited Ru. Langmuir, 13 (1997) 6829-6835.

[16] R. G. C. S. Reis, C. A. Martins, G. A. Câmara. The Electrooxidation of 2-Propanol: An Example of an Alternative Way to Look at In Situ FTIR Data. Electrocatal., 1 (2010) 116-121.

[17] M. J. Giz, G. A. Câmara, G. Maia. The ethanol electrooxidation reaction at rough PtRu electrodeposits: A FTIRS study. Electrochem. Commun., 11 (2009) 1586-1589;

[18] M. Chatterjee, A. Chatterjee, S. Ghosh, I. Basumallick. Electrooxidation of ethanol and ethylene glycol on carbon-supported nanoPt and -PtRu catalyst in acid solution. Electrochim. Acta, 54 (2009) 7299-7304.

[19] G. A. Câmara, R. B. Lima, T. Iwasita. The influence of PtRu atomic composition on the yields of ethanol oxidation: A study by in situ FTIR spectroscopy. J. Electroanal. Chem., 585 (2005) 128-131.

[20] G. A. B. Mello, M. J. Giz, G. A. Câmara, A. Crisci, M. Chatenet. Search for multi-functional catalysts: The electrooxidation of acetaldehyde on Platinum-Ruthenium-Rhodium electrodeposits. J. Electroanal. Chem., 660 (2011) 85-90.

[21] M. Chen, Y. Xing. Polymer-Mediated Synthesis of Highly Dispersed Pt Nanoparticles on Carbon Black. Langmuir, 21 (2005) 93349338.

[22] R. Guilliam, D. Kirk, S Thorpe. Influence of Structural, Microstructural and Electrical Properties on Electrocatalytic Performance at the Nanoscale. Electrocatal., 2 (2011) 1-19. 
[23] S. J. Lee, S. Mukerjee, E. A. Ticianelli, J. McBreen. Electrocatalysis of $\mathrm{CO}$ tolerance in hydrogen oxidation reaction in PEM fuel cells. Electrochimica Acta, 44 (1999) 3283 \pm 3293

[24] Z. Liu, J. E. Hu, Qi Wang, K. Gaskell, A. I. Frenkel, G. S. Jackson, B. Eichhorn. PtMo Alloy and MoOx@Pt Core-Shell Nanoparticles as Highly CO-Tolerant Electrocatalysts. J. Am. Chem. Soc., 131 (2009) 6924-6925.

[25] K. J. J. Mayrhofer, M. Arenz, B. B. Blizanac, V. Stamenkovic, P. N. Ross, N. M. Markovic. CO surface electrochemistry on Ptnanoparticles: A selective review. Electrochim. Acta, 50 (2005) 5144-5154.

[26] V. del Colle, A. Berná, G. Tremiliosi-Filho, E. Herrero, J.M. Feliú. Ethanol electrooxidation onto stepped surfaces modified by $\mathrm{Ru}$ deposition: electrochemical and spectroscopic studies. Phys. Chem. Chem. Phys., 10 (2008) 3766-3773.

[27] T. Iwasita. Electrocatalysis of methanol oxidation. Electrochim. Acta, 47 (2002) 3663-3674.

[28] T. Iwasita, X. H. Xia. Adsorption of water at Pt( 111) electrode in $\mathrm{HClO}_{4}$ solutions. The potential of zero charge. J. Electroanal. Chem., 411 (1996) 95-102.

[29] J. Schnaidt, M. Heinen, D. Denot, Z. Jusys, R.J. Behm. Electrooxidation of glycerol studied by combined in situ IR spectroscopy and online mass spectrometry under continuous flow conditions. J. Electroanal. Chem., 661 (2011) 250-265.

[30] Y. Kwon, M. T. M. Koper. Combining voltammetry with HPLC: application to electro-oxidation of glycerol. Anal. Chem., 82 (2010) 5420-5424.

[31] T. Iwasita, F. C. Nart. In situ infrared spectroscopy at electrochemical interfaces. Prog. Surf. Sci., 55 (1997) 271-340.

[32] E. A. Batista, G. R. P. Malpass, A. J. Motheo, T. Iwasita. New mechanistic aspects of methanol oxidation. J. Electroanal. Chem., 571 (2004) 273-282. 


\section{Conclusiones Generales}

Si bien durante el desarrollo de cada tema y al final de cada capitulo se han escrito conclusiones particulares, en la parte final de este trabajo de Tesis quisimos escribir una sección que incluyera otras conclusiones que están directamente relacionadas con el progreso de nuestro grupo y con una visión más general del tema.

En estos años de trabajo fueron utilizados un número muy variado de carbones, con aspecto macroscópico similar pero con características a nivel microscópico muy diferentes, lo cual hace que sean útiles para diversas aplicaciones, en muchos casos complementarias, como fue señalado en la Introducción de esta Tesis y también comprobado durante el desarrollo de la misma.

La aplicación de un modelo físicoquímico para la impedancia de electrodos porosos a materiales tan disimiles, permitió un entendimiento mucho mayor al que se tenía hasta el momento con respecto al comportamiento de este tipo de sistemas electroquímicos. Esto se debe a que se cubrió un espectro muy grande de áreas interfaciales, conductividades efectivas de los sólidos (Conductividades electrónicas de los materiales) y conductividades efectivas del electrolito. Si bien nuestro grupo tenia una experiencia importante en el tema, hasta el momento no habian sido empleados materiales porosos con áreas interfaciales tan grandes y conductividades tan bajas, lo que generó numerosas discusiones, tanto del punto de vista experimental como teórico, que finalizaron en la utilización de un modelo más general y abarcador que aquél utilizado hasta el momento, como así también en 
un entendimiento más profundo de los fenómenos y parámetros involucrados en el funcionamiento de electrodos constituidos por materiales porosos. Así, los parámetros más importantes a controlar son:

i) Conductividad efectiva del sólido: cuanto mayor sea el valor de este parámetro, mayor será la conductividad electrónica en el sólido y por lo tanto, mejor el desempeño del electrodo. Para ello es necesario optimizar la cantidad de agrupaciones "tipo grafito" interconectadas de la matriz carbonosa.

ii) Alta conductividad del electrolito: cuanto mayor sea este parámetro, mayor será la movilidad de los iones en la matriz porosa. En este caso, resultan favorables poros relativamente grandes y poco tortuosos.

iii) Área interfacial: es necesario optimizar este parámetro para cualquier aplicación deseada. Los mayores valores de éste son obtenidos a través de una importante presencia de nano y microporos.

Lamentablemente, estos parámetros no son independientes, sino que en la práctica están totalmente relacionados. En forma general, un aumento del área interfacial está directamente relacionado con la cantidad de poros de un material. A mayor cantidad de poros, más área expuesta tendremos. Además, es necesario que la accesibilidad del electrolito sea la mayor posible, o sea, una situación ideal sería aquella en la cual cada poro del material estuviera inundado por el electrolito, permitiendo una óptima formación de la doble capa eléctrica y una rápida entrada y salida de eventuales reactivos y productos de reacción. Pero, si imaginamos que partimos de un material de carbono con una conductividad electrónica óptima y sin poros, como lo sería un grafito perfecto, y comenzamos a aumentar su área interfacial generando poros en éste, paulatinamente produciremos defectos en las láminas de grafeno del material de partida y por lo tanto disminuirá la conductividad electrónica inicial. Por lo tanto, para cualquier aplicación 
deberemos optimizar la cantidad y tipo de poros del carbón obtenido de modo de generar un material con el área interfacial deseada, lograda a través de una cantidad mínima de poros y cuyo tamaño sea el adecuado para contar con conductividades y difusividades máximas. Si estos parámetros resultan muy pequeños, el electrolito, y por lo tanto los eventuales reactivos no podrán acceder al material activo afectando directamente la cantidad de energía producida por el sistema. $\mathrm{Si}$, por el contrario, estos son demasiado grandes, la necesidad de un número muy elevado de éstos para alcanzar un valor determinado de área interfacial, (para igual volumen de poros, cuanto más pequeños sean, mayor área interfacial generarán) afectará negativamente la conductividad electrónica del material, comprometiendo la potencia del dispositivo.

Otra conclusión importante de esta Tesis es que desde el punto de vista de las aplicaciones que poseen cada uno de estos materiales carbonosos, la caracterización realizada midiendo isotermas de BET es mucho menos interesante y útil que aquélla realizada por vía electroquímica, mediante el empleo de la espectroscopia de impedancia electroquímica, EIE. Como fue mostrado en los Capítulos 3 y 4, es esta última técnica la que permite obtener parámetros fisicoquímicos mediante los cuales es posible explicar el funcionamiento del material para una aplicación dada o, en caso contrario, una medida de EIE y un posterior tratamiento de los datos obtenidos permite predecir varios aspectos del funcionamiento de un material carbonoso en una aplicación dada.

Por último, estos conocimientos permitirán optimizar la matriz porosa de catalizadores compuestos de nanopartículas metálicas soportadas sobre diferentes tipos de carbones, y así obtener mejores densidades de corriente en la reacción de electrooxidación de glicerol. 